Alexander Spermann

Negative

Einkommensteuer,

Lohnsubventionen und

Langzeitarbeitslosigkeit 


\section{Alexander Spermann}

\section{Negative Einkommensteuer, Lohnsubventionen und Langzeitarbeitslosigkeit}

Langzeitarbeitslosigkeit und Langzeitsozialhilfebezug sind Kennzeichen struktureller Arbeitslosigkeit. Die leistungsfeindliche Ausgestaltung des Systems der Arbeitslosenunterstützung und der Sozialhilfe mit - ökonomisch betrachtet - exorbitant hohen „Spitzensteuersätzen“ auf die eigenen Verdienste von Hilfeempfängern trägt zur Verlängerung des Hilfebezugs bei. In dieser Arbeit werden Alternativen zum Status quo vorgestellt und kritisch diskutiert. Ein eigener Reformvorschlag - das Einstiegsgeld für Langzeitarbeitslose - wird entwickelt. Das Einstiegsgeld wird seit 1999 in Modellversuchen in 16 Städten und Kreisen in Baden-Württemberg und Hessen in der Praxis getestet.

Alexander Spermann wurde 1962 in München geboren. Das Studium der Volkswirtschaftslehre an den Universitäten Passau und Freiburg schloß er mit dem Diplom 1988 ab. Nach der Promotion 1992 und der Habilitation 1999 folgte die Ernennung zum Privatdozenten an der Universität Freiburg. 2000 gründete er die Firma Economic R \& C, Wissenschaftliche Beratung und Projektevaluation, in München. 
Negative Einkommensteuer,

Lohnsubventionen und Langzeitarbeitslosigkeit 


\section{FINANZWISSENSCHAFTLICHE SCHRIFTEN}

Herausgegeben von den Professoren

Albers ( $\dagger$ ), Krause-Junk, Littmann, Oberhauser, Pohmer, Schmidt

Band 104

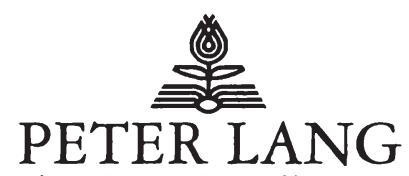

Frankfurt am Main · Berlin · Bern · Bruxelles · New York · Oxford · Wien 


\section{Alexander Spermann}

\section{Negative Einkommensteuer, Lohnsubventionen und Langzeitarbeitslosigkeit}

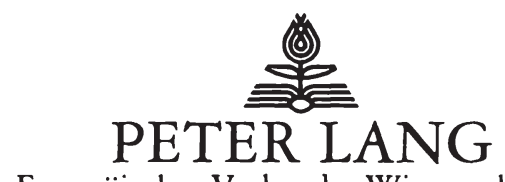

Europäischer Verlag der Wissenschaften 
Die Deutsche Bibliothek - CIP-Einheitsaufnahme

Spermann, Alexander:

Negative Einkommensteuer, Lohnsubventionen und

Langzeitarbeitslosigkeit / Alexander Spermann. - Frankfurt am

Main ; Berlin ; Bern ; Bruxelles ; New York ; Oxford ; Wien :

Lang, 2001

(Finanzwissenschaftliche Schriften; Bd. 104)

Zugl.: Freiburg (Breisgau), Univ., Habil.-Schr., 1999

ISBN3-631-36689-2

Open Access: The online version of this publication is published on www.peterlang.com and www.econstor.eu under the international Creative Commons License CC-BY 4.0. Learn more on how you can use and share this work: http://creativecommons. org/licenses/by/4.0.

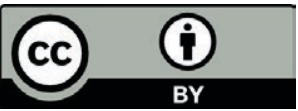

This book is available Open Access thanks to the kind support of ZBW - Leibniz-Informationszentrum Wirtschaft.

Gedruckt auf alterungsbeständigem, säurefreiem Papier.

\author{
ISSN 0170-8252 \\ ISBN3-631-36689-2 \\ ISBN 978-3-631-75152-7 (eBook) \\ (C) Peter Lang GmbH \\ Europäischer Verlag der Wissenschaften \\ Frankfurt am Main 2001 \\ Alle Rechte vorbehalten.
}

Das Werk einschließlich aller seiner Teile ist urheberrechtlich geschützt. Jede Verwertung außerhalb der engen Grenzen des

Urheberrechtsgesetzes ist ohne Zustimmung des Verlages unzulässig und strafbar. Das gilt insbesondere für Vervielfältigungen, Übersetzungen, Mikroverfilmungen und die Einspeicherung und Verarbeitung in elektronischen Systemen.

Printed in Germany 123467

www.peterlang.de 


\section{Vorwort}

Die vorliegende Arbeit ist eine unveränderte Version meiner im Jahre 1999 von der Wirtschaftswissenschaftlichen Fakultät der Universität Freiburg akzeptierten Habilitationsschrift. Kernstück dieser Arbeit ist ein sozialpolitischer Reformvorschlag: das sogenannte Einstiegsgeld für Langzeitarbeitslose bzw. die zielgruppenorientierte negative Einkommensteuer. Das Einstiegsgeld erhöht - zeitlich befristet - die Leistungsanreize für langzeitarbeitslose Transferempfänger. Da die Wirkungsmechanismen eines solchen Eingriffes in der Realität äußerst komplex sind, wird für die probeweise Implementation auf Bundes- oder Landesebene plädiert, um empirische Erkenntnisse gewinnen zu können, bevor weitergehende Reformen des Transfersystems (wie die negative Einkommensteuer bzw. das Bürgergeld) verwirklicht werden.

Der Reformvorschlag Einstiegsgeld wird nach einer ausführlichen Beschreibung der Ursachen der Langzeitarbeitslosigkeit und des Status quo für Transferempfänger vor dem Hintergrund einer dogmengeschichtlichen Betrachtung der negativen Einkommensteuer als ein speziell auf die deutsche Institutionen abgestimmtes und deshalb unmittelbar in die sozialpolitische Praxis umsetzbares Konzept entwickelt. Das Konzept ist keine Reißbrettarbeit, sondern das Ergebnis eines jahrelangen Diskussionsprozesses mit Betroffenen, Sozialhilfepraktikern, Verbandsvertretern, Journalisten und Wissenschaftlern verschiedener Fachrichtungen. Damit wird diese Habilitationsschrift dem selbst gestellten Anspruch einer praxisrelevanten, interdisziplinär und polit-ökonomisch konzipierten Arbeit gerecht.

In der Zwischenzeit wird das Einstiegsgeld in 16 Städten und Gemeinden in den Bundesländern Baden-Württemberg und Hessen im Auftrag der jeweiligen Sozialministerien experimentell getestet. Die Modellversuche sind zum Teil als soziale Experimente mit Kontrollgruppen konzipiert, was in den USA und Kanada üblich, in Deutschland jedoch ein Novum im Bereich der Arbeitsmarktforschung ist - sie werden vom Institut für Angewandte Wirtschaftsforschung (IAW) in Tübingen unter meiner Mitarbeit evaluiert. Mit einer abschließenden Beurteilung ist im Jahre $2003 \mathrm{zu}$ rechnen. Zwischen der ursprünglichen Idee zum Einstiegsgeld (1994), der Realisierung der Idee und der Auswertung der Experimente werden dann fast zehn Jahre liegen. Nun bin ich selbst gespannt, welche Ergebnisse die Experimente in BadenWürttemberg und Hessen bringen werden.

Ich bin dem Erstkorrektor - Prof. Dr. Dr. h.c. Hans-Hermann Francke - zu besonderem Dank für seine liberale Haltung verpflichtet. Im Gegensatz zu den meisten Professoren gab er keinen starren methodischen Rahmen für die Konzeption der Arbeit vor, statt dessen unterstützte er den eingeschlagenen Weg, erlaubte ein Höchstmaß an selbständigem Arbeiten - und sein Ego erträgt es auch, nicht im Literaturverzeichnis zu erscheinen. Auch dem Zweitkorrektor - Prof. Dr. Bernd Raffelhüschen - sei gedankt für seine intensive

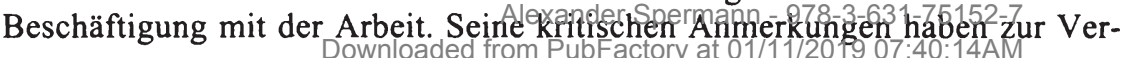


besserung der Arbeit beigetragen. Meinen Kollegen Prof. Dr. Jochen Michaelis, PD Dr. Jürgen Jerger und PD Dr. Michael Pflüger danke ich herzlich für ihre kritischen Kommentare über viele Jahre hinweg - sie haben durch zahllose warnende Hinweise dazu beigetragen, dass Anspruch und Wirklichkeit dieser Arbeit nicht zu weit auseinanderklaffen. Weiterhin bedanke ich mich bei zahllosen nationalen und internationalen Kritikern, Gutachtern, Studenten und Praktikern, ohne deren Kommentare diese Arbeit nicht in dieser Differenziertheit vorliegen würde.

Die Habilitationsschrift war sehr rechercheintensiv, vor allem wegen des hohen Aktualitätsgrads, der Vielfalt der involvierten Institutionen und des interdisziplinären Charakters. Ohne die jahrelange geduldige Unterstützung durch Dipl.-Vw. Pascal Krimmer und Dr. Christian Pohnke wäre diese Arbeit auch nach sechs Jahren nicht fertig geworden. Vielen Dank! Beide haben sich vom Forschen anstecken lassen: Christian wurde vom Erstkorrektor promoviert, Pascal promoviert beim Zweitkorrektor.

Wer sich für den weiteren Verlauf des Einstiegsgeldes interessiert, ist eingeladen, sich auf der Homepage des IAW (www.iaw.edu) oder auf meiner Homepage (www.economic-rc.com) zu informieren. 


\section{Inhaltsverzeichnis}

Abbildungsverzeichnis

XI

Kapitel 1: Einführung.

Kapitel 2: Arbeits-Fehlanreize im Sozialsystem und

Langzeitarbeitslosigkeit ............................................................. 7

2.1 Zum Aufbau des Kapitels .................................................................

2.2 Umfang und Struktur der Langzeitarbeitslosigkeit..................................

2.3 Einflußfaktoren auf die Dauer der Arbeitslosigkeit................................17

2.4 Fehlanreiz Nr. 1: Das Problem des Lohnabstandes ................................. 18

2.4.1 Der Verlauf der Lohnabstandsdiskussion .......................................18

2.4.2 Die Interpretation des Lohnabstandsgebots...................................20

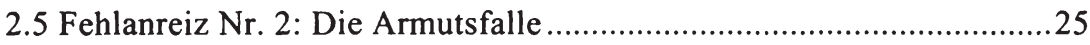

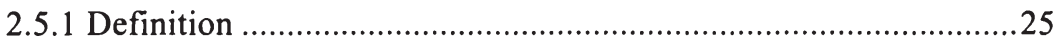

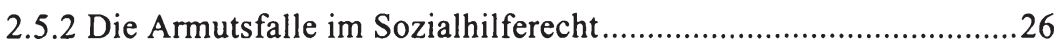

2.5.3 Die Armutsfalle im Arbeitsförderungsgesetz .................................31

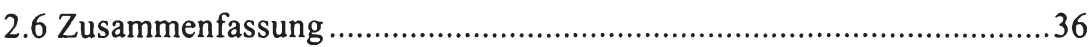

Kapitel 3: Die Negative Einkommensteuer als beschäftigungspolitischer Lösungsansatz - Ergebnisse einer über fünfzigjährigen Diskussion ....................................................... 39

3.1 Wichtige Negativsteuerkonzeptionen im Rückblick ..............................39

3.1.1 Zur Auswahl der Negativsteuerkonzeptionen.................................39

3.1.2 Die Sozialdividende der Lady Rhys-Williams (1942/53)..............40

3.1.3 Das Armutslückenkonzept von Friedman (1962/68) ......................47

3.1.4 Die graduelle Integration von Tobin (1965/67) ............................51

3.2 Die Bürgergeld-Diskussion der neunziger Jahre ………………….......57

3.2.1 Das Bürgergeldkonzept von Mitschke (1994/95) ……….............57

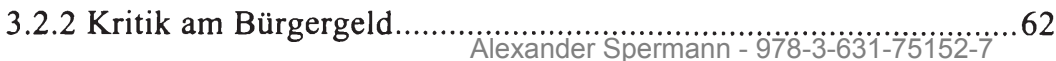




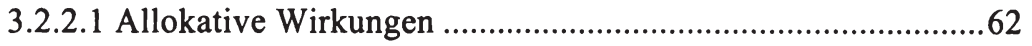

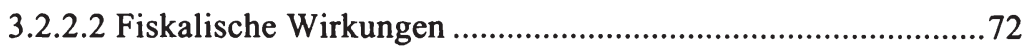

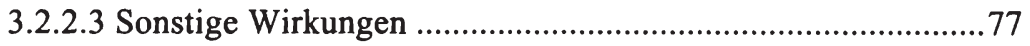

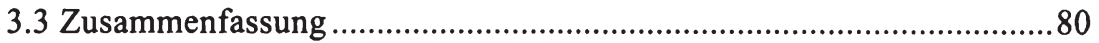

Kapitel 4: Aktuelle Lohnsubventionsmodelle .........................85

4.1 Zur Auswahl der Lohnsubventionsmodelle .......................................85

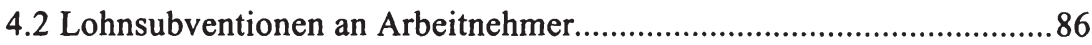

4.2.1 Der „Earned Income Tax Credit“ ..................................................86

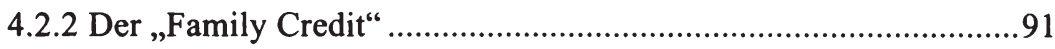

4.2.3 Die „Negative Wage Tax“(NWT) ...............................................92

4.2.4 Kombi-Einkommensmodelle ........................................................96

4.3 Lohnsubventionen an Arbeitgeber...................................................98

4.3.1 Traditionelle Lohnsubventionen ...............................................98

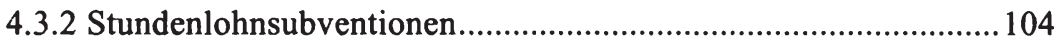

4.3.3 Das „Benefit-Transfer Program“.................................................107

4.4 Lohnsubventionen und Arbeitspflicht ...............................................111

4.4.1 „Welfare-to-Work“-Programme .................................................111

4.4.2 Das „Armutslückenkonzept“" von Vaubel...................................118

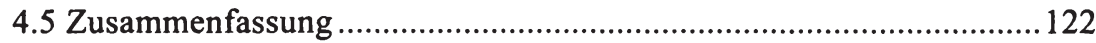

Kapitel 5: Das „Einstiegsgeld“ für Langzeitarbeitslose - ein

Vorschlag zur Einführung einer zielgruppenorientierten negativen Einkommensteuer in Deutschland........................ 125

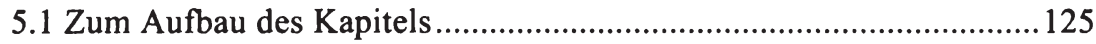

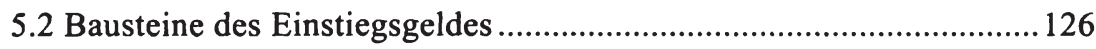

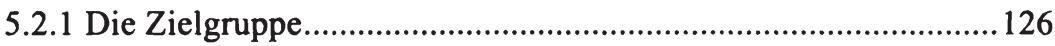

5.2.2 Das Anrechnungsverfahren ...................................................128

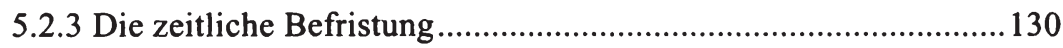

5.2.4 Die Kombination mit Einstiegstarifen ...................................... 130

5.2.5 Administrative Ausgestaltung ...................................................131

5.2.6 Das Darlehensmodell................................................................ 131 


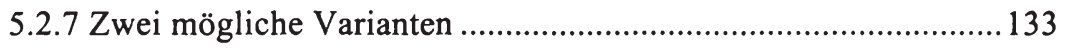

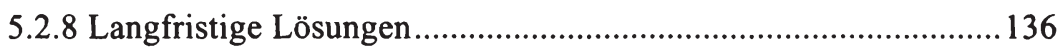

5.3 Beschäftigungswirkungen des Einstiegsgeldes im Vergleich zum

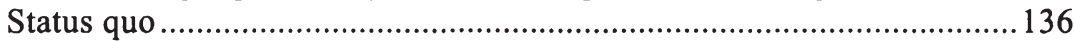

5.3.1 Zur Auswahl des Analyseinstrumentariums ...............................136

5.3.2 Das Einstiegsgeld im Einkommen-Freizeit-Modell....................137

5.3.3 Das Einstiegsgeld im kompetitiven Arbeitsmarktmodell ............138

5.3.4 Das Einstiegsgeld im modifizierten Modell gleichgewichtiger Arbeitslosigkeit ............................................................................. 141

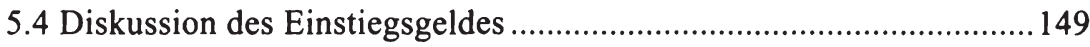

5.4.1 Vergleich mit dem Status quo .................................................. 149

5.4.2 Vergleich mit Lohnsubventionen an Arbeitnehmer..................... 163

5.4.3 Vergleich mit Lohnsubventionen an Arbeitgeber........................ 165

5.4.4 Welfare-to-Work und Einstiegsgeld ........................................... 170

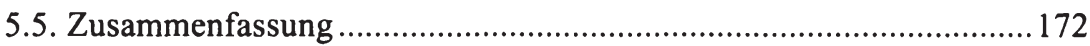

Kapitel 6: Schlußfolgerungen ................................... 175

Literaturverzeichnis .................................................. 181 
Alexander Spermann - 978-3-631-75152-7 Downloaded from PubFactory at 01/11/2019 07:40:14AM via free access 


\section{Abbildungsverzeichnis}

Abbildung 1: Offizieller Bestand an Arbeitslosen und Arbeitslosenquote in Westdeutschland (1980-1996)

Abbildung 2: Offizielle Entwicklung der Langzeitarbeitslosigkeit in Westdeutschland (1980-1996).

Abbildung 3: Betroffenheit versus Dauer der Arbeitslosigkeit in Westdeutschland (1980-1996) 10

Abbildung 4: Anteil der Langzeitarbeitslosen an der Gesamtarbeitslosen nach OECD-Daten (1982-1996) ....11

Abbildung 5: Gesamte Sozialhilfeempfängerzahl und Empfänger laufender Hilfe zum Lebensunterhalt in

Westdeutschland in 1000 (1980-1996) 13

Abbildung 6: Reale gesamte Sozialhilfeausgaben und reale Ausgaben der Hilfe zum Lebensunterhalt in Westdeutschland in Mrd. DM (1980-1996)

Abbildung 7: Reale gesamte Sozialhilfeausgaben und reale gesamte Nettoausgaben in Westdeutschland in Mrd. DM (19801996)

Abbildung 8: Armutsfalle im Sozialhilferecht - Alleinstehende ohne Kind

Abbildung 9: Armutsfalle im Sozialhilferecht - Verheiratete mit zwei Kindern 30

Abbildung 10: Armutsfalle im Arbeitsförderungsgesetz -

"Durchschnittlicher" Langzeitarbeitsloser ohne Kind...34

Abbildung 11: Armutsfalle im Arbeitsförderungsgesetz -

"Durchschnittlicher" Langzeitarbeitsloser mit zwei

Kindern. 
Abbildung 12: Die Sozialdividende der Lady Rhys-Williams $(1942 / 1953)$

Abbildung 13: Das Armutslückenkonzept von Friedman (1962/1968).49

Abbildung 14: Die graduelle Integration von Tobin (1965/67)

(Ehepaar mit 3 Kindern)

Abbildung 15: Das Bürgergeldmodell von Mitschke (1994/95) mit

"Abschmelzungstarif"

Abbildung 16: Die Armutsfalle im Sozialhilferecht im Einkommen-

Freizeit-Modell

Abbildung 17: Die allokativen Wirkungen des Bürgergeldkonzepts von Mitschke (1994/95) mit "Abschmelzungstarif" im Einkommen-Freizeit-Modell ...................................64

Abbildung 18: Der "Earned Income Tax Credit" (EITC)......................87

Abbildung 19: Der "Family Credit"....................................................91

Abbildung 20: Die "Negative Wage Tax" (NWT) ................................93

Abbildung 21: Vergleich einer Negative Wage Tax mit einer

kostenidentischen Negativen Einkommensteuer im

Einkommen-Freizeit-Modell

Abbildung 22: Das "Kombi-Einkommen" der CDU/CSU-FDP-

Koalition vom 19.12.1997

Abbildung 23: Der "Targeted Jobs Tax Credit" (TJTC) ...................... 100 Abbildung 24: Die "Einkommenshilfe für niedrige Erwerbseinkommen" von Scharpf (1994) 105

Abbildung 25: Das "Benefit-Transfer Program" (BTP) von Snower (1994)

Abbildung 26: Die nutzenniveau-neutrale Einführung des

Armutslückenkonzepts von Vaubel (1996) im

Einkommen-Freizeit-Modell 
Abbildung 27: Die nettoeinkommens-neutrale Einführung des Armutslückenkonzepts von Vaubel (1996)

Abbildung 28: Das "Einstiegsgeld" für Langzeitarbeitslose mit Einkommensobergrenze - Verheiratete mit zwei Kindern

Abbildung 29: Das "Einstiegsgeld" für Langzeitarbeitslose als degressive Lohnsubvention - Verheiratete mit zwei Kindern

Abbildung 30: Die Arbeitsangebotswirkung des Einstiegsgeldes im Einkommen-Freizeit-Modell

Abbildung 31: Die Beschäftigungswirkung des Einstiegsgeldes im kompetitiven Arbeitsmarktmodell

Abbildung 32: Das modifizierte Modell gleichgewichtiger Arbeitslosigkeit (WS-PS-Modell)

Abbildung 33: Die Beschäftigungswirkung des Einstiegsgeldes im modifizierten Modell gleichgewichtiger

Arbeitslosigkeit 148

Abbildung 34: Benefit-Transfer Program (BTP) als Arbeitgeber-

Lohnsubvention und Einstiegsgeld als ArbeitnehmerLohnsubvention im Vergleich 166 
Alexander Spermann - 978-3-631-75152-7 Downloaded from PubFactory at 01/11/2019 07:40:14AM via free access 


\section{Kapitel 1: Einführung}

„Die Verfestigung der Unterbeschäftigung in Form von Langzeitarbeitslosigkeit stellt zweifelsfrei die größte arbeitsmarktpolitische Herausforderung dar" (Franz 1995, S. 21).

Die Verbreitung der Informationstechnologien verändert die Arbeitswelt auf dramatische Weise. Vielbeachtete Autoren befürchten das „Ende der Arbeit“ (vgl. Rifkin 1995) durch den „Terror der Ökonomie“ (vgl. Forrester 1997). Pessimisten vermuten, daß die „Zukunft des Kapitalismus“ (vgl. Thurow 1996) ein „Kapitalismus ohne Arbeit“ sein könnte (vgl. Beck 1997, 1998). Die Wirkungen des internationalen Standortwettbewerbs werden als „Globalisierungsfalle" (vgl. Martin/Schumann 1996) beschrieben, die Wohlstand, Demokratie und Sozialstaat gefährden. Gemeinsamer Nenner der aufgeführten Publikationen ist es, daß Bestseller-Autoren die Ängste der Menschen vor der „schöpferischen Zerstörung“ (vgl. Schumpeter 1961) des marktwirtschaftlichen Wettbewerbs mit reißerischen Buchtiteln vermarkten. Für eine sachliche Analyse des Zusammenhangs zwischen Arbeitsmarkt und sozialer Sicherung sind diese Werke wenig hilfreich.

Die Ursachenanalyse ist wesentlich komplexer. Unstrittig ist, daß die Nachfrage nach geringqualifizierter Arbeit relativ zur Nachfrage nach qualifizierter Arbeit in den Industrieländern abgenommen hat. Arbeitslosigkeit und Langzeitarbeitslosigkeit treffen vor allem Geringqualifizierte. Einigkeit besteht in der wissenschaftlichen Diskussion, daß sowohl technologischer Wandel als auch internationaler Handel die Arbeitsmarktchancen Geringqualifizierter verschlechtern. Strittig ist jedoch die relative Bedeutung von Globalisierung und technologischem Wandel für die Arbeitsmarktchancen geringqualifizierter Arbeitnehmer (vgl. Landmann/Pflüger 1996). Die empirische Evidenz für Deutschland ist widersprüchlich. Fitzenberger (1997) kommt in einer empirischen Untersuchung mit Daten für Westdeutschland von 1975 bis 1990 zum Ergebnis, da $\beta$ die Arbeitsmarktentwicklung für niedrigqualifizierte Arbeitnehmer durch den Außenhandel bestimmt wurde, während Lücke (1997) für den Beobachtungszeitraum 1970 bis 1991 diese Hypothese verwirft. Rodrik (1997) betont die gestiegene Elastizität der Arbeitsnachfrage durch die internationale Verflechtung: Arbeitnehmer verschiedener Nationalitäten können durch Auslagerungen von Produktionsstätten, Außenhandel und ausländische Direktinvestitionen leichter substituiert werden. Dadurch steigt die Verhandlungsmacht der inländischen Arbeitgeber im Lohnverhandlungsprozeß, weil sie glaubwürdig mit der kostengünstigeren Produktion im Ausland drohen 
können. Die empirische Relevanz der These von der „disziplinierenden Wirkung eines internationalen Arbeitskräftereservoirs" ist jedoch noch weitgehend unklar.

Wenn zum jetzigen Zeitpunkt die relative Bedeutung von Globalisierung und technologischem Wandel nicht abschließend geklärt werden kann, dann muß man für die Ursachenanalyse vielleicht die Vogelperspektive eines Wirtschaftshistorikers einnehmen, der in hundert Jahren über das Phänomen nachdenkt, wie Paqué (1997) vorschlägt. Der Wirtschaftshistoriker wird zwei langfristige Entwicklungen erkennen: Die Industrialisierung vom Anfang des 19. bis in die zweite Hälfte des 20. Jahrhunderts, die von einem Trend zu einer gleicheren Einkommensverteilung begleitet wurde, weil geringqualifizierte Arbeitskräfte dank eines komplementären Kapitalstocks relativ hohe Löhne erzielen konnten. Die darauf folgende schleichende De-Industrialisierung machte diesen Prozeß wieder rückgängig, allerdings auf hohem Einkommensniveau. Gering qualifizierte Arbeitnehmer erzielen in der Dienstleistungsgesellschaft relativ niedrigere Reallöhne, weil ihre Arbeitsproduktivität bei geringer Kapitalintensität der Dienstleistungen relativ geringer ist.

Weitgehende Einigkeit besteht jedoch in der Literatur, wie unterschiedlich flexible Arbeitsmärkte auf diese exogenen Schocks reagieren. Üblicherweise wird zwischen einem „europäischen Szenario“ mit unflexiblen Arbeitsmärkten und einem ,amerikanischen Szenario“ mit flexiblen Arbeitsmärkten unterschieden. Der auch im europäischen Vergleich relativ unflexible deutsche Arbeitsmarkt (vgl. OECD 1997a,b) läßt geringere Beschäftigung, höhere Arbeitslosigkeit und höhere Reallöhne im Niedriglohnsektor sowie eine relativ geringere Lohnspreizung zwischen den Löhnen hoch- und geringqualifizierter Arbeitnehmer im Vergleich zu flexibleren Arbeitsmärkten erwarten. Krugman (1994) bringt die unterschiedlichen Wirkungen auf den Punkt: „Europe Jobless, America Penniless“.

Technologischer Wandel und Globalisierung bei relativ unflexiblen Arbeitsmärkten haben zur Erodierung des sozialversicherungspflichtigen Normalarbeitsverhältnisses geführt und damit die Grundlage des Sozial- und Wohlfahrtsstaates europäischer Prägung in Gefahr gebracht. Hinzu kommt, daß die finanziellen Grundlagen des Sozialstaats durch seinen Erfolg in Frage gestellt werden. $\mathrm{Da}$ der Anteil der alten Menschen in Deutschland, die Ansprüche an den Sozialstaat erworben haben, in der Zukunft weiter zunehmen wird, ist nicht nur die Konsequenz einer über fünfzigjährigen Periode ohne Krieg und der geringen Fertilitätsrate seit den siebziger Jahren, sondern auch das Ergebnis der gestiegenen Lebenserwartung dank der medizinischen Versorgung durch den Wohlfahrtsstaat. Zusätzliche Ausgaben kamen in den neunziger Jahren als Folgewirkungen der politisch gewollten Wiedervereinigung hinzu. Die von der Politik und den Tarifpartnern gewählte Transformationsstrategie bürdete den sozialen Sicherungssystemen hohe Lasten auf - mit der Konsequenz steigender Steuer- und Abgabensätze. 
Der relative Arbeitsnachfragerückgang nach geringqualifizierter Arbeit, die Erodierung des Normalarbeitsverhältnisses, die relativ hohe Steuer- und Abgabenbelastung - alle diese Einflußfaktoren tragen dazu bei, daß insbesondere das Nettoeinkommen geringqualifizierter Arbeitnehmer mit Familien in die Nähe des Sozialhilfeniveaus abgesunken ist. Bei Verlust des Arbeitsplatzes werden institutionelle Regelungen, die in Zeiten der Vollbeschäftigung geschaffen wurden und lange Zeit unschädlich waren, plötzlich für die Arbeitsangebotsentscheidung relevant. Akut gewordene Fehlanreize des Sozialsystems gelten nach Ansicht des Wissenschaftlichen Beirats beim Bundesministerium der Wirtschaft (1996a) und der Deutschen Bundesbank (1996a) als ein wichtiges Hindernis für die Überwindung von Langzeitarbeitslosigkeit. Vor diesem Hintergrund werden in der vorliegenden Arbeit die Wechselwirkungen der bestehenden deutschen Grundsicherung in Form der Sozialhilfe sowie der Arbeitslosenunterstützung (Arbeitslosengeld und -hilfe) mit verschiedenen Segmenten des Niedriglohnsektors des Arbeitsmarktes betrachtet. Für die problemadäquate Behandlung dieses Problemfeldes ist eine detaillierte institutionelle Analyse zwingend erforderlich. Nur die Froschperspektive erlaubt die Entwicklung eines - und das ist der Anspruch dieser Arbeit realisierbaren Reformvorschlags, der auf die deutschen Institutionen abgestimmt ist. Bisherige Reformvorschläge, die Negativsteuerkonzepte und Lohnsubventionen zur Abfederung des strukturellen und technologischen Wandels in einer globalisierten Welt empfehlen, sind zu allgemein gehalten (vgl. Feenstra u. Lewis 1994, Feenstra 1998, Mc Kinsey Global Institute 1997, Sachverständigenrat 1998).

Die Betrachtung ausgewählter arbeitsrechtlicher und sozialrechtlicher Normen ist jedoch mit der Gefahr verbunden, daß andere Probleme mindestens gleicher Dringlichkeit verdrängt werden (vgl. Lampert 1995, S. 512). Doch gibt es insbesondere dann keine Alternative zum wohlüberlegten Herauspicken eines intensiv diskutierten Teilproblems, wenn - wie in diesem Themengebiet sowohl die Diagnose als auch die Therapie umstritten sind. Dennoch ist sich der Autor bewußt, daß der in dieser Arbeit entwickelte Reformvorschlag in ein Gesamtkonzept für die Reform des Sozialstaates und des Arbeitsmarktes eingebettet werden muß. Im Rahmen dieser Arbeit kann noch nicht einmal ein Gesamtkonzept für die Reform der Sozialhilfe entwickelt werden, doch ist der hier zu entwickelnde Vorschlag einer zielgruppenorientierten negativen Einkommensteuer („Einstiegsgeld“ für Langzeitarbeitslose) als Reform der bestehenden sozialen Grundsicherung in Form der Sozialhilfe zu verstehen. In der Klassifikation von Hauser (1995a, S. 129f) handelt es sich um eine reine Sozialhilfestrategie. Soweit das Einstiegsgeld als Verbesserung der bestehenden Regelungen im Arbeitsförderungsgesetz konzipiert ist, darf es als effizientere Ausgestaltung arbeitsmarktrechtlicher Regelungen interpretiert werden. Lampert (1995, S. 512) befürchtet weiterhin, daß falsche oder suboptimale Therapien gewählt werden, weil die Ursachenanalyse zu eingeengt betrieben 
wird. Sowohl bei der Darstellung der Problemanalyse als auch von Lösungsansätzen dominiert zwar auch in dieser Arbeit die allokative und fiskalische Analyse, doch hat der Autor versucht, der sozialpolitischen Dimension des Problems durch ein interdisziplinäres Literaturstudium Rechnung zu tragen. Wer als Ökonom über eine leistungsfreundliche Ausgestaltung des Transfersystems nachdenkt, könnte unmittelbar zu dem Schluß kommen: Eine Welt ohne soziale Sicherung ist die anzustrebende first best-Welt, weil dann keine preisverzerrenden Steuern erhoben werden müssen. Anders formuliert: Wenn es keine Subvention für Freizeit gibt, dann werden alle Haushalte Arbeit anbieten. In einer solchen Welt könnte die unsichtbare Hand des Marktes den Wohlstand der Nation maximieren, ohne von der öffentlichen Hand gestört zu werden. In dieser Arbeit wird jedoch nicht der Sozial- oder Wohlfahrtsstaat europäischer Prägung per se in Frage gestellt. Wenn man als Ökonom eine leistungsfreundliche Ausgestaltung des Transfersystems ohne generelle Absenkung des Transferniveaus vorschlägt, dann hält man offensichtlich eine staatliche Mindestsicherung auch aus ökonomischen Gründen für notwendig. Die Vorzüge einer staatlichen Grundsicherung gehen in der derzeitigen Diskussion über Ineffizienzen und Ungerechtigkeiten im Sozialstaat fast verloren. Dabei ist weitgehend unstrittig, daß die Sicherung des sozialen Friedens und die Eindämmung von Kriminalität zu seinen wichtigsten Errungenschaften zählt. Ein Blick in Länder mit kaum ausgebauten sozialen Sicherungssystemen verdeutlicht das hohe Niveau an öffentlicher Sicherheit, das in Deutschland existiert.

Einen systematischen Ansatz einer Theorie der Sozialpolitik entwickeln Berthold $(1991,1997)$ und Sinn (1994). Der Sozialstaat in einer Marktwirtschaft soll demnach die allokativen Unzulänglichkeiten auf den Arbeitsmärkten (schlechte Arbeitsbedingungen, mangelnde Sicherheit am Arbeitsplatz, unsichere Arbeitsplätze), auf den Kapital- und Versicherungsmärkten (Absicherung gegen die materiellen Folgen der Risikotatbestände Krankheit, Unfall, Arbeitslosigkeit, Pflegebedürftigkeit und Alter) vermindern. Der Sozialstaat soll das Gut „Sicherheit“ produzieren können. Da die Streuung des Lebenseinkommens eines Individuums nach der Geburt nicht voraussehbar ist, stellt die Existenz eines Wohlfahrtsstaates eine wohlfahrtssteigernde Versicherung dar, die Lebenskarrieren sicherer macht. Wie mit jeder Versicherung ist damit Einkommmensumverteilung von den Glücklichen zu den weniger Glücklichen verbunden. Umverteilung durch Besteuerung und Versicherung sind demnach zwei Seiten einer Medaille. Auf diese Weise erhöht der Wohlfahrtsstaat die Risikobereitschaft der Individuen. Das soziale Netz erlaubt es, daß Unternehmer ein höheres Risiko bei Investitionsentscheidungen eingehen können.

$\mathrm{Ob}$ der Sozialstaat auch distributive Fehlentwicklungen (existierende Armut, soziale Ungerechtigkeiten, ungleich verteilte Handlungsrechte) beseitigen soll, ist dagegen fraglich. Nach Berthold (1997, S. 12f.) hat der Sozialstaat die „Aufgabe, die Güter 'Sicherheit' und 'Gerechtigkeit' bereitzustellen, wenn sie 
auf privaten Märkten nicht oder nur ineffizient angeboten werden und eine realistische Chance besteht, daß ein staatliches oder staatlich initiiertes Angebot effizienter ausfällt“". Dagegen wendet jedoch Hayek (1996a,b) ein, daß der Begriff ,soziale Gerechtigkeit“ für eine Gesellschaft freier Menschen keinen Sinn habe. Üblicherweise werde diese nichtssagende Formel dazu benutzt, Sonderansprüche zu rechtfertigen, ohne daß man dies begründen müßte. Die völlige Inhaltslosigkeit des Begriffs zeige sich an der Tatsache, daß es keine Übereinstimmung darüber gibt, was soziale Gerechtigkeit im Einzelfall erfordert. Alles, was sich finden läßt, sind individuelle Urteile über als ungerecht empfundene Einzelfälle. Eine allgemeine Regel, aus der für Einzelfälle abgeleitet werden könne, was ,sozial gerecht“ ist, gebe es nicht, weshalb dieser Begriff intellektuell unredlich sei.

Dagegen sieht Berthold (1997, S. 17) in der Produktion des Gutes Gerechtigkeit die eigentliche Aufgabe des Sozialstaates. Die Einschätzung, was gerecht sei, beruhe zwar auf einem Werturteil, und entziehe sich somit einer ökonomischen Betrachtung. Doch bestehe in den meisten hochentwickelten Volkswirtschaften weitgehend Einigkeit zwischen den verschiedenen Gruppen in der Bevölkerung, daß allen Individuen ein - wie auch immer definiertes - Existenzminimum garantiert werden soll. Der Marktmechanismus versagt, weil die Produktion des Gutes „Gerechtigkeit“ mit positiven externen Effekten wie sozialer Friede oder geringere Kriminalitätsrate (vgl. Phelps 1994) verbunden ist. Individuell rationales Trittbrettfahrer-Verhalten führt deshalb zur Unterversorgung mit freiwilligen Unterstützungsleistungen trotz philanthropischer Motive der Individuen. Deshalb sollte der Sozialstaat dieses Gut herstellen.

Es bleibt festzuhalten: Die Existenz eines Sozialstaats läßt sich aus allokativen und distributiven Gründen rechtfertigen. Dennoch ist zu überlegen, ob der Sozialstaat die Produktion einzelner Güter unter Effizienzgesichtspunkten inzwischen zumindest zum Teil an private Träger abgeben sollte - Kapital- und Versicherungsmärkte funktionieren derzeit weit besser als zu den Anfangszeiten des Sozialstaates Ende des 19. Jahrhunderts. Im Mittelpunkt der vorliegenden Arbeit steht jedoch die Frage, wie angesichts hoher und langandauernder Arbeitslosigkeit die bestehende Grundsicherung in Form der Sozialhilfe sowie die Arbeitslosenversicherung leistungsfreundlicher ausgestaltet werden kann, so daß die öffentliche Hand die unsichtbare Hand des Marktes weniger stört. Insofern soll ein konkreter Beitrag für die Reform des Sozialstaats geleistet werden. Der Leser sollte sich dennoch stets bewußt sein, daß zum Beispiel die Sozialhilfeausgaben nur etwa vier (!) Prozent des Sozialbudgets des Staates ausmachen.

Im zweiten Kapitel dieser Arbeit wird die derzeit unterschätzte Dimension der Langzeitarbeitslosigkeit und des Langzeitsozialhilfebezugs verdeutlicht. Von den Einflußfaktoren, die zum Langzeithilfebezug beitragen, werden zwei Fehlanreize detailliert analysiert: der Lohnabstand zwischen Transfereinkommen und unteren Lohngruppen sowie die fast vollständige Anrechnung 
von Zusatzverdiensten auf die Arbeitslosenunterstützung bzw. die Sozialhilfe von Hilfeempfängern (Armutsfalle).

Im dritten Kapitel wird der Frage nachgegangen, ob Negativsteuerkonzeptionen ein Lösungsweg zur Überwindung der beschriebenen Fehlanreize sein können. Dazu werden die Konzeptionen von Rhys-Williams, Friedman, Tobin und Mitschke dargestellt. Im Mittelpunkt der allokativen und fiskalischen Analyse steht das in den neunziger Jahre in Wissenschaft und Politik intensiv diskutierte „Bürgergeld“.

Im vierten Kapitel werden aktuelle Lohnsubventionsmodelle dargestellt, die ebenfalls zum Abbau der Fehlanreize im deutschen Sozialsystem beitragen könnten. Drei Typen von Lohnsubventionsmodellen werden unterschieden: Lohnsubventionen an Arbeitnehmer, Lohnsubventionen an Arbeitgeber und Lohnsubventionen in Verbindung mit einer Arbeitspflicht (Welfare-to-WorkProgramme).

Im fünften Kapitel werden die verschiedenen Bausteine einer sogenannten zielgruppenorientierten negativen Einkommensteuer („Einstiegsgeld“ für Langzeitarbeitslose) dargestellt. Der Reformvorschlag Einstiegsgeld ist aus der Kritik am Bürgergeld entwickelt worden. Die Konzeption eines Einstiegsgeldes vermeidet die entscheidenden Nachteile des Bürgergeldes, ohne wesentliche Vorteile aufgeben zu müssen. Die Arbeitsangebots- und Beschäftigungswirkungen des Einstiegsgeldes werden zunächst in verschiedenen theoretischen Analyserahmen im Vergleich zum Status quo abgeleitet. Über diesen partialanalytischen Analyserahmen hinaus findet eine ausführliche Diskussion möglicher Arbeitsmarktwirkungen statt. Dabei werden Wechselwirkungen zwischen den verschiedenen Segmenten des Niedriglohnsektors ebenso diskutiert wie mögliche langfristige Folgewirkungen. Die Diskussion umfaßt auch den Vergleich mit anderen Lohnsubventionsmodellen an Arbeitnehmer und an Arbeitgeber und klärt die Beziehung zwischen Einstiegsgeld und Welfare-to-Work-Programmen.

Im sechsten Kapitel werden Schlußfolgerungen für die aktuelle wirtschaftsund sozialpolitische Diskussion gezogen und der zukünftige Forschungsbedarf skizziert. 


\section{Kapitel 2: Arbeits-Fehlanreize im Sozialsystem und Lang- zeitarbeitslosigkeit}

\subsection{Zum Aufbau des Kapitels}

Vor dem Hintergrund hoher und langanhaltender Arbeitslosigkeit wird in dieser Arbeit eine auf die Zielgruppe Langzeitarbeitslose gerichtete negative Einkommensteuer („Einstiegsgeld“ für Langzeitarbeitslose) vorgeschlagen. Deshalb ist eine detaillierte Analyse der Langzeitarbeitslosigkeit notwendig. Umfang und Struktur der Langzeitarbeitslosigkeit werden in Kapitel 2.2 im Spiegel der Arbeitslosen- und Sozialhilfestatistik dargestellt. In Kapitel 2.3 werden Einflußfaktoren auf die Dauer der Langzeitarbeitslosigkeit untersucht - mit dem Ergebnis, daß Fehlanreize im Sozialsystem eine wichtige Rolle spielen. In den Kapiteln 2.4 und 2.5 werden die beiden wichtigsten und am intensivsten diskutierten Fehlanreize im Sozialsystem - das Lohnabstandsproblem und die sogenannte Armutsfalle dargestellt. Eine Zusammenfassung der wichtigsten Ergebnisse findet sich in Kapitel 2.6.

\subsection{Umfang und Struktur der Langzeitarbeitslosigkeit}

Der Anteil der Langzeitarbeitslosen (= Erwerbspersonen, die seit mindestens einem Jahr ununterbrochen arbeitslos sind) an den Arbeitslosen hat sich in den letzten fünfzehn Jahren stark erhöht. Im Jahre 1995 betrug der Anteil nach Angaben der Bundesanstalt für Arbeit 32,7 \%, nach Angaben der OECD 48,3\% und nach Angaben des Instituts für Arbeitsmarkt- und Berufsforschung (IAB) sogar 63,2 \% (vgl. Karr 1997a). Diese erheblichen Unterschiede zwischen dem offiziell ausgewiesenen Anteil der Langzeitarbeitslosen und den höheren Zahlen anderer Institutionen machen es notwendig, die statistische Erfassung von Langzeitarbeitslosigkeit genauer zu beleuchten.

In der offiziellen Arbeitsmarktstatistik der Bundesanstalt für Arbeit (BA) werden lediglich die registrierten Arbeitslosen ausgewiesen; die sogenannte „stille Reserve“ der entmutigten Arbeitslosen, die im Jahre 1996 auf mindestens 2,5 Millionen Personen geschätzt wird, bleibt unberücksichtigt (vgl. Deutsches Institut für Wirtschaftsforschung 1997). Die traditionell wichtigsten Kennziffern zur Beschreibung der Arbeitsmarktlage - der Bestand an Arbeitslosen und die Arbeitslosenquote - sind in Abbildung 1 wiedergegeben. Es 
zeigt sich, daß die Arbeitslosenquote Mitte der neunziger Jahre immer neue historische Höchststände erreicht hat.

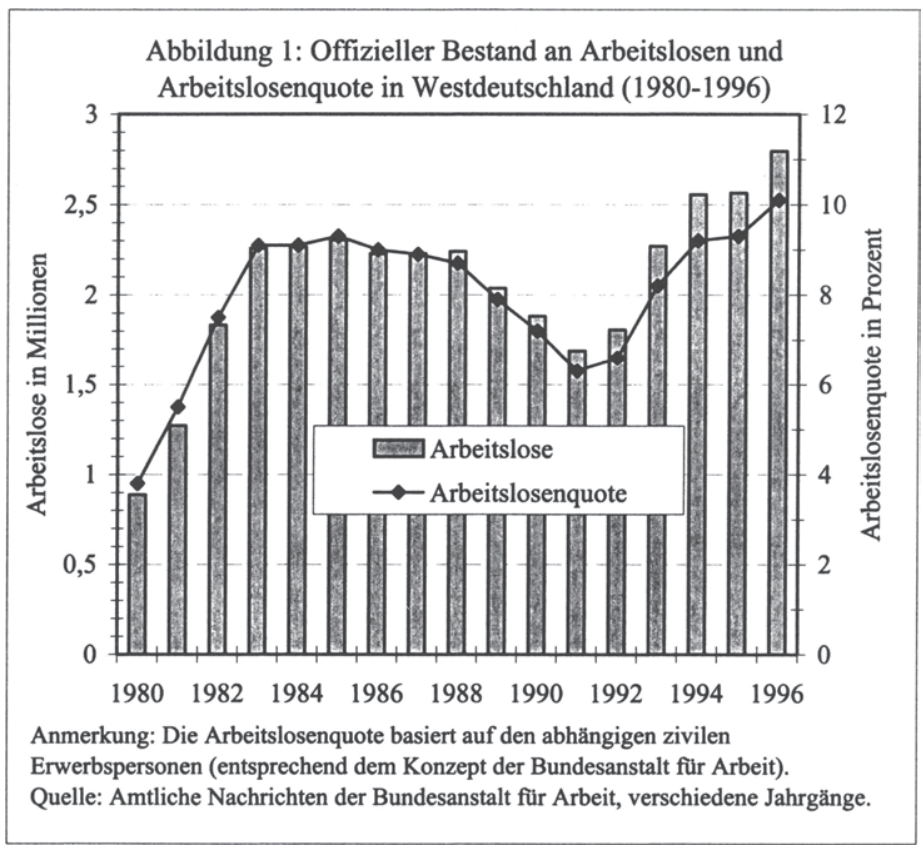

Der offizielle Bestand an Langzeitarbeitslosen hat in den neunziger Jahren ebenfalls immer neue Höchststände erreicht. Der Anteil der Langzeitarbeitslosen an den Arbeitslosen schwankt in den neunziger Jahren um den Wert von $30 \%$. Der Bestand an Langzeitarbeitslosen und ihr Anteil an den gesamten Arbeitslosen sind in Abbildung 2 für den Zeitraum 1980 bis 1996 illustriert.

Die offiziellen Zahlen zur Langzeitarbeitslosigkeit stellen jedoch nur eine Untergrenze der Langzeitarbeitslosigkeit dar. Die von der BA ausgewiesene Dauer der Arbeitslosigkeit bezieht sich auf die letzte Periode der Registrierung. Durch kurzfristige Beschäftigung, Krankheitszeiten, Umzüge oder Bildungsmaßnahmen wird die Periode unterbrochen. Hinzu kommt, daß vom 1.1.1986 an für ältere Arbeitnehmer ab 58 Jahren die Möglichkeit besteht, Arbeitslosengeld zu beziehen, auch wenn sie nicht bereit sind, eine Arbeit aufzunehmen. Diese Personengruppe muß dann im Rahmen von sogenannten Aufhebungsverträgen zum frühest möglichen Zeitpunkt, in der Regel mit 60 Jahren, in Rente gehen. Teilnehmer an dieser Vorruhestandsregelung werden nach $\S 105 \mathrm{c}$ Arbeitsförderungsgesetz (AFG) jedoch nicht als (Langzeit-) Arbeitslose gezählt (vgl. Rudolph 1992); im März 1995 erhielten rund 
151.600 Personen Leistungen nach § 105c AFG, wobei der Anteil der Langzeitarbeitslosen statistisch nicht erfaßt wird (vgl. Deutscher Bundestag 1995, S. 3).

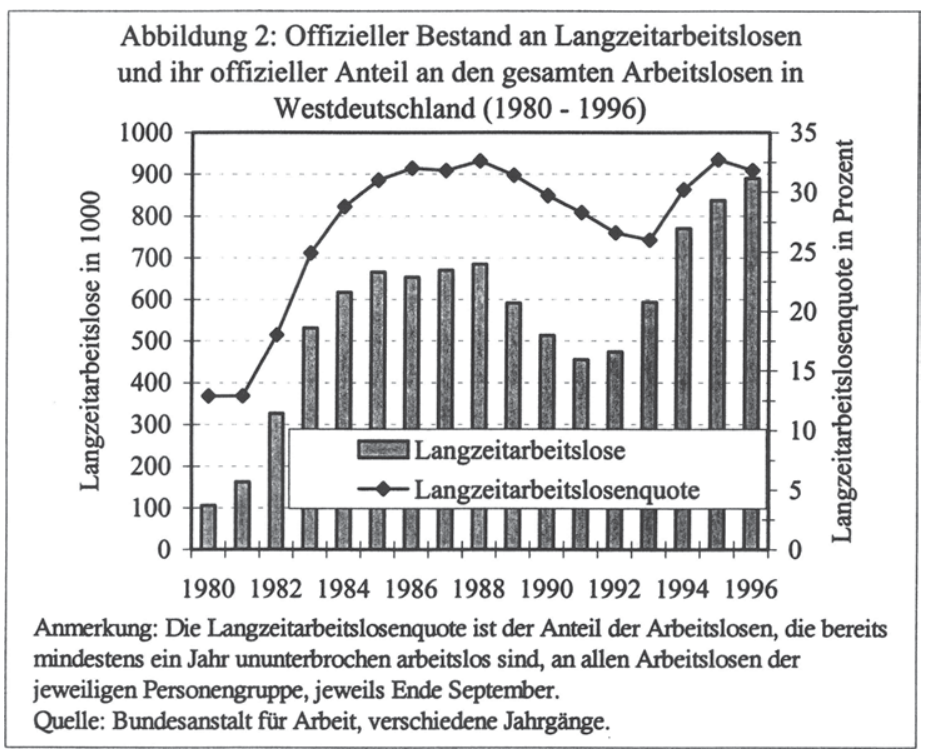

Einen tieferen Einblick in die Entwicklung der Arbeitslosigkeit vermittelt die Zerlegung der Arbeitslosenquote in ihre Komponenten Betroffenheit und vollendete Dauer. Die „Betroffenheit von Arbeitslosigkeit“ ist definiert als Wahrscheinlichkeit, in einem Jahr den Arbeitsplatz zu verlieren. Die Betroffenheit wird gemessen als Quotient der Zugänge in Arbeitslosigkeit (Fälle) und der abhängigen Erwerbspersonen in Prozent (vgl. Institut für Arbeitsmarkt- und Berufsforschung 1997, S. 60). Betroffenheit beinhaltet die beiden Dimensionen Risiko und Anzahl der individuellen Arbeitslosigkeitsperioden, so $\mathrm{da} \beta$ dieselbe Person innerhalb des betreffenden Jahres mehrfach den Weg in die Arbeitslosigkeit angetreten haben kann (vgl. Franz 1996b, S. $351 \mathrm{ff}$ ). Die vollendete Dauer der Arbeitslosigkeit wird in Wochen gemessen. Beide Komponenten sind in Abbildung 3 für den Zeitraum 1980 bis 1996 für Westdeutschland illustriert.

Es zeigt sich, daß die Betroffenheit durch Arbeitslosigkeit im betrachteten Zeitraum nach konjunkturbedingten Schwankungen auf einem etwas unter 20 $\%$ liegenden Niveau seit einigen Jahren nahezu unverändert geblieben ist. Dagegen nahm die durchschnittliche Dauer der Arbeitslosigkeit im betrachteten Zeitraum drastisch zu. 


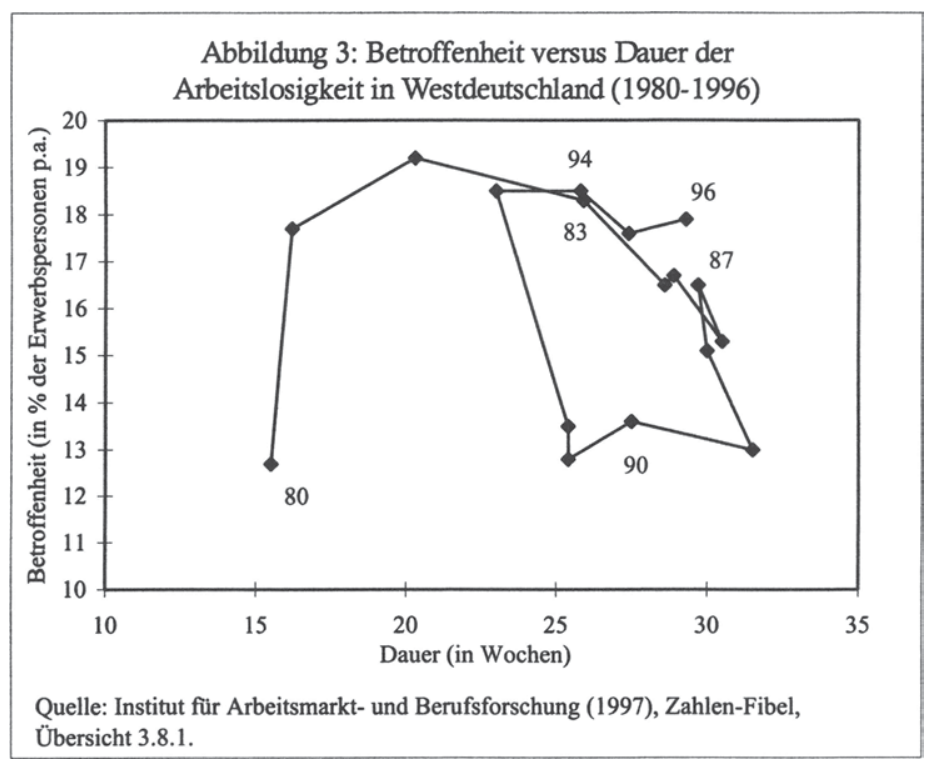

Die Statistik der OECD weist wesentlich höhere Anteile der Langzeitarbeitslosigkeit als die offizielle Statistik aus. Statistische Basis für die OECD-Daten ist die sogenannte "Stichprobenmethode“, mit der auch nicht registrierte Arbeitssuchende durch Befragungen erfaßt werden. (vgl. OECD 1987, Franz 1996c, Velling 1994). Die OECD-Daten bilden die Grundlage für internationale Vergleiche. Typischerweise fallen die „OECD standardisierten Arbeitslosenquoten" (Franz 1996c, S. 347) geringer als die Quoten der offiziellen Statistik aus. Das liegt daran, daß bei den Arbeitslosenquoten der BA allein die abhängig Erwerbstätigen als Nennergröße verwendet werden, während die OECD die Gesamtzahl der Erwerbspersonen (einschließlich Selbständige und Soldaten) verwendet. Dagegen sind die von der OECD ausgewiesenen Anteile der Langzeitarbeitslosen an der Gesamtarbeitslosigkeit höher als die der offiziellen Statistik. Hintergrund ist, daß die Stichprobenmethode auch arbeitssuchende Personen erfaßt, die nicht beim Arbeitsamt gemeldet, aber dem Arbeitsmarkt grundsätzlich zur Verfügung stehen (vgl. OECD 1987; Franz 1996c, S. 342f; van Suntum 1997, S. 12f). In Abbildung 4 wird der Anteil der Langzeitarbeitslosen an den gesamten Arbeitslosen für den Zeitraum 19821996 in Bezug zur Arbeitslosenquote gesetzt. Es zeigt sich, daß der Anteil der Langzeitarbeitslosen bereits in der zweiten Hälfte der achtziger Jahre bei nahezu $50 \%$ gelegen hat und - nach einem vorübergehenden, wiedervereinigungsbedingten Rückgang - Mitte der neunziger Jahre wieder auf etwa $50 \%$ gestiegen ist. 
Karr (1997a,b) weist darauf hin, daß sowohl die offizielle als auch die OECDStatistik das Ausmaß der Langzeitarbeitslosigkeit verschleiert. „In grober Annäherung kann gesagt werden, daß Langzeitarbeitslosigkeit etwa doppelt so hoch ist wie offiziell ausgewiesen" (Karr 1997a, S. 37). Der wesentliche Grund für die konzeptionelle Untererfassung der Langzeitarbeitslosigkeit liegt darin, daß nur jene als Langzeitarbeitslose erfaßt werden, bei denen das Ereignis schon eingetreten ist. Eine Bestandsstatistik, die die Arbeitslosen zu einem bestimmten Stichtag erfaßt, zählt jene Arbeitslose nicht, die erst in den nächsten Tagen, Wochen oder Monaten zu Langzeitarbeitslosen werden. Das führt gegenwärtig zu dem kuriosen Ergebnis, daß der Anteil von Langzeitarbeitslosen in der offiziellen Statistik zunimmt, wenn die Dauer der Arbeitslosigkeit bei unveränderter Anzahl von arbeitslosen Personen zunimmt. Dieses Problem läßt sich letztlich nur durch eine stromgrößenorientierte Arbeitsmarktstatistik lösen, die den Prozeßcharakter des Arbeitsmarktes berücksichtigt (vgl. Cramer et al. 1986).

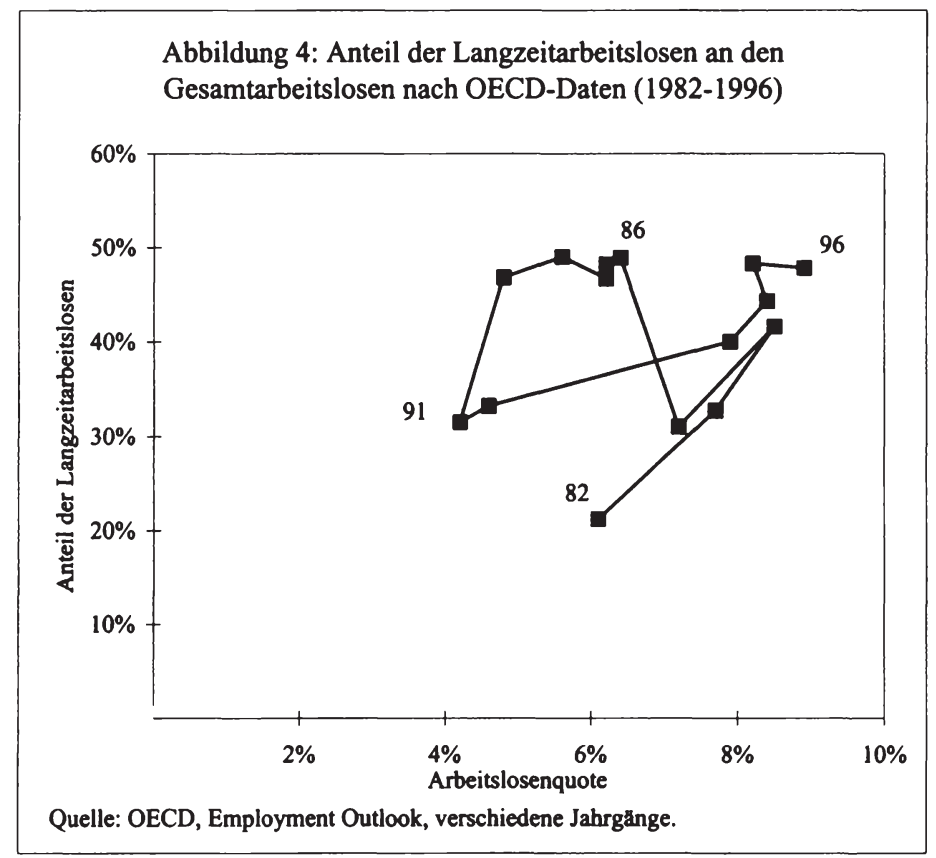

Die Auswirkungen der hohen Arbeitslosigkeit, vor allem jedoch der hohen Langzeitarbeitslosigkeit spiegeln sich auch in der Sozialhilfestatistik wider. Nach der offiziellen Sozialhilfestatistik gilt inzwischen jeder dritte Sozialhilfeempfänger als bedürftig wegen langanhaltender Arbeitslosigkeit (vgl. Neu- 
häuser 1995b). Nach einer Langzeitstudie (1983-1989) auf der Basis von 586 Aktenfällen in Bremen beantragen sogar $47 \%$ der Sozialhilfeempfänger wegen Arbeitslosigkeit Sozialhilfe (vgl. Leibfried/Leisering et al. 1995, S. 85). (Langzeit-)Arbeitslosigkeit könnte auch die Dauer des Sozialhilfebezugs erhöhen. Leibfried/Leisering et al. (1995) betonen jedoch, daß die Zunahme des Anteils Arbeitsloser unter den Sozialhilfeempfängern in Bremen eher den Anteil der Kurzzeitbezieher in den achtziger Jahren erhöht hat; Aussagen für die neunziger Jahre und für das gesamte Bundesgebiet liegen nicht vor. Da das Statistische Bundesamt im Jahre 1997 erstmals die Dauer des Sozialhilfebezugs ausgewiesen hat, ist jedoch bekannt, daß von den rund 2,5 Millionen Empfängern laufender Hilfe zum Lebensunterhalt Ende 1995 über 1,2 Millionen Personen seit über einem Jahr Sozialhilfe bezogen. Das entspricht einem Anteil von etwa 50 \% (vgl. Statistisches Bundesamt 1997e). In einigen Kommunen dürfte der Anteil der Langzeitsozialhilfeempfänger jedoch wesentlich höher sein. So bezogen im Jahre 1996 knapp 80 \% der Freiburger Sozialhilfeempfänger seit über einem Jahr Sozialhilfe (vgl. Amt für Statistik und Einwohnerwesen der Stadt Freiburg im Breisgau 1997, S. 19f.).

Die hohe Arbeitslosigkeit gilt als Hauptursache für die hohen Zuwächse der Sozialhilfeempfängerzahlen. Typischerweise beziehen Langzeitarbeitslose laufende Hilfe zum Lebensunterhalt. Zusätzlich oder alternativ können Bedürftige Hilfe in besonderen Lebenslagen erhalten. Demnach ist zwischen Zuwächsen der gesamten Sozialhilfeempfänger und den Zuwächsen der Empfänger der laufenden Hilfe zum Lebensunterhalt zu unterscheiden. Beide Zeitreihen sind in Abbildung 5 dokumentiert:

Die Zahl aller Sozialhilfeempfänger verdoppelte sich zwischen 1980 und 1993 von 2,1 Millionen auf 4,3 Millionen Personen; die gesamte Sozialhilfeempfängerzahl wird seit der Neustrukturierung der Sozialhilfestatistik 1994 nicht mehr erfaßt. Auch die Zahl der Empfänger laufender Hilfe zum Lebensunterhalt stieg um mehr als das zweifache - von knapp einer Million auf über zwei Millionen Personen in Westdeutschland bzw. 2,5 Millionen Personen in Gesamtdeutschland (vgl. Statistisches Bundesamt 1997a, S. 44). Die Empfängerzahlen sind jedoch seit der Neustrukturierung der Sozialhilfestatistik vom Berichtsjahr 1994 an mit Vorsicht zu interpretieren. Auffällig ist, daß offensichtlich bewußt ein wesentlich niedrigeres Niveau an Empfängern laufender Hilfe zum Lebensunterhalt offiziell ausgewiesen wird: Vor der Sozialhilfestatistikreform wurden im Jahre 1993 bereits knapp 3,5 Millionen Bezieher allein für Westdeutschland angegeben (Deutsche Bundesbank 1996b, S. 52). Hintergrund ist, daß von 1994 an Asylbewerber nicht mehr in der Sozialhilfestatistik aufgeführt werden (vgl. Hoffmann/Beck 1994, Statistisches Bundesamt 1997c,d). Ergänzend ist deshalb anzumerken, daß im Jahre 1995488.974 Personen Regelleistungen und 170.054 Personen besondere Leistungen nach dem Asylbewerbergesetz erhielten (vgl. Statistisches Bundesamt 1997d). Hinzu kommen 1,4 Millionen Personen, die im Jahre 1995 
Hilfe in besonderen Lebenslagen erhielten (vgl. Statistisches Bundesamt 1997b), wobei zu beachten ist, daß eine Person sowohl Hilfe zum Lebensunterhalt als auch Hilfe in besonderen Lebenslagen beziehen kann; die Schnittmenge wird nicht (mehr) statistisch erfaßt.

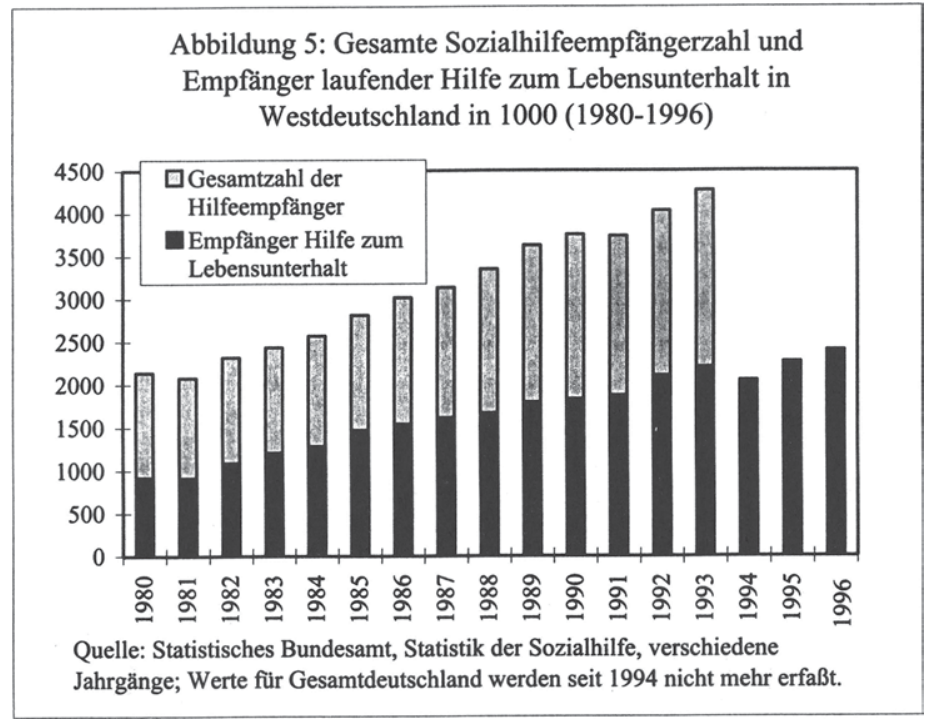

Um eine realistische Vorstellung zum Ausgabenumfang zu vermitteln, ist es sinnvoll, die gesamten Sozialhilfeausgaben (Hilfe zum Lebensunterhalt und Hilfe in besonderen Lebenslagen) mit den Ausgaben für Hilfe zum Lebensunterhalt zu vergleichen. Wie der Vergleich in Abbildung 6 zeigt, sind zwar beide Ausgabenkategorien real stark gestiegen, der Anteil der Hilfe zum Lebensunterhalt an den Gesamtausgaben blieb jedoch mit einem Drittel relativ konstant. Das reale Ausgabenwachstum bei der Sozialhilfe ist demnach nicht überproportional von den Ausgaben für Langzeitarbeitslose getrieben worden. Vielmehr sind die realen Sozialhilfeausgaben aus einer Vielzahl von Gründen gestiegen - Pflegebedürftigkeit und Zuwanderung spielen dabei eine wichtige Rolle (vgl. Deutsche Bundesbank 1996b, Frick et al. 1996). Im Jahr 1996 gingen die gesamten Sozialhilfeausgaben in Westdeutschland auf nominal 43,3 Mrd. DM (Gesamtdeutschland: nominal 49,8 Mrd. DM) leicht zurück. Der Grund: Die Einführung der Pflegeversicherung führte zu einer Kostenentlastung bei der Hilfe in besonderen Lebenslagen (vgl. Statistisches Bundesamt $1997 \mathrm{f}$ u. Statistisches Bundesamt 1998b). Der Ausgabenrückgang ist demnach kein Zeichen für eine geringere finanzielle Belastung des Staates, sondern lediglich Ausdruck einer Umschichtung von steuerfinanzierten Ausgaben in beitragsfinanzierte Ausgaben zur Kostenentlastung der Kommunen. 
Der leichte reale Ausgabenrückgang im Jahr 1994 ist wiederum die Konsequenz der Neustrukturierung der Sozialhilfestatistik: Die von diesem Berichtsjahr an nicht mehr in der Sozialhilfestatistik berücksichtigten Ausgaben für Asylbewerber betragen jährlich nominal etwa 5 Milliarden DM in Westdeutschland (vgl. Statistisches Bundesamt 1997f).

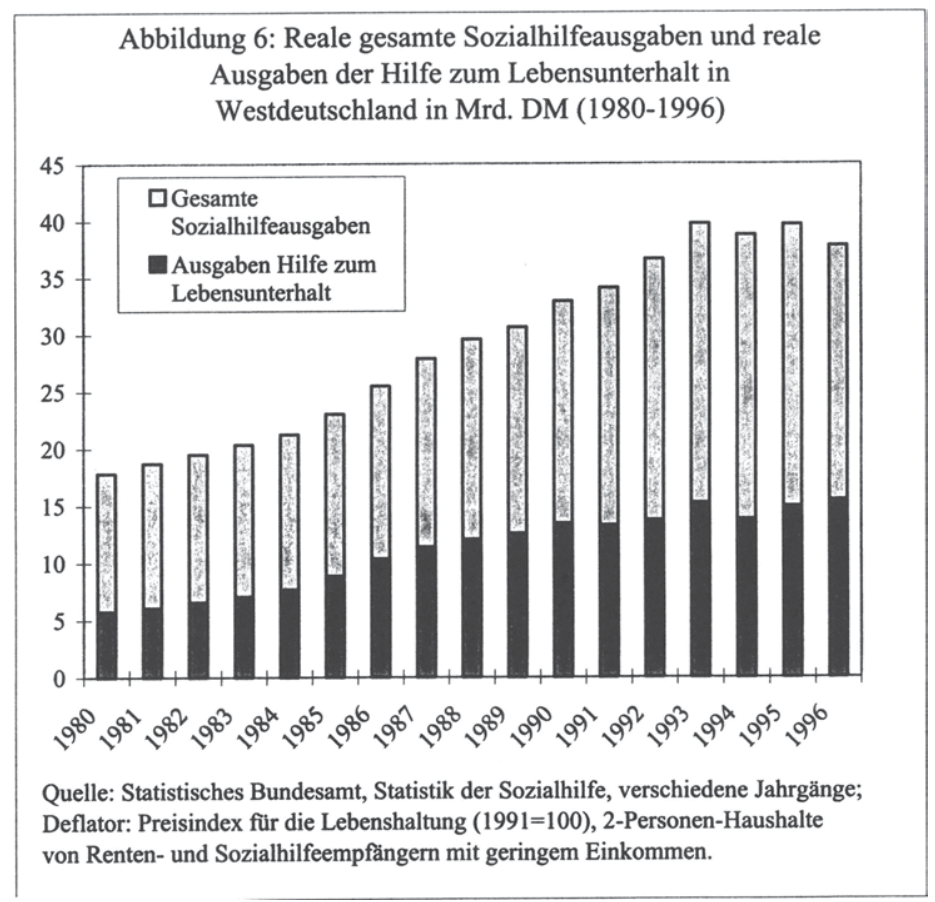

Andererseits ist die finanzielle Belastung des Staates durch Sozialhilfe nicht so hoch wie die ausschließliche Betrachtung der Ausgaben nahelegt. In beträchtlichem Umfang können Einnahmen gegengerechnet werden. Die Entwicklung der realen Nettoausgaben im Zeitraum 1980-1996 wird in Abbildung 7 im Vergleich zu den realen gesamten Sozialhilfeausgaben wiedergegeben:

Die finanzielle Belastung der Kommunen durch (Langzeit-)Arbeitslosigkeit wird jedoch auch durch die gesamten Nettoausgaben deutlich überschätzt. Relevant sind die Nettoausgaben für Hilfe zum Lebensunterhalt außerhalb von Einrichtungen, die erst seit wenigen Jahren vom Statistischen Bundesamt erhoben werden und deshalb nicht in den Abbildungen 6 und 7 wiedergegeben werden - sie betrugen im Jahre 1995 nominal „lediglich“ 14,9 Mrd. DM in Gesamtdeutschland (vgl. Neuhäuser 1997, S. 335). 
Die Struktur der Langzeitarbeitslosen hat sich seit 1980 sowohl in der Arbeitsmarkt- als auch in der Sozialhilfestatistik gewandelt. Nach einer Untersuchung von Rudolph (1992) für den Zeitraum 1984-89 sind geringqualifizierte Arbeiter (oftmals ohne berufliche Ausbildung), ältere Arbeitnehmer ab 45 Jahre und gesundheitlich beeinträchtigte Arbeitnehmer die wichtigsten Personengruppen, die mit einem hohen Risiko langzeitarbeitslos werden. Die Kombination dieser Merkmale führt zu einem sehr hohem Risiko, langzeitarbeitslos zu werden. Dagegen kommen Steiner/Kaltenborn (1995) in einer Strukturanalyse für den Zeitraum 1980-94 zu einem abweichenden Ergebnis: „Problemgruppen des Arbeitsmarktes sind vor allem schwerbehinderte und ältere Arbeitslose, nicht aber Frauen und Arbeitslose ohne Berufsausbildung" (Steiner/Kaltenborn 1995, S. 48f.). Als Intuition für ihr Ergebnis bieten sie an, daß bei der Gruppe der Geringqualifizierten die mit dem Erwerb von berufs- und betriebsspezifischer Qualifikation verbundenen Mobilitätskosten eine geringe Rolle spielen - mit der Konsequenz, daß einerseits Kündigungen eher erfolgen, andererseits aber auch die Hemmschwelle bei der Einstellung bzw. der Annahme eines Beschäftigungsangebots deutlich niedriger als bei den Arbeitslosen mit höherer Berufsausbildung liegt.

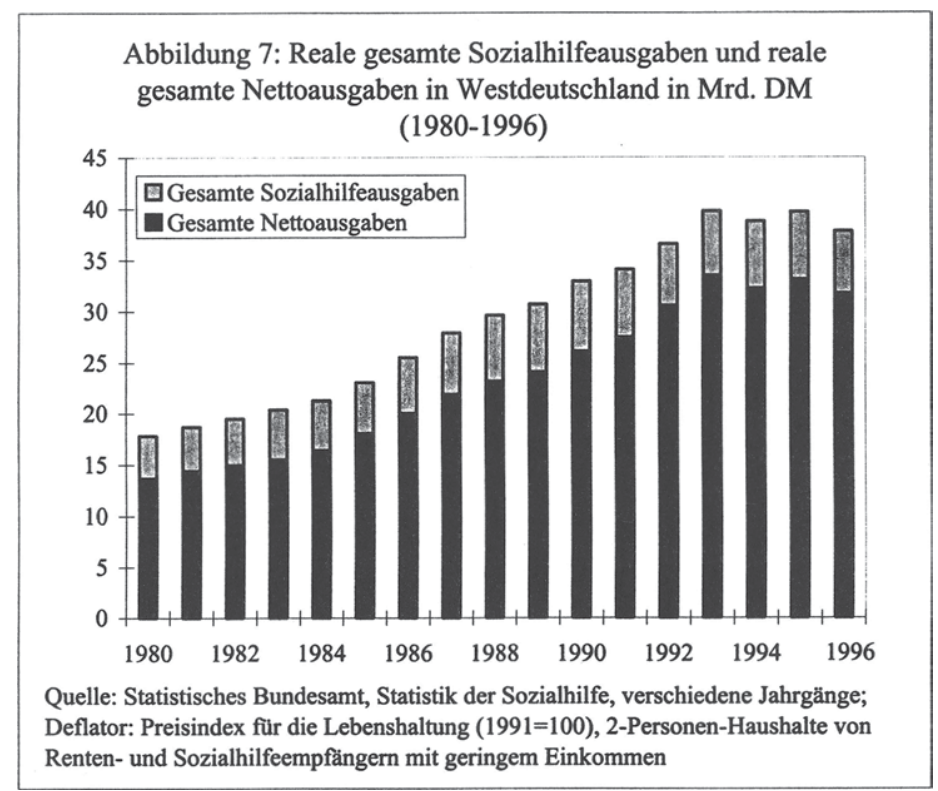

Die Struktur der Langzeitarbeitslosigkeit hat sich seit 1980 zu Lasten älterer Arbeitnehmer verschoben; Langzeitarbeitslosigkeit spielt derzeit bei jugendlichen Arbeitslosen unter 25 Jahren eine geringe Rolle, und die Jugendarbeits- 
losigkeit ist in Deutschland im internationalen Vergleich gering. Der geschlechtsspezifische Unterschied in bezug auf die Dauer der Arbeitslosigkeit ist in Westdeutschland relativ gering und hat sich in den neunziger Jahren weiter vermindert (vgl. Steiner/Kaltenborn 1995, S. 46). Dagegen sind in Ostdeutschland drei Viertel aller Langzeitarbeitslosen Frauen (vgl. van Suntum 1997, S. 15).

Die heutige Sozialhilfeempfängerstruktur ist vor allem durch Kurzeit- und Langzeitarbeitslose sowie Alleinerziehende mit Kindern gekennzeichnet (vgl. Neuhäuser 1995b). Stellten ältere Personen in den sechziger und siebziger Jahren typischerweise den größten Anteil an den Sozialhilfeempfängern, so hat ihr Anteil in den achtziger und neunziger Jahren deutlich abgenommen (vgl. Semrau 1990, Beck 1992). Dagegen ist der Anteil der Kinder und Jugendlichen unter 18 Jahren an den Sozialhilfeempfängern bis Ende des Jahres 1995 auf 38,3 \% gestiegen. Damit waren knapp eine Million Kinder und Jugendliche auf Sozialhilfe angewiesen, wovon 464.000 Kinder in Haushalten von alleinerziehenden Frauen lebten (vgl. Statistisches Bundesamt 1997g); genauere dynamische Analysen nach der neuen Sozialhilfestatistik liegen derzeit nicht vor (vgl. Hoffmann/Beck 1994).

Die große Bedeutung von Alleinerziehenden in der Sozialhilfeempfängerstatistik spiegelt den gesellschaftlichen Wandel wider - die Zahl der Alleinerziehenden ist in den letzten Jahren stark angestiegen. Alleinerziehende sind ein typisches Beispiel für nicht registrierte Arbeitslose, die jedoch bei Befragungen im Rahmen der dynamischen Armutsforschung durchaus den Wunsch äußern, eine Teilzeit- oder Ganztagsstelle anzunehmen (vgl. Zwick 1994 u. Leibfried/Leisering et al. 1995). Deshalb kann zumindest ein Teil von ihnen zur Problemgruppe der Langzeitarbeitslosen gerechnet werden, auch wenn sie in den offiziellen Arbeitsmarktstatistiken nicht als Problemgruppe identifiziert werden.

Zusammenfassend bleibt festzuhalten, daß die offizielle Arbeitsmarktstatistik das Ausmaß der Langzeitarbeitslosigkeit unterschätzt. Nach Angaben der realitätsnäher erhobenen Statistik der OECD sind gut die Hälfte aller Arbeitslosen seit über einem Jahr arbeitslos. Nach der Neustrukturierung der Sozialhilfestatistik sind jetzt auch Daten zum Langzeitsozialhilfebezug verfügbar. Nach Angaben des Statistisches Bundesamts sind knapp die Hälfte aller Bezieher laufender Hilfe zum Lebensunterhalt seit über einem Jahr auf Sozialhilfe angewiesen. Auch hat sich die Struktur der Langzeitarbeitslosigkeit verändert: Die Analyse der Arbeitsmarktstatistiken ergibt, daß vor allem schwerbehinderte und ältere Arbeitslose, nicht aber Frauen und Arbeitslose ohne Berufsausbildung zu den wichtigsten Problemgruppen des Arbeitsmarktes in Westdeutschland zählen; in Ostdeutschland sind dagegen insbesondere Frauen von Langzeitarbeitslosigkeit betroffen. Die Analyse der Sozialhilfeempfängerstatistik ergibt unter Einbeziehung der Erkenntnisse der dynamischen Armutsforschung, daß alleinerziehende Frauen als nicht registrierte aber den- 
noch arbeitssuchende Personen ebenfalls zur Problemgruppe der Langzeitarbeitslosen zählen könnten.

\subsection{Einflußfaktoren auf die Dauer der Arbeitslosigkeit}

Für die Entstehung und Dauerhaftigkeit der Langzeitarbeitslosigkeit spielen mehrere Faktoren eine wichtige Rolle. Erstens ist die schon in Kapitel 2.2 ausgeführte Konzentration von nachteiligen Merkmalen bei betroffenen Personen von Bedeutung. Zweitens besteht die Tendenz zur Selbstverstärkung durch Dequalifikation und Entmutigung. Langzeitarbeitslosigkeit wird von Unternehmen als Signal für geringe Produktivität gewertet. Unabhängig davon, ob diese Einschätzung im Einzelfall gerechtfertigt ist, werden bei gleicher formaler Qualifikation Beschäftigte oder kurzfristig arbeitslose Bewerber einem Langzeitarbeitslosen vorgezogen. Diese Zurückhaltung der Unternehmen gegenüber der Einstellung von Langzeitarbeitslosen mag durch allgemeine und spezielle Kündigungsvorschriften verstärkt werden. Hinzu kommen Entmutigungseffekte auf Seiten der Langzeitarbeitslosen, die sich negativ auf ihre Suchaktivitäten auswirken (vgl. Sachverständigenrat 1995, S. 251).

Steiner (1994) kritisiert diese sogenannte „Stigmatisierungs- und Humankapital"-Hypothese. In einer empirischen Analyse auf der Basis des Sozioökonomischen Panels für den Zeitraum 1983 bis 1992 wird bestätigt, daß sich Langzeitarbeitslosigkeit auf eine mit zunehmender Dauer stark sinkende durchschnittliche Abgangsrate aus der Arbeitslosigkeit zurückführen läßt. Es läßt sich jedoch zeigen, daß die abnehmende durchschnittliche Abgangsrate das Ergebnis eines Sortierprozesses ist: Der Anteil der Personen mit von Beginn an relativ niedrigen Wiederbeschäftigungschancen nimmt mit zunehmender Arbeitslosigkeitsdauer im Bestand zu, die Gruppe mit hohen Abgangsraten scheidet dagegen sehr schnell aus dem Bestand aus. Aus diesem Ergebnis werden weitreichende wirtschaftspolitische Schlußfolgerung gezogen: Maßnahmen für bestimmte Problemgruppen sollten gleich von Beginn ihrer Arbeitslosigkeit an eingesetzt werden (vgl. Steiner 1994, S. 25).

Drittens gilt die Höhe der Arbeitslosenunterstützung als wichtiger Einflußfaktor. Burda (1988) erklärt in einer empirischen Studie für 14 OECD-Länder im Jahre 1985 die unterschiedliche Dauer der Arbeitslosigkeit in diesen Ländern mit den unterschiedlichen Niveaus der Arbeitslosenunterstützung. Sein Ergebnis: Je höher das Arbeitslosengeld, desto länger dauert die Arbeitslosigkeit (vgl. auch Katz/Meyer 1990 u. Atkinson/Micklewright 1991).

Viertens ist die maximale Bezugsdauer von Arbeitslosengeld für die Dauer der Arbeitslosigkeit von Bedeutung, wie Hunt (1995) in einer empirischen Studie auf der Basis des Sozioökonomischen Panels für Westdeutschland in den achtziger Jahren zeigt. Die Gesetzesänderungen im Arbeitsförderungsgesetz, die von 1985 an die maximale Bezugsdauer von Arbeitslosengeld für 
ältere Arbeitnehmer auf bis zu 32 Monate ausdehnten, führten zu erheblich höherer Arbeitslosigkeitsdauer. Zu einem ähnlichen Ergebnis kommen Bogai et al. (1994) in einer Befragung von über 45 Jahre alten Langzeitarbeitslosen aus dem Jahre 1992. Danach streben nur 43 Prozent der Befragten eine neue Beschäftigung an, während ein Viertel die Arbeitslosigkeit als Vorstufe zum vorgezogenen Ruhestand betrachtet. Steiner (1997) untersucht das Zusammenwirken von zeitlich befristetem Arbeitslosengeld und zeitlich unbefristeter Arbeitslosenhilfe auf die Dauer der Arbeitslosigkeit. Seine empirische Analyse zeigt, daß bereits eine relativ kurze Anspruchsdauer auf Arbeitslosengeld mit einem höheren Anteil an Langzeitarbeitslosen verbunden ist, falls im Anschluß ein Anspruch auf Arbeitslosenhilfe besteht. Dieses Ergebnis gilt für Männer, dagegen ist der Einfluß auf Frauen sehr gering. Winter-Ebmer (1998) zeigt anhand eines Quasi-Experiments am Beispiel der Verlängerung der Arbeitslosenunterstützung für ältere Arbeitnehmer in bestimmten Regionen Österreichs im Jahre 1988, daß Männer auf die Dauer der Arbeitslosenunterstützung reagieren: Die Verlängerung der Bezugsdauer um 157 Wochen erhöhte die Inanspruchnahme von Arbeitslosenunterstützung um 5 Wochen; für Frauen konnte kein signifikanter Einfluß nachgewiesen werden. Dagegen erhöhte sich die Bezugszeit für die Gruppe der bisherigen Langzeithilfeempfänger unabhängig vom Geschlecht der Empfänger von Arbeitslosenunterstützung.

Fünftens gelten Fehlanreize im Sozialsystem als Hindernis zur Überwindung von Langzeitarbeitslosigkeit. Dabei gelten der als zu gering empfundene Lohnabstand zwischen Sozial- und Arbeitseinkommen sowie die Vollanrechnung von Zusatzeinkommen auf Hilfeleistungen (Armutsfalle) als die wichtigsten Fehlanreize (vgl. Wissenschaftlicher Beirat beim Bundesministerium für Wirtschaft 1996a, Deutsche Bundesbank 1996a). Beide Fehlanreize stehen im Mittelpunkt dieser Arbeit und werden detailliert in den folgenden Kapiteln dargestellt.

\subsection{Fehlanreiz Nr. 1: Das Problem des Lohnabstandes}

\subsubsection{Der Verlauf der Lohnabstandsdiskussion}

Die Jahreswende 1992/93 markierte den Anfang der Lohnabstandsdiskussion der neunziger Jahre. Finanzminister Theo Waigel fragte öffentlich, „ob es richtig sei, daß mancher Sozialhilfeempfänger pro Monat mehr erhalte als sein Nachbar, der Arbeitslosengeld oder gar Lohn beziehe" (Frankfurter Allgemeine Zeitung vom 19.12.1992). Bundeskanzler Helmut Kohl fand es nicht mehr in Ordnung, „wenn jemand im Bereich der Sozialhilfe, ohne eine Leistung zu erbringen, mehr von der Sozialgemeinschaft bekomme als derjenige, der arbeite" (Süddeutsche Zeitung vom 4.1.1993). Und die Bundesvereini- 
gung der Deutschen Arbeitgeberverbände (BDA) stellte die rhetorische Frage: „Lohnt sich Arbeit noch?“" (Mediendienst der BDA vom 7.1.1993).

Finanzminister, Bundeskanzler und die BDA stützten sich in ihren Ausführungen auf eine Studie des Instituts der Deutschen Wirtschaft (IW). Darin heißt es, daß zwar im allgemeinen ein Abstand zwischen Sozialhilfebezügen und dem Nettoeinkommen in Leichtlohngruppen noch gewahrt ist. Doch es gebe Fälle, bei denen das nicht mehr zutreffe. So wird das Beispiel eines alleinverdienenden Mannes angeführt, der Frau und Kind mit seinem Verdienst versorgt und monatlich kaum mehr auf dem Konto hat als eine vergleichbare Familie, die ausschließlich von der Sozialhilfe lebt. Bei zwei und mehr Kindern bleibt das Nettoarbeitseinkommen bereits um 250 Mark und mehr im Monat hinter der Sozialhilfe zurück (vgl. Seffen 1992).

$\mathrm{Zu}$ diesem Zeitpunkt war bereits ein Gutachten vom Bundesministerium für Familie und Senioren beim Otto-Blume-Instituts für Sozialforschung und $\mathrm{Ge}$ sellschaftspolitik (ISG) in Auftrag gegeben worden. Im Juli 1993 wurde dieses Gutachten vorgelegt (vgl. Breuer/Engels 1993) - es bildete die Grundlage zu einem Bericht der Bundesregierung zur Frage der Einhaltung des Lohnabstandsgebotes nach $\S 22$ Abs. 2 Bundessozialhilfegesetz (BSHG). Die damalige Familienministerin Hannelore Rönsch gab die Ergebnisse des Berichts am 29.12.1993 bekannt: „Im Bundesdurchschnitt wird das Lohnabstandsgebot gewahrt. Diese Werte lassen aber keine Aussagen über die Einhaltung des Lohnabstandsgebots in jedem einzelnen Bundesland zu. Da die Sozialhilfe sich an der individuellen Situation des Hilfeempfängers orientiert, kann sie im Einzelfall unter Umständen auch über dem durchschnittlichen Einkommen unterer Lohn- und Gehaltsgruppen liegen. Das Lohnabstandsgebot bezieht sich allein auf Durchschnittsfälle" (Bundesministerium für Familie, Senioren, Frauen und Jugend 1993b, S. 1-2).

Nach Ansicht der Ministerin ist „der Lohnabstand dann ausreichend, wenn es für Sozialhilfeempfänger im Durchschnittsfall einen finanziellen Anreiz gibt, eine Erwerbstätigkeit auszuüben. Um dies zu gewährleisten, muß ein erwerbstätiger Sozialhilfeempfänger mehr Geld zur Verfügung haben als ein Sozialhilfeempfänger, der keiner Erwerbstätigkeit nachgeht. Zugleich muß ein erwerbstätiger Sozialhilfeempfänger mit seiner Sozialhilfe unter einem durchschnittlichen Arbeitnehmereinkommen in einer unteren Lohngruppe bleiben“" (Hervorhebungen des Autors, Bundesministerium für Familie, Senioren, Frauen und Jugend 1993b, S. 3).

Anfang April 1995 stellte Bundesgesundheitsminister Horst Seehofer, dessen Ministerium inzwischen für Sozialhilfefragen zuständig ist, „Eckpunkte für eine Reform der Sozialhilfe" vor. Die Eckpunkte sahen vor, das Lohnabstandsgebot zu konkretisieren: Die Sozialhilfeleistungen sollten von 1999 an um $15 \%$ unter dem verfügbaren Einkommen von verheirateten Alleinverdienern mit drei Kindern unterer Lohn- und Gehaltsgruppen liegen. Seehofer betonte, daß durch die von 1996 an geplanten höheren Kindergeldzahlungen 
der Lohnabstand in den westlichen Ländern mehr als $16 \%$ betrage. In Ostdeutschland würde der Abstand von zu diesem Zeitpunkt 13,5\% durch die ebenfalls geplante Orientierung der Sozialhilfezuwächse am Anstieg der Nettolöhne und -gehälter von 1996 bis 1999 auf $15 \%$ steigen (vgl. Seehofer 1995). Der entsprechende Gesetzentwurf wurde im Juli 1995 vom Bundeskabinett verabschiedet.

Ein Bericht der Deutschen Bundesbank löste im Februar 1996 erneut eine Lohnabstandsdiskussion aus. Die Bundesbank berechnete den Lohnabstand explizit nicht anhand industrieller Durchschnittslöhne, sondern der tariflichen Mindestlöhne in drei verschiedenen Wirtschaftsbereichen auf der Basis der hessischen Tarifabschlüsse für 1995. Das Ergebnis: Der Lohnabstand gegenüber der Sozialhilfe verringert sich mit wachsender Familiengröße erheblich. Für Alleinerziehende mit einem Kind lohnt es sich kaum noch, eine reguläre Erwerbstätigkeit in der untersten Lohngruppe aufzunehmen. Für verheiratete Alleinverdiener mit zwei Kindern liegt das verfügbare Mindesteinkommen bei einfachen Hilfstätigkeiten im Hotel- und Gaststättengewerbe oder im Einzelhandel sogar unter dem Sozialhilfeniveau: der Lohnabstand wird in diesen Fällen negativ (vgl. Deutsche Bundesbank 1996a, S. 64f.).

Gegen die Berechnungen der Bundesbank wandte sich das Bundesministerium für Gesundheit mit Vehemenz. Das Ministerium bezichtigte die Bundesbank, mit „unzutreffenden Zahlen“ zu arbeiten: „Die Bemessung der Sozialhilfe kann sich im übrigen nicht an beliebig ausgewählten Mindesttarifen orientieren, sondern muß die statistisch nachweisbaren durchschnittlichen Effektivverdienste berücksichtigen, wie sie die amtliche Lohnstatistik ausweist. Dabei können auch nur die durchschnittlichen Arbeitsentgelte unterer Lohnund Gehaltsgruppen, nicht aber einzelne Tarifentgelte sowie regional, sektoral oder nach Tätigkeitsmerkmalen differenzierte Einkommen unterster Lohngruppen berücksichtigt werden" (Bundesministerium für Gesundheit 1996).

Im Juni 1996 einigte sich die damalige CDU/CSU-FDP-Koalition und die Opposition im Vermittlungsausschuß von Bundestag und Bundesrat. Die Opposition wehrte sich erfolgreich gegen eine prozentuale Festlegung des Lohnabstandsgebotes, die sie als Verdoppelung des bestehenden Lohnabstandes interpretierte. Das „Gesetz zur Reform des Sozialhilferechts" trat am ersten August 1996 in Kraft (vgl. Bundesgesetzblatt 1996, S. 1088-1100). Die Konkretisierung des Lohnabstandsgebotes wurde nicht verabschiedet.

\subsubsection{Die Interpretation des Lohnabstandsgebots}

Die Interpretation des Lohnabstandsgebots ist in mehrfacher Hinsicht umstritten. Erstens wird diskutiert, ob die Nettoeinkommen unterer oder unterster Lohn- und Gehaltsgruppen mit den Sozialhilfeleistungen verglichen werden sollen. Zweitens ist die Vergleichsgröße „Nettoeinkommen“ umstritten. Drittens liegen unterschiedliche Berechnungsmethoden für die Höhe des verfügbaren Einkommens von Sozialhilfeempfängern vor. Viertens ist die Berech- 
nung des Zuwachses der verfügbaren Einkommen der Erwerbstätigen und der Sozialhilfeempfänger kontrovers. Fünftens ist der Begriff des Lohnabstandes in zweifacher Hinsicht interpretationsfähig. Dementsprechend liegen unterschiedliche Berechnungen zum Lohnabstand vor, die im folgenden detaillierter analysiert werden.

\section{(1) Untere versus unterste Lohngruppen als Bezugsgröße}

Das Lohnabstandsgebot ist in $\S 22$ Abs. 3 BSHG festgelegt. Es wurde durch das Gesetz zur Umsetzung des Föderalen Konsolidierungsprogramms (FKPG) vom 23.6.1993 neu formuliert: „Bei größeren Haushaltsgemeinschaften mit vier oder mehr Personen müssen die Regelsätze in ihrem jeweiligen Geltungsbereich zusammen mit den Durchschnittsbeträgen für die Kosten der Unterkunft und Heizung und unter Berücksichtigung des abzusetzenden Betrages nach $\S 76$ Abs. 2a Nr. 1 BSHG unter den jeweils erzielten monatlichen durchschnittlichen Nettoarbeitsentgelten unterer Lohn- und Gehaltsgruppen zuzüglich Kindergeld und Wohngeld bleiben" (Bundesministerium für Familie, Senioren, Frauen und Jugend 1993a, S. 4).

Das Gesetz sieht demnach vor, untere Lohngruppen zum Vergleich mit Sozialhilfeleistungen heranzuziehen. Deshalb ist die Berechnungsmethode der Deutschen Bundesbank zurecht vom Bundesministerium für Gesundheit und Familie kritisiert worden. Die Analyse der Bundesbank macht jedoch deutlich, daß die verfügbaren Einkommen von Alleinverdienern mit mehreren Kindern unter den Sozialhilfeleistungen liegen können. In diesem Fall besteht jedoch Anspruch auf ergänzende Sozialhilfe, so daß sich - zusammen mit dem in Kapitel 2.5 beschriebenen Anrechnungsverfahren - ein relativ zu Nicht-Erwerbstätigen höheres verfügbares Einkommen ergibt.

$\mathrm{Ob}$ die Gruppe von Erwerbstätigen, die trotz Ganztagsbeschäftigung kein Nettoeinkommen über dem Sozialhilfeniveau erzielen kann, zugenommen hat - darüber existieren keine detaillierten Untersuchungen auf Bundesebene. Empirisch belegt ist jedoch, daß unzureichendes Erwerbs-einkommen bei Alleinerziehenden „eine zunehmende Rolle“ spielt (Deutsche Bundesbank 1996b, S. 42). Eine Analyse der Empfängerhaushalte von Sozialhilfe (Hilfe zum Lebensunterhalt) für das Jahr 1993 zeigt, daß unzureichendes Erwerbseinkommen bei alleinerziehenden Frauen (12,4\%) und bei Ehepaaren mit Kindern (11,5\%) die Hauptursache für die Gewährung von ergänzender Sozialhilfe waren (vgl. Neuhäuser 1995b, S. 710). Sozialhilfeberichte einzelner Städte deuten darauf hin, daß die Zahl der Vollerwerbstätigen mit Anspruch auf ergänzende Sozialhilfe stark zunimmt (vgl. Amt für Statistik und Einwohnerwesen der Stadt Freiburg 1991, 1997). Neuere Ergebnisse der dynamischen Armutsforschung zeigen, daß diese Gruppe auch am längsten in der Sozialhilfe verbleibt (vgl. Andreß 1994, S. 95). 


\section{(2) Umstrittene Vergleichsgröße „Nettoeinkommen “}

Hauser (1995b) hält den im Gesetz für die Berechnung des Lohnabstands herangezogenen Vergleich zwischen dem Nettoeinkommen eines Vollzeit-Alleinverdieners unterer Lohngruppen mit dem Sozialhilfeanspruch einer fünfköpfigen Familie zuzüglich Wohngeld und Kindergeld für unzulässig. Er betont, daß das Nettoeinkommen eines Arbeitnehmers nur einen Teil seines durch Erwerbstätigkeit erzielten ökonomischen Ertrags darstellt. Tatsächlich werden mit den von Arbeitnehmer und -geber gezahlten Sozialversicherungsbeiträgen auch Versicherungsansprüche gegen die Gesetzliche Krankenversicherung, die Arbeitslosenversicherung, die Gesetzliche Rentenversicherung und die Pflegeversicherung erworben. Hinzu kommt, daß die nichterwerbstätigen Mitglieder dieser Modellfamilie kostenfrei gegen Krankheit mitversichert sind. Für den Arbeitnehmer besteht weiterhin ein Krankengeldanspruch für den Zeitraum nach dem Ende der Lohnfortzahlung. In der Gesetzlichen Rentenversicherung wird neben dem eigenen Anspruch auf Berufsoder Erwerbsunfähigkeitsrente und Altersrente auch ein Anspruch auf Witwen- und Waisenrente für Hinterbliebene erworben.

Alle diese Ansprüche erwirbt ein Sozialhilfeempfänger gegenwärtig nicht. Die bestehende Formulierung des Lohnabstandsgebots behandelt sämtliche Sozialversicherungsbeiträge wie Steuern, bei denen keine Gegenleistung zugerechnet werden kann, kritisiert Hauser. Dies widerspreche den Grundprinzipien unseres Sozialversicherungssystems als das der Sozialhilfe vorgelagerten Sicherungssystems.

Unter Berücksichtigung dieser Überlegungen berechnet Hauser den „ökonomisch wahren" Abstand. Dabei bewertet er die aufgebauten Ansprüche näherungsweise mit der Höhe der Beiträge. Daraus ergibt sich für einen auf die Vergleichsgröße „Nettoeinkommen“ bezogenen $15 \%$-igen Lohnabstand ein ökonomisch wahrer Lohnabstand von 40 \%. Hausers Fazit: Es bestehen beträchtliche ökonomische Arbeitsanreize.

\section{(3) Berechnung des verfügbaren Einkommens von Sozialhilfeempfängern}

In der wissenschaftlichen Diskussion und in der Medienberichterstattung wird die Berechnung des verfügbaren Einkommens von Sozialhilfeempfängern kaum problematisiert. Als allgemein akzeptierte Berechnungsmethode für die Sozialhilfe gilt die Summe aus Regelsatz, Mietzuschuß und einer Pauschale für einmalige Leistungen (vgl. Deutsche Bundesbank 1996a). Diese Berechnungsmethode vernachlässigt jedoch einzelne Einkommenskomponenten, die für die Berechnung des Lohnabstandes von Bedeutung sein könnten. So wird von Praktikern und Betroffenen häufig darauf hingewiesen, daß die vom Sozialamt übernommene Miete in Ballungsgebieten mit Einkommensvorteilen für Hilfeempfänger verbunden ist; Erwerbstätige erhalten aufgrund der niedrigen Einkommensgrenzen für die Gewährung von Wohngeld oft kein oder aufgrund des niedrigen Niveaus des Wohngeldes nur geringe Transferbeträge (vgl. Expertenkommission Wohnungspolitik 1995; Hubert 1996). 
Auch die Nichtanrechnung des Erziehungsgeldes - 600 DM/Monat in den ersten beiden Lebensjahren eines Kindes - auf die Sozialhilfe bringt finanzielle Vorteile für Hilfeempfänger mit Kindern gegenüber Erwerbstätigen mit Kindern (vgl. Brühl 1996, S. 89-91). Vollerwerbstätige, deren jährliches Nettoeinkommen nur knapp über dem Sozialhilfeniveau liegt (29.400 DM bei Verheirateten/23.700 DM bei Ledigen), müssen mit Kürzung des Erziehungsgeldes nach $\S 5$ Bundeserziehungsgeldgesetz rechnen - nur in den ersten sechs Monaten wird Erziehungsgeld auch Personen mit höheren Einkommen (100.000 DM bei Verheirateten/75.000 DM bei Ledigen) gewährt (vgl. Bundesministerium für Familie, Senioren, Frauen und Jugend 1996). Darüberhinaus werden in der Regel die monatlichen Beiträge für den Krabbelstubenund/oder Kindergartenplatz vom Jugendamt übernommen.

Fazit: In Einzelfällen liegt das tatsächlich verfügbare Einkommen von Hilfeempfängern über dem üblicherweise errechneten durchschnittlichen Sozialhilfeeinkommen, das zur Berechnung des Lohnabstandes herangezogen wird. Das ist zwar nicht überraschend, doch bleibt festzuhalten: Der Lohnabstand kann insbesondere bei Alleinerziehenden/Familien mit Kindern in Ballungsräumen aufgrund der Erstattung der Mietkosten, der Nichtanrechnung des Erziehungsgeldes und der Übernahme der Beiträge für Krabbelstuben- und Kindergartenplätze in Einzelfällen sehr gering oder gar negativ sein - selbst wenn das Durchschnittseinkommen unterer Lohngruppen zum Vergleich herangezogen wird. Eine Bewertung der Sozialversicherungsansprüche in Höhe der Beiträge zur Berechnung eines ökonomisch wahren Lohnabstands erscheint fragwürdig, eine Neuberechnung mit diskutierten Werten sollte zumindest zum Vergleich herangezogen werden.

(4) Berechnung des Zuwachses der verfügbaren Einkommen der Erwerbstätigen und der Sozialhilfeempfänger im Zeitablauf

Siebert (1994a, 1995b) legt Beispielsrechnungen für die Entwicklung der Sozialhilfe (Summe aus Regelsatz, Mietzuschuß und einer Pauschale für einmalige Leistungen) und der Nettoverdienste unterster Lohngruppen (Hilfsarbeiter, Leistungsgruppe 3) für den Zeitraum 1970 bis 1993 vor. Danach ist die Sozialhilfe bei geringfügigen Unterschieden zwischen den einzelnen Haushaltstypen um etwa 6 Prozent angestiegen, der Nettoverdienst eines ledigen Industriearbeiters jedoch nur um 4,8 Prozent, der eines verheirateten Industriearbeiters mit einem Kind um 5,1 Prozent, der eines Dreipersonenhaushalts um 5,1 Prozent, die nominale Nettolohn- und Nettogehaltssumme je beschäftigten Arbeitnehmer um 5 Prozent. Der Abstand zwischen Sozialhilfe und Nettoverdienst hat sich demnach in den letzten beiden Jahrzehnten verringert. Der Hintergrund: Sozialhilfe wird bedarfsorientiert bemessen, der Lohn dagegen leistungsorientiert.

Hauser (1995b) vergleicht die Entwicklung des Sozialhilferegelsatzes und verschiedener durchschnittlicher Einkommensgrößen von 1963 bis 1993. Es zeigt sich, daß der Regelsatz trendmäßig mit der Entwicklung der Nettolohn 
und -gehaltssumme je Beschäftigtem Schritt gehalten hat. Hauser betont jedoch, daß sich die Haushaltsstruktur in diesen drei Jahrzehnten verändert hat die Frauenerwerbstätigkeit nahm zu, so daß es nunmehr wesentlich mehr Zwei- oder Mehrverdienerhaushalte gibt als früher. Damit stellt sich für Hauser die Frage, ob der Einverdienerhaushalt - wie im Lohnabstandsgebot unterstellt - noch die zutreffende Vergleichskategorie ist. Um Veränderungen in der Haushaltsstruktur zu berücksichtigen, hat das Statistische Bundesamt unter Verwendung einer von der OECD entwickelten Äquivalenzskala die Haushaltseinkommen in gewichtete Pro-Kopf-Einkommen umgerechnet und eine Zeitreihe von 1972 bis 1993 ermittelt. Zieht man diese Zeitreihe - das „verfügbare Einkommen je Verbrauchereinheit" - zum Vergleich heran, so zeigt sich: Der Regelsatz der Sozialhilfe ist etwa von 1982 an deutlich hinter dieser Größe zurückgeblieben. Hauser weist zwar noch darauf hin, daß die Sozialhilfe die überdurchschnittlich gestiegenen Mieten übernimmt. Dagegen müssen Arbeitnehmer die Mietkosten unter Berücksichtigung des Wohngeldes selbst tragen. „Insgesamt kann man aber von einem merklichen Zurückbleiben der Sozialhilfeempfänger hinter der allgemeinen Wohlstandsentwicklung sprechen" (Hauser 1995b, S. 431).

\section{(5) Lohnabstandsgebot I und II}

Die Expertenkommission „Alternative Steuer-Transfer-Systeme“ unter Vorsitz von Krause-Junk hat erstmals verschiedene Definitionen des Lohnabstands herausgearbeitet. Die herkömmliche Definition besagt, daß das Lohneinkommen generell zur Existenzsicherung ausreichen sollte. Ein Vollerwerbstätiger, bei dem kein besonderer Bedarf - z.B. wegen Kinderreichtum, Behinderung, hoher Mietbelastung usw. - vorliegt, sollte nicht zusätzlich zu seinem Erwerbseinkommen noch auf steuerfinanzierte Sozialtransfers angewiesen sein (vgl. Experten-Kommission „Alternative Steuer-Transfer-Systeme“ 1996, S. 63f.). Daß ein Vollzeiteinkommen auch in den unteren Lohngruppen der produktivitätsschwachen Branchen zum individuellen Lebensunterhalt oberhalb der Sozialhilfeschwelle ausreichen soll, entspricht nicht nur der Vorstellung des Gesetzgebers, sondern auch der Gewerkschaften (vgl. Bäcker 1993, S. 646). Diese Definition des Lohnabstandes soll in dieser Arbeit als Lohnabstandsgebot I bezeichnet werden.

Davon zu unterscheiden ist folgende Definition des Lohnabstandes: Ein Erwerbstätiger soll unter Berücksichtigung von staatlichen Transfers stets besser gestellt sein als Nicht-Erwerbstätige (vgl. Experten-Kommission „Alternative Steuer-Transfer-Systeme“ 1996, S. 63). Diese Definition soll als Lohnabstandsgebot II bezeichnet werden.

Zusammenfassend läßt sich festhalten, daß das Lohnabstandsgebot des Sozialhilferechts (Lohnabstandsgebot I) in Durchschnittsfällen gewahrt ist. Der 1993 gesetzlich konkretisierte Lohnabstand bezieht sich auf das Verhältnis von Sozialhilfe und den durchschnittlichen Nettoeinkommen unterer Lohngruppen. Die gesetzlich vorgesehenen Bezugsgrößen sind zum einen die Sozi- 
alhilfe als Summe aus Regelsatz, Mietzuschuß und einmaligen Leistungen, und zum anderen die Nettoeinkommen unterer Lohngruppen. Als ReferenzHaushaltstypen wurden Haushaltsgemeinschaften bis zu fünf Personen festgelegt. In Einzelfällen können die Leistungen der Sozialhilfe jedoch über den Nettolöhnen und -gehältern liegen. Das gilt insbesondere für Familien mit mehreren Kindern, die Anspruch auf Erziehungsgeld haben, deren Beiträge für Krabbelstuben bzw. Kindergartenplätze vom Jugendamt finanziert werden und die in Ballungszentren mit hoher Mietbelastung wohnen.

Löst man sich von der gesetzlichen Vorgabe des Lohnabstandsgebots, läßt sich sowohl ein großer positiver als auch ein negativer Lohnabstand errechnen. So beträgt der „ökonomisch wahre“ Lohnabstand für Hauser (1995b) etwa $40 \%$, die Deutsche Bundesbank (1996a) berechnet dagegen negative Lohnabstände. Beide Berechnungsmethoden haben für sich genommen ihre Berechtigung - sie sind jedoch letztlich willkürliche Interpretationen des gesetzlichen Lohnabstandsgebots.

Für Verwirrung könnte die von der OECD benutzte Definition für den Lohnabstand führen. Die OECD (1996, S. 25) wählte den Begriff „Arbeitslosenfalle“ (unemployment trap). Dieser Begriff wurde in den letzten Jahren für den im folgenden Kapitel darzustellenden zweiten Fehlanreiz im Sozialsystem - die Armutsfalle - verwendet (vgl. Spermann 1996; Jerger/Spermann 1997a). Er wurde jedoch auch mit einer weiteren Bedeutung in die arbeitsmarktökonomische Literatur eingeführt (vgl. Saint-Paul 1995a). Aufgrund der Mehrdeutigkeit des Begriffes Arbeitslosenfalle soll er im weiteren Verlauf der Arbeit nicht mehr benutzt werden. Der Fehlanreiz Nr. 1 wird demnach als das Problem des Lohnabstandes bezeichnet, der Fehlanreiz Nr. 2 wird Armutsfalle genannt.

\subsection{Fehlanreiz Nr. 2: Die Armutsfalle}

\subsubsection{Definition}

Die sogenannte Armutsfalle (poverty trap) für Transferempfänger entsteht dadurch, daß erzielte Arbeitseinkommen mit dem weitgehenden Entzug von Transfers verbunden sind - mit der Konsequenz, daß sich Zusatzverdienste unter dem Transferniveau finanziell nicht lohnen. Transferempfänger werden entmutigt, Vollzeitstellen im Niedriglohnbereich, aber auch gut bezahlte Teilzeitjobs anzunehmen. Dies gilt insbesondere für Familien mit mehreren Kindern.

Die Armutsfalle ist ein Arbeitsanreizproblem, das in den meisten europäischen Ländern, aber auch in den USA, Kanada und Australien existiert (vgl. OECD 1994b, S. 265ff.; OECD 1997d; Moffit 1992; Card/Robins 1996; Lambert 1995). Im folgenden wird die Armutsfalle in Deutschland beschrieben 
und unter vereinfachenden Annahmen grafisch modelliert; ausführlichere Darstellungen finden sich bei Boss $(1994,1996)$ und Gern $(1995,1996$ b). Dabei wird unterschieden zwischen der Armutsfalle für Empfänger von Sozialhilfe und für Empfänger von Arbeitslosenunterstützung.

\subsubsection{Die Armutsfalle im Sozialhilferecht}

Die Armutsfalle des Sozialhilferechts wird anhand von zwei Personengruppen - Einzelpersonen und Familien mit zwei Kindern - in einem Bruttoeinkommen-Nettoeinkommen-Diagramm dargestellt. Würden ausschließlich Einzelpersonen betrachtet, gingen wichtige Einsichten verloren. Zum einen sind Familien mit Kindern nach der Neuregelung des Familienlastenausgleichs im Jahre 1996 erst von einem relativ hohen Bruttoeinkommen an steuerpflichtig; das steuerfreie Existenzminimum liegt weit über dem steuerfreien Grundfreibetrag. Zum anderen erhalten einkommensschwache Familien das steuerfreie Bundeserziehungsgeld für Kinder in den ersten beiden Lebensjahren; das Erziehungsgeld beträgt monatlich maximal $600 \mathrm{DM}$ je Kind, so daß der Anteil am verfügbaren Einkommen von Geringverdienern bedeutsam ist. Zum dritten wirken sich die Anrechnungsregeln des Status quo auch auf das Arbeitsangebot von Familienangehörigen aus. Wird ein Haushaltsmitglied arbeitslos und erwirbt Anspruch auf Arbeitslosenunterstützung und/oder Sozialhilfe, so wird das Einkommen der anderen erwerbstätigen Haushaltsmitglieder nach den bestehenden Regeln angerechnet (vgl. OECD 1996, S. 45).

Um die Darstellung nicht unnötig zu komplizieren, wird auf die Illustration von Wohngeld verzichtet. Beide Haushaltstypen erhalten Wohngeld. Wohngeld ist steuerfrei, wird jedoch voll auf die Sozialhilfe angerechnet (vgl. Hubert 1996).

Als Status quo wird die rechtliche Situation vom Juli 1995 angenommen. Dieser Zeitpunkt erscheint zweckmäßig, um auf die von der Deutschen Bundesbank (1996a) für verschiedene Haushaltstypen ermittelten Daten zurückgreifen zu können; die geringfügige Erhöhung der Regelsätze der Sozialhilfe zum 1. Juli 1996, die leicht veränderten Werte für Mietzuschüsse und einmalige Leistungen im Jahre 1996 und die Sozialhilfereform vom 1. August 1996 bleiben bei der Modellierung des Status quo unberücksichtigt.

Die Sozialhilfeleistungen im Rahmen der Hilfe zum laufenden Lebensunterhalt setzen sich aus dem Regelsatz, einem Mietzuschuß und einmaligen Leistungen zusammen (vgl. Brühl 1996, Schellhorn u.a. 1993).

Der Regelsatz dient dazu, die laufenden Ausgaben für Ernährung, hauswirtschaftlichen Bedarf einschließlich Haushaltsenergie sowie für persönliche Bedürfnisse des täglichen Lebens zu decken. Regelsätze werden für Haushaltsvorstände und - altersabhängig - für Haushaltsangehörige festgesetzt. Die Höhe der Regelsätze wird von den Landesregierungen festgelegt - sie sind von Bundesland zu Bundesland unterschiedlich. In den meisten Bundeslän- 
dern betrug der Regelsatz am 1.7.1996 für den Haushaltsvorstand 531 DM im Monat (vgl. Brühl 1996, S. 26/27).

Der Mietzuschuß umfaßt die Unterkunfts- und Heizungskosten. Laufende Leistungen für die Unterkunft werden in Höhe der tatsächlichen Aufwendungen gewährt - dazu zählen Miete, Aufwendungen für ein Eigenheim und Hotelkosten. Sind die Mietkosten unangemessen hoch, ist der Sozialhilfeträger nicht zur Kostenübernahme verpflichtet. In Anbetracht der geringen Verfügbarkeit kostengünstiger Wohnungen in Ballungsräumen müssen jedoch häufig hohe Mieten übernommen werden. Heizungskosten in Höhe der tatsächlichen Aufwendungen müssen ebenfalls erstattet werden (vgl. Brühl 1996, S. 42-48). Einmalige Leistungen sind nach dem Bundessozialhilfegesetz für denjenigen notwendigen Unterhaltsbedarf zu erbringen, der nicht von den laufenden Leistungen $\mathrm{zu}$ decken ist. Diese Leistungen sind jedoch keineswegs einmalig, sondern zusätzlich zu gewähren. Der gesetzliche Begriff ist deshalb irreführend. Unter einmaligen Leistungen ist zum Beispiel der Zusatzbedarf an Kleidung, Hausrat und Gebrauchsgütern zu verstehen (vgl. Brühl 1996, S. 5383).

Eigene Verdienste von Hilfeempfängern müssen beim Sozialamt angegeben werden. Von dem erzielten Bruttoeinkommen werden nach $\S 76$ Abs. 2 BSHG zur Ermittlung des bereinigten Nettoeinkommens entrichtete Steuern und Pflichtbeiträge zur Sozialversicherung abgezogen. Weiterhin wird ein sogenannter Absetzungsbetrag für Erwerbstätige nach $\S 76 \mathrm{Abs}$. 2a BSHG berücksichtigt; der Absetzungsbetrag ersetzt den früheren Mehrbedarfszuschlag gemäß $\S 23$ Abs. 4 Nr. 1, 24 BSHG a.F.. Die Höhe des Absetzungsbetrags soll durch eine Rechtsverordnung bestimmt werden ( $\S 76$ Abs. 3 BSHG), die jedoch bis heute nicht erlassen wurde (Stand: Ende 1997). Statt dessen werden die Empfehlungen des Deutschen Vereins für öffentliche und private Fürsorge herangezogen (vgl. Brühl 1996, S. 98-101). Sie sind Grundlage für die - von Bundesland zu Bundesland unterschiedlichen - Sozialhilfe-Richtlinien.

Entsprechend den Empfehlungen des Deutschen Vereins gilt derzeit nach den Sozialhilferichtlinien des Landes Baden-Württemberg für Erwerbstätige ein Abzugsbetrag in Höhe von $25 \%$ des Regelsatzes eines Haushaltsvorstandes dieser sogenannte „Sockelbetrag“ beträgt bei einem Regelsatz von $531 \mathrm{DM}$ im Monat 132,75 DM. Übersteigt das Erwerbseinkommen den Sockelbetrag, so werden $15 \%$ des den Sockelbetrag übersteigenden Erwerbseinkommens als sogenannter "Steigerungsbetrag“ angerechnet. Insgesamt soll der Absetzungsbetrag höchstens 50 \% des Regelsatzes eines Haushaltsvorstandes betragen. Der maximale Absetzungsbetrag liegt im gewählten Zahlenbeispiel bei 265,50 DM im Monat (vgl. Brühl 1996, S. 100f.).

Ein Zahlenbeispiel: Bei einem Erwerbseinkommen eines alleinstehenden Haushaltsvorstandes von 1017,75 DM im Monat verbleiben maximal 265,50 DM im Monat beim Hilfeempfänger - zuzüglich zum Sozialhilfeeinkommen: 


$$
\begin{aligned}
& \text { Sockelbetrag } \\
+ & \text { Steigerungsbetrag } \\
= & \text { Absetzungsbetrag }
\end{aligned}
$$

$$
\begin{array}{ll}
25 \% \text { von } 531 \mathrm{DM} & =132,75 \mathrm{DM} \\
15 \% \text { von } 885 \mathrm{DM}= & \\
(1017,75-132,75 \mathrm{DM}) & =132,75 \mathrm{DM} \\
\max 50 \% \text { von } 531 \mathrm{DM} & =265,50 \mathrm{DM}
\end{array}
$$

Das verfügbare Einkommen des betrachteten Hilfeempfängers würde demnach bei einem Eigenverdienst von 1017,75 DM die Summe aus Sozialhilfeleistung und Absetzungsbetrag, also 1360,50 DM/Monat (1095 DM/Monat plus 265,50 DM/Monat) betragen.

Für die Modellierung des Status quo wird aus Vereinfachungsgründen ein Regelsatz von $520 \mathrm{DM}$ im Monat angenommen, der dem Durchschnittswert für das Jahr 1995 entspricht, und lediglich der Sockelbetrag, nicht jedoch der Steigerungsbetrag berücksichtigt. Sozialversicherungsbeiträge werden als Steuern mit einem Grenzsteuersatz von $20 \%$ über dem abgabenfreien Einkommensniveau von $610 \mathrm{DM} /$ Monat (Einkommensgrenze für geringfügige Beschäftigung im Jahre 1997) interpretiert. Bruttoeinkommen über dem steuerfreien Existenzminimum von $12.000 \mathrm{DM}$ im Jahr werden annahmegemäß in Anlehnung an die steuerrechtlichen Regelungen des Jahres 1996 mit einem Grenzsteuersatz von $26 \%$ besteuert, bei Familien mit Kindern werden familienbedingte Freibeträge bei der Berechnung des steuerfreien Bruttoeinkommens berücksichtigt.

Den Leser mag es stören, daß ein Durchschnittswert für den Regelsatz von 1995, die steuerlichen Regelungen von 1996 und die geringfügigen Beschäftigungsgrenzen von 1997 für die Modellierung des Status quo herangezogen wurden. Doch wurde hier ein Kompromiß zwischen möglichst großer Aktualität und einfachen Zahlen gesucht. Exakte Berechnungen der Armutsfalle sind nur im Einzelfall möglich, schon allein deshalb, weil die Regelsätze von Bundesland zu Bundesland unterschiedlich sind.

Die Armutsfalle läßt sich unter den getroffenen vereinfachenden Annahmen nach den Daten der Deutschen Bundesbank (1996a) und der Sozialhilferichtlinien des Landes Baden-Württemberg (40. Erg.-Lief., Feb. 1997) für die beiden Personengruppen in Brutto-/Nettoeinkommen-Diagrammen darstellen: Eine alleinstehende Person ohne Kind erhielt im Jahr 1995 laufende Hilfe zum Lebensunterhalt in Höhe von monatlich 1095 DM - dieser Wert ist an der Ordinate der Abbildung 8 abgetragen. Ein Zuverdienst in Höhe des Abzugsbetrags von $25 \%$ des angenommenen Regelsatzes, also $130 \mathrm{DM}$ im Monat, wird nicht auf den Hilfeanspruch angerechnet. Das Nettoeinkommen beträgt dann bei einem Zuverdienst in dieser Höhe 1225 DM/Monat - die Nettoeinkommensgerade verläuft parallel zur $45^{\circ}$-Linie. Im Bruttoeinkommensbereich zwischen 130 und $1561 \mathrm{DM} /$ Monat werden Zusatzverdienste annahmegemäß vollständig angerechnet. Die Armutsfalle befindet sich unter Berücksichtigung von Sozialversicherungsbeiträgen und Steuerzahlungen in diesem Brut- 
toeinkommensbereich - die Nettoeinkommensgerade verläuft parallel zur Abszisse.

Unterhalb der $45^{\circ}$-Linie verläuft die Nettoeinkommensgerade des Status quo. Von einem Bruttoeinkommen von $610 \mathrm{DM} /$ Monat an, wird annahmegemäß der Beitragssatz zur Sozialversicherung $\mathrm{t}_{\mathrm{sv}}$ von $20 \%$ erhoben. Über dem steuerfreien Existenzminimum von 1000 DM/Monat kommt der Grenzsteuersatz $\mathrm{t}_{\text {sTQ }}$ von $26 \%$ hinzu, so daß der Grenzsteuersatz auf $46 \%$ steigt.

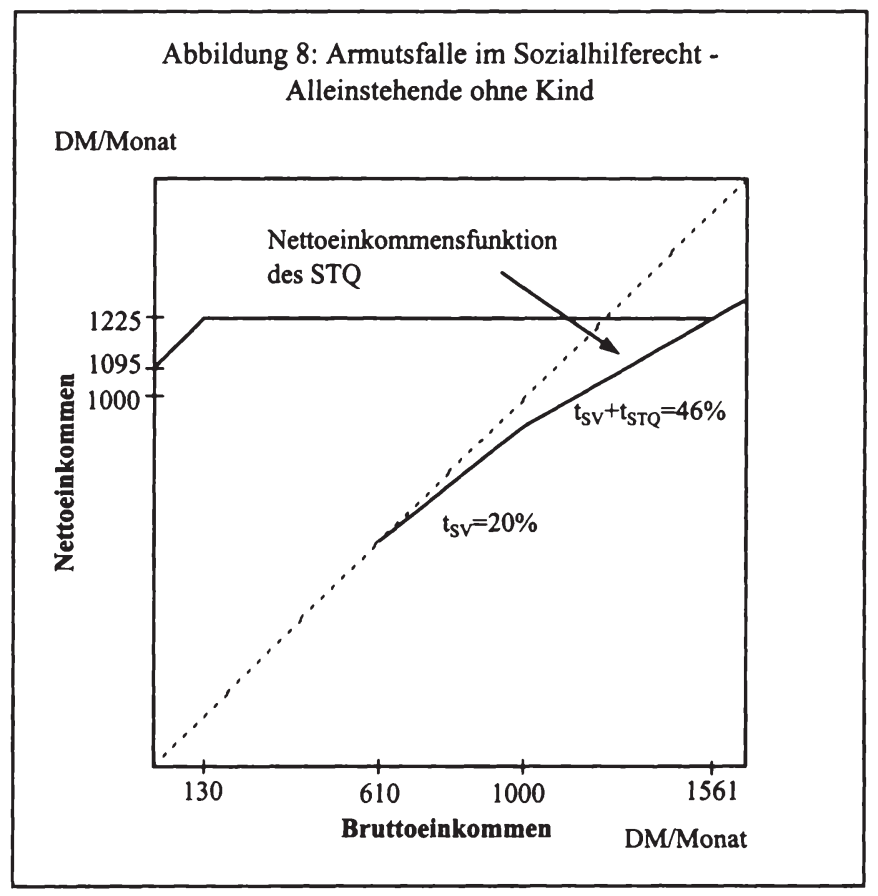

In Abbildung 9 ist die Armutsfalle für eine Familie mit zwei Kindern (verheirateter Alleinverdiener, Steuerklasse III/2) im Brutto-/Netto-einkommen Diagramm illustriert. Verheiratete mit zwei Kindern erhielten im Jahr 1995 laufende Hilfe zum Lebensunterhalt in Höhe von monatlich 2753 DM - dieser Wert ist an der Ordinate abgetragen. Der anrechnungsfreie Zuverdienst beträgt ein Drittel des Regelsatzes, also 173 DM/Monat - das Nettoeinkommen erhöht sich bei einem Zuverdienst in dieser Höhe auf 2926 DM/Monat. Die Armutsfalle liegt im Bruttoeinkommensbereich zwischen 173 und 3505 DM/Monat.

Zu beachten ist, daß nach dem Jahressteuergesetz 1996 im Rahmen des Familienlastenausgleichs Kindergeld in Höhe von 400 DM im Monat gezahlt wird oder ein Kinderfreibetrag in Höhe von 6264 DM im Jahr gewährt wird. Unter 
Berücksichtigung des Familienlastenausgleichs bleibt für Verheiratete mit zwei Kindern ein Bruttojahresverdienst in Höhe von 54.001 DM steuerfrei (vgl. Bundesgesetzblatt 1995, S. 1250-1413). Dieser Betrag liegt weit über dem Grundfreibetrag. Damit beginnt die Besteuerung DM mit dem Einkommensteuersatz $t_{\text {STQ }}$ von $26 \%$ erst von einem monatlichen Bruttoeinkommen von mehr als $4500 \mathrm{DM}$ an. Zusammen mit dem Beitragssatz zur Sozialversicherung $\mathrm{t}_{\mathrm{sv}}$ werden Bruttoeinkommen von über $4500 \mathrm{DM} / \mathrm{Monat}$ mit einem Grenzsteuersatz von $46 \%$ besteuert.

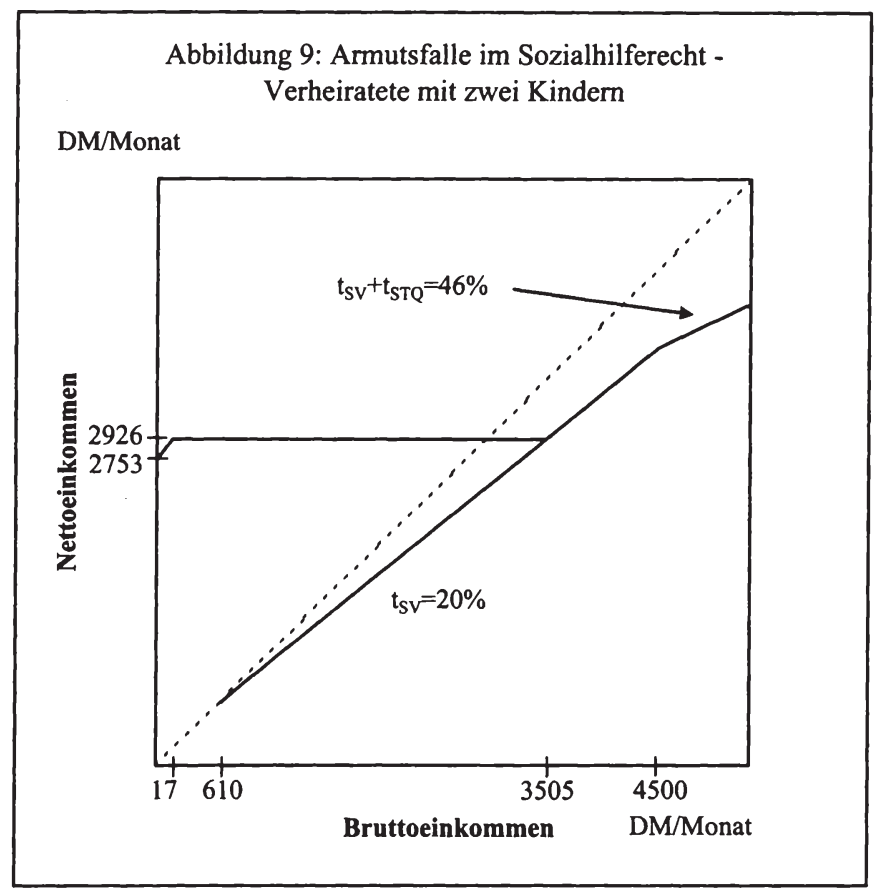

Erziehungsgeld wird nicht mit der Sozialhilfe verrechnet und muß auch nicht versteuert werden. Das Erziehungsgeld von $600 \mathrm{DM}$ im Monat für jedes Kind, das zwei Jahre lang gewährt wird, kann deshalb einen beträchtlichen Anteil des verfügbaren Einkommens einer Familie betragen. In den ersten sechs Monaten besteht Anspruch auf das volle Erziehungsgeld, wenn das nach $\S 6$ Bundeserziehungsgeldgesetz maßgebliche Jahreseinkommen 100.000 DM pro Jahr bei Verheirateten nicht überschreitet. Vom 7. bis zum 24. Lebensmonat des Kindes wird das volle Erziehungsgeld im betrachteten Fall einer Familie mit zwei Kindern nur bei einem Jahreseinkommen bis zu 33.600 DM voll gewährt. Anspruch auf gemindertes Erziehungsgeld besteht bis zu einem Jahres- 
einkommen von 50.400 DM (vgl. Bundesministerium für Familie, Senioren, Frauen und Jugend 1996).

Besonderer Erwähnung bedarf die Funktionsweise der ergänzenden Sozialhilfe. Häufig wird behauptet, daß der Übergang vom Sozialhilfeeinkommen auf das Vollzeit-Nettoeinkommen in typischen Niedriglohnbereichen mit Einkommensverlusten verbunden sei. Das ist jedoch falsch. Das Anrechnungsverfahren stellt sicher, daß ein erwerbstätiger Sozialhilfeempfänger in Höhe des Absetzungsbetrags finanziell besser gestellt ist als ein nicht erwerbstätiger Sozialhilfeempfänger.

Ein Zahlenbeispiel: Ein Verheirateter mit zwei Kindern, der als Alleinverdiener mit einer Vollzeitstelle ein monatliches Bruttoeinkommen von 2000 DM, nach Abzug der Sozialversicherungsbeiträge über ein monatliches Nettoeinkommen von $1600 \mathrm{DM}$ verfügt, hat Anspruch auf ergänzende Sozialhilfe in Höhe von 1326 DM im Monat, so daß sein verfügbares Einkommen 2926 DM/Monat beträgt. Damit stellt er sich um $173 \mathrm{DM} /$ Monat besser als ein nicht-erwerbstätiger Sozialhilfeempfänger. Das Lohnabstandsgebot I ist in diesem Fall verletzt, das Lohnabstandsgebot II ist dagegen erfüllt (vgl. Kapitel 2.4.2).

Ergänzende Sozialhilfe erhalten Erwerbstätige jedoch nur, wenn sie ihren Rechtsanspruch beim Sozialamt geltend machen. Wer das aus Scham oder Unwissenheit nicht tut, stellt sich finanziell tatsächlich schlechter als nichterwerbstätige Hilfeempfänger. Diese Personengruppe gilt dann als „,verdeckt arm" - sie wird auf $33 \%$ bis $50 \%$ der derzeitigen Sozialhilfeempfänger geschätzt, also auf bis zu über einer Million Menschen (vgl. Hauser 1995b, S. 430).

\subsubsection{Die Armutsfalle im Arbeitsförderungsgesetz}

Die Armutsfalle des Arbeitsförderungsgesetzes wird anhand eines „durchschnittlichen" Langzeitarbeitslosen im Brutto-/Nettoeinkommen-Diagramm illustriert. Dazu müssen die Arbeitslosenunterstützung und die Anrechnungsregeln für Zusatzverdienste erläutert werden. Als Status quo wird die rechtliche Situation vom März 1997 angenommen. Die Reform des Arbeitsförderungsgesetzes zum 1. April 1997 bleibt bei der Modellierung des Status quo unberücksichtigt.

Arbeitslosenunterstützung wird im Rahmen des Arbeitsförderungsgesetzes (AFG) als Arbeitslosengeld oder Arbeitslosenhilfe gewährt. Im folgenden werden kurz die wichtigsten Charakteristika dargestellt; ausführliche Darstellungen finden sich in Gagel (1995) und Stascheit/Turk (1996).

Arbeitslosengeld erhält, wer innerhalb der letzten drei Jahre mindestens ein Jahr einer beitragspflichtigen Beschäftigung nachging. Die Anspruchsdauer beträgt zwischen 6 Monaten und 32 Monaten - je länger in die Arbeitslosenversicherung einbezahlt wurde und je älter der Antragsteller, desto länger ist die Anspruchsdauer. Die Höhe des Arbeitslosengeldes richtet sich nach dem 
Nettoeinkommen, das durchschnittlich vor der Antragstellung verdient wurde. Es beträgt entweder $60 \%$ für Arbeitslose ohne Kind oder $67 \%$ für Arbeitslose mit mindestens einem Kind. Das maximale Arbeitslosengeld orientiert sich an der sogenannten Leistungsbemessungsgrenze, die wiederum von der sogenannten Beitragsbemessungsgrenze abhängt. Dieser Zusammenhang ist für das Verständnis der Diskussion des Einstiegsgeldes von Bedeutung, so $\mathrm{da} ß$ er an dieser Stelle ausführlicher behandelt werden soll.

Ein Zahlenbeispiel: Im Jahr 1996 betrug die Beitragsbemessungsgrenze für die Berechnung des monatlichen Beitrags zur Arbeitslosenversicherung 8000 DM/Monat - bis zu diesem Betrag wird der Arbeitslosenversicherungsbeitragssatz von $6,5 \%$ in den alten Bundesländer erhoben, so daß ein monatlicher Höchstbetrag (Arbeitnehmer- und Arbeitgeberanteil) von $520 \mathrm{DM}$ in Westdeutschland zu zahlen ist. Da das Arbeitslosengeld wöchentlich ausgezahlt wird, muß die Beitragsbemessungsgrenze auf die Woche umgerechnet werden - es ergibt sich das wöchentliche Bruttoeinkommen von $1870 \mathrm{DM}$. Von diesem Bruttoeinkommen werden Steuern und Sozialversicherungsbeiträge abgezogen, so da $\beta$ sich ein pauschaliertes Nettoeinkommen ergibt. Das maximale Arbeitslosengeld beträgt zum Beispiel für einen Arbeitslosen ohne Kind $564 \mathrm{DM} /$ Woche (60\% des pauschalierten Nettoeinkommens) und für einen Verheirateten mit zwei Kindern 759 DM/Woche (67\% des pauschalierten Nettoeinkommens).

Arbeitslosenhilfe wird als sogenannte Anschluß-Arbeitslosenhilfe nach Ablauf des zeitlich befristeten Arbeitslosengeldes bezahlt. Sie wird als Anwartschafts-Arbeitslosenhilfe bezahlt, wenn vor Antragstellung mindestens 150 Kalendertage einer beitragspflichtigen Beschäftigung nachgegangen wurde. Unterschiede zum Arbeitslosengeld bestehen darin, daß dem Bezug der steuerfinanzierten Arbeitslosenhilfe eine Bedürftigkeitsprüfung vorausgeht und keine zeitliche Befristung existiert - es handelt sich deshalb um keine Sozialversicherungsleistung, sondern um einen zeitlich unbefristeten, steuerfinanzierten Transfer. Insofern ähnelt die Arbeitslosenhilfe der von den Kommunen und Ländern finanzierten Sozialhilfe.

Die Höhe der Arbeitslosenhilfe hängt jedoch wie das Arbeitslosengeld - und im Gegensatz zur Sozialhilfe - vom Nettoeinkommen vor Antragstellung ab; es beträgt $53 \%$ des pauschalierten Nettoeinkommens für Arbeitslose ohne Kind und $57 \%$ des pauschalierten Nettoeinkommens für Arbeitslose mit Kind. Die maximale wöchentliche Arbeitslosenhilfe beträgt für einen Arbeitslosen ohne Kind 498,60 DM, für einen verheirateten Arbeitslosen mit Kind 645,60 DM.

Die Anrechnung von Nebeneinkommen ist für Arbeitslosengeld und -hilfe gleich geregelt. Als Nebenbeschäftigungen im Sinne des Arbeitsförderungsgesetzes (1996) gelten Tätigkeiten von weniger als 18 Stunden je Woche. Wer mehr als 18 Stunden arbeitet, gilt nicht mehr als arbeitslos. Nebeneinkommen 
aus Nebenbeschäftigungen werden nach $\S 115$ AFG auf den Hilfeanspruch angerechnet.

Nimmt ein Arbeitsloser mit Beginn der Arbeitslosigkeit eine Nebenbeschäftigung auf, so wird das bereinigte Nebeneinkommen - vom Bruttoeinkommen dürfen Sozialversicherungsbeiträge und Steuer sowie Werbungskosten abgezogen werden - in drei Stufen angerechnet. Ein Freibetrag von wöchentlich 30 DM wird nicht auf die Arbeitslosenunterstützung angerechnet (1. Stufe: Freibetragsregelung). Übersteigt das bereinigte wöchentliche Nettoeinkommen den Freibetrag, so wird der übersteigende Betrag zur Hälfte von der Arbeitslosenunterstützung abgezogen (2. Stufe: Halbe/Halbe-Regel). Das bereinigte wöchentliche Nettoeinkommen wird voll auf die Arbeitslosenunterstützung angerechnet, wenn die nach der zweiten Stufe verbleibende Unterstützungszahlung zusammen mit dem bereinigten Nettoeinkommen $80 \%$ des für die Unterstützungszahlung maßgebenden früheren wöchentlichen Nettoeinkommens übersteigt (3. Stufe: Kappungsgrenze nach der $80 \%$-Regel).

Diese komplizierte Anrechnungsregel soll am Beispiel eines „durchschnittlichen Langzeitarbeitslosen" verdeutlicht werden. Zur Vereinfachung wird angenommen, daß Langzeitarbeitslose in der Regel Arbeitslosenhilfebezieher sind, die im Durchschnitt etwa 1000 DM im Monat (53\% des pauschalierten Nettoeinkommens von $1887 \mathrm{DM} /$ Monat) Arbeitslosenhilfe beziehen. Unter den getroffenen Annahmen betrug ihr durchschnittliches Bruttoeinkommen vor der Arbeitslosigkeit 2787 DM/Monat. Nebeneinkommen in Höhe von 120 DM/Monat werden nicht auf ihren Hilfeanspruch angerechnet (Stufe 1). Netto-Zusatzverdienste zwischen 120 und 1509 DM/Monat ( $80 \%$ des bereinigten Nettoeinkommens von 1887 DM/Monat) werden zur Hälfte auf die Arbeitslosenhilfe angerechnet (Stufe 2), darüberliegende Netto-Nebeneinkommen werden dagegen voll angerechnet (Stufe 3).

Im Brutto-/Nettoeinkommen-Diagramm der Abbildung 10 ergibt sich folgender Verlauf der Nettoeinkommensgeraden. An der Ordinate ist das Nettoeinkommen von $1000 \mathrm{DM} / \mathrm{Monat}$ abgetragen, das ohne Nebeneinkommen als Arbeitslosenhilfe gezahlt wird. Es erhöht sich bei einen monatlichen Zusatzverdienst von $120 \mathrm{DM}$ auf $1120 \mathrm{DM} / \mathrm{Monat}$ - die Nettoeinkommensgerade verläuft parallel zur $45^{\circ}$-Linie.

In welchem Bruttoeinkommensbereich liegt in diesem Fall die Armutsfalle? Das Nettoeinkommen nach der $80 \%$-Regel liegt bei 1509 DM/Monat. Der entsprechende Bruttozusatzverdienst beträgt $970 \mathrm{DM} / \mathrm{Monat}$, so daß sich unter den getroffenen Annahmen ein Nettoeinkommen von $898 \mathrm{DM} /$ Monat ergibt. Dieses Nettoeinkommen führt - zusammen mit der um die Anrechnung nach den ersten beiden Stufen verringerten Arbeitslosenhilfe - zu einer Kappungsgrenze von $1509 \mathrm{DM} /$ Monat. Die Armutsfalle liegt demnach im Bruttoeinkommensbereich zwischen $970 \mathrm{DM}$ und $2087 \mathrm{DM} /$ Monat. Zu beachten ist, daß der effektive Grenzsteuersatz über einem Bruttoeinkommen von 610 DM 
nicht auf $70 \%$ steigt - das wird durch die Regelungen in $\S 157$ Abs. 3 AFG und $\S 166$ SGB VI sichergestellt.

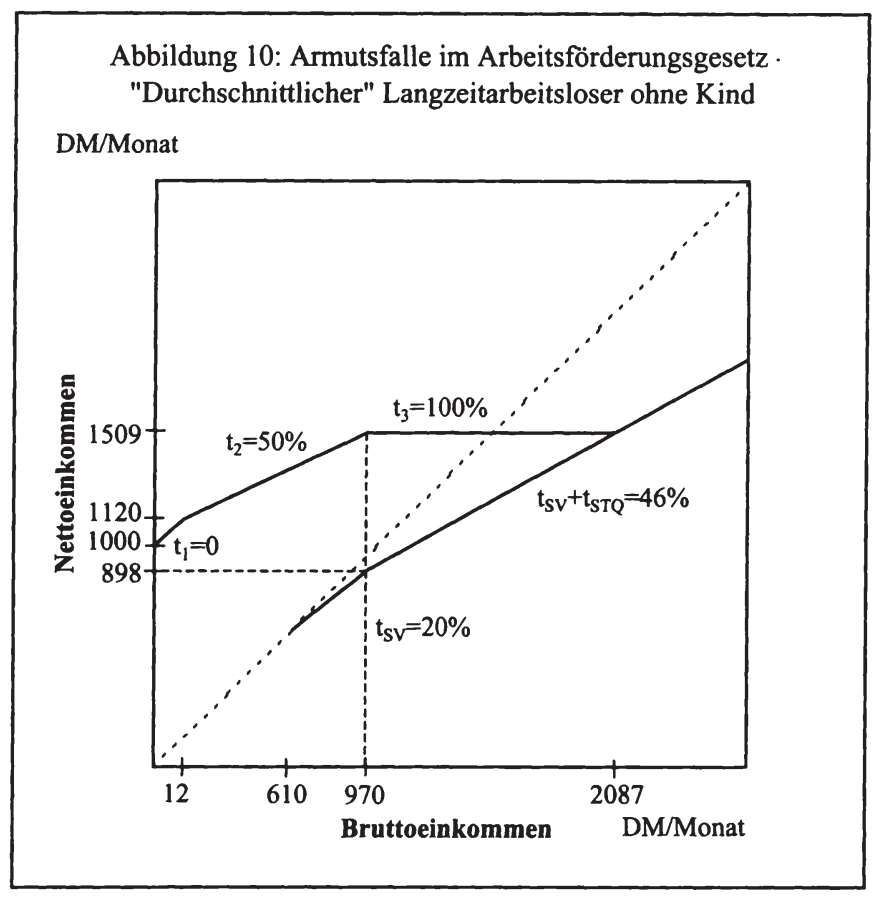

Die Situation für einen durchschnittlichen Langzeitarbeitslosen mit Kind ändert sich zum einen wegen des höheren Arbeitslosenhilfesatzes, der die Kappungsgrenze nach der $80 \%$-Regel verändert. Zum anderen setzt die Besteuerung erst bei einem höheren Bruttoeinkommen ein. Für den Bezug von 1000 DM/Monat Arbeitslosenhilfe (57\% des bereinigten Nettoeinkommens von $1754 \mathrm{DM} /$ Monat) muß ein Verheirateter mit zwei Kindern deshalb nur ein Bruttoeinkommen von 2040 DM/Monat erzielen. Die Kappungsgrenze sinkt auf $1403 \mathrm{DM} /$ Monat (80 \% des bereinigten Nettoeinkommens von 1754 $\mathrm{DM} /$ Monat).

In Abbildung 11 ist die Armutsfalle für einen Verheirateten mit zwei Kindern im Brutto-/Nettoeinkommen-Diagramm illustriert. An der Ordinate ist das Nettoeinkommen von $1000 \mathrm{DM} /$ Monat abgetragen, das als Arbeitslosenhilfe ausgezahlt wird. Die Nettoeinkommensgerade verläuft bis zu einem Bruttoeinkommen von $120 \mathrm{DM} /$ Monat parallel zur $45^{\circ}$-Linie.

In welchem Bruttoeinkommensbereich liegt in diesem Fall die Armutsfalle? Das Nettoeinkommen nach der $80 \%$-Regel liegt bei 1403 DM/Monat. Der entsprechende Bruttozusatzverdienst beträgt $708 \mathrm{DM} /$ Monat, so daß sich un- 
ter den getroffenen Annahmen ein Nettoeinkommen von $688 \mathrm{DM} / \mathrm{Monat}$ ergibt. Dieses Nettoeinkommen führt - zusammen mit der um die Anrechnung nach den ersten beiden Stufen verringerten Arbeitslosenhilfe - zu einer Kappungsgrenze von $1403 \mathrm{DM} /$ Monat. Die Armutsfalle liegt demnach im Bruttoeinkommensbereich zwischen $708 \mathrm{DM}$ und $1601 \mathrm{DM} /$ Monat.

Es fällt auf, daß sich für Arbeitslose mit Kindern, die $57 \%$ des letzten Nettoeinkommens beziehen, nur geringere Zusatzverdienste finanziell lohnen als für Arbeitslose ohne Kindern - ein kaum beachtetes Phänomen, das sich durch die Kappungsgrenze nach der $80 \%$-Regel erklären läßt. Andererseits endet die Armutsfalle bereits bei einem Bruttoeinkommen von $1601 \mathrm{DM} / \mathrm{Monat}$ (zum Vergleich: $2087 \mathrm{DM} /$ Monat bei einen durchschnittlichen Arbeitslosen ohne Kind). Das liegt an der Besteuerung, die bei Verheirateten mit zwei Kindern, erst bei einem Bruttoeinkommen von $4500 \mathrm{DM} /$ Monat einsetzt - die Nettoeinkommensfunktion des Status quo verläuft steiler als bei Arbeitslosen ohne Kinder.

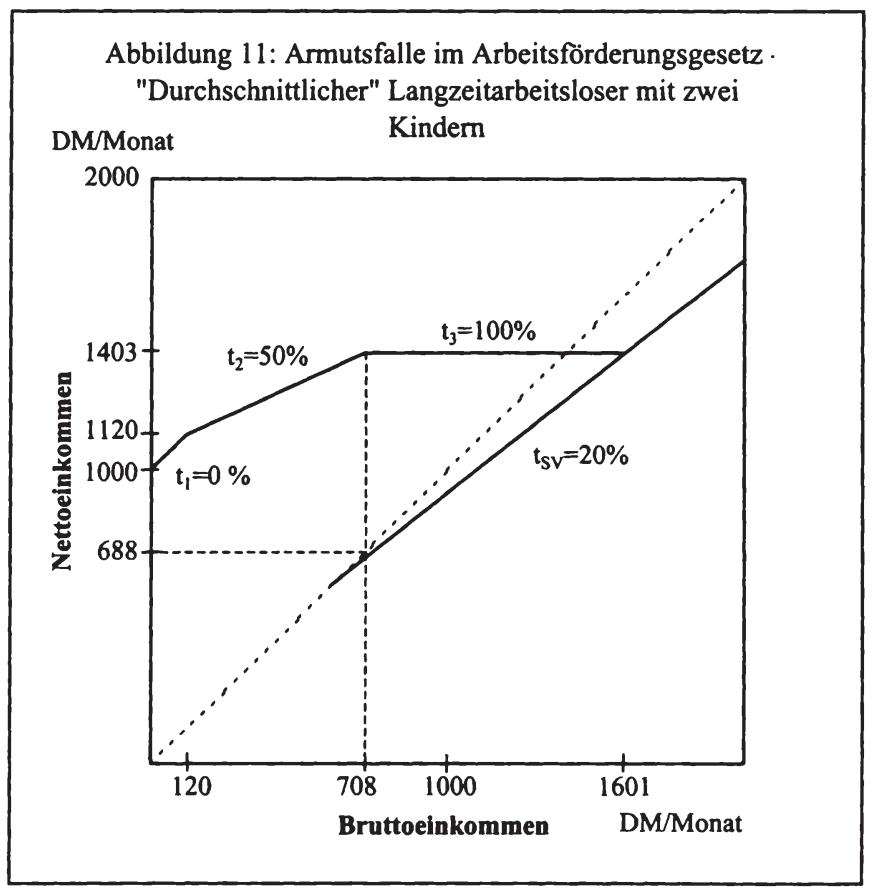

Schließlich ist anzumerken, daß mit der Neuregelung des Arbeitsförderungsgesetzes zum 1.4.1997 die Anrechnungsbestimmungen erheblich verschärft worden sind: Bisher konnten Arbeitslose geringfügige Beschäftigungen annehmen, die weniger als 18 Stunden je Woche in Anspruch nahmen, ohne ih- 
ren Status als Arbeitslose zu verlieren. Künftig entfällt nach $\S 118$ Abs. 1 SGB III der Anspruch auf Arbeitslosenunterstützung, wenn die Arbeitszeit mehr als 15 Stunden wöchentlich beträgt. Seit dem 1. Januar 1998 lohnen sich für die Mehrheit der durchschnittlichen Langzeitarbeitslosen, denen 1000 DM/Monat ausgezahlt werden, nach $\S 141$ SGB III nur noch minimale Beschäftigungen in Höhe des neuen Mindestfreibetrags von $310 \mathrm{DM} / \mathrm{Monat}$; dieser Betrag entspricht 1/14 der Bezugsgrenze der Arbeitslosenversicherung. Die individuelle Kappungsgrenze für Zusatzverdienste in Höhe von $20 \%$ der ausgezahlten Arbeitslosenunterstützung, die ebenfalls neu eingeführt wird, kommt in der Regel nicht zum Zuge, weil $20 \%$ der monatlichen Arbeitslosenunterstützung nur im Ausnahmefall mehr als $310 \mathrm{DM}$ betragen. Für den durchschnittlichen Langzeitarbeitslosen ist der Mindestfreibetrag relevant.

\subsection{Zusammenfassung}

1. Die Analyse verschiedener Arbeitsmarktstatistiken hat gezeigt, daß der offiziell ausgewiesene Anteil der Langzeitarbeitslosen an den Arbeitslosen mit etwa $30 \%$ die Dimension des Problems verschleiert. Tatsächlich deuten die Daten der OECD und von Statistikexperten der Bundesanstalt für Arbeit darauf hin, daß der Anteil der Langzeitarbeitslosen bei etwa 50-60\% liegen dürfte.

2. Langzeitarbeitslosigkeit spiegelt sich auch in der Sozialhilfestatistik wider. Inzwischen gilt jeder dritte Hilfeempfänger wegen Arbeitslosigkeit als bedürftig. Langzeitarbeitslosigkeit trägt zu einem gewissen Teil auch zum Langzeitsozialhilfebezug bei. Bundesweit lag der Anteil der Langzeitsozialhilfeempfänger im Jahre 1995 bei knapp $50 \%$. In einzelnen Kommunen - wie der Stadt Freiburg - bezogen im Jahre 1996 sogar knapp 80 \% der Sozialhilfeempfänger seit über einem Jahr Sozialhilfe.

3. Die Zahl der Sozialhilfeempfänger hat sich zwischen 1980 und 1993 von etwa zwei auf über vier Millionen Personen erhöht. Von 1994 an gilt jedoch die reformierte Sozialhilfestatistik, so daß die Empfänger von Hilfe zum Lebensunterhalt und Hilfe in besonderen Lebenslagen getrennt ausgewiesen werden - eine Gesamtzahl wird nicht mehr ermittelt. Langzeitarbeitslose beziehen in der Regel Hilfe zum Lebensunterhalt. Vor der Sozialhilfestatistikreform bezogen knapp 3,5 Millionen Personen alleine in Westdeutschland laufende Hilfe zum Lebensunterhalt. Nach der Sozialhilfestatistikreform wurde diese hohe Zahl nach unten korrigiert. Derzeit beziehen nach der offiziellen Sozialhilfestatistik nur etwa 2,5 Millionen Personen in Ost- und Westdeutschland laufende Hilfe zum Lebensunterhalt (1995). Offensichtlich wurde mit der Sozialhilfestatistikreform angestrebt, niedrigere offizielle Zahlen auszuweisen - den Zuwachs an Sozialhilfeempfängern kann die neue Sozialhilfestatistik jedoch nicht verschleiern. 
4. Die gesamten Sozialhilfeausgaben in Ost- und Westdeutschland betrugen 45 Milliarden DM (1995). In der Regel werden in der Öffentlichkeit diese hohen Ausgaben berichtet. Für die Beurteilung der Belastung der Kommunen durch (Langzeit-)Arbeitslosigkeit sind jedoch lediglich die Nettoausgaben für die laufende Hilfe zum Lebensunterhalt außerhalb von Einrichtungen relevant - sie betragen ,nur“ 14,9 Mrd. DM in Ost- und Westdeutschland (1995).

5. Die Struktur der Langzeitarbeitslosigkeit hat sich seit 1980 stark verändert. Als Problemgruppen des Arbeitsmarktes gelten vor allem schwerbehinderte und ältere Arbeitslose. Neuere empirische Studien deuten darauf hin, daß Arbeitslose ohne Berufsausbildung eine Problemgruppe geringerer Bedeutung sind. Frauen sind lediglich in Ostdeutschland überproportional unter den Arbeitslosen vertreten. Neuere Ergebnisse der dynamischen Armutsforschung weisen jedoch darauf hin, daß Alleinerziehende mit Kindern in Ost- und Westdeutschland zu den Problemgruppen des Arbeitsmarktes zählen, auch wenn sie in den offiziellen Arbeitsmarktstatistiken nur eine unbedeutende Rolle spielen.

6. Für die Entstehung und Dauerhaftigkeit der Langzeitarbeitslosigkeit sind die Höhe und die maximale Bezugsdauer von Arbeitslosenunterstützung, der geringe Lohnabstand der Sozialhilfe zu unteren Lohngruppen sowie die weitgehende Vollanrechnung von Zusatzverdiensten auf den Hilfeanspruch von Arbeitslosen als Einflußfaktoren im wesentlichen unstrittig. Dagegen geriet die Stigmatisierungs- und Humankapital-Hypothese, nach der Langzeitarbeitslosigkeit ein sich selbstverstärkender Prozeß durch Dequalifikation und Entmutigung der Arbeitslosen ist, in die Kritik. Neuere empirische Untersuchungen kommen zu dem Ergebnis, daß die Konzentration von nachteiligen Merkmalen mit einer hohen Wahrscheinlichkeit zu Langzeitarbeitslosigkeit führt.

7. Ein wichtiger Fehlanreiz des Sozialsystems, der die Überwindung von Langzeitarbeitslosigkeit behindert, ist der geringe Lohnabstand zwischen Sozialhilfe und unteren Lohngruppen. Über die Definition des sogenannten Lohnabstandsgebots ist von 1992 an viel gestritten worden. Inzwischen ist jedoch geklärt, daß der gesetzlich vorgesehene Lohnabstand im Durchschnitt existiert - er ist jedoch gering. In Einzelfällen kann der Lohnabstand auch negativ sein, doch besteht dann - was häufig übersehen wird - Anspruch auf ergänzende Sozialhilfe, wenn der Erwerbstätige bedürftig ist. Wird ergänzende Sozialhilfe gewährt, so stellt der sogenannte Absetzungsbetrag den Lohnabstand zwischen erwerbstätigen und nicht-erwerbstätigen Sozialhilfeempfängern sicher. Doch ist auch dieser Lohnabstand gering.

8. Ein zweiter wichtiger Fehlanreiz des Sozialsystems ist die sogenannte Armutsfalle. Die Armutsfalle wird unter Berücksichtigung von Steuer- und Sozialversicherungspflicht sowohl im Sozialhilferecht als auch im Arbeitsförderungsgesetz für zwei Haushaltstypen grafisch unter vereinfachenden Annahmen modelliert. Es wird gezeigt, daß sich niedrigentlohnte Vollzeitjobs 
für Verheiratete mit zwei Kindern finanziell kaum lohnen, wenn sie Empfänger von Sozialhilfe und/oder Arbeitslosenunterstützung sind. Die Arbeitsanreizprobleme nehmen mit zunehmender Familiengröße zu.

9. Die Armutsfalle im Arbeitsförderungsgesetz (1996) ist nicht so ausgeprägt wie im Sozialhilferecht: Für Alleinstehende lohnen sich Zusatzverdienste von etwa 1000 DM im Monat. Für Arbeitslose mit Kindern, die Anspruch auf den höheren Arbeitslosenhilfesatz von 57 \% des letzten Nettoeinkommens haben, lohnt sich jedoch nur ein geringerer Zusatzverdienst - ein kaum beachtetes Phänomen, das sich durch die Kappungsgrenze nach der $80 \%$-Regel erklären läßt. Mit dem neuen Sozialgesetzbuch (SGB) III, das vom 1.1.1998 an das Arbeitsförderungsgesetz ersetzt, wurden die Anrechnungsbestimmungen jedoch erheblich verschärft: Für die betrachteten „durchschnittlichen“ Langzeitarbeitslosen sind nur noch minimale Beschäftigungen in Höhe des neuen Freibetrags von $310 \mathrm{DM} /$ Monat (Westdeutschland) finanziell attraktiv. 


\section{Kapitel 3: Die Negative Einkommensteuer als beschäfti-} gungspolitischer Lösungsansatz - Ergebnisse einer über fünfzigjährigen Diskussion

\subsection{Wichtige Negativsteuerkonzeptionen im Rückblick}

\subsubsection{Zur Auswahl der Negativsteuerkonzeptionen}

Die Aufstockung von Einkommen unter dem Existenzminimum durch staatliche Transfers bzw. durch eine Negativsteuer geht zurück auf das Speenhamland-System, das 1795 in Berkshire eingeführt wurde und in weiten Teilen Englands Verbreitung fand. Dieses System scheiterte letztlich am Moral hazard-Verhalten der Arbeitgeber: Die Löhne wurden zu Lasten des Steuerzahlers gesenkt, das System wurde zu teuer. Mit der Reform des Armengesetzes von 1834 wurde versucht, das Moral hazard-Problem zu lösen, in dem nur Arme in Armenhäusern staatliche Unterstützungsleistungen erhielten (vgl. Green 1967, S. 51 ff.; Polanyi 1995, S. 113ff.).

Mit der Einführung der Sozialversicherung zu Beginn des zwanzigsten Jahrhunderts begann eine neue Phase beitragsfinanzierter sozialer Sicherung in England (vgl. Rhys-Williams 1953, S. 37). Voraussetzung für den Bezug von Arbeitslosenunterstützung war der Schadensfall Arbeitslosigkeit. Armengesetz und Arbeitslosenversicherung setzten ein steuer- bzw. beitragsfinanziertes Unterstützungsniveau fest, das negative Auswirkungen auf die ökonomische Attraktivität gering entlohnter Tätigkeiten hatte - die Unterstützungsleistung ging verloren, wenn das Armenhaus verlassen oder Arbeit aufgenommen wurde.

Diesen Zustand wollte Lady Rhys-Williams mit ihrem Vorschlag einer Sozialdividende für England in den vierziger Jahren ändern (vgl. Kapitel 3.1.2). Ihr Beitrag gilt als erste umfassende Negativsteuerkonzeption. In den letzten fünf Jahrzehnten wurde eine Vielzahl von mehr oder weniger detaillierten Vorschlägen präsentiert, die von Rhys-Williams inspiriert wurden. In diesem Kapitel sollen lediglich diejenigen Konzeptionen vorgestellt werden, die neben dem Rhys-Williams-Vorschlag für die aktuelle Bürgergelddiskussion von zentraler Bedeutung sind. Dazu gehören aus Sicht des Autors nur noch die Vorschläge der amerikanischen Ökonomen Friedman und Tobin aus den sechziger Jahren. Demnach wird in diesem Kapitel nicht der wohl uneinlösbare Anspruch auf Vollständigkeit erhoben. Der Leser sei dazu auf die Monographien bzw. Übersichtsartikel von Green (1967), Schmidt (1971), Otten (1977), van Almsick (1981), Metze (1982), Kaltenborn (1995) und Sesselmeier et al. (1996) verwiesen. 
Es wird auch nicht - wie in Teilen der Literatur üblich - zwischen Sozialdividende, Grundsicherung und negativer Einkommensteuer unterschieden. Statt dessen wird der Oberbegriff „Negativsteuerkonzeptionen“ verwendet, der die enge ökonomische Verwandtschaft dieser Vorschläge betont, ohne daß Detailunterschiede in Abrede gestellt werden sollen. Der Leser sollte sich jedoch bewußt sein, daß sich hinter den Etiketten Negative Einkommensteuer/Negative Income Tax (NIT) und Sozialdividende/Grundeinkommen/Basic Income (BI) die aus Sicht des Autors anachronistische „Rechts-Links“ Auseinandersetzung verbirgt: „With NIT, which tends to be the right-wing solution, the main priority is to hold down costs,...At the other extreme, for advocates of full BI, the key variable is the income guarantee..." (Parker 1989, S. 141).

Der „technische“ Oberbegriff Negativsteuerkonzeption stellt auf die prinzipielle Ähnlichkeit von Negativer Einkommensteuer und Sozialdividende ab, weil beide an den gleichen ökonomischen Variablen ansetzen: „Negative income taxation does not really differ in principle from social dividend taxation" (Green 1967, S. 61). Dem Autor ist jedoch bewußt, daß auch administrative und juristische Unterschiede bestehen (vgl. Parker 1989, S. 140ff.). Zum Verständnis der Bürgergelddiskussion der neunziger Jahre erscheint die gewählte Systematisierung allerdings zweckmäßig.

Die Darstellung der Negativsteuerkonzeptionen erfolgt einheitlich in grafischer und algebraischer Form. Zum besseren Verständnis wird eine moderne finanzwissenschaftliche Terminologie gewählt. Bei der Auswahl der zentralen Kritikpunkte und der Probleme der praktischen Umsetzung der einzelnen Negativsteuerkonzeptionen war entscheidend, daß die Argumente für die Bürgergelddiskussion der neunziger Jahre relevant sind oder sein könnten.

\subsubsection{Die Sozialdividende der Lady Rhys-Williams (1942/53)}

Der Reformvorschlag der Lady Rhys-Williams geht auf eine Broschüre aus dem Jahre 1942 zurück.' Eine ausführliche Beschreibung und Diskussion des „Rhys-Williams-Scheme“ findet sich in ihrem Buch „Taxation and Incentives" von 1953. Ausgangspunkt ihres Vorschlags sind zum einen die Vollanrechnung von Zusatzverdiensten auf den Transferanspruch (Armutsfalle) und zum anderen das komplizierte und unübersichtliche Steuer- und Transfersystem. Beide Kritikpunkte am Status quo, die auch die aktuelle Diskussion prägen (vgl. Kapitel 2), wurden bereits in den vierziger Jahren eindrucksvoll beschrieben.

1 Die Broschüre „Something to Look Forward to“, die die Autorin im August 1942 privat veröffentlichte, erschien im August 1943 in einer überarbeiteten und erweiterten Fassung unter demselben Titel in Buchform (vgl. Rhys-Williams 1953, S. 125). Teile dieser Fassung sind in Rhys-Williams (1953) abgedruckt. Das Buch von 1943 ist in Deutschland nicht erhältlich. 
Rhys-Williams geißelt die „Tyrannei der bestehenden Arbeitslosenversicherung", die Arbeitslose und ihre Familien davon abhalte, sich auf anderen Wegen selbst zu helfen. ${ }^{2}$ Sie beklagt, daß geringfügige Zusatzverdienste der Arbeitslosen und ihrer Familienangehörigen mit dem Entzug der Arbeitslosenunterstützung bestraft werden. Dadurch gehen dem Staat produktive Arbeitskräfte in großem Umfang verloren, und die Arbeitslosen und ihre Familien werden auf die „hoffnungslose Untätigkeit reduziert, die Kartoonisten in ihren Zeichnungen so gut wiedergeben". Es sei deshalb keine Überraschung, daß „Menschen nach Jahren erzwungener Untätigkeit nicht mehr auf dem Arbeitsmarkt vermittelbar sind" (vgl. Rhys-Williams 1953, S. 120-22, Übersetzungen des Verfassers). Dabei betont Rhys-Williams ausdrücklich, daß Transferempfänger arbeiten wollten, institutionelle Fehlregelungen die Untätigkeit der Menschen jedoch erzwingen.

Bereits 1942 weist Rhys-Williams auf das Lohnabstandsproblem hin. So sei es für einen Mann mit drei oder vier Kindern profitabler, untätig zu bleiben als sich um Arbeit zu kümmern, falls es sich nicht um eine außergewöhnlich gut bezahlte Arbeit handelt. „Der Unterschied im Lebensstandard zwischen einem hart arbeitenden Mann und einem, der überhaupt nichts tut, ist so gering, daß es kaum einen Anreiz gibt, einen Arbeitsplatz zu bekommen" (RhysWilliams 1942, zit. nach Rhys-Williams 1953, S. 121, Übersetzung des Verfassers).

Die von Rhys-Williams ebenfalls kritisierte Komplexität des Steuer- und Transfersystems der vierziger Jahre wird anschaulich von Meade (1948) beschrieben. Er kritisiert die Vielzahl der Institutionen, die „zu dem Zweck konstruiert wurden, den Reichen oder relativ Reichen Geld wegzunehmen, um einen Teil davon den Armen oder relativ Armen zu geben“. Fast beschwörend stellt er die Frage, ob diese „Umverteilungsmaschinerie“ nicht wesentlich vereinfacht werden könnte - mit der Konsequenz, die Einkommensverteilung zu verbessern (Meade 1948, S. 42f., Übersetzungen des Verfassers).

Vor diesem Hintergrund entstand der radikale Reformvorschlag von RhysWilliams, der vorsieht, das bestehende Transfer- und Sozialversicherungssystem und den Grundfreibetrag der Einkommensteuer abzuschaffen. Statt dessen soll ein „verschmolzenes“ Steuer- und Transfersystem eingeführt werden. Kernelement soll eine Sozialdividende (social dividend) sein, die wöchentlich an alle Bürger (Männer, Frauen und Kinder) auszuzahlen ist - unabhängig von ihrer Bedürftigkeit. Dazu schlägt sie die Ausgabe von Gutscheinen (coupon, voucher) vor, die bei Banken oder Postämtern eingelöst werden können. Der Wert der Gutscheine für Kinder soll jedoch niedriger als der für Erwachsene sein. Die Sozialdividende soll durch eine Einkommensteuer mit konstantem

2 Die Arbeitslosenversicherung existiert in Großbritannien seit 1912 in einigen Industrien.

Sie wurde 1920 auf alle Arbeitergruppen ausgedehnt (vgl. Beveridge 1943, S.9). 
Grenzsteuersatz und mit einer im Vergleich zur bestehenden Einkommensteuer verbreiterten Bemessungsgrundlage finanziert werden.

Nach Parker (1989, S. 102ff.) ist der Rhys-Williams-Vorschlag als „Full Basic Income" zu klassifizieren. In der Literatur findet sich aber auch der Begriff „Credit Income Tax“ (CIT) für das Rhys-Williams-Schema (vgl. Kesselman/Garfinkel 1978 u. Haveman 1996a). Liefmann-Keil (1961, S. 58) betont, daß die Sozialdividende als Grundsicherung für alle Bürger interpretiert werden kann. Entscheidendes Klassifizierungsmerkmal ist, daß ein Grundeinkommen (basic income) durch einen konstanten Grenzsteuersatz (flat rate tax) auf alle positiven Einkommen finanziert werden soll.

Rhys-Williams veränderte ihren Reformvorschlag als Reaktion auf die vor allem von Booker (1946) und Meade (1948) betonten negativen Anreizeffekte für Erwerbstätige. Negative Anreize gehen von dem relativ hohen Grenzsteuersatz aus, mit dem das hohe Grundsicherungsniveau finanziert werden müßte. Der modifizierte Reformvorschlag von Rhys-Williams (1953) sieht deshalb eine geringere Höhe der Sozialdividende vor. Außerdem soll das Sozialversicherungssystem (Arbeitslosigkeit, Krankheit, Rente) ${ }^{3}$ und die Zusatzeinkommensteuer für Besserverdienende (,surtax“) bestehen bleiben. Der RhysWilliams- Vorschlag von 1953, der im folgenden ausführlich dargestellt werden soll, ist demnach bereits eine „Kompromißversion“ (vgl. Hague 1953, S. 378; Atkinson 1969, S. 187).

Die Idee der Sozialdividende läßt sich mit Hilfe des Original-Zahlenbeispiels (Schema E) für eine Einzelperson in einem Brutto-/NettoeinkommenDiagramm in Abbildung 12 illustrieren (vgl. Rhys-Williams 1953, S. 128-131 u. S. 163-165): ${ }^{4}$

Die Sozialdividende S beträgt 8 Schilling je Woche und je erwachsene Person. Jedem Bürger steht demnach ein verfügbares Nettoeinkommen von 20,8 Pfund im Jahr zu - dieser Wert ist an der Ordinate abgetragen.

Jedes positive Einkommen soll mit einem Grenzsteuersatz $t_{1}$ von $20 \%$ besteuert werden („Social Security“ oder „Welfare tax“). Die Steuer wird vom Arbeitgeber an den Staat abgeführt. Die effektive Steuerschuld ergibt sich aus dem Vergleich zwischen ausgezahltem Transfer und vom Arbeitgeber abgeführtem Steuerbetrag. Ist der Transfer größer als die Steuerschuld, ergibt sich ein Nettotransfer bzw. eine Negativsteuer. Ist der Transfer dagegen geringer als die Steuerschuld, ergibt sich eine effektive, positive Steuerschuld.

3 Die Zwangskrankenversicherung wurde 1912 eingeführt. Das erste Altersrentengesetz wurde 1908 verabschiedet (vgl. Beveridge 1943, S. 9).

4 Schema E ist eines von fünf Schemen, die Lady Rhys-Williams vorstellt - es ist das Schema, welches politisch diskutiert wurde. Rhys-Williams betont jedoch, daß Schema D mit einer Sozialdividende, die zusätzlich zu den Sozialversicherungsleistungen gezahlt werden soll, und einem relativ zu Schema E höheren Grenzsteuersatz ihren eigenen Vorstellungen am nächsten kommt (vgl. Rhys-Williams 1953, S. 159-162). 
Die Sozialdividende S bestimmt den Ordinatenabschnitt, der Grenzsteuersatz die Steigung der Nettoeinkommensfunktion des Rhys-Williams Vorschlags $\left(Y_{R W}^{n}\right)$, die in Abbildung 12 gezeichnet ist:

$Y_{R W}^{n}=S+\left(1-t_{1}\right) Y^{b}=20,8+(1-0,2) Y^{b}=20,8+0,8 Y^{b}$

für $\mathrm{Y}^{\mathrm{b}}<600 \mathrm{Pfund} / \mathrm{Jahr}$, wobei $\mathrm{Y}^{\mathrm{b}}$ das Bruttoeinkommen darstellt.

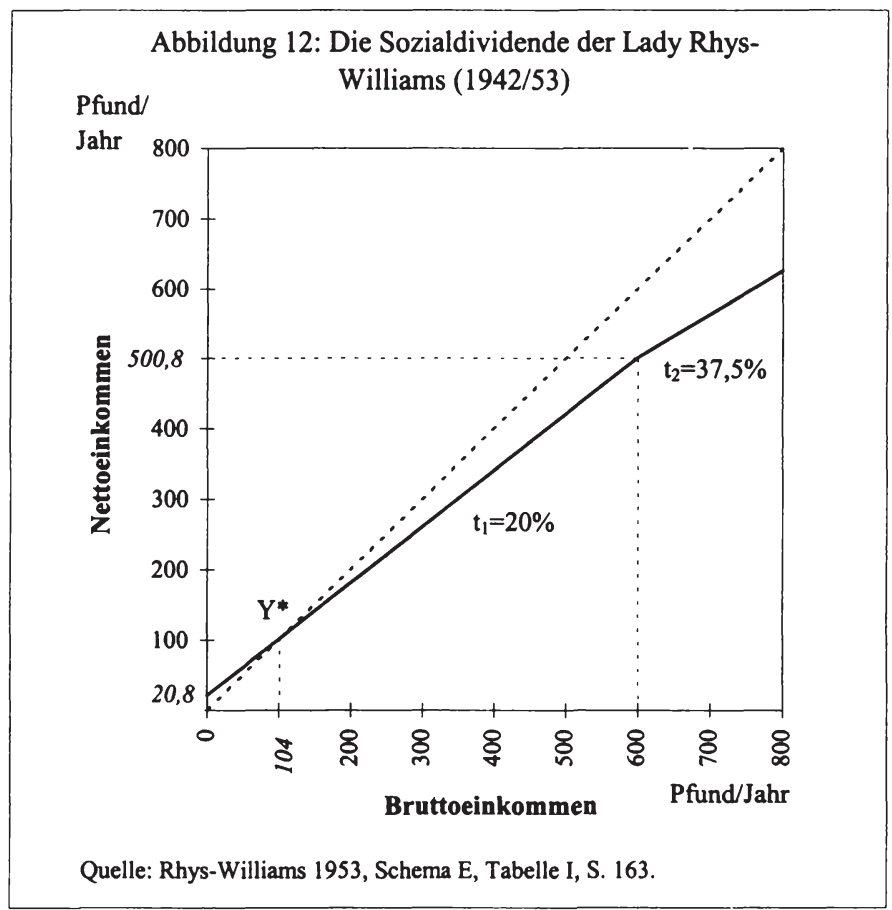

Das hat zur Konsequenz, daß Einkommensbezieher bis zu einem transferfreien Einkommen (,break-even-Einkommen“) Y* von 104 Pfund/Jahr Transfers erhalten; das break-even Einkommen ist definiert als das Einkommen, das weder mit Transferzahlungen noch mit Steuerzahlungen verbunden ist - es berechnet sich aus dem Schnittpunkt der Nettoeinkommensfunktion und der $45^{\circ}$-Linie. ${ }^{5}$ Erst darüber liegende Einkommen zahlen effektiv Steuern. Um die Sozialdividende für alle Bürger finanzieren zu können, ist ein höherer Grenzsteuersatz für Besserverdienende (,Welfare tax“ und „surtax“) von $t_{2}=37,5 \%$

Zur Berechnung des Break-even-Einkommens: $Y^{b}=Y^{m}=20,8+0,8 Y^{b}$, so daß sich für $Y^{*}=20,8 / 0,2=104$ ergibt. Sesselmeier et al. (1996) kommen zu einem anderen Wert für die Transfergrenze. Dabei bleibt jedoch unklar, welches Grundeinkommen unterstellt wird. 
von einem Einkommen von $600 \mathrm{Pfund} / \mathrm{Jahr}$ an vorgesehen. ${ }^{6}$ Dadurch verringert sich die Steigung der Nettoeinkommensfunktion.

Nach Rhys-Williams (1953) ist die Einführung einer Sozialdividende mit mehreren praktischen Vorteilen verbunden. Zum einen führt die Vereinfachung des Steuer- und Transfersystems zu erheblichen Verwaltungskosteneinsparungen - mit dem Folgeeffekt, daß sich die Steuervermeidungs- und Transferbeschaffungsaktivitäten der Bürger reduzieren werden; die mit der Einlösung der Gutscheine verbundenen zusätzlichen administrativen Kosten schätzt Rhys-Williams dagegen gering ein. Zum anderen verbessert der geringe Grenzsteuersatz von $20 \%$, der für den Großteil der Erwerbstätigen gilt, den Anreiz zu arbeiten. Zum dritten erhöhen sich die Chancen zur Selbsthilfe Arbeitslose können ihr Nettoeinkommen beispielsweise durch Teilzeitarbeit verbessern.

Rhys-Williams betont auch einige psychologische Vorteile ihres Vorschlags. Die Sozialdividende wird unabhängig davon ausgezahlt, ob ein Bürger erwerbstätig oder vermögend ist. Damit entfällt ein Fehlanreiz, der mit der Bedürftigkeitsprüfung verbunden ist: Bisher wurde die Sparbereitschaft untergraben, weil Sparer vom Transferbezug ausgeschlossen wurden, solange sie dank ihrer Ersparnisse nicht bedürftig waren. Dieser Vorteil der Sozialdividende hat nach Ansicht von Rhys-Williams nicht den Preis, daß die abschrekkende Wirkung der Bedürftigkeitsprüfung verloren geht: Die Bürger haben bereits das Schamgefühl überwunden, Transfers zu beziehen, weil sie ein relativ hohes Leistungsniveau ohne großes öffentliches Aufsehen erhalten können.

Ein weiterer Vorteil besteht darin, daß die bestehende Beitragsfinanzierung der Sozialversicherung über eine Arbeitseinkommensteuer abgeschafft wird. Statt dessen wird eine Steuer auf das Arbeits- und Kapitaleinkommen zur Finanzierung des Transfersystems herangezogen, die Rhys-Williams als gerechter ansieht (vgl. Green 1967, S. 53). Rhys-Williams beschreibt weiterhin die Vorteile der Sozialdividende für Frauen, die durch einen wöchentlichen Bargeldbetrag von der Willkür ihrer erwerbstätigen Männer unabhängig werden könnten.

Meade (1948) sieht einen positiven Effekt auf die Einkommensverteilung, je höher die Sozialdividende und je höher der Grenzsteuersatz ausfällt. Auch ließen sich nach Meade die nationalen Ausgaben und Einnahmen durch Va-

6 Nach Schema E erhöht sich von einem Einkommen in Höhe von 600 Pfund an der Steuersatz um die sogenannte ,surtax“, die 3,5 Schilling/Pfund beträgt, auf 7,5 Schilling/Pfund, also $37,5 \%$ (vgl. Rhys-Williams 1953, S.129 u. 163). Sesselmeier et al. (1996) berechnen dagegen einen Grenzsteuersatz von 57,5\%. Dieser hohe Grenzsteuersatz läßt sich jedoch nicht anhand der von Rhys-Williams vorgeschlagenen fün Schemen nachvollziehen. Statt dessen dürfte diese Berechnung auf einer Fehlinterpretation der „surtax“ basieren (vgl. Rhys-Williams 1953, S. 163, Anmerkung 1). 
riationen des Grenzsteuersatzes besser steuern als bisher, so daß Inflation und Deflation leichter vermieden werden könnten.

Die wichtigsten Nachteile einer Einführung der Sozialdividende sind allokativer und fiskalischer Art. Meade (1948) und Peacock (1952) warnen vor den negativen Wirkungen auf die Arbeitsanreize der Bürger. Zum einen sehen sie die Gefahr, daß sich viele Bürger mit dem Nettoeinkommen in Höhe der Sozialdividende zufriedengeben - statt zu arbeiten. Zum anderen heben sie den Anreiz hervor, weniger zu arbeiten - statt mehr zu arbeiten. Atkinson (1969) kritisiert, daß Rhys-Williams sich einseitig auf den ersten Aspekt des Anreizproblems fixiert, obwohl „freiwillige“ Arbeitslosigkeit aufgrund zu geringer finanzieller Arbeitsanreize kein zentrales Problem darstelle. Dagegen zeigt er in einer mikroökonomischen Analyse, daß die Mehrheit der bereits Erwerbstätigen mit verschlechterten Arbeitsanreizen konfrontiert ist: Einkommensund Substitutionseffekt wirken in Richtung weniger Arbeitseinsatz (vgl. ausführlich Kapitel 3.2.2.1).

Die Kosten der Einführung einer (unmodifizierten) Sozialdividende in England werden von Booker (1946) auf 3,1 Milliarden Pfund für das Budgetjahr $1945 / 46$ geschätzt. Um einen Grenzsteuersatz von $20 \%$ realisieren zu können, müßte die Bemessungsgrundlage etwa 8 Milliarden Pfund betragen - dieser Betrag entspricht ungefähr dem Nettoinlandsprodukt der damaligen Zeit. Da$\mathrm{zu}$ wäre eine erhebliche Verbreiterung der Bemessungsgrundlage auf bisher nicht besteuerte Einkommensanteile wie Kapitaleinkommen und nicht ausgeschüttete Gewinne nötig. Booker zweifelt die Realisierbarkeit dieses Vorhabens an. Er weist außerdem darauf hin, daß Anpassungsreaktionen der privaten Haushalte und Firmen auf die Verbreiterung der Bemessungsgrundlage in seinen Berechnungen nicht berücksichtigt sind.

Die Kosten der Einführung einer Sozialdividende in den USA liegen nach den Berechnungen von Green (1967, S. 138ff.) zwischen 26 und 53 Mrd. Dollar für das Jahr 1964. Atkinson (1969) berechnet die Kosten der Einführung der Sozialdividende in England und kommt auf einen Wert von 12,8 Milliarden Pfund für das Jahr 1967. Bei einem gesamten zu versteuernden Einkommen von etwa 25 Milliarden Pfund (1967), wäre ein Grenzsteuersatz von 51,7 \% nötig, um die Sozialdividende zu finanzieren! Berechnungen von Atkinson (1989) zu Sozialdividenden-Vorschlägen kommen zu Grenzsteuersätzen in ähnlicher Größenordnung. Atkinson relativiert auch die möglichen Verwaltungskostenersparnisse. Er betont, daß es mehr Steuerpflichtige gäbe, die auch mehr Einkommensarten als bisher angeben müßten.

Aber auch Gerechtigkeitsaspekte werden als Nachteile der Sozialdividende aufgeführt. Meade (1948) argumentiert, daß der Rhys-Williams-Vorschlag die Ungleichheit erhöhen würde, weil sich der Lohnabstand zwischen Erwerbstätigen und Arbeitslosen im Vergleich zur bisherigen Situation vergrößerte. Sein Punkt: Ein Erwerbstätiger stellt sich dank der Sozialdividende in Kombination mit der Besteuerung des Bruttoeinkommens finanziell relativ besser 
als ein Arbeitsloser. Der Lohnabstand zwischen Nettoeinkommen und Transferanspruch erhöht sich - im Gegensatz zur bestehenden Situation, in der sich Beschäftigungsverhältnisse mit Einkommen bis zum Transferniveau aufgrund der Vollanrechnung nicht einkommenserhöhend auswirken. Dieses distributive Argument erscheint aus heutiger Sicht zumindest als ungewöhnlich, weil doch gerade der fehlende Lohnabstand zwischen einem Erwerbstätigen und einem Arbeitslosen aus allokativer Sicht kritisiert wird (vgl. Kapitel 2).

Atkinson (1969) nennt die Gewinner und Verlierer bei der Einführung einer Sozialdividende. Gewinner sind zum einen Geringverdiener in der unteren Hälfte der Einkommensverteilung, die zum Zeitpunkt der Umstellung keine Transfers erhielten. Zum anderen profitieren Spitzenverdiener, deren Durchschnittssteuersatz unter dem bisherigen Niveau liegen wird; dieses Argument ist jedoch nur gültig, wenn der Grenzsteuersatz über den gesamten Einkommensbereich konstant ist - Abbildung 12 zeigt jedoch die Rhys-Williams Kompromißversion von 1953 mit höherem Grenzsteuersatz für Spitzenverdiener. Verlierer werden einige der bisherigen Transferempfänger sein, deren Kombination aus Einzeltransfers nicht in vollem Umfang durch den Pauschaltransfer "Sozialdividende“ ersetzt wird. Dies wird auf Personen mit überdurchschnittlicher Mietbelastung und außergewöhnlichem Bedarf zutreffen.

Praktische Umsetzung: Das Konzept von Rhys-Williams wurde in den vierziger Jahren von der Liberalen Partei aufgegriffen und in höchsten politischen Kreisen vorgestellt. Letztlich entschloß sich die britische Regierung jedoch für den „Beveridge-Plan“ (Beveridge 1943), der ein Sozialversicherungssystem vorsah.' Meade (1972) entwickelte den Rhys-Williams Vorschlag weiter. Derzeit befindet sich der „Basic Income/flat rate tax“-Vorschlag von Atkinson/Sutherland (1991) und Atkinson (1995) in der internationalen Diskussion; Atkinson bezieht sich ausdrücklich auf Rhys-Williams und Meade.

Für die heutige bundespolitische Diskussion spielt das Konzept der Sozialdividende oder einer Grundsicherung weiterhin eine gewisse Rolle. So hat der Deutsche Paritätische Wohlfahrtsverband (DPWV) eine bedarfsorientierte Grundsicherung vorgeschlagen (vgl. Deutscher Paritätischer Wohlfahrtsverband 1992, 1993). Die Sozialdemokratische Partei vertritt ebenfalls ein Konzept für eine bedarfsorientierte Grundsicherung, das von Hauser (1996) wesentlich geprägt wurde. Auch die Partei Bündnis 90/Die Grünen diskutiert ein Grundsicherungsmodell, das von Kaltenborn (1997) entwickelt wurde (vgl. Spermann 1997 für eine kritische Auseinandersetzung). Alle aktuell vorgeschlagenen Grundsicherungskonzepte sind jedoch nicht annähernd so radikal

7 Sesselmeier et al. (1996) interpretieren dagegen den Beveridge-Plan als Negativsteuermodell. Nach Ansicht des Autors handelt es sich jedoch explizit um einen Vorschlag zur Verbesserung der bestehenden Sozialversicherung. Dem Autor ist auch kein weiteres Werk bekannt, das den Beveridge-Plan als Negativsteuermodell einschätzt (vgl. die ausführliche Kritik am Beveridge-System von Parker 1989, S. 19ff.). 
wie der Rhys-Williams-Vorschlag, weil das bestehende Sozialversicherungsund Steuersystem nicht grundsätzlich verändert werden soll. Vertreter einer bedarfsorientierten Grundsicherung möchten insbesondere ergänzende Grundsicherungselemente in das bestehende Sozialversicherungs- und Transfersystem integrieren.

\subsubsection{Das Armutslückenkonzept von Friedman (1962/68)}

Als Maßnahme zur Bekämpfung von Armut wurde das sogenannte „Armutslückenkonzept" (poverty gap) von Milton Friedman 1962 in seinem Buch „Kapitalismus und Freiheit" (Friedman 1962; deutsche Übersetzung: Friedman 1971) vorgeschlagen. Die Vor- und Nachteile seiner Variante einer negativen Einkommensteuer diskutierte er sechs Jahre später ausführlich in einem Aufsatz (Friedman 1968a), der in zwei Kolumnen in der Zeitschrift „Newsweek“ einem breiteren Publikum zugänglich gemacht wurde (Friedman 1968 b,c). Mit diesen Beiträgen wollte sich Friedman von Vertretern anderer Versionen der negativen Einkommensteuer deutlich abgrenzen. Er betonte, daß er bereits seit zwei Jahrzehnten für den Ersatz des bestehenden Transfersystems durch eine negative Einkommensteuer eintritt. Dagegen seien Pläne, die die negative Einkommensteuer zusätzlich zum bestehenden Transfersystem einführen wollen, unverantwortlich.

Aus seiner Sicht hat das bestehende Wohlfahrtssystem in den USA drei wesentliche Mängel (vgl. Friedman 1968a). Zum einen bestehen erhebliche Anreizprobleme aufgrund der Vollanrechnung von Verdiensten auf den Transferanspruch. Deshalb würden Wohlfahrtsprogramme dazu tendieren, arme Leute zu produzieren. Zum anderen wird die persönliche Freiheit und Würde der Menschen durch Bedürftigkeitsprüfung und Gewährung von Sachleistungen verletzt. Zum dritten betätigten sich die Sozialarbeiter als Detektive und Polizisten statt den Armen zu helfen und sie zu beraten. Deshalb sei die Personalfluktuation in den Sozialämtern sehr hoch.

Die Innovation der von Friedman vorgeschlagenen Version einer negativen Einkommensteuer besteht in zwei Punkten:

1. Das positive Einkommensteuersystem soll unverändert bleiben: Friedman sucht ausdrücklich nach einer Lösung, die in das bestehende Einkommensteuersystem eingefügt werden kann. Für seinen Reformvorschlag nimmt er deshalb die bestehenden Steuerfreibeträge als gegeben hin. Daraus ergibt sich das Konzept der Armutslücke.

2. Die Armutslücke beträgt die Differenz zwischen Freibetrag (transferfreies Einkommen $=$ break-even Einkommen $=$ steuerfreies Existenzminimum $\mathrm{Y}^{*}$ ) und garantiertem Mindesteinkommen (minimum guaranteed income $\mathrm{M}$ ). Eine Armutslücke ist die zwangsläufige Konsequenz, wenn ein Anrechnungssatz für Zusatzverdienste unterhalb von $100 \%$ bei unverändertem steuerfreiem Existenzminimum eingeführt werden soll: das garantierte Mindesteinkommen muß unter dem Freibetrag liegen. Formal zeigt sich dieser Zusammenhang in 
der Bestimmungsformel für $\mathrm{Y}^{*}=\mathrm{M} / \mathrm{t}{ }^{8}$ Wenn $\mathrm{t}$ bei konstantem $\mathrm{Y}^{*}$ gesenkt werden soll, dann muß $\mathrm{M}$ zwangsläufig sinken. Auch in Abbildung 13 erkennt man diesen Zusammenhang: Die Nettoeinkommensfunktion oberhalb der $45^{\circ}$ Linie muß in $\mathrm{Y}^{*}$ aufgrund des abnehmenden Anrechnungssatzes nach unten gedreht werden, so daß dieser Teil der Nettoeinkommensfunktion steiler wird. Dadurch beginnt die Nettoeinkommensfunktion bei einem geringeren Wert von $\mathrm{M}$ :

Das Armutslückenkonzept soll anhand des Originalbeispiels von 1962 für eine Einzelperson im Brutto-/Nettoeinkommen-Diagramm in Abbildung 13 dargestellt werden (Friedman 1962, S. 245f.):

Friedman schlägt ein garantiertes Mindesteinkommen $\mathbf{M}$ für eine einzelne Person in Höhe von 300 Dollar/Jahr vor. Zusatzverdienste bis zum transferfreien Einkommen $Y^{\prime}$ von 600 Dollar/Jahr sollen zur Hälfte angerechnet werden. Der Anrechnungssatz (=Transferentzugsrate) $t_{1}$, der ökonomisch wie ein Grenzsteuersatz auf Zusatzverdienste wirkt, beträgt demnach $50 \%$. Bruttoeinkommen $\mathrm{Y}^{\mathrm{b}}$ über dem Freibetrag von 600 Dollar/Jahr sollen wie im bestehenden System einem positiven Grenzsteuersatz von $t_{2}=14 \%$ unterliegen.

Das Friedman-Modell läßt sich durch folgende Nettoeinkommensfunktion ausdrücken:

$Y_{\text {Friedman }}^{n}=M+\left(1-t_{1}\right) Y^{b}=300+(1-0,5) Y^{b}=300+0,5 Y^{b}$

für $\mathrm{Y}^{\mathrm{b}}<\mathrm{Y}^{*}=600$ Dollar/Jahr.

Im Falle der Nichterwerbstätigkeit erhält eine Person lediglich 300 Dollar/Jahr, also die Hälfte des Existenzminimums. Die Armutslücke beträgt in diesem Zahlenbeispiel demnach 300 Dollar/Jahr, also die Differenz aus Freibetrag $\left(\mathrm{Y}^{\prime}=600 \mathrm{Dollar} / \mathrm{Jahr}\right)$ und garantiertem Mindesteinkommen $(\mathrm{M}=300$ Dollar/Jahr). Friedman betont ausdrücklich, daß er höhere Freibeträge und einen geringeren Anrechnungssatz vorziehen würde. Dazu wären jedoch weitreichende Veränderungen des positiven Einkommensteuersystems nötig (Friedman 1968a, S. 212).

Friedman selbst erklärt sein Modell auf komplizierte Art und Weise. Sein Beispiel: Ein Geringverdiener mit einem Bruttoeinkommen von 100 Dollar unterhalb des Freibetrags, also 500 Dollar, erhält die Hälfte des Differenzbetrags, also 50 Dollar (0,5·(600-500)), als Transfer ausbezahlt. Dadurch erhöht sich sein Nettoeinkommen auf 550 Dollar. Mit diesem Zahlenbeispiel will Friedman hervorheben, daß bisher von Geringverdienern nicht ausnutzbare

8 Die Bestimmungsformel ergibt sich aus dem Schnittpunkt der Nettoeinkommensfunktion und der $45^{\circ}$-Linie (vgl. Boadway/Wildasin 1984, S. 448ff.). 
Freibeträge als Transfers ausgezahlt werden sollen. Eingesetzt in die Nettoeinkommensfunktion ergibt sich selbstverständlich das gleiche Ergebnis. ${ }^{9}$

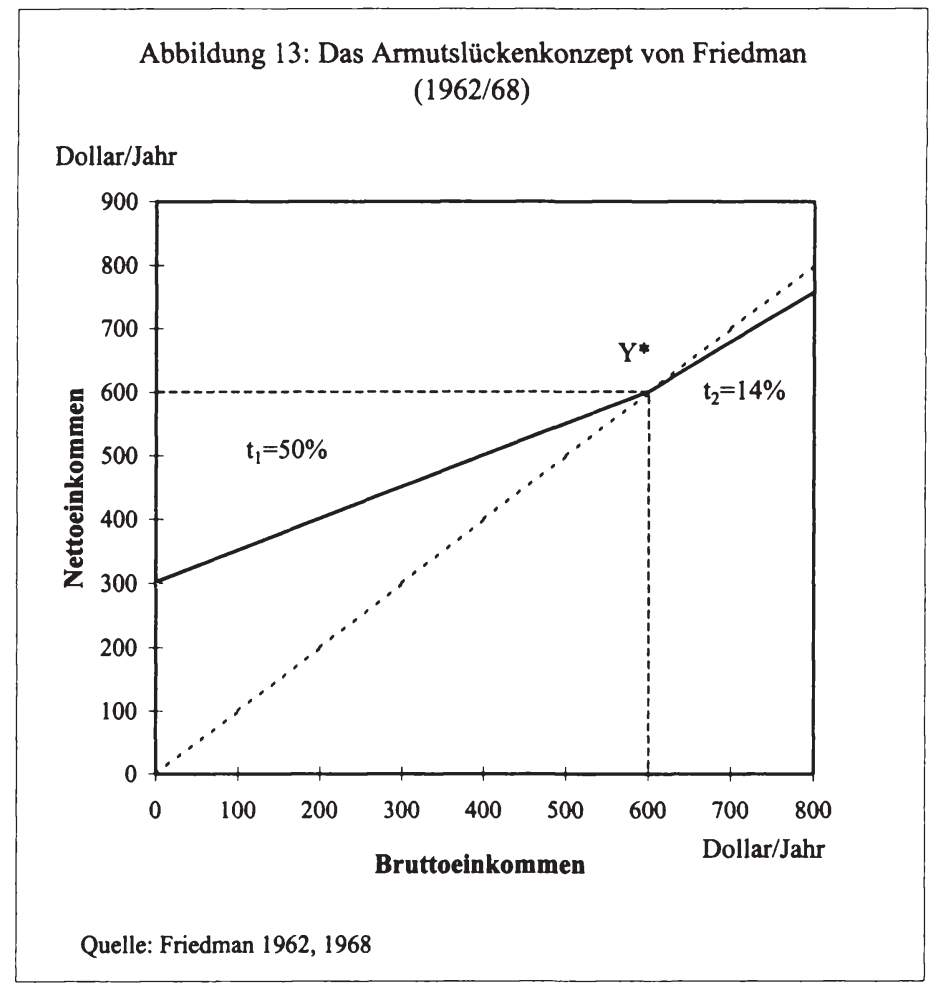

Die Auszahlung der Transfers ist analog zum Quellenabzugsverfahren bei der Lohnsteuer und zum Veranlagungsverfahren bei der Einkommensteuer vorgesehen: Lohnnegativsteuerempfänger erhalten die Transfers zusammen mit ihrem monatlichen Lohn, Einkommennegativsteuerempfänger erhalten sie als „negative Einkommensteuervorauszahlungen“. Dazu ist es jedoch notwendig, daß jeder Bürger eine Einkommensteuererklärung abgibt. Administrativ soll die Negativsteuer wie die positive Steuer über die Finanzämter abgewickelt werden.

Zeckhauser (1971) weist zu Recht darauf hin, daß der Begriff Negativsteuer unglücklich gewählt ist. Aus Sicht des Individuums bestehe ein positiver

9 Das Nettoeinkommen ergibt sich aus $\mathrm{Y}_{\text {Friedman }}^{\mathrm{n}}=300+0,5 \cdot 500=550$. Der Transfer in Höhe von 50 Dollar ergibt sich aus der Differenz zwischen Netto- und Bruttoeinkommen $(550-500=50)$ 
Grenzsteuersatz auf Zusatzverdienste - im Friedman-Modell in Höhe von $t_{1}=50 \%$. Insofern existiert weiterhin ein positiver Grenzsteuersatz, negativ sei die Steuer nur im aggregierten Sinne.

Die Vorteile einer negativen Einkommensteuer nach dem Armutslückenkonzept sieht Friedman zum einen darin, daß die öffentlichen Mittel auf die wirklich Bedürftigen konzentriert werden. Ursache für den Transferbezug ist dann ausschließlich Einkommensarmut, nicht die Tatsache, alt oder arbeitslos zu sein - Eigenschaften, die häufig mit Armut verbunden werden, es aber nicht zwangsläufig sind. Zum anderen werden Bedürftige als verantwortliche Individuen behandelt, weil sie über einen bestimmten Geldbetrag selbst verfügen dürfen. Zum dritten wird die Eigeninitiative der Transferempfänger gestärkt, in dem die Aufnahme einer Erwerbstätigkeit durch höheres Nettoeinkommen belohnt wird. Durch eine Teilanrechnung von Zusatzverdiensten können sich Bedürftige durch kleine Schritte selbst helfen. Viertens sind die fiskalischen Kosten geringer als beim bestehenden System, wenn die Sozialhilfe ersetzt und andere Wohlfahrtsprogramme leicht gekürzt würden. Hinzu kommen die zusätzlichen Einnahmen, wenn die positiven Arbeitsanreize zu mehr Beschäftigung von derzeit Bedürftigen führten. Fünftens könnte die schwerfällige und teure Wohlfahrtsbürokratie weitgehend beseitigt werden. Das Personal könnte sich dann wieder auf seine Beratungsaufgaben konzentrieren. Außerdem kann die negative Einkommensteuer im Gegensatz zu bestehenden Programmen im Kampf gegen die Armut nicht als „politischer Schmiergeldfonds" (Friedman 1968a, S. 213) benutzt werden.

Der wesentliche Nachteil des Armutslückenkonzeptes liegt auf den ersten Blick in dem zu geringen garantierten Mindesteinkommen, das das zum Leben notwendige Existenzminimum nicht abdeckt. Friedman betont jedoch, $\mathrm{da}$ er ein bundesweites Mindesteinkommen vorschlägt. Zwar sei dieses Mindesteinkommen unter dem derzeit in einigen wohlhabenden Bundesstaaten gewährten Sozialhilfeniveau, doch liege es wahrscheinlich über dem Niveau der meisten Bundesstaaten - die Lebenshaltungskosten in einzelnen Bundesländern sind sehr unterschiedlich. Auch sind die Bundesstaaten dazu aufgerufen, eine landesweite ergänzende negative Einkommensteuer einzuführen. Besser wäre es jedoch, wenn private Wohlfahrtsorganisationen das Existenzminimum absichern würden.

Green (1967, S. 138ff.) berechnete die zusätzlichen Kosten für die Einführung des Friedman-Plans auf 7 bis 9 Milliarden Dollar im Jahre 1964. Friedman hält diese Zahlen für übertrieben, konzediert jedoch, daß sein Reformvorschlag in einer Übergangsperiode von ein bis zwei Jahren „etwas höhere Kosten“ (Friedman 1968b) verursachen könnte. Er hält jedoch entgegen, daß nach einer Übergangsperiode die zu erwartenden positiven Beschäftigungseffekte zu Einsparungen führen würden.

Ein weiterer Nachteil könnte darin bestehen, daß die Höhe des garantierten Grundeinkommen und des Anrechnungssatzes für Zusatzverdienste von 
Transferempfängern unter politischem Druck stünden - mit der Konsequenz, daß die Freibeträge und das garantierte Mindesteinkommen laufend erhöht würden. Friedman (1962) gestand diesen Schwachpunkt zunächst zu, revidierte jedoch seine Meinung aus zwei Gründen. Zum einen sei die negative Einkommensteuer mit der positiven Einkommensteuer eng verknüpft. Deshalb würden höhere Freibeträge, die bei gleichbleibenden Staatsausgaben mit höheren Grenzsteuersätzen für Einkommensbezieher über den Freibeträgen verbunden wären, jeden Steuerzahler offensichtlich belasten. Zum anderen sei die negative Einkommensteuer nicht auf eine große Wohlfahrtsbürokratie angewiesen, die ein Eigeninteresse an der Ausweitung ihres Budgets habe. Deshalb glaubt Friedman (1968a), daß die negative Einkommensteuer weniger als das bestehende System für politischen Druck anfällig ist.

Den Vorwurf, sein Reformvorschlag sei mit der Abschaffung der Bedürftigkeitsprüfung verbunden, kontert Friedman mit dem Verweis auf ein Mißverständnis. Bedürftig ist, wer ein Einkommen unter dem Freibetrag verdient. Bei einer negativen Einkommensteuer gelte der gleiche Maßstab wie bei der Berechnung der Steuerschuld: das zu versteuernde Einkommen.

Das Armutslückenkonzept wurde in den sechziger Jahren in den USA diskutiert (vgl. Green 1967). Die Diskussion veranlaßte das amerikanische „Office of Economic Opportunity“ (OEO) Aufträge zur Feldforschung zu vergeben, um die Bedenken Präsident Johnsons gegen die Negativsteuer zu zerstreuen (vgl. Mitschke 1994a, S. 154). In der aktuellen bundesdeutschen Diskussion ist der Friedman-Vorschlag von Vaubel (1996) aufgegriffen worden. Das Armutslückenkonzept von Vaubel wird im vierten Kapitel ausführlich dargestellt und beurteilt.

\subsubsection{Die graduelle Integration von Tobin (1965/67)}

In seinem Aufsatz „On Improving the Economic Status of the Negro“ von 1965 entwickelte James Tobin eine Konzeption, um die Verdienstmöglichkeiten von farbigen und weißen Niedrigeinkommensbeziehern zu verbessern. Zusammen mit Joseph Pechman und Peter Mieszkowski erweiterte er 1967 seinen Reformvorschlag: Die sogenannte graduelle Integration von Steuerund Transfersystem zielt auf die Aufstockung niedriger Familieneinkommen ab.

Tobin kritisiert insbesondere die Bedürftigkeitsprüfung des bestehenden Transfersystems. Zum einen seien die Prüfungskriterien sehr restriktiv, zum anderen sei die Prüfung für die Hilfeempfänger unwürdig, zum dritten wirke sie wie ein $100 \%$-iger Grenzsteuersatz auf die eigenen Verdienste der Hilfeempfänger, weil Zusatzverdienste den Transferanspruch in gleicher Höhe reduzieren. Die Konsequenz sei, daß Armut und Abhängigkeit von der Wohlfahrt von einer Generation zur anderen weitergegeben werde und die Mauer zwischen den Armen und dem Rest der Gesellschaft immer höher werde (vgl. Tobin/Pechman/Mieszkowski 1967, S. 1). Hinzu kommt, daß insbesondere 
Familienväter den Sprung über die Armutsfalle nicht schafften - mit der Konsequenz, daß sie zu Faulheit und zu einem Leben in Abhängigkeit von Unterstützungsleistungen gezwungen werden statt Arbeitserfahrungen sammeln zu können. Auch entfällt aufgrund der Vermögensüberprüfung der Anreiz zur Ersparnisbildung. Das wichtigste amerikanische Wohlfahrtsprogramm der sechziger Jahre - Aid for Dependent Children - bewirke absurderweise, daß die Familien zerstört würden. Das liegt daran, daß arbeitsfähige Männer selbst wenn sie arbeitslos sind - nicht im Haushalt der Transferempfängerinnen wohnen dürfen (vgl. Tobin 1965, S. 890f.).

Die bürokratische Überwachung und Gängelung der Hilfeempfänger führt nach Tobin zur Unterhöhlung ihres Selbstwertgefühls und ihrer Selbsthilfefähigkeiten. $\mathrm{Zu}$ sehr würde bei der Durchführung der Bedürftigkeitsprüfung darauf geachtet, daß die Steuerzahler nicht betrogen werden (cheating). Dabei würde die Zeit der Antragsteller als freies Gut angesehen - sie sind in der Wohlfahrtsbürokratie häufig mit Suchen und Warten beschäftigt.

Besonders hebt Tobin hervor, daß vor allem schwarze aber auch weiße Väter von normalen und intakten Familien häufig nicht in der Lage sind, einen ausreichend bezahlten Job zu finden. Nationaler Reichtum und Wachstum seien zwar „leistungsfähige Motoren, um die ökonomische Stellung der Schwarzen zu verbessern", doch reichten diese Faktoren nicht aus und würden ihre Stellung auch nicht schnell genug verbessern, auch wenn der Arbeitsmarkt gut funktionierte (vgl. Tobin 1965, S. 879). Das liegt daran, daß insbesondere Farbige diskriminiert werden und in der Regel schlecht ausgebildet sind (vgl. Tobin 1965, S. 887ff.).

Tobins Ziel ist es, die Verdienstmöglichkeiten der einkommensschwachen schwarzen und weißen Familien durch eine Teilanrechnung von Zusatzverdiensten zu verbessern. Andere Mittel wie Mindestlöhne seien kontraproduktiv, weil die potentiellen Nutznießer erst gar nicht beschäftigt würden. Sein Vorschlag zeichnet sich durch zwei innovative Elemente aus:

1. Das positive Einkommensteuersystem bleibt unverändert, aber es wird mit der negativen Einkommensteuer verschmolzen (vgl. Green 1967, S. 61).

2. Die negative Einkommensteuer beschränkt sich auf die Zielgruppe „einkommensschwache Familien" - der Tobin-Vorschlag ist somit die erste zielgruppenorientierte Konzeption einer negativen Einkommensteuer (vgl. Metze 1982, S. 794).

Das Konzept der graduellen Integration von Tobin soll anhand des Originalbeispiels von Tobin (1965) für eine Familie mit fünf Personen im Brutto-/ Nettoeinkommen-Diagramm in Abbildung 14 dargestellt werden:

Tobin sieht einen Grundfreibetrag für jedes Familienmitglied in Höhe von 400 \$ im Jahr vor. Bei einer fünfköpfigen Familie ergibt sich somit ein maximaler Grundfreibetrag von $2000 \$ / \mathrm{Jahr}$, der an der Ordinate abgetragen ist. Dieser Betrag wird im Falle der Nichterwerbstätigkeit als Ersatz für bestehende Transferleistungen ausgezahlt. Als Anrechnungssatz für Zusatzverdienste 
schlägt Tobin ein Drittel vor $\left(t_{1}=0,33\right)$, so daß zwei Drittel des Bruttoeinkommens beim Transferempfänger verbleiben. Daraus ergibt sich ein transferfreies Einkommen $\left(\mathrm{Y}^{*}\right)$ von 6000 \$/Jahr im Fall der betrachteten Familie.

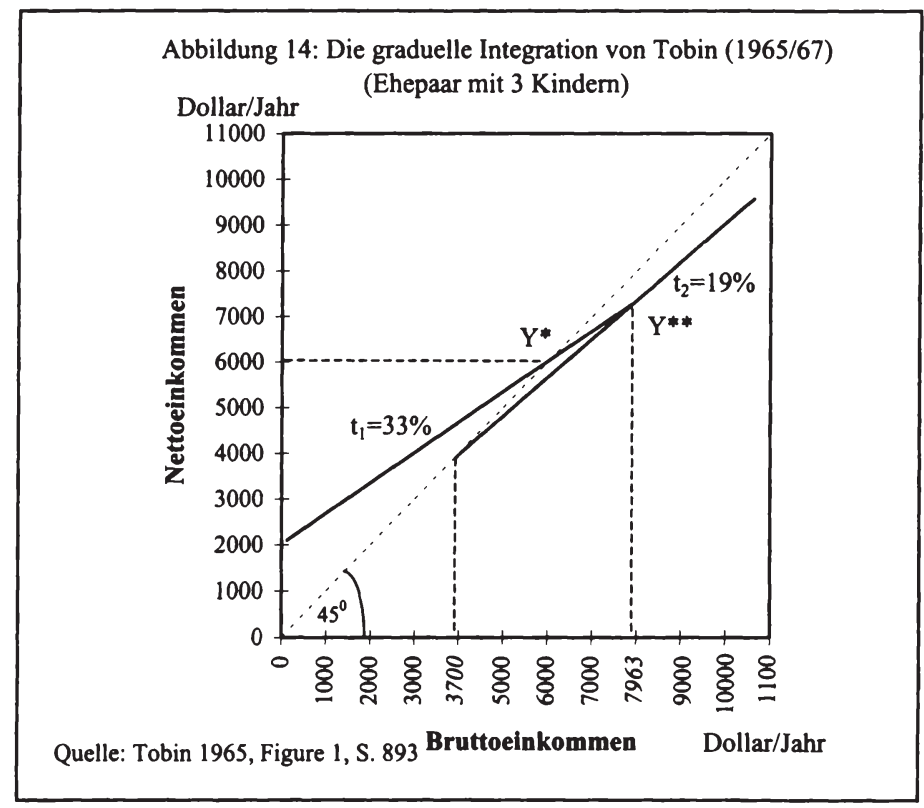

Die Besonderheit des Tobin-Vorschlags liegt darin, daß die positive Einkommensteuer bereits bei Bruttoeinkommen unter dem transferfreien Einkommen erhoben wird. Im amerikanischen Steuersystem der damaligen Zeit mußte die betrachtete Familie erst bei einem Bruttoeinkommen oberhalb von 3700 $\$ /$ Jahr Steuern entrichten. Damit überlappen sich positiver und negativer Einkommensteuerbereich. Die Nettoeinkommensfunktion des Tobin-Plans mündet bei einem sogenannten "tax-break-even income“ von $\mathrm{Y}^{* *}=7963 \$ / \mathrm{Jahr}$ in die Nettoeinkommensfunktion des bestehenden Einkommensteuersystems. Erst von diesem Bruttoeinkommen an wird die Steuerschuld des bisherigen System bezahlt. Zur damaligen Zeit betrug der Grenzsteuersatz $t_{2}$ beim taxbreak-even income $19 \%$.

Das Tobin-Modell läßt sich durch folgende Nettoeinkommensfunktion ausdrücken:

$Y_{\text {Tobin }}^{n}=M+\left(1-t_{1}\right) Y^{b}=2000+(1-0,33) Y^{b}=2000+0,66 Y^{b}$

für $\mathrm{Y}^{\mathrm{b}}<\mathrm{Y}^{* *}=7963$ Dollar/Jahr. 
Diese Konstruktion hat zur Konsequenz, daß vier Gruppen von Bruttoeinkommensbeziehern zu unterscheiden sind:

1. Im Bruttoeinkommensbereich von 0 bis $3700 \$ / \mathrm{Jahr}$ wird das bisher nicht besteuerte Familieneinkommen durch einen einkommensabhängigen Transfer aufgestockt. Bei einem Bruttoeinkommen von 3700 \$/Jahr ergibt sich nach der Bestimmungsgleichung für das Tobin-Modell ein Nettoeinkommen von 4442 \$/Jahr. Das Bruttoeinkommen wird demnach um eine negative Einkommensteuer in Höhe von 742 \$/Jahr aufgestockt (vgl. die Tabelle von Tobin/Pechman/Mieszkowski 1967, S. 5).

2. Im Bruttoeinkommensbereich von $3700 \$ / \mathrm{Jahr}$ bis $6000 \$ / \mathrm{Jahr}$ entfällt die Besteuerung der Einkünfte. Zusätzlich wird das Familieneinkommen durch einen einkommensabhängigen Transfer aufgestockt.

3. Im Bruttoeinkommensbereich von 6000 \$/Jahr bis 7963 \$/Jahr wird die im Rahmen des bestehenden Einkommensteuersystems berechnete Steuerschuld vermindert. Bei einem Bruttoeinkommen von 7963 \$/Jahr - dem tax-breakeven income - ergibt sich nach dem Tobin-Modell eine gleich hohe Steuerschuld wie im bestehenden Einkommensteuersystem. ${ }^{10}$ Ein Zahlenbeispiel zur Illustration: Ein Bruttoeinkommen von 6000 \$/Jahr wird gerade nicht mehr durch eine negative Einkommensteuer aufgestockt. Es muß aber im Gegensatz zum Status quo auch keine Einkommensteuer bezahlt werden. Brutto- und Nettoeinkommen fallen deshalb zusammen, der Steuerausfall durch die Einführung des Tobin-Modells beträgt bei einem - aus Vereinfachungsgründen angenommenen Grenzsteuersatz von $\mathrm{t}_{2}=19 \%$ über dem steuerfreien Existenzminimum von 3700 \$/Jahr genau 437 \$/Jahr. ${ }^{1}$

4. Bezieher von Bruttoeinkommen über $7963 \$ / J a h r$ bleiben vom TobinModell unberührt - sie tragen ceteris paribus die gleiche Steuerschuld wie bisher, wenn man für einen Moment von den zu finanzierenden Zusatzkosten des Tobin-Modells absieht.

Tobin (1965) geht von jährlichen Bruttokosten seines Modells in Höhe von 15 Milliarden \$ aus, wovon die Einsparungen von Sozialhilfeleistungen in Höhe von 5,6 Milliarden $\$ / \mathrm{Jahr}$ abgezogen werden müssen. Weitere Einsparungen bei anderen Transferprogrammen seien möglich. Das Programm ist nach Tobins Auffassung teuer, aber es ließe sich auch schrittweise einführen - die Höhe der Grundfreibeträge könnte allmählich steigen. Dabei könnten die mit

10 Unter den vereinfachenden Annahmen über das amerikanische Steuersytem läßt sich das von Tobin angegebene tax-break-even income nicht exakt berechnen.

"Bei $Y^{b}=6000$ ergibt sich für $Y_{\text {Tobin }}^{n}=2000+(1-0,33) 6000=6000$. Im Status quo ergibt sich jedoch ein geringeres Nettoeinkommen $Y_{S T Q}^{n}=3700+(1-0,19)(6000-3700)=5563$.

Der Steuerausfall beträgt demnach $Y_{\text {Tobin }}^{n}-Y_{S T Q}^{n}=6000-5563=437$. 
dem Wachstum der Wirtschaft verbundenen zusätzlichen Steuereinnahmen den finanziellen Spielraum zur Finanzierung des Modells schaffen.

In Tobin/Pechman/Mieszkowski (1967) wird das Grundmodell von Tobin (1965) erweitert und ausführlich diskutiert. Die Autoren sehen nach Anzahl der Familienmitglieder gestaffelte Grundfreibeträge vor. Dabei unterscheiden sie einen Grundfreibetrag, der mit dem Existenzminimum zusammenfällt (High Schedule H), und einen Grundfreibetrag, der nur einen Teil des Existenzminimums abdeckt (Low Schedule L). Außerdem schlagen sie zwei unterschiedliche Transferentzugsraten vor: $331 / 3$ und 50 Prozent. Daraus ergeben sich vier mögliche Varianten des Tobin-Modells.

Tobin et al. (1967) plädieren für eine breite Bemessungsgrundlage einer negativen Einkommensteuer, damit ausschließlich Bedürftige Transferleistungen erhalten. Am einfachsten sei es, sämtliche Abzüge von der Bemessungsgrundlage, die im Rahmen der positiven Einkommensteuerermittlung möglich sind, nicht zu erlauben. Eine Ausnahme sollten nicht vermeidbare Ausgaben sein, zum Beispiel für medizinische Zwecke, die ein - gemessen am Grundfreibetrag - zumutbares Maß übersteigen. Für Landwirte soll der Wert selbsterzeugter und selbstverbrauchter Nahrungsmittel als Einkommen gerechnet werden. Staatliche, nicht bedürftigkeitsgeprüfte Transferleistungen wie Arbeitslosengeld, aber auch private Transferleistungen wie Geschenke sollen Bestandteil der Bemessungsgrundlage sein.

Eine besondere Rolle spielt die bei Bedürftigkeit gewährte Sozialhilfe, die auf kommunaler und Bundesstaatenebene bezahlt wird. Sozialhilfeleistungen sollten nicht in die Bemessungsgrundlage der negativen Einkommensteuer einfließen. Sozialhilfe soll ergänzend bezahlt werden, insbesondere wenn die niedrigeren Freibeträge der L-Variante gewährt werden. Aber auch bei Einführung der H-Variante könnten ergänzende Sozialhilfeleistungen in einzelnen Bundesstaaten nötig sein, um das bestehende Transferniveau zu gewährleisten.

Als Folge des Nebeneinander einer bundesweiten negativen Einkommensteuer und ergänzender Sozialhilfe der untergeordneten Gebietskörperschaften werden die Anreizprobleme des bestehenden Systems jedoch nur teilweise beseitigt: Eigene Einkünfte der Hilfeempfänger werden voll auf die Sozialhilfe angerechnet, so daß sie sich in Höhe der ergänzenden Sozialhilfe finanziell nicht lohnen. Tobin et al. (1967) schlagen deshalb vor, den Anrechnungssatz auf Zusatzverdienste der negativen Einkommensteuer auf das bestehende Transfersystem zu übertragen.

Sozialversicherungssystem und negative Einkommensteuer sollten nach Ansicht von Tobin et al. (1967) weiterhin getrennt bleiben. Theoretisch sei es möglich, die Sozialversicherungsleistungen so hoch anzusetzen, daß Leistungen der negativen Einkommensteuer überflüssig wären. Doch dürfte dieser Weg teuer und ineffizient sein, weil auch Nicht-Bedürftige von den Leistungserhöhungen profitieren würden. Deshalb sei es sinnvoll, bestehende So- 
zialversicherungsleistungen in die Bemessungsgrundlage der negativen Einkommensteuer einzubeziehen - mit der wünschenswerten Konsequenz, daß lediglich Bedürftige Anspruch auf staatliche Transfers haben.

Vermögen sollte nach Ansicht von Tobin et al. (1967) grundsätzlich bei der Berechnung der negativen Einkommensteuer berücksichtigt werden. Sie schlagen einen eigenen Anrechnungssatz auf Kapital vor. So könnte eine 10 $\%$-ige Anrechnung auf Nettovermögen über einem Freibetrag, der das Achtfache des Grundfreibetrags beträgt, eingeführt werden. In unserem Zahlenbeispiel müßte sich die Familie mit fünf Kindern mit einem ursprünglichen Grundfreibetrag von $2000 \$ / \mathrm{Jahr}$ bei einem Nettovermögen in Höhe von 30000 \$ zehn Prozent von $14000 \$(=30000 \$-(8 \times 2000 \$))$, also $1400 \$$, anrechnen lassen. Der Grundfreibetrag unter Berücksichtigung der Vermögensanrechnung würde demnach auf $600 \$ / J a h r$ sinken.

Die Bruttokosten schwanken nach ihren Schätzungen zwischen 7 Milliarden \$/Jahr für die L-50-Variante und 49,3 Milliarden \$/Jahr für die H-33 1/3Variante. Dabei wurden zum einen die Bevölkerungszahlen sowie Familieneinkommen und -strukturen aus dem Jahre 1962, zum anderen die Einkommensteuergesetze des Jahres 1965 zugrundegelegt. Bei der Berechnung der Nettokosten sind die Kostenersparnisse durch den Wegfall einzelner Transferleistungen und die Mehreinnahmen durch die Verbreiterung der Bemessungsgrundlage zu berücksichtigen. Die Nettokosten betragen 20 Milliarden \$/Jahr für die $\mathrm{H}-50$-Variante, mehr als 40 Milliarden $\$ / \mathrm{Jahr}$ für die $\mathrm{H}-33$ Variante, 10 Milliarden \$/Jahr für die L-33-Variante und weniger als 5 Milliarden \$/Jahr für die L-50-Variante (vgl. Tobin et al. 1967, S. 24-26).

Das Tobin-Modell ist in der L-Variante als Armutslückenkonzept im Sinne von Friedman, in der H-Variante jedoch als Sozialdividendenkonzept im Sinne von Rhys-Williams zu interpretieren.

Zusammenfassend läßt sich festhalten, daß der Ersatz bestehender Transferleistungen durch die betrachteten Modelle einer negativen Einkommensteuer mit Mehrkosten für den Staat verbunden ist - besonders die Einführungskosten von Sozialdividenden-Modellen sind sehr hoch. Mittel- und langfristig hoffen die Befürworter der Negativsteueridee auf Einsparungen durch geringere Verwaltungskosten und geringere Transferzahlungen bzw. zusätzliche Steuereinnahmen aufgrund höherer Beschäftigung. Es hat sich gezeigt, daß die negativen Arbeitsanreizwirkungen für bereits Erwerbstätige von der Geburtsstunde der Negativsteueridee an diskutiert wurden. Auf eine detaillierte allokative Analyse der einzelnen Negativsteuerkonzeptionen wurde in diesem Kapitel jedoch verzichtet - sinnvoller erscheint es, die in den neunziger Jahren diskutierte deutsche Version einer Negativsteuer genauer zu untersuchen: das Bürgergeld. 


\subsection{Die Bürgergeld-Diskussion der neunziger Jahre}

\subsubsection{Das Bürgergeldkonzept von Mitschke (1994/95)}

Bereits im Jahre 1973 entwarfen Engels/Mitschke/Starkloff das Grundkonzept der „Staatsbürgersteuer“ - ein geschlossenes System der persönlichen Besteuerung und Subventionierung, das direkte Steuern und bestimmte Subventionen ersetzen sollte. In dieser Arbeit wird der Begriff „Bürgergeld“ eingeführt (vgl. Engels/Mitschke/Starkloff 1973, S. 14). Ein detailliert ausgearbeitetes Konzept zur Integration aller Direktsteuern und Sozialtransfers der Bundesrepublik Deutschland legte Mitschke zwölf Jahre später vor (vgl. Mitschke 1985). Sein „totales Integrationsmodell“ besteht aus zwei wesentlichen Komponenten: dem Bürgergeld und der „Bürgersteuer“. Das Bürgergeld soll bestehende steuerfinanzierte Transfers ersetzen, die Bürgersteuer soll bestehende direkte Steuern durch eine umfassende Lebenseinkommensbesteuerung ersetzen (vgl. Mitschke 1985, S. 53 u. Schildbach 1997). Ein Jahr später legte der Kronberger Kreis den Entwurf einer Neuordnung von direkten Steuern und Sozialleistungen unter dem Titel Bürgersteuer vor - auf der Basis der Untersuchung von Mitschke (vgl. Engels et al. 1986). In den neunziger Jahren erlebte ein Teilelement des totalen Integrationsmodells von Mitschke (1985) das Bürgergeld - vor dem Hintergrund hoher Arbeitslosigkeit eine Renaissance. Im September 1993 stellte Mitschke das Bürgergeld auf einer Fachtagung der Christlich-Demokratischen Arbeitnehmerschaft (CDA) und der Wirtschaftsvereinigung der CDU (WIV) vor (vgl. Mitschke 1994a,b,c).

Entsprechend einer Koalitionsvereinbarung der Regierungsparteien CDU/CSU-FDP vom November 1994 sollte eine Expertenkommission Lösungsvorschläge prüfen, um soziale Hilfen zielgenauer zu leisten, Anreize für reguläre Erwerbsarbeit zu stärken und Sozialbürokratie abzubauen. Die Expertenkommission unter Vorsitz von Krause-Junk nahm ihre Arbeit im April 1995 auf und legte im Mai 1996 ihr Gutachten vor, in dem das Bürgergeld abgelehnt wird (vgl. Experten-Kommission „Alternative Steuer-TransferSysteme“ 1996, Krause-Junk 1996); interessanterweise arbeitete Mitschke bis zum 18. März 1996 in der Expertenkommission mit.

In diesem Kapitel wird das aktuelle Bürgergeldkonzept von Mitschke in grafischer und algebraischer Form dargestellt. Im Gegensatz zu den Veröffentlichungen der siebziger und achtziger Jahre zielt Mitschke auf ein „duales Integrationsmodell" ab, das sich auf eine tarifäre Koordination von steuerfinanzierten Sozialleistungen und bestehendem Einkommensteuersystem beschränkt (vgl. Mitschke 1995a, S. 81f.); das Ziel einer tarifären Integration im Sinne des totalen Integrationsmodells wird aus Gründen der politischen Konsensfähigkeit zurückgestellt (vgl. Schildbach 1997, S. 22). Das Bürgergeld 
könnte zwar die beschriebenen Fehlanreize im Sozialsystem beseitigen, jedoch ergibt sich selbst bei dem bescheideneren Ziel einer tarifären Koordination eine Vielzahl von Problemen. Im folgenden wird das Bürgergeldkonzept von Mitschke in Anlehnung an die Ausführungen der ExpertenKommission dargestellt und unter fiskalischen, allokativen, sozial- und verteilungspolitischen, steuersystematischen und politökonomischen Gesichtspunkten kritisch analysiert.

Der Grundgedanke eines Bürgergeldsystems besteht darin, den Steuer-tarif um einen Negativbereich für auszuzahlende Sozialleistungen zu erweitern. Dabei sollen steuerfinanzierte Sozialleistungen durch einen nach Alter differenzierten Universaltransfer - das Bürgergeld - ersetzt werden. Für die Integration im Rahmen des Bürgergeldkonzepts kommen grundsätzlich das Kindergeld, das Erziehungsgeld, das Wohngeld, die Leistungen nach dem Bundesausbildungsförderungsgesetz (BAföG), die gesamte Sozialhilfe (Hilfe zum Lebensunterhalt und Hilfe in besonderen Lebenslagen), die Arbeitslosenhilfe, bedürftigkeits- und personenbezogene Objektsubventionen im sozialen Wohnungsbau, in der Landwirtschaft, im öffentlichen Nahverkehr, in der Jugendhilfe und im Kommunalbereich und Umverteilungs- und Mindestsicherungselemente in der Sozialversicherung in Frage (vgl. Mitschke 1995a, S. 80f.). Als kurzfristig integrationsfähige Sozialleistungen sieht Mitschke das Kinder-, Erziehungs- und Wohngeld sowie die BAföG-Leistungen an. Sozialhilfeleistungen sollten nach seiner Ansicht erst mittelfristig integriert werden. Die Einbeziehung der Arbeitslosenhilfe sieht Mitschke kritisch. Sie setze voraus, daß die Arbeitslosenversicherung neu geordnet wird. Außerdem würden Arbeitnehmer früher als bisher von der Erwerbssphäre entfremdet (vgl. Mitschke 1994a, S. 155f.). Ausdrücklich sieht Mitschke eine haushaltsneutrale Umstellung auf das Bürgergeldkonzept vor.

Das duale Integrationsmodell akzeptiert die unterschiedlichen Bemessungsgrundlagen von Sozialleistungen, die nach dem Haushaltsprinzip vergeben werden, und Steuern, die nach dem Individualprinzip erhoben werden. Der integrierte Tarifverlauf des Bürgergeldes läßt sich deshalb durch folgende Grundelemente kennzeichnen (vgl. Experten-Kommission „Alternative Steuer-Transfer-Systeme“"1996):

1. Die Höhe des Bürgergeldes wird auf jährlich $12.000 \mathrm{DM}$ je Erwachsenen und auf (mindestens) 6.000 DM je minderjährigem Kind festgelegt. Das „Kinderbürgergeld“ sollte altersabhängig gestaffelt werden. Das Bürgergeld soll die Sozialhilfe, die Arbeitslosenhilfe, das Kindergeld, das Wohngeld und die BAföG-Leistungen ersetzen.

2. Bruttoeinkommen sind bis zur Transfergrenze mit $50 \%$ auf den Bürgergeldanspruch anzurechnen.

3. Die Lage der Transfergrenze hängt von der Höhe des Bürgergeldes ab. Für alleinstehende Erwachsene läge sie bei 24.000 DM, bei einer Familie mit 
zwei Kindern läge sie zwischen 60.000 DM und 80.000 DM - je nach Altersstaffelung des Kinderbürgergeldes.

4. Der Übergang zur Einkommensbesteuerung ist der kritische Punkt des dualen Integrationsmodells. Konsequenterweise müßte die Transfergrenze den neuen Grundfreibetrag markieren - mit der Folge, daß es zu erheblichen Steuerentlastungen höherer Einkommensschichten und damit zu sehr hohen Steuerausfällen käme. Mitschke betont jedoch, daß eine allgemeine Steuersenkung keine zwingende Folge der Integration von Steuer- und Transfersystem sei. Vielmehr hat das Bundesverfassungsgericht in seinem Beschluß zum einkommensteuerlichen Grundfreibetrag (BVerfG-Beschluß v. 25.9.1992) die Möglichkeit offen gelassen, den (Grund-)Freibetrag mit steigendem Einkommen deutlich abzuschmelzen. Mitschke hat jedoch den „Abschmelzungstarif“ nie konkretisiert.

Das Bürgergeldmodell von Mitschke läßt sich unter Berücksichtigung des Abschmelzungstarifs im Brutto-/Nettoeinkommen-Diagramm in Abbildung 15 anschaulich darstellen:

Das maximale Bürgergeld B beträgt jährlich $12.000 \mathrm{DM}$ je Erwachsenen und ist an der Ordinate abgetragen. Bruttoeinkommen bis zur Transfergrenze von 24.000 DM ( $\left.\mathrm{Y}^{*}\right)$ vermindern den Bürgergeldanspruch zur Hälfte - die Transferentzugsrate beträgt $50 \%$ und wirkt wie ein Grenzsteuersatz auf Zusatzverdienste $\left(t_{B G}\right)$. Bruttoeinkommen oberhalb des transferfreien Einkommens müssen aufgrund der unterstellten Abschmelzung mit einem relativ höheren Grenzsteuersatz als im Status quo besteuert werden - der neue Grenzsteuersatz wird als „Mitschke-Grenzsteuersatz“ $t_{M I}$ bezeichnet und setzt sich aus dem Grenzsteuersatz des Status quo $t_{\text {STQ }}$ und dem abschmelzungsbedingten Grenzsteuersatz $\mathrm{t}_{\mathrm{AB}}>0$ zusammen.

Dieser Modellierung des Abschmelzungstarifs liegen folgende Überlegungen zugrunde (vgl. Experten-Kommission „Alternative Steuer-Transfer-Systeme“ 1996, S. 28ff.). Wird mit dem Verweis auf die sehr hohen Steuerausfälle die Verdoppelung der Grundfreibeträge (,verschobener“ Einkommensteuertarif) abgelehnt, könnten unveränderte Grenzsteuersätze für Einkommensbezieher oberhalb der Transfergrenze nur durch einen sogenannten „abgeschnittenen“ Einkommensteuertarif realisiert werden. Dann würden zum Beispiel bei einer Transfergrenze von $24.000 \mathrm{DM} / \mathrm{Jahr}$ für einen Ledigen bei darüberliegenden „zu versteuernden Einkommen“ die Grenzsteuersätze des Status quo gelten mit der Konsequenz einer Sprungstelle in der Nettoeinkommensgeraden bei 24.000 DM/Jahr. Diese Lösung hält Mitschke (1994c, S. 9) für problematisch. Wenn verschobener und abgeschnittener Einkommensteuertarif allerdings nicht als Lösung für den Übergang vom Transferbereich in den Einkommensteuerbereich in Frage kommen, dann bleibt nur noch die Möglichkeit einer Abschmelzung der Steuervorteile. Eine Abschmelzung hat jedoch zur Konsequenz, da $\beta$ der Grenzsteuersatz in einem bestimmten Einkommensbereich oberhalb der Transfergrenze ansteigen muß - auch wenn eine haushalts- 
neutrale Umstellung auf das Bürgergeld gewährleistet ist. Das ist der entscheidende Punkt für die Begründung eines positiven Abschmelzungsgrenzsteuersatzes.

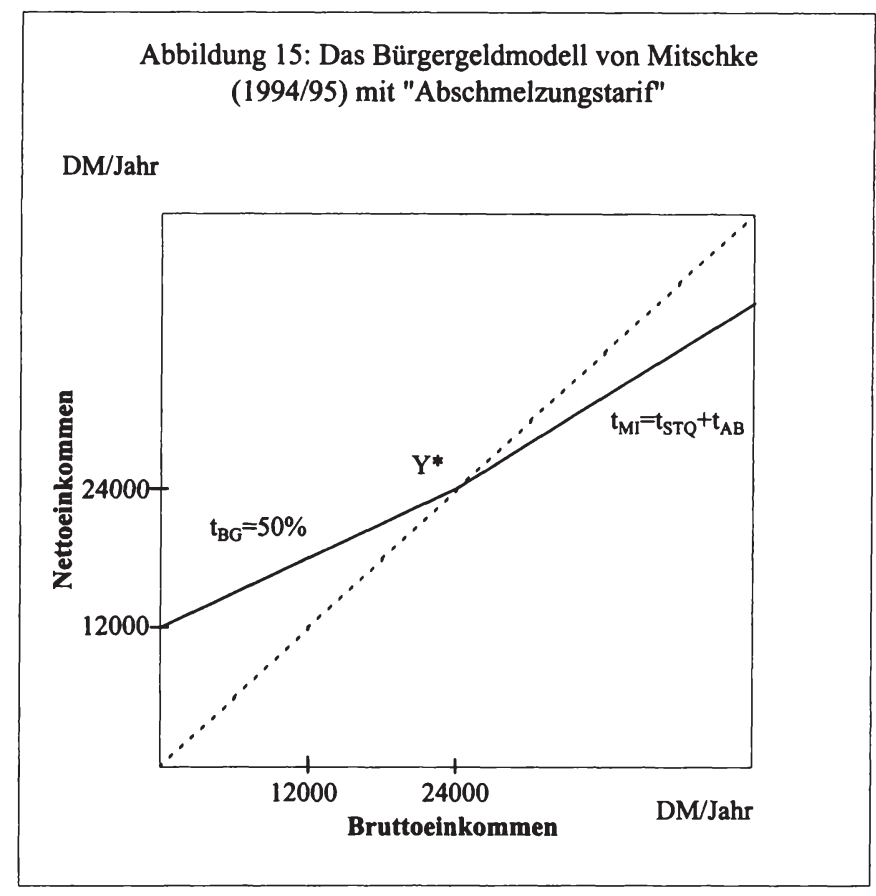

Das Bürgergeldmodell von Mitschke (1994a,b,c; 1995a,b) läßt sich durch folgende Nettoeinkommensfunktion für den Transferbereich ausdrücken:

$\mathrm{Y}_{\text {Mitschke }}^{\mathrm{n}}=\mathrm{B}+\left(1-\mathrm{t}_{\mathrm{BG}}\right) \mathrm{Y}^{\mathrm{b}}=12000+(1-0,5) \mathrm{Y}^{\mathrm{b}}=12000+0,5 \mathrm{Y}^{\mathrm{b}}$

für $\mathrm{Y}^{\mathrm{b}}<\mathrm{Y}^{*}=24000 \mathrm{DM} / \mathrm{Jahr}$.

Mitschke betont die Funktion des Bürgergeldes als Grundsicherung, die umfassender als die derzeitige de facto-Grundsicherung durch Sozialhilfe ist. So soll insbesondere die Bedürftigkeitsprüfung weitgehend entfallen: Bedürftig ist, wer Bruttoeinkommen unter der Transfergrenze erzielt. Das Bürgergeld stellt auf Einkommensarmut ab, es soll ermessensfrei, pauschaliert und unbefristet gewährt werden, auf Familienregreß und die Vermögensprüfung wird verzichtet. ${ }^{12}$

12 Im totalen Integrationsmodell von Mitschke (1985) ist neben einer Reform der Mindestsicherung auch eine große Steuerreform - Ersatz der Einkommensteuer durch eine Konsumbesteuerung und Reinvermögenszuwachssteuer am Lebensende - vorgesehen. So soll die Reinvermögenszuwachssteuer die (inzwischen abgeschaffte) Vermögensteuer und Erb- 
Der Bürgergeldanspruch wird mit Erwerbs- und Vermögenseinkünften verrechnet. Dementsprechend sinken die Ausgaben für Bürgergeld, je höher das so definierte Bruttoeinkommen von Erwerbstätigen ausfällt - der vertikale Abstand zwischen der Nettoeinkommensgeraden des Bürgergeldes und der $45^{\circ}$-Linie verringert sich bis zur Transfergrenze (vgl. Abbildung 15). Die Verrechnung des Bürgergeldanspruchs mit dem verdienten Bruttoeinkommen soll das Finanzamt vornehmen.

Der wesentliche Vorteil des Bürgergeldes gegenüber dem Status quo besteht darin, daß der Fehlanreiz Armutsfalle vollständig und dauerhaft beseitigt ist: Über den gesamten Bruttoeinkommensbereich gibt es keinen anreizfeindlichen Grenzsteuersatz von über $50 \%$ mehr. Auch das Lohnabstandsgebot II ist durch die Arithmetik des Systems immer gewahrt, das Lohnabstandsgebot I ist bei einem Bürgergeldsystem nicht mehr sinnvoll.

Das Bürgergeldkonzept ist nach Mitschke mit sozial- und verteilungspolitischen Vorteilen verbunden. Statt einer schwer durchschaubaren Zuständigkeitsvielfalt entsteht eine transparente Verwaltung, die den Bürgern viele Behördengänge erspart und den Kontakt zwischen Bürger und Staat vereinfacht. Techniken der Leistungskumulation und des Leistungsmißbrauchs von seiten der Leistungsempfänger werden durch die Integration erschwert. Auch wird die Stigmatisierung von Sozialhilfe- und Wohngeld-empfängern abgeschwächt (vgl. Mitschke 1994c).

Administrative Vorzüge des Bürgergeldkonzeptes ergeben sich aus der Konzentration von Aufgaben beim Finanzamt. So wird die Zielgenauigkeit der Leistungen erheblich gesteigert, weil eine Behörde Anspruchs- und Begünstigungstatbestände bearbeitet. Dem Wegfall von Bearbeitungsvorgängen bei den Sozialbehörden steht nach Einschätzung von Mitschke kein nur entfernt vergleichbarer Arbeitszuwachs bei den Finanzämtern gegenüber, weil identische oder unnötig abweichende Daten nicht mehr durch verschiedene Behörden mehrfach erhoben werden müssen. Es entsteht ein heilsamer Zwang auf Bürger und Parlament, Steuer- und Sozialpolitik als ganzheitliches Problem anzugehen (vgl. Mitschke 1994a).

In einer Simulationsstudie von Hüther (1990) wird gezeigt, daß die Einführung des Bürgergeldes die „breite Masse der Bevölkerung“ besser stellt, was unter sozialpolitischen Gesichtspunkten begrüßenswert erscheint (vgl. Hüther 1990, S. 258).

Nach Berechnungen von Mitschke (1985) für das Jahr 1982 kann das totale Integrationsmodell, nach Berechnungen von Mitschke (1994a,b,c) für das Jahr 1992 kann das duale Integrationsmodell bei Wahrung strikter Haushaltsneutralität ohne Steuererhöhungen eingeführt werden. Mitschke betont, da $\beta$ Haushaltsneutralität auch ohne das Kalkül administrativer Ersparnisse und

schaftsteuer ersetzen (vgl. Mitschke 1995a, S. 81). Im totalen Integrationsmodell ist das Bürgergeld eine negative Konsumsteuer (vgl. Schildbach 1997, S. 23). 
entfallender Mindestsicherungselemente in der gesetzlichen Sozialversicherung erreicht wird (vgl. Mitschke 1995a, S. 82). Außerdem werden lediglich die Umstellungskosten berechnet - es handelt sich demnach um ein ,statisches Kalkül der 'first-order-effects', ohne die zu erwartende Netto-Haushaltsentlastung durch die beabsichtigten Anpassungsreaktionen" (vgl. Mitschke 1995a, S. 81). Hüther (1990) errechnet sogar einen Finanzminderbedarf von rund 51 Milliarden DM für das totale Integrationsmodell, was sich aus Unterschieden der Modellannahmen, des statistischen Ausgangsmaterials und des Berechnungszeitraums ergibt (vgl. Mitschke 1994a, S. 157).

\subsubsection{Kritik am Bürgergeld}

\subsubsection{Allokative Wirkungen}

Die typischen Lehrbuchanalysen stellen die statischen allokativen Wirkungen der Einführung einer negativen Einkommensteuer in einem partialanalytischen Einkommen-Freizeit-Modell dar. Üblicherweise wird dabei unterstellt, daß die negative Einkommensteuer als Grundsicherung in eine first-best Ökonomie eingeführt wird und durch die Erhebung positiver Steuern finanziert werden muß (vgl. Atkinson/Stiglitz 1980, Kap. 2; Boadway/Wildasin 1984, Kap. 14; Rosen 1995, Kap. 9). Das Ergebnis ist dann eindeutig: Einkommensund Substitutionseffekt wirken in Richtung auf eine Verminderung des Arbeitsangebots.

Dieser Vergleich ist jedoch irrelevant in einer second-best Welt, in der bereits eine Grundsicherung existiert: „Führt man eine Negativsteuer in der Bundesrepublik ein, so wären die Wirkungen auf das Arbeitsangebot nicht am Referenzsystem fehlender Existenzsicherung, sondern vom Ausgangspunkt des derzeitigen hohen Stands der sozialen Fürsorge abzuschätzen“ (Mitschke 1994a, S. 154). Die Analysen von Prinz (1989), Weeber (1992) und Siebert/Stähler (1995) erfüllen diese Anforderung. Diese Arbeiten ziehen das Einkommen-Freizeit-Modell als theoretischen Analyserahmen heran.

Im folgenden werden die allokativen Wirkungen des Bürgergeldkonzepts von Mitschke 1994/95 im Rahmen des Einkommen-Freizeit-Modells untersucht. Bei der Analyse wird - im Gegensatz zur bestehenden Literatur - der Abschmelzungstarif explizit berücksichtigt. In Abbildung 16 ist das (Arbeits-) Einkommen, das ausschließlich zu Konsumzwecken verwendet wird, an der Ordinate abgetragen, an der Abszisse ist Freizeit in Stunden abgetragen. Die Budgetgerade ist negativ geneigt, weil der Konsum von Freizeit mit geringerem Einkommen verbunden ist - die Steigung der Budgetgeraden wird durch den Nettolohnsatz bestimmt. In der Ausgangssituation existiert eine Grundsicherung in Form der Sozialhilfe SH, die mit einer Transferentzugsrate von $\mathrm{t}_{\mathrm{SH}}=100 \%$ für eigenes Bruttoeinkommen bis zur Höhe des Sozialhilfeniveaus verbunden ist; von Absetzungsbeträgen wird aus Vereinfachungsgründen abstrahiert. Die Sozialhilfeausgaben werden im Status quo durch einen positiven 
Grenzsteuersatz $t_{\mathrm{STQ}}>0$ für Bruttoeinkommen über dem Sozialhilfeniveau finanziert - die Steigung der Budgetgeraden ist in diesem Bruttoeinkommensbereich durch den Nettolohn w(1-t $\left.\mathrm{t}_{\mathrm{STQ}}\right)$ bestimmt; von Sozialversicherungsbeiträgen wird aus Vereinfachungsgründen ebenfalls abstrahiert.

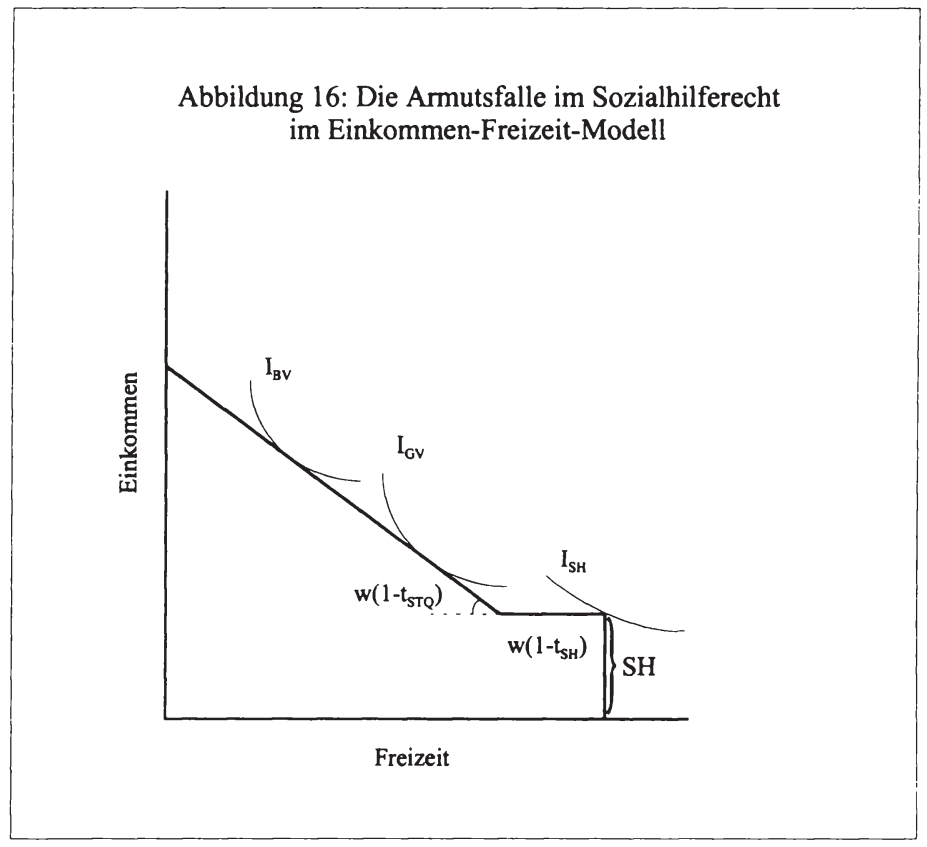

In Abbildung 16 werden drei Haushaltstypen betrachtet: Sozialhilfeempfänger, Gering- und Besserverdienende. Für Sozialhilfeempfänger ist es im Status quo bei konvexen Indifferenzkurven nutzenmaximal, keine Arbeit anzubieten - die Indifferenzkurve eines Sozialhilfeempfänger $\mathrm{I}_{\mathrm{SH}}$ tangiert die Budgetgerade im Eckpunkt. Die Indifferenzkurve eines Geringverdieners $\mathrm{I}_{\mathrm{GV}}$ tangiert die Budgetgerade im unteren Einkommensbereich, die Indifferenzkurve eines Besserverdieners $I_{B V}$ tangiert die Budgetgerade im oberen Einkommensbereich (vgl. van Almsick 1981, S. 126ff. für eine formale Analyse). Die Einführung des Bürgergeldes bei unverändertem Existenzminimum (=Sozialhilfeniveau $\mathrm{SH}$ ) mit einem Grenzsteuersatz von $\mathrm{t}_{\mathrm{BG}}=50 \%$ auf Zusatzverdienste verändert die Budgetgerade - der Knick der Budgetgerade wird beseitigt zugunsten eines kontinuierlichen Verlaufs, wie Abbildung 17 zeigt: Die Steigung der Budgetgeraden bis zur Transfergrenze $\mathrm{Y}^{*}$ wird durch den Nettolohn $w\left(1-t_{B G}\right)$ bestimmt, Bruttoeinkommen über der Transfergrenze unterliegen annahmegemäß dem Mitschke-Grenzsteuersatz $t_{M I}$, der sich aus dem 
Grenzsteuersatz des Status quo $\mathrm{t}_{\mathrm{STQ}}$ und dem abschmelzungsbedingten Grenzsteuersatz $\mathrm{t}_{\mathrm{AB}}>0$ zusammensetzt.

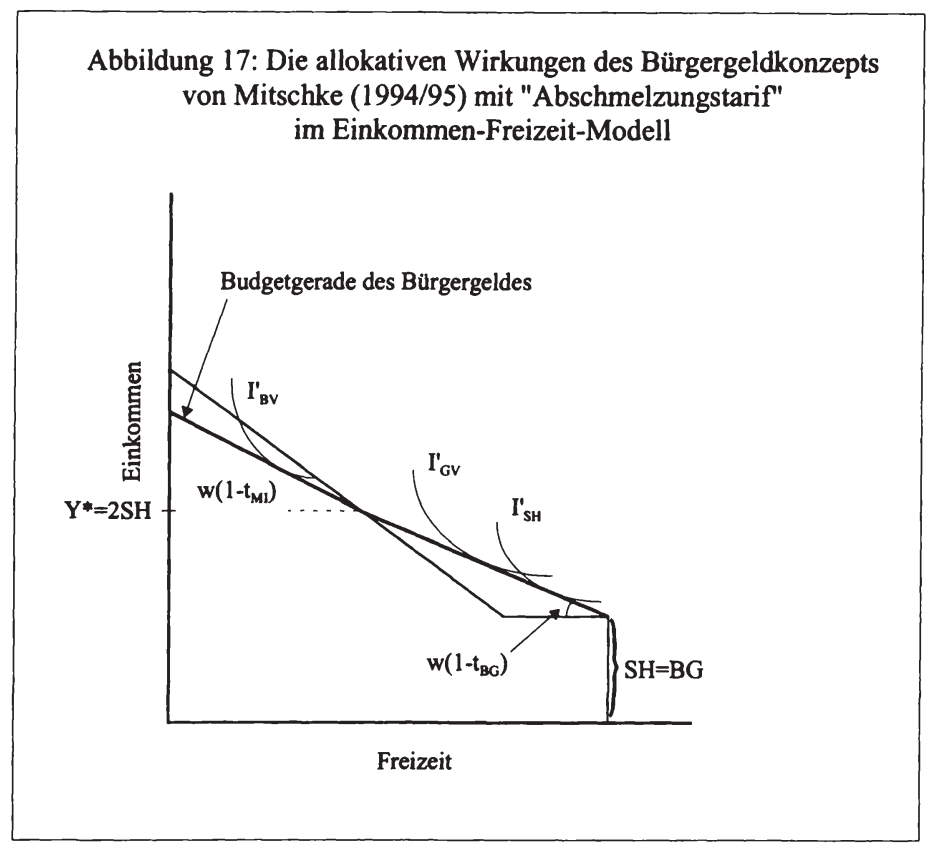

(1) Reaktionen von Sozialhilfe- bzw. Bürgergeldempfängern

Die Einführung des Bürgergeldes hat zur Konsequenz, daß es für bisherige Sozialhilfeempfänger bei normalen Präferenzen nutzenmaximal ist, Arbeit anzubieten, weil ausschließlich der Substitutionseffekt in Richtung höheres Arbeitsangebot wirkt; der Einkommenseffekt existiert in diesem Fall nicht (vgl. Dickert/Houser/Scholz 1995, S. 5). Deshalb tangiert die neue Indifferenzkurve $\mathrm{I}_{\mathrm{SH}}$ die Budgetgerade links von der Randlösung. Dieser Effekt läßt sich auch empirisch für die USA bestätigen (vgl. Dickert/Houser/Scholz 1995, Eissa/Liebman 1996, Scholz 1996).

Kritiker führen im wesentlichen vier Argumente gegen die Wirksamkeit verbesserter Arbeitsanreize an. Erstens wird argumentiert, daß Hilfeempfänger eine hohe Präferenz für Freizeit hätten. Im Rahmen des Einkommen-FreizeitModells werden den Sozialhilfeempfängern somit sehr steile Indifferenzkurven unterstellt, so daß die Ecklösung trotz des geringeren Grenzsteuersatzes für sie nutzenmaximal bleibt. So wurde beispielsweise von seiten des 
Deutschen Städtetags auf der Basis einer Umfrage bei seinen Mitgliedsstädten behauptet, daß etwa 30 Prozent der Sozialhilfeempfänger im Jahre 1993 Arbeitsangebote im Rahmen der Hilfe zur Arbeit abgelehnt haben (vgl. Fuchs 1994, S. 14f.). Diese Zahl ist jedoch aus mehreren Gründen nicht aussagekräftig. Zum einen konnten von 180 befragten Mitgliedsstädten mit 31.590 Beschäftigungsmöglichkeiten lediglich 85 Städte mit 17.818 Beschäftigungsmöglichkeiten Daten zu Ablehnungen zur Verfügung stellen; über die Hälfte der befragten Mitgliedsstädte mit knapp der Hälfte aller Beschäftigungsmöglichkeiten, die keine entsprechende Statistik führen, gaben dagegen an, da $\beta$ „die Nachfrage der Hilfesuchenden nach Beschäftigung das Angebot übersteigt und Ablehnungen so gut wie nicht vorkommen“ (Fuchs 1994, S. 15). Zum anderen ist der ermittelte Prozentsatz zu hoch. Bezieht man die Zahl der erfaßten Ablehnungen (5.353) auf die Zahl der in der Umfrage ermittelten Beschäftigungsmöglichkeiten (31.590), so ergibt sich ein wesentlich niedrigerer Prozentsatz an Ablehnungen, nämlich 17 Prozent. Geht man - wie vom Städtetag hochgerechnet - von bundesweit 90.667 Beschäftigungsmöglichkeiten aus und nimmt man weiterhin an, daß auch in den verbliebenen Städten kaum Ablehnungen registriert werden, so ergibt sich eine Ablehnungsquote von 6 Prozent. Zum dritten muß noch berücksichtigt werden, daß Mehrfachablehnungen von Sozialhilfeempfängern statistisch nicht erkennbar sind (vgl. Hakkenberg/Wagner 1996). Interessanterweise äußert sich derselbe Autor in einer Auswertung zu einer aktuellen Umfrage von 1997 wesentlich vorsichtiger zum Umfang der Ablehnung von Beschäftigungsangeboten (vgl. Fuchs 1997, S. 23). Die Annahme steiler Indifferenzkurven dürfte demnach nur für einen sehr geringen Teil der arbeitsfähigen Sozialhilfeempfänger zutreffen.

Zweitens wird argumentiert, daß das Problem der Arbeitslosigkeit keine Folge fehlender Arbeitsanreize, sondern eine Folge fehlender Arbeitsplätze sei (vgl. Bäcker/Steffen 1995a,b; Bäcker/Hanesch 1997). Dabei wird unterstellt, daß die in Kapitel 2 beschriebene Armutsfalle „eine fingierte Wirklichkeit“ (Bäkker/Steffen 1995a, S. 44) darstelle. Diese Einschätzung basiert auf dem Werturteil, daß auch sehr hohe Transferentzugsraten die Arbeitsanreize von Hilfeempfängern kaum beeinträchtigen. Die Ursachenanalyse dieser Kritiker unterstellt weiterhin, daß nur eine begrenzte Anzahl von Arbeitsplätzen vorhanden ist. Layard (1994, S. 144) bezeichnet die diesen Ängsten zugrundeliegende Vorstellung als „lump-of-labour fallacy“ bzw. als „lump-of-output fallacy“ (Layard et al. 1994, S. 107) - es ist ein Trugschluß, daß das Arbeitsvolumen bzw. das Gütervolumen gegeben ist. Die Arbeits- bzw. Güternachfrage kann nach Ansicht dieser Kritiker lediglich durch makroökonomische Nachfragepolitik beeinflußt werden. Dabei wird übersehen, daß der Anteil konjunkturell bedingter Arbeitslosigkeit gering ist (vgl. OECD 1997b).

Drittens wird auf die geringe Bedeutung finanzieller Arbeitsanreize hingewiesen (vgl. Hackenberg/Wagner 1996, 1997; Hackenberg/Sell 1997). So seien Langzeitarbeitslose häufig „Multiproblemlagenfälle“ - zu Qualifikationsdefi- 
ziten kommen „Umfeldprobleme“ wie zum Beispiel Verschuldung und/oder Suchtkrankheiten. Bei dieser Gruppe seien finanzielle Arbeitsanreize wirkungslos. Außerdem sei Arbeitslosigkeit mit hohen nicht-pekuniären Kosten wie vermindertes Wohlbefinden (vgl. Winkelmann/Winkelmann 1995) verbunden, so daß arbeitslose Menschen im Durchschnitt einen enormen Anreiz zu arbeiten haben. Die neoklassische Sichtweise der Langzeitarbeitslosigkeit als finanzielles Anreizproblem sei deshalb eindimensional und stark verkürzt. Zweifellos ist die Anzahl von weitgehend erwerbs-, vielleicht sogar arbeitsunfähigen Personen in einem an sich erwerbsfähigen Alter zum Beispiel durch Suchtprobleme erschreckend hoch. Andererseits gelten nach offiziellen Schätzungen etwa 700.000 Sozialhilfeempfänger als arbeitsfähig (vgl. Presse- und Informationsamt der Bundesregierung, Sozialpolitische Umschau v. 25.5.1998, S. 18). Für die Gruppe arbeitsfähiger Hilfeempfänger dürften finanzielle Arbeitsanreize jedoch von Bedeutung sein.

Viertens wird angeführt, daß finanzielle Arbeitsanreize überschätzt werden. Statt dessen seien die Arbeitsbedingungen viel wichtiger (vgl. Klös 1997b, Falk/Klös 1997). Tatsächlich ist in ehrenamtlich organisierten Gruppen eine intrinsische Motivation zur Arbeit zu beobachten. So sind nach Schätzungen etwa zwölf Millionen Menschen in Ost- und Westdeutschland ehrenamtlich engagiert, davon sind rund 1,5 Millionen bei Wohlfahrtsverbänden durchschnittlich vier Stunden pro Woche unentgeltlich tätig (vgl. Meyer 1999) meist jedoch auf der Basis finanzieller Absicherung durch die Eltern, Ehepartner oder eigenen Vermögens. Auch kann die steigende Zahl an Selbständigen als Indiz für Selbstverwirklichung im Beruf gewertet werden: Zwischen 1991 und 1995 hat sich die Zahl der Selbständigen um rund 300.000 auf etwa 3,34 Millionen Menschen erhöht. Andererseits darf nicht übersehen werden, daß die Grenze zwischen freiwilliger und erzwungener Selbständigkeit flieBend ist: Bis zu einer Million Menschen gelten als scheinselbständig (vgl. Dietrich 1996).

Es bleibt festzuhalten: Finanzielle Gründe spielen eine wichtige Rolle, sind jedoch nicht der einzig vorstellbare Arbeitsanreiz. Unentgeltliche Arbeiten oder Tätigkeiten, die dauerhaft mit minimalen Nettoeinkommenszuwächsen im Vergleich zur Sozialhilfe verbunden sind, dürften für den Großteil der arbeitsfähigen Hilfeempfänger bzw. Langzeitarbeitslosen wenig interessant sein. Ein Beleg für diese Einschätzung könnte die zunehmende Bedeutung von Schwarzarbeit sein, die mit einem Grenzsteuersatz von Null Prozent auf Zusatzverdienste verbunden ist: Nach Berechnungen von Schneider (1997a,b) für das Jahr 1994 wurden 13,1 \% des Bruttoinlandsprodukts illegal abgabenund steuerfrei erwirtschaftet - seriöse Angaben zum Anteil der schwarz arbeitenden Hilfeempfänger liegen nicht vor (vgl. Klös 1997b). Andererseits wird nicht abgestritten, daß ein nicht unbedeutender Anteil der Hilfeempfänger sich in einer multidimensionalen Problemlage befindet - mit der 
Konsequenz, daß therapeutische Maßnahmen wichtiger als finanzielle Arbeitsanreize sind.

\section{(2) Reaktionen von Geringverdienern}

Geringverdiener werden bei normalen Präferenzen ihr Arbeitsangebot vermindern. In der Lehrbuchliteratur wird üblicherweise argumentiert, daß sowohl der Einkommens- als auch der Substitutionseffekt in Richtung weniger Arbeitsangebot wirken, wenn Freizeit ein normales Gut ist - die neue Indifferenzkurve $\mathrm{I}_{\mathrm{GV}}^{\prime}$ tangiert die Budgetgerade rechts vom ursprünglichen Optimum (vgl. Boadway/Wildasin 1984, S. $451 \mathrm{ff}$.). An dieser Stelle ist es jedoch zum besseren Verständnis folgender Kapitel zweckmäßig, drei Einzeleffekte zu isolieren (vgl. Green 1967, Kesselman 1969). Ein „pauschaltransferbedingter“ Einkommenseffekt ist von dem klassischen, durch die Lohnsatzveränderung bewirkten Substitutions- und Einkommenseffekt zu unterscheiden. Der ,pauschaltransferbedingte" Einkommenseffekt wirkt in Richtung weniger Arbeit, wenn Freizeit ein normales Gut ist. Dagegen wirken der klassische Substitutions- und Einkommenseffekt in unterschiedliche Richtungen: Der Substitutionseffekt wirkt in Richtung geringeres Arbeitsangebot, weil die Opportunitätskosten des normalen Gutes Freizeit gesunken sind; der Einkommenseffekt wirkt in Richtung höheres Arbeitsangebot, weil die Haushalte versuchen, den Einkommensverlust durch Mehrarbeit auszugleichen. Der Effekt auf das Arbeitsangebot ist demnach aufgrund des klassischen Lohnsatzeffektes unbestimmt, erst zusammen mit dem pauschaltransferbedingten Einkommenseffekt wird der Gesamteffekt eindeutig: Das Arbeitsangebot der Geringverdiener geht durch die Einführung einer Negativen Einkommensteuer zurück.

Die Ergebnisse der Feldexperimente zwischen 1968 und 1982 in den USA bestätigten diese theoretische Einsicht weitgehend. Insgesamt wurden vier Feldexperimente durchgeführt: das New Jersey-Experiment (1968-72), das Rural-Experiment (1969-73), das Gary-Experiment (1971-74) und das SeattleDenver-Experiment (1971-82). Überblicksartige Zusammenfassungen finden sich in Killingsworth (1983), Robins (1985), Hausman (1985), Burtless (1986) und Pencavel (1986). Mit diesen Feldexperimenten sollten die Arbeitsangebotsreaktionen von Familien auf die Einführung einer negativen Einkommensteuer bestimmt werden. Robins (1985) kommt zu dem Ergebnis, daß die empirischen Ergebnisse der Feldexperimente in $80 \%$ aller Fälle mit den Ergebnissen der Theorie übereinstimmen. Bei der Interpretation der Ergebnisse der Feldexperimente besteht in der Literatur weitgehender Konsens, daß das Arbeitsangebot als Reaktion auf die Einführung einer negativen Einkommensteuer zurückgegangen ist, allerdings nicht sehr stark (vgl. Atkinson/Stiglitz 1980, S. 55; Boadway/Wildasin 1984, S. 453f.; Rosen 1995, S. 183). Die Ergebnisse der Feldexperimente sind für die Abschätzung der Reaktionen von Geringverdienern bei bestehender Grundsicherung relevant. 


\section{(3) Reaktionen von Besserverdienenden}

Der Gesamteffekt auf das Arbeitsangebot von Besserverdienenden ist theoretisch unbestimmt: Die Erhöhung des Grenzsteuersatzes um $t_{A B}$ hat zur Folge, daß der Substitutionseffekt in Richtung weniger Arbeit, der Einkommenseffekt jedoch in Richtung mehr Arbeit wirkt. Internationale und nationale empirische Studien zeigen, daß das Arbeitsangebot von Männern wenig auf Veränderungen des Nettolohnes reagiert, bei Frauen jedoch stärkere Reaktionen zu erwarten sind (vgl. Blundell 1992, Zimmermann 1993, Heckman 1993a, Franz 1996b für einen Überblick). Insgesamt ist ein Rückgang des Arbeitsangebots bei steigenden Grenzsteuersätzen zu erwarten.

Der theoretisch mögliche Fall einer rückwärts geneigten Arbeitsangebotskurve, bei der der Einkommenseffekt den Substitutionseffekt überkompensiert, läßt sich für Männer empirisch beobachten. Aber auch geringfügig positive Werte der unkompensierten Lohnelastizität wurden für Männer gefunden. Für Frauen ist die unkompensierte Lohnelastizität in der Regel stark positiv (vgl. Franz 1996b, Zimmermann 1993, Blundell 1992).

Betrachtet man alle drei Gruppen von Individuen, so hängt der Ge-samteffekt auf das Arbeitsangebot offensichtlich von der Verteilung der Haushalte auf die untersuchten Haushaltstypen und der Stärke der Reaktionen der Haushaltstypen ab. Die statische Partialanalyse im Einkommen-Freizeit-Modell unter Berücksichtigung des Abschmelzungstarifs von Mitschke und verfügbarer empirischer Studien hat gezeigt, daß die Erhöhung der Grenzsteuersätze für Gering- und Besserverdienende zu einem leichten Rückgang ihres Arbeitsangebots führen dürfte. Dagegen dürfte die Senkung des Grenzsteuersatzes für Empfänger von Sozialhilfe bzw. Bürgergeld mit einer Erhöhung ihres Arbeitsangebotes verbunden sein. So ist dem Fazit von Siebert/Stähler (1995, S. 390) zuzustimmen: „Eine Abnahme des Arbeitsangebots insgesamt kann nicht ausgeschlossen werden“.

Die restriktiven Annahmen des statischen Einkommen-Freizeit-Modells werden jedoch kritisiert. Insbesondere wird die Annahme flexibler Arbeitszeiten hinterfragt: In der Realität sei die Arbeitszeit weitgehend durch vertragliche Vereinbarungen fixiert (vgl. Pahlke 1976, S. 227) - ein grundsätzlich richtiger Einwand, der angesichts der Vielfalt an Beschäftigungsverhältnissen in den neunziger Jahren jedoch an Gewicht verloren hat. Heckman (1993a) betont, $\mathrm{da} ß$ deutlich zwischen der Entscheidung, die Arbeitszeit zu variieren, und der Partizipationsentscheidung unterschieden werden muß. Beide Entscheidungen sind in der Bürgergelddiskussion von Bedeutung: Es geht sowohl um die Frage, ob (im Rahmen der Absetzungsbeträge) bereits erwerbstätige Sozialhilfeempfänger mehr arbeiten, als auch um die Frage, ob Sozialhilfe- bzw. Bürgergeldempfänger überhaupt arbeiten.

Zur Frage der Partizipationsentscheidung unterer Einkommensschichten liegt eine empirische Untersuchung für Deutschland vor (vgl. Andreß/StrengmannKuhn 1997). Ausgangspunkt der Analyse ist eine Auszählung des Sozio-Öko- 
nomischen Panels (SOEP) für die Jahre 1991-92. Danach ist das Arbeitsangebot einkommensschwacher Haushalte in Ost- und Westdeutschland deutlich geringer als in allen anderen Haushalten. Gleichzeitig ist die Inanspruchnahme staatlicher Transfers einkommensschwacher Schichten relativ größer. So stellt sich die Frage, ob staatliche Transfers negative Auswirkungen auf das Arbeitsangebot von Niedrigeinkommensbeziehern haben. Zur Untersuchung dieser Fragestellung modellieren die Autoren ausschließlich die Partizipationsentscheidung. Dazu werden gepoolte SOEP-Daten für die Jahre 1991-92 mit Hilfe eines Probit-Modells für drei Personengruppen (Alleinstehende und Alleinerziehende, Männer in Paarhaushalten, Frauen in Paarhaushalten) geschätzt. Das Ergebnis: „Auch wenn man Nichterwerbseinkommen, Lohnsätze, Kinder, Entmutigungseffekte und das Geschlecht kontrolliert, das Arbeitsangebot bleibt im unteren Einkommensbereich signifikant geringer" (Andreß/Strengmann-Kuhn 1997, S. 521). Staatliche Transfers haben zwar im Einklang mit der theoretischen mikroökonomischen Analyse eine negative Wirkung auf das Arbeitsangebot, doch tritt dieser Effekt nicht verstärkt bei unteren Einkommensschichten auf. Die Autoren interpretieren die Ergebnisse in der Weise, daß die Höhe staatlicher Transfers nur eine unter mehreren möglichen Ursachen für ein geringes Arbeitsangebot ist. Anders formuliert: Das statische Einkommen-Freizeit Modell ist im Hinblick auf die Partizipationsentscheidung empirisch relevant. Ein wichtiger Grund für das geringe Arbeitsangebot unterer Einkommensschichten bleibt ihrer Ansicht nach jedoch unberücksichtigt: Die Autoren vermuten, daß ,deshalb keine Arbeit gesucht wird, weil die Chance, auf dem Arbeitsmarkt eine Arbeit zu finden, eher gering eingeschätzt wird“ (Andreß/ Strengmann-Kuhn 1997, S. 522). Diese Einschätzung widerspricht jedoch der arbeitsmarktökonomischen Grundeinsicht, daß ein höheres Arbeitsangebot bei einer elastischen Arbeitsnachfrage neue Jobs nach sich zieht: „People cause jobs“ (Layard 1997b, S. 343). Den Fehlanreiz „Armutsfalle“ erwähnen die Autoren nicht.

Die in der Lehrbuchliteratur übliche Partialanalyse des Bürgergeldes greift jedoch zu kurz. Ergänzend sind auch die dynamischen allokativen Wirkungen abzuschätzen, worauf bereits Diamond (1968, S. 298ff.) hingewiesen hat. Auch Atkinson/Stiglitz (1980, S. 572) betonen: „In the assessment of proposals for income maintenance, the general equilibrium and longer-run effects may well be important, although they are frequently ignored". In der Literatur finden sich sechs Effekte, die für die Bürgergelddiskussion von Bedeutung sind.

Erstens ist die intertemporale Allokation zu beachten. In Kapitel 3.1.2 wurde als Vorteil der Sozialdividende herausgearbeitet, daß - im Gegensatz zu einem System mit Bedürftigkeitsprüfung - die Sparbereitschaft nicht untergraben wird (vgl. Rhys-Williams 1953, S. 134ff.). Diamond (1968, S. 298ff.) unterstützt dieses Argument durch einen - wenn auch rudimentären - Vergleich zwischen einem System ohne Grundsicherung, einem System mit Grundsi- 
cherung im Sinne des Status quo (Bedürftigkeitsprüfung, Armutsfalle) und einer negativen Einkommensteuer. Sein Ergebnis: Aufgrund einer Grundsicherung im Sinne des Status quo kann der erwartete Zinsertrag in einem intertemporalen Modell sogar negativ werden. Wird die Bedürftigkeitsprüfung lediglich auf das Einkommen - und nicht auf Vermögen - bezogen, so steigt der erwartete Zinsertrag. So scheint eine negative Einkommensteuer mit geringeren intertemporalen Verzerrungen als der Status quo verbunden zu sein. Dieses Ergebnis sollte jedoch nur als erste Vorüberlegung für eine rigorose Analyse verstanden werden, weil die Modellannahmen sehr restriktiv sind. Zum Beispiel wird von einem konstanten Arbeitsangebot ausgegangen und von der Art der Finanzierung der Grundsicherung abstrahiert.

Zweitens sind die Auswirkungen auf die Qualifizierungsbemühungen zu betrachten (vgl. Diamond 1968, Atkinson/Stiglitz 1980). So könnte die Einführung eines Bürgergeldes zukünftige Arbeitsanbieter dazu veranlassen, „sich mit geringeren Produktivitäten abzufinden, da die geringeren Einkommen durch Sozialtransfers und geringeren Arbeitseinsatz überkompensiert werden. Dies bedeutete geringere Investitionen in das Humankapital, da aus einer langfristigen Planungsperspektive eines Arbeitnehmers eine zusätzliche Investition in Humankapital nur dann vorgenommen wird, wenn die zusätzlichen Kosten den Gegenwartswert des zusätzlichen Einkommens übersteigen“ (Siebert/Stähler 1995, S. 391).

Drittens sind langfristige Auswirkungen auf Gewohnheiten (habits) und soziale Normen der Bürgergeldempfänger zu erwarten (vgl. Lindbeck 1995, 1997). Gewohnheiten werden in der soziologischen und psychologischen Literatur als Routineverhalten charakterisiert. Soziale Normen werden in dieser Literatur als erlerntes oder von Dritten erwartetes Verhalten definiert. Ökonomische Anreize sind mit materiellen Belohnungen verbunden, soziale Normen implizieren soziale Belohnungen wie zum Beispiel Wertschätzung oder Mißbilligung durch Dritte sowie Stolz oder Scham. Wenn eine soziale Norm Bestandteil des Wertesystems eines Individuums ist, dann führt die Erfüllung einer sozialen Norm zu Selbstachtung oder Schuldgefühlen und damit zu einer Veränderung des Nutzens eines Individuums. Haushalte mit hoher Präferenz für Freizeit werden durch ein Bürgergeld systematisch subventioniert. Individuen, deren Präferenzen bisher eher arbeitsorientiert waren, könnten ihre Gewohnheiten entsprechend anpassen. Auch könnte die soziale Norm, daß der Bezug staatlicher Transferleistungen mit einem Stigma verbunden ist, sich auflösen. Daß die Nichteinhaltung dieser sozialen Norm nicht mehr zu einem Reputationsverlust gegenüber Dritten führt, ist insbesondere bei jungen Menschen zu befürchten. Es besteht das Risiko, daß eine große Gruppe von „ziellosen Menschen“ (drifters) entsteht, die sich vom offiziellen Arbeitsmarkt zurückzieht und statt dessen Transfers mit Gelegenheitseinkünften aus der Schattenwirtschaft oder aus kriminellen Aktivitäten kombiniert. 
Viertens sind die Konsequenzen für die Lohnstruktur zu beachten (vgl. Siebert 1994, 1995). Sozialhilfe bzw. Bürgergeld sind Fixpunkte für die Lohnstruktur: Wenn das Grundsicherungsniveau steigt, dann verschieben sich auch die unteren Lohngruppen nach oben - mit der Konsequenz, daß die Lohnstruktur verzerrt wird und die Differenzierungsspanne zwischen dem höchsten und niedrigsten Lohn gestaucht wird. „Das hat zur Folge, daß die Nachfrage nach Arbeitskräften in den unteren Lohngruppen abnimmt. Dies wiederum verursacht Arbeitslosigkeit. Hier wirkt das Einkommen aus sozialer Absicherung wie ein Mindestlohn“ (Siebert 1994, S. 148f.). Diese Überlegungen basieren jedoch auf der Vorstellung, daß ein Lohnabstand im Sinne des Lohnabstandsgebots I sinnvoll ist. Das Lohnabstandsgebot I, wonach das Nettoeinkommen unterer Lohngruppen über dem Sozialhilfeniveau liegen soll, ist jedoch nach der Einführung eines Bürgergeldes nicht mehr sinnvoll definiert (vgl. Kap. 2.4.2). Wird jedoch im Sinne von Mitschke unterstellt, daß die Einführung eines Bürgergeldes nicht mit einer Verdoppelung des Grundfreibetrags einhergeht, wird die Lohnstruktur über den von Siebert beschriebenen Kanal nicht verzerrt - der Fixpunkt für die Lohnstruktur bleibt unverändert. Wird das Bürgergeld in Verbindung mit neuen Niedriglohngruppen eingeführt, so könnte sich die Differenzierungsspanne sogar erhöhen. Andererseits werden die Grenzsteuersätze für Besserverdienende durch den Abschmelzungstarif steigen, so daß deren Nettoeinkommen sinken. Der Nettoeffekt auf die Differenzierungsspanne ist deshalb unbestimmt.

Fünftens ist Moral hazard-Verhalten der Tarifparteien zu befürchten: „Die Tarifvertragsparteien würden die Auswirkung der Lohnabschlüsse auf die Arbeitslosigkeit kaum in Betracht ziehen - jeder wäre durch das 'Bürgergeld' abgesichert" (Siebert 1994, S. 159f.). Als aktuelles Beispiel für Moral hazard zu Lasten des Staates gelten die hohen Tarifabschlüsse 1991 in Ostdeutschland. Die hohen ostdeutschen Tarifabschlüsse waren aus verschiedenen Gründen sowohl für die Arbeitgeber als auch die Arbeitnehmer vorteilhaft (vgl. Michaelis/Spermann 1991, S. 622). Die Tarifvereinbarungen sind vor dem Hintergrund der Arbeitslosenversicherung und Sozialhilfe mit relativ großzügigen Versicherungs- bzw. Transferleistungen zu sehen, die die hochlohnbedingte hohe Arbeitslosigkeit für die Betroffenen finanziell abmildern. Sinn/Sinn (1992, S. 185f.) befürchten, daß alle Dämme bei den Tarifverhandlungen brechen würden, wenn der Staat auf Lohnerhöhungen und wachsende Arbeitslosigkeit mit kompensierenden Subventionen reagieren würde. Auf diese Weise könnte ein lediglich einkommensabhängiges Bürgergeld an Stelle der nur Bedürftigen zugänglichen Arbeitslosen- und Sozialhilfe höhere Lohnabschlüsse fördern.

Sechstens spielt das Moral hazard-Verhalten der Arbeitgeber und Arbeitnehmer auf der betrieblichen Ebene zu Lasten des Staates eine wichtige Rolle. Konkret wird befürchtet, daß sich Arbeitgeber und -nehmer auf niedrigere Löhne einigen, weil sie die Aufstockung durch ein Bürgergeld mit in ihr Kal- 
kül einbeziehen. Bereits das englische Speenhamland-System des 18./19. Jahrhunderts scheiterte an diesem Problem (vgl. Kapitel 3.1.1). Der Vorteil niedriger Lohnabschlüsse ist für die Arbeitgeber offensichtlich, für die Arbeitnehmer dagegen zu erläutern. Zunächst ist festzuhalten, daß niedrigere Lohnvereinbarungen trotz des zunehmenden Nettotransfers durch das Bürgergeld zu niedrigeren Nettoeinkommen der Bürgergeldempfänger führen - das liegt an der positiv geneigten Nettoeinkommensgeraden des Bürgergeldes. Das heißt, daß der einzelne Arbeitnehmer kein Interesse an niedrigen Löhnen haben wird - trotz Bürgergeld. Niedrigere Löhne werden für Arbeitnehmer nur dann interessant, wenn sie sich mit ihrem Arbeitgeber offiziell auf einen niedrigeren Lohn einigen. Dann steigt ihr Nettoeinkommen bei unverändertem Arbeitseinsatz, weil das Bürgergeld zunimmt. Den Zuwachs an Bürgergeld - ihren staatlich finanzierten „Kooperationsgewinn“ - könnten sie sich mit ihrem Arbeitgeber teilen. Das sogenannte „underreporting“ ist für Arbeitnehmer und -geber lohnend. Dieser in der aktuellen Bürgergelddiskussion kaum beachtete Aspekt wurde bereits von Tobin et al. (1967) erkannt und im Rahmen der Auswertung der Feldexperimente zur negativen Einkommensteuer in den USA diskutiert (vgl. Burtless 1986, Ashenfelter 1986).

\subsubsection{Fiskalische Wirkungen}

Die von Mitschke und Hüther behauptete Haushaltsneutralität wird durch die Ergebnisse mehrerer Simulationsstudien sowohl für das totale als auch das duale Integrationsmodell in Frage gestellt. Die Kostenberechnung von Mitschke (1985) und die Gruppensimulation von Hüther (1990) auf der Basis der DIW-Verteilungsrechnung für das totale Integrationsmodell wird von Becker (1995) detailliert kritisiert - mit dem Ergebnis, daß nach ihrer Ansicht eine haushaltsneutrale Finanzierung nicht gewährleistet ist. Die Kosten für das hier interessierende duale Integrationsmodell werden gemäß Becker (1995) aus mehreren Gründen unterschätzt. Zum einen wird ein Teil der überwiegend von Transfers lebenden Personen (z.B. nicht steuerpflichtige Rentner/innen) nicht erfaßt. Zum anderen ist zu vermuten, daß die Zahl der potentiellen Bürgergeldempfänger tendenziell unterschätzt wird, weil die Transfergrenze wegen der unterschiedlichen Einkommensbegriffe von Steuergesetz und Bürgergeldkonzept „,angepaßt“ werden müsste. Zum dritten werden sämtliche wiedervereinigungsbedingten Strukturveränderungen durch die vorgenommene „Hochrechnung“ der Datenbasis von 1986 auf das Untersuchungsjahr 1992 vernachlässigt. Die Einkommensverteilung in Ostdeutschland ist jedoch stärker auf den unteren Bereich konzentriert. Becker (1995) kommt zu dem Schluß, daß aufgrund der vereinfachenden Strukturkonstanzund Verteilungsannahmen sowie die von der Steuer-, Sozialhilfe- und Arbeitslosenhilfestatistik nicht erfaßten Bevölkerungsgruppen „mit einem deutlich höheren Transfervolumen zu rechnen wäre" (Becker 1995, S. 317). 
Beckers eigene Simulation basiert auf anonymisierten Individualdaten der Einkommens- und Verbrauchsstichprobe (EVS) 1988 - jüngere Mikrodaten vergleichbarer Qualität standen nicht zur Verfügung. Die Untersuchung bezieht sich auf das Bürgergeldkonzept der neunziger Jahre und beschränkt sich auf Privathaushalte mit deutschem Haushaltsvorstand in den alten Bundesländern. Becker simuliert den Ersatz der von Mitschke (1995a) vorgeschlagenen steuerfinanzierten Transfers (außer Hilfe in besonderen Lebenslagen) durch ein Bürgergeld, die Auswirkungen auf das Steuersystem bleiben jedoch unberücksichtigt. Das Ergebnis: „Für 1988 summieren sich die Bruttokosten 1988 bei einem Transferentzugssatz von $50 \%$ auf ungefähr $100 \mathrm{Mrd}$. DM" (Becker 1995, S. 332). Es wären ca. 12 Millionen Haushalte mit gut 26 Millionen Personen anspruchsberechtigt gewesen, so daß das Transfervolumen etwa $80 \%$ der Bruttokosten umfaßt, Steuerausfälle machen nur etwa $20 \%$ der Bruttokosten aus. Von den Bruttokosten sind die Kostenersparnisse durch wegfallende Transfers abzuziehen: Die Nettokosten der Einführung der politisch diskutierten Bürgergeldvariante betragen demnach über $64 \mathrm{Mrd}$. DM.

Mitschke (1995b) kritisiert an Beckers Berechnungen, daß erhebliche Beträge der Gegenfinanzierung nicht berücksichtigt werden. Das Bürgergeldmodell sieht nicht nur - wie von Becker unterstellt - den Ersatz steuerfinanzierter Transfers vor. Vielmehr müßten zum Beispiel auch personenbezogene Hilfen über sozial motivierte Objektsubventionen insbesondere im Wohnungsbau und Nahverkehr, in der Landwirtschaft, im Bildungswesen und in der Jugendhilfe sowie Umverteilungslasten in der Sozialversicherung, insbesondere in der gesetzlichen Rentenversicherung, gegengerechnet werden. Unter Berücksichtigung der vernachlässigten Gegenfinanzierungsposten kommt Mitschke zu einem Nettoüberschuß von $12 \mathrm{Mrd}$. DM bei der Einführung des Bürgergeldes im Jahre 1988.

Eine Simulationsstudie zur negativen Einkommensteuer legte das Deutsche Institut für Wirtschaftsforschung (DIW) erstmals im Jahre 1994 vor (DIWStudie I). Das Ergebnis: „Soll die Grundsicherung nicht beschnitten werden, dann entstünden - je nach Ausgestaltung - Kosten in Höhe von $65 \mathrm{Mrd}$. DM bis $173 \mathrm{Mrd}$. DM, im wesentlichen durch Steuerausfälle“ (Meinhardt et al. 1994). Bei einem Grundfreibetrag von 24.000/48.000 DM/Jahr für Alleinstehende bzw. Verheiratete und einem $50 \%$-igen Anrechnungssatz auf eigenes Einkommen (Variante 2 der DIW-Berechnungen) ergeben sich Steuerausfälle von 156,9 Mrd. DM. Hinzu kommen Zusatzausgaben für Bürgergeld in Höhe von $10 \mathrm{Mrd}$. DM für Steuerpflichtige, deren „Nettoeinkommen auch unter Berücksichtigung der hohen steuerlichen Freibeträge und der Anrechnung des Einkommens unter den Minimalbeträgen bleibt" (Meinhardt et al. 1994, S. 694). Auch fällt noch ein Betrag von etwa 20 Mrd. DM an, der an Haushalte ohne Erwerbseinkommen zu zahlen ist. Da Wohngeldbezieher zum Teil auch Sozialhilfe empfangen, müssen diesen nicht erfaßten Sozialhilfehaushalten rund $3 \mathrm{Mrd}$. DM als Bürgergeld zugerechnet werden. Weiterhin ist 
die Dunkelziffer beim Sozialhilfebezug zu berücksichtigen: Anspruchsberechigte Haushalte beantragen häufig aus Scham oder Unwissenheit keine Sozialhilfe - sie würden jedoch das Bürgergeld automatisch erhalten. Diese Kosten für die Beseitigung der Dunkelziffer werden auf $15 \mathrm{Mrd}$. DM geschätzt. Einsparungen ergeben sich aus dem Wegfall der laufenden Hilfe zum Lebensunterhalt und eines großen Teils des Wohngeldes - die Einsparungen werden auf 32 Mrd. DM veranschlagt. Die Einführungskosten des Bürgergeldes im Sinne von Mitschke würden demnach 173 Mrd. DM im Jahr 1995 betragen.

Auch diese Berechnungen werden von Mitschke (1995a) in mehrfacher Hinsicht kritisiert. Zum einen werden dem Bürgergeldsystem unzulässigerweise die Steuerausfälle zugerechnet, die sich aus der verfassungsgerichtlich angeordneten steuerlichen Freistellung des Existenzminimums ergeben. Becker (1995) schließt sich diesem Kritikpunkt an und bereinigt die Kosten um diese Steuerausfälle. Dadurch reduzieren sich die Einführungskosten für das Bürgergeldkonzept von Mitschke (Variante 2 der DIW-Studie I) von $173 \mathrm{Mrd}$. DM auf 108,9 Mrd. DM im Jahr der Einführung 1995 (vgl. Becker 1995, S. 322). Zum anderen kritisiert Mitschke an der DIW-Studie, daß dem Bürgergeldkonzept $\mathrm{zu}$ Unrecht jene Steuerausfälle zugerechnet werden, die eine Ausdehnung der Steuerbefreiung niedrigerer Einkommen auf alle Steuerpflichtigen verursachen würde - der Abschmelzungstarif bleibt unberücksichtigt. Die Autoren des DIW akzeptieren diesen Kritikpunkt, weisen jedoch darauf hin, daß ein hoher Grenzsteuersatz oberhalb der Transfergrenze der Preis für die Abschmelzung des Grundfreibetrages wäre - dies würde der wesentlichen Intention des Bürgergeldkonzeptes entgegenstehen (vgl. Meinhardt et al. 1994, S. 630). Zum dritten weist Mitschke darauf hin, daß - neben den bereits genannten Gegenfinanzierungsposten - die erwarteten positiven Beschäftigungseffekte den Einführungskosten nicht gegengerechnet werden. Becker (1995) betont jedoch, daß die Datenbasis für empirische Aufkommens- und Verteilungsanalysen im Sinne der effektiven Inzidenz fehlen. Ohne diese Datenbasis könnten die indirekten Effekte von Verhaltensanpassungen der Wirtschaftssubjekte und Rückwirkungen infolge von makroökonomischen Kreislaufzusammenhängen nicht dynamisch simuliert werden. Dementsprechend sind nur partialanalytische Schätzungen, im besten Fall formale Inzidenzanalysen auf der Basis statischer Simulationen möglich (vgl. Becker 1995, S. 309f.).

Sesselmeier et al. (1996) versuchen dennoch die positiven Beschäftigungseffekte überschlagsmäßig zu quantifizieren. Sie unterstellen eine ähnliche Beschäftigungsentwicklung im Niedriglohnbereich der primären Dienstleistungen wie in den USA in den letzten zehn Jahren und errechnen auf diese Weise eine „zusätzliche Beschäftigung im Niedriglohnbereich mit Hilfe der Negativen Einkommensteuer von ca. 2,5 Mio. Personen" (Sesselmeier et al. 1996, S. 165). Das Fazit ihrer Simulationsstudie: „Stellt man Steuerausfälle, Transferzahlungen im Rahmen der Negativen Einkommensteuer und Einsparungen 
zusammen ergeben sich gesamte Kosten des integrierten Steuer-TransferModells von 95 bis 140,2 Mrd. DM“" (Sesselmeier et al. 1996, S. 170). Nach Ansicht der DIW-Autoren ist es jedoch empirisch unklar, ob das Bürgergeld die tatsächliche Nachfrage nach gering qualifizierter Arbeit erhöht. Den Umfang möglicher Einsparungen durch positive Beschäftigungseffekte schätzen sie gering ein - auf lediglich , $3 \%$ der Nettokosten, die bei der Umstellung auf ein Bürgergeldsystem anfallen würden" (Meinhardt et al. 1996, S. 543).

Die Simulationsergebnisse der Kieler Studie von Gern (1996a,b) deuten darauf hin, daß die Kosten der Einführung eines Bürgergeldkonzeptes „bei Verzicht auf eine Bedürftigkeitsprüfung dramatische Größenordnungen" (Gern 1996b, S. 206) annehmen könnten. Bei einem Anrechnungssatz von $50 \%$ ergeben sich Einführungskosten zwischen 205 und 421 Mrd. DM. Selbst bei einer Absenkung des Existenzminimums um ein Drittel sinken die Einführungskosten nicht unter $80 \mathrm{Mrd}$. DM (vgl. Gern 1996b, S. 223).

Das Deutsche Institut für Wirtschaftsforschung hat im Jahre 1996 im Auftrag der Expertenkommission „Alternative Steuer-Transfer-Systeme“ eine aktuelle Schätzung der Kosten der Einführung eines Bürgergeldkonzepts (DIW-Studie II) vorgelegt (vgl. Meinhardt et al. 1996). Dabei berücksichtigen die Autoren zum Teil die Kritikpunkte an der DIW-Studie I. Dennoch bestätigen die neuen Berechnungen im wesentlichen die Simulationsergebnisse des Jahres 1994: Die Nettokosten für die Variante mit einer Transferentzugsrate von $50 \%$ belaufen sich auf 172,8 Mrd. DM. Unter Berücksichtigung fehlender Gegenfinanzierungsposten korrigiert Mitschke (1996) die DIW-Zahlen. Nach seinen Berechnungen ergibt sich ein Netto-Überschuß von 6,1 Mrd. DM.

Hüther (1997) analysiert die oben beschriebenen Berechnungen im Auftrag der Zukunftskommission der Friedrich-Ebert-Stiftung. Hüther legt keine eigene Simulationsstudie vor, sondern untersucht die Frage, ,inwieweit die fiskalischen Auswirkungen einer Einführung des Bürgergeldes auf methodisch und empirisch angemessener Grundlage ermittelt wurden" (Hüther 1997, S. 2). Die Analyse ergibt in bezug auf das DIW-Gutachten "grundlegende Zweifel“ an allen ausgewiesenen Ergebnissen. So würden die Resultate auf ,fragwürdigen Berechnungswegen“ erzielt, weil "mit einfachsten Mitteln gearbeitet" wurde (vgl. Hüther 1997, S. 9-11). Auch die Untersuchung von Becker (1995), die in der Fachzeitschrift „Finanzarchiv“ erschienen ist, wird desavouiert: „Grundsätzlich ist zu fragen, welchen wissenschaftlichen Anspruch eine empirische Untersuchung stellt, die so konzipiert ist, daß sie sich einer intersubjektiven Überprüfung - wegen nicht möglicher Status quo-Simulation - entziehen muß" (Hüther 1997, S. 22). Dagegen wird das Gutachten des Kieler Weltwirtschaftsinstituts hervorgehoben, weil es sich „schon von seiner Anlage, seiner Struktur und seiner Ausführung im einzelnen sehr wohltuend von dem des DIW unterscheidet" (Hüther 1997, S. 13). Die modellgestützten Berechnungen des Kieler Instituts verwendet er zusammen mit den makroökonomischen statistisch gestützten Überschlagsrechnungen von Mitschke 
(1985), um zu folgendem Ergebnis zu kommen: Die Nettobelastung für die öffentlichen Haushalte dürfte unter Berücksichtigung von sachlich begründeten Gegenfinanzierungsposten bei rund $24 \mathrm{Mrd}$. DM liegen, so daß die Bürgergeldreform als machbar anzusehen ist. Dementsprechend hat sich die $\mathrm{Zu}$ kunftskommission der Friedrich-Ebert-Stiftung für die Einführung des Bürgergeldes ausgesprochen.

Schätzungen zu möglichen Kostenersparnissen, die sich aus der Verwaltungsintegration ergeben könnten, liegen derzeit nicht vor. Höhere Verwaltungskosten könnten sich durch die allgemeine Steuererklärungspflicht ergeben: Die von den Beamten der Finanzämter zu bearbeitenden Fälle werden zum Beispiel um den Kreis der Sozialhilfe- und Wohngeld-empfänger erweitert. Es müßte eine Bürgergeldstelle beim Finanzamt eingerichtet werden, die eng mit den weiterhin bestehenden Ämtern kooperiert. Der Arbeitsaufwand für die Finanzämter wird um so mehr zunehmen, je mehr Bürgergeldempfänger anspruchsberechtigt sind: Siebert (1995) geht von 10 Millionen zusätzlichen Fällen unmittelbar nach Einführung des Bürgergeldes aus. Würden unterschiedliche Einkommensbegriffe für die Berechnung der positiven und negativen Einkommensteuerschuld existieren, dann wäre ein erhöhter Arbeitsaufwand je Fall zu erwarten. Auch die monatliche Auszahlung des Bürgergeldes würde Mehraufwand für die Finanzkassen bedeuten. Dem stehen Arbeitsentlastungen insbesondere bei den Sozial- und Arbeitsämtern gegenüber, die jedoch nicht $\mathrm{zu}$ hoch eingeschätzt werden dürfen. Schließlich sollen sich ihre Mitarbeiter vermehrt Beratungstätigkeiten widmen. Andererseits könnten die Ausgaben je Person sinken, weil die derzeit mögliche legale Kumulierung von Sozialleistungen durch die Harmonisierung der Anspruchstatbestände weitgehend ausgeschlossen werden kann.

Es hat sich gezeigt, daß die Höhe der Einführungskosten des Bürgergeldes heftig umstritten ist. Dieser Streit ist nach Ansicht des Autors wenig fruchtbar und lenkt von den wichtigen Fragen ab. Er ist wenig fruchtbar, weil jede Reform des Steuer- und Transfersystems bei entsprechendem politischen Willen haushaltsneutral konzipiert werden kann. Ist es politökonomisch möglich, Subventionen in erheblichem Umfang zur Gegenfinanzierung zu streichen, gibt es keine Finanzierungsprobleme. Der Streit lenkt aber vor allen Dingen von den statischen und dynamischen allokativen Wirkungen der Einführung des Bürgergeldes ab. Entscheidend für die Beurteilung des Bürgergeldmodells unter Berücksichtigung des Abschmelzungstarifs ist, ob positive Beschäftigungswirkungen $\mathrm{zu}$ erwarten sind. Die mit den Beschäftigungswirkungen verbundenen diskontierten fiskalischen Einsparungen in der Zukunft müßten dann mit den Einführungskosten des Bürgergeldes verglichen werden. Eine solche Simulationsstudie steht für Deutschland noch aus.

Dagegen liegen entsprechende Simulationsstudien für Großbritannien vor. Duncan/Weeks (1997) führen Mikrosimulationen einer Grundsicherungsreform für Großbritannien auf der Basis verschiedener Varianten eines diskreten 
Arbeitsangebotsmodells durch. Sie simulieren eine hypothetische Reform, bei der bestehende Transfers durch ein Bürgergeld (basic income) ersetzt werden. Konkret simulieren sie das Modell von Callan/Sutherland (1997) für Großbritannien. Callan/Sutherland (1997) simulieren den Ersatz der Sozialhilfe und Sozialversicherungsleistungen durch ein „safety net Basic Income“ - ohne Berücksichtigung von Verhaltensanpassungen. Sie kommen zu dem Ergebnis, $\mathrm{da} ß$ eine aufkommensneutrale Reform durch eine Einkommensteuer mit einem Grenzsteuersatz von 38,7\% auf alle zu versteuernden Einkommen zu finanzieren wäre. Diese Größenordnung überrascht angesichts vorliegender Kostenschätzungen zum Rhys-Williams-Vorschlag nicht (vgl. Kapitel 3.1.2). Dagegen berücksichtigen Duncan/Weeks (1997) diskrete Verhaltensanpassungen des Arbeitsangebots verheirateter Frauen. So ist es im Rahmen ihres Simulationsmodells möglich, entweder nicht oder Teilzeit- bzw. Vollzeit zu arbeiten - eine kontinuierliche Variation des Arbeitsangebots halten sie für unrealistisch. Dazu wählen sie aus dem Datenpool des Familiy Expenditure Survey, der Informationen über das Arbeitsangebot und die Konsumentscheidungen von 8.600 Haushalten enthält, zufällig 1.971 verheiratete Frauen aus. Um die Güte des Schätzmodells zu prüfen, simulieren sie zunächst eine aufkommensneutrale Einführung der Grundsicherung ohne Berücksichtigung von Verhaltensanpassungen - und können den Wert des Grenzsteuersatzes der Berechnungen von Callan/Sutherland (1997) reproduzieren. Unter Berücksichtigung der Verhaltensanpassungen ergibt sich ein gemischtes Bild: Von 150 nicht erwerbstätigen Frauen nimmt nur eine Frau eine Teilzeittätigkeit auf. Von 719 Frauen, die vor der simulierten Reform teilzeitbeschäftigt waren, stellen 17 ihre Tätigkeit ein und 35 nehmen einen Ganztagsjob an. Von 561 ganztags beschäftigten Frauen stellen 9 ihre Tätigkeit ganz ein und 29 nehmen einen Teilzeitjob an.

Diese Simulationsergebnisse dürfen als erste seriöse Simulation der Einführung eines Bürgergeldes in Großbritannien interpretiert werden. Die Ergebnisse sind widersprüchlich, die Beschäftigungseffekte sind nicht eindeutig, und die Mehrheit der simulierten Übergänge ist negativ. Vor diesem Hintergrund wird in dieser Arbeit bewußt keine eigene Simulationsstudie zur Einführung des Bürgergeldes in Deutschland unter Berücksichtigung von Verhaltensanpassungen vorgelegt. Theoretische wie bisher vorliegende empirische Studien lassen keine eindeutigen Effekte erwarten. Statt dessen wird in Kapitel 5 eine Negativsteuervariante entwickelt, die die wesentlichen allokativen und fiskalischen Probleme des Bürgergeldes vermeidet.

\subsubsection{Sonstige Wirkungen}

\section{(1) Sozial- und verteilungspolitische Aspekte}

Der Übergang von der Sozialhilfe auf das Bürgergeld macht die Bedürftigkeitsprüfung in der derzeitigen Form überflüssig. Unberücksichtigt blieben zum Beispiel mögliche private Unterhaltsansprüche oder Vermögensgegen- 
stände des Bürgergeldempfängers (vgl. Krause-Junk 1997, S. 554). Darin wird ein Verstoß gegen das Subsidiaritätsprinzip gesehen, wonach Sozialhilfe nachrangig zu gewähren ist (vgl. Sachverständigenrat 1993, S. 311 u. § 2 BSHG). Die Priorität für eigenverantwortliches Handeln könnte somit aus dem Bewußtsein verdrängt werden, das der Aufgabe der Sozialhilfe entsprechende Prinzip der Hilfe zur Selbsthilfe durch ein Anspruchsdenken der Bürgergeldempfänger (vor allem bei jungen Menschen, die erst in das Arbeitsleben hineinwachsen müssen) ersetzt werden (vgl. Siebert 1994, 1995, 1996). Weiterhin wird kritisiert, daß das pauschalierte Bürgergeld keine ausreichende Differenzierung der Leistungen mehr erlaube. Besondere Förderungen bestimmter Verhaltensweisen, zum Beispiel der Kinderbetreuung und des familiengerechten Wohnens hätten in dieser Konzeption keinen Platz mehr, was als ungerecht empfunden wird (vgl. Krause-Junk 1997, S. 555; Bäcker/Ebert 1996, S. 314).

Bäcker/Ebert (1996, S. 320) befürchten, daß die Einführung eines Bürgergeldes zu einer Absenkung des Existenzminimums führen könnte, um die hohen Einführungskosten zu begrenzen. Ob das Bürgergeld als Abbau von Sozialpolitik gewertet werden muß, hängt wesentlich davon $a b$, welche soziale Leistungen letztlich im Bürgergeld aufgehen. Nach Ansicht von Krause-Junk (1997, S. 555) käme es zu einer „drastischen Verschlechterung der staatlichen Unterstützung“" durch das Bürgergeldkonzept von Mitschke.

Die Verteilungswirkungen verschiedener Bürgergeldkonzepte werden von Gern $(1996 a, b)$ simuliert. Gern weist ausdrücklich darauf hin, daß nur direkte Auswirkungen auf das verfügbare Einkommen im Sinne einer statischen formalen Inzidenzanalyse untersucht werden: „Verhaltens-anpassungen oder die Möglichkeit, daß sich bei einem Bürgergeldsystem vermehrte Erwerbsmöglichkeiten bieten können, werden nicht berücksichtigt" (Gern 1996b, S. 152f.). Weiterhin bleibt der Abschmelzungstarif von Mitschke unberücksichtigt, so daß bei einem Existenzminimum in Höhe der derzeitigen Sozialhilfe und einer Transferentzugsrate von $50 \%$ eine Verdoppelung des Grundfreibetrages simuliert wird (Bürgergeldvariante 1A). Dementsprechend ergibt sich für die meisten Haushalte ein Anstieg des verfügbaren Einkommens im Vergleich zum Status quo. Lediglich bei sehr geringen Einkommen von Alleinstehenden ist es in zwei kurzen Einkommensintervallen etwas niedriger, „Zunächst deshalb, weil das Erwerbseinkommen früher angerechnet wird als im herrschenden System, dann deshalb, weil mit Überschreiten der Freigrenze bei den Sozialabgaben das verfügbare Einkommen einmalig spürbar sinkt" (Gern 1996b, S. 153).

\section{(2) Steuersystematische Aspekte}

Nach Krause-Junk (1997) sind aus steuersystematischer Sicht zwei Fragenkomplexe zu unterscheiden. Zum einen ist zu fragen, ob der Einkommensteuertarif problemlos in den negativen Bereich zu projizieren ist. Das wäre dann 
der Fall, wenn die Bemessungsgrundlage identisch wäre. Bemessungsgrundlage für die Berechnung der positiven Einkommensteuerschuld ist das zu versteuernde Einkommen - mit allen mindernden Tatbeständen wie Steuerbefreiungen, -begünstigungen und Sonderausgaben. So stellt sich die Frage, „ob jemand ein zusätzliches Bürgergeld erhalten sollte, weil seine Einkünfte z.T. steuerbefreit sind, weil er hohe Freibeträge geltend machen kann oder weil er z.B. Sonderabschreibungen ausnutzt" (Krause-Junk 1997, S. 552). Würde der einheitliche Einkommensbegriff aufgegeben werden, ginge jedoch ein wichtiger Vorteil des integrierten Steuer- und Transfersystems verloren.

Zum anderen stellt sich die Frage der Zuständigkeit der Finanzverwaltung in Fragen der Sozialpolitik. Die Expertenkommission „Alternative Steuer-Transfer-Systeme“ (1996) hat mehrere Probleme einer vollständigen Verwaltungsintegration herausgearbeitet, die mit einem als „Steuer-transferamt“ fungierenden Finanzamt verbunden wären. Die Einführung eines Bürgergeldes würde den rechtlichen, insbesondere den verfassungsrechtlichen Rahmen stark verändern. Finanzausgleichsprobleme ließen sich nach Ansicht der Kommission in sehr schwierigen und langwierigen Verhandlungen lösen. Verwaltungskompetenzen würden sich von Bundes- und Kommunalbehörden auf Landesbehörden verschieben. Verwaltungsverfahren und Rechtsweg, die derzeit weitgehend einheitlich gestaltet sind, würden kompliziert: Organisatorische und personalwirtschaftliche Probleme müßten gelöst, die Finanzgerichte müßten ausgebaut werden. Es käme zu einem Kompetenzzuwachs beim Bundesministerium für Finanzen. Auch ergeben sich aus der Konzentration personenbezogener Steuer- und Sozialdaten bei einer Behörde Datenschutzprobleme.

\section{(3) Politökonomische Aspekte}

Meltzer/Richard (1985) kritisieren, daß die Befürworter einer negativen Einkommensteuer das Eigeninteresse rationaler Wähler und stimmenmaximierender Politiker vernachlässigen. In einer formalen Analyse zeigen sie, daß Umverteilung durch zweckgebundene, nicht-monetäre Transfers - und nicht durch monetäre Transfers - im Eigeninteresse der arbeitenden und steuerzahlenden Wähler in den USA liegt. Die Intuition für dieses Ergebnis ist leicht nachvollziehbar: Personen mit geringer Produktivität, denen im Rahmen der negativen Einkommensteuer ein bestimmter Geldbetrag zur Verfügung gestellt wird, können gemäß ihrer Präferenzen verschiedene Güter konsumieren. Erhalten sie jedoch Sach- und Dienstleistungen (z.B. Lebensmittelmarken, medizinische Dienste), so besteht ein Anreiz zu arbeiten, um sich weitere gewünschte Konsumgüter kaufen zu können - vorausgesetzt, die bezogenen Sach- und Dienstleistungen dürfen oder können nicht verkauft werden. Daß Transferempfänger arbeiten, liegt im Eigeninteresse derjenigen, die die Transferzahlungen finanzieren. Da der „entscheidende Wähler“ ein Steuerzahler ist, 
kommt es zu keiner Mehrheitsentscheidung für die Einführung einer negativen Einkommensteuer.

Siebert $(1994,1995,1996)$ befürchtet, daß das Bürgergeld zu einer im politischen Prozeß bestimmten Variable in der Verteilungsdebatte werden könnte. Die Parteien müßten sich, wenn sie Wahlen gewinnen wollten, darin überbieten, das Bürgergeld zu erhöhen. Diese Gefahr sah bereits Friedman (1962), allerdings revidierte er seine Einschätzung aus verschiedenen Gründen (vgl. Friedman 1968a u. Kap. 3.1.3).

Das Eigeninteresse von Politikern an der Einführung eines Bürgergeldes könnte auch gering sein, weil der eigene Handlungsspielraum eingeschränkt wird. Wahlgeschenke, deren Finanzierung dem Wähler häufig unklar bleibt, wären nur noch in geringerem Umfang möglich (vgl. Spermann 1994, S. 110). Auch stehen Interessenkonflikte zwischen den Gebietskörperschaften dem Ersatz bestehender Sozialleistungen durch ein Bürgergeld entgegen, die jedoch als lösbar erscheinen (vgl. Experten-Kommission „Alternative SteuerTransfer-Systeme“ 1996, S. 80f.). Widerstand ist auch von budgetmaximierenden Bürokraten bei den Sozial-, Wohnungs- und Arbeitsämtern zu erwarten, die mit finanziellen und Machteinbußen aufgrund der Verschiebung der Verwaltungskompetenzen von der Bundes- und Kommunalebene auf die Länderebene rechnen müssen.

\subsection{Zusammenfassung}

Ziel dieses Kapitels war es, zunächst die Wurzeln der Negativsteuerdiskussion offenzulegen. Dazu wurden die nach Ansicht des Verfassers wichtigsten Negativsteuerkonzeptionen vorgestellt und kritisch reflektiert. Dieser historische Rückblick ermöglicht wichtige Einsichten für die aktuelle Diskussion zur Einführung einer Negativsteuer, die von 1993 an vor dem Hintergrund hoher und langanhaltender Arbeitslosigkeit unter dem Etikett „Bürgergeld“ in Politik und Wissenschaft intensiv geführt wird. Überblicksartige Zusammenfassungen der Bürgergeld-Diskussion finden sich bei Erbe/Erbe (1993), Kress (1994), Scherf (1994), Spermann (1994), Dichmann (1995), Erbe (1995), Fuest (1995), Krupp (1995), Experten-Kommission „Alternative SteuerTransfer-Systeme“ (1996), Hauser (1996), Kaltenborn (1995), Sesselmeier et al. (1996), Feist (1997) und Krause-Junk (1997).

Die wichtigsten Ergebnisse dieses Kapitels lassen sich in zwölf Punkten zusammenfassen:

1. Das Speenhamland-System, das 1795 in Berkshire eingeführt wurde und in weiten Teilen Englands Verbreitung fand, wird als frühes Praxisbeispiel einer negativen Einkommensteuer angeführt. Das System scheiterte letztlich am Moral hazard-Verhalten der Arbeitgeber: Lohnsenkungen wurden unter 
Verweis auf die Transferzahlungen des Staates durchgesetzt - mit der Konsequenz, daß das System für den Fiskus zu teuer wurde.

2. Der Vorschlag einer Sozialdividende der Lady Rhys-Williams (1943/53) gilt als die Geburtsstunde der Idee einer negativen Einkommensteuer. Ausgangspunkt ihres Vorschlags ist die im zweiten Kapitel ausführlich geschilderte Armutsfalle und die hohe Komplexität des Steuer- und Transfersystems. Rhys-Williams weist ausdrücklich darauf hin, daß Transferempfänger arbeiten wollen, institutionelle Fehlregelungen ihre Untätigkeit jedoch erzwingen. Auch betont sie die Verzerrung der intertemporalen Allokation durch die existierende Bedürftigkeitsprüfung. Ihr Reformvorschlag ist gekennzeichnet durch ein an alle Bürger zu zahlendes Grundeinkommen (Sozialdividende), das durch einen konstanten Grenzsteuersatz (flat rate tax) auf Arbeits- und Kapitaleinkommen finanziert werden soll.

3. Die Diskussion der Sozialdividende hat gezeigt, daß bereits frühzeitig die wichtigsten Schwächen des Reformvorschlags erkannt wurden. Im Mittelpunkt der Kritik stehen - wie in der Bürgergelddiskussion - die negativen Auswirkungen auf die Arbeitsanreize bereits Erwerbstätiger und die hohen fiskalischen Kosten.

4. Der Vorschlag einer Sozialdividende wird in der Literatur vor allem in Zusammenhang mit Optimalsteuerkonzepten auch heute noch diskutiert. In der politischen Diskussion spielen lediglich sehr gemäßigte Versionen des radikalen Grundsicherungskonzepts von Rhys-Williams eine gewisse Rolle. Die Vorschläge einer bedarfsorientierten Grundsicherung wie sie zum Beispiel von der SPD und der Partei Bündnis90/Die Grünen vertreten werden, stellen nicht das Sozialversicherungssystem in Frage, sondern wollen es um Grundsicherungselemente ergänzen. Dennoch stellen sich bei diesen gemäBigten Reformvorschlägen grundsätzlich dieselben allokativen und fiskalischen Probleme - wenn auch weniger drastisch.

5. Das Armutslückenkonzept der negativen Einkommensteuer wurde von Milton Friedman (1962/68a,b,c) als Ersatz für das bestehende Transfersystem vorgeschlagen; das System der positiven Einkommensteuer und der Sozialversicherung wollte Friedman zunächst unangetastet lassen. Bei Friedmans Vorschlag für eine bundesweite negative Einkommensteuer soll der maximale Transferbetrag das Existenzminimum nicht abdecken. Die dadurch entstehende Armutslücke ist die unausweichliche Konsequenz einer Teilanrechnung von Zusatzverdiensten bei unverändertem steuerfreien Existenzminimum. Diese Konstruktion ermöglicht es jedoch, daß die Einführungskosten relativ gering und die Verschlechterung der Arbeitsanreize bereits Erwerbstätiger minimal sind. Auf den zweiten Blick ist die Armutslücke jedoch von geringerer Bedeutung, weil Friedman für ergänzende Systeme der negativen Einkommensteuer auf der Ebene der Bundesstaaten plädiert. Bei einer kombinierten Negativsteuer auf Bundes- und Landesebene müßten die fiskalischen und allokativen Wirkungen erneut diskutiert werden - eine Auseinanderset- 
zung, die sich in der Literatur nicht findet. Das Armutslückenkonzept von Friedman wurde von Vaubel (1996) aufgegriffen und für Deutschland vorgeschlagen.

6. Die graduelle Integration des Steuer- und Transfersystems wurde von Tobin (1965/67) vorgeschlagen. Sie stellt zumindest in der L-Variante eine Kombination aus Sozialdividenden- und Armutslückenkonzept dar. Auch Tobins Vorschlag läßt das bestehende System der Einkommensteuer und der Sozialversicherung unverändert. Die Innovation Tobins besteht vor allem darin, daß die negative Einkommensteuer lediglich für „einkommensschwache Familien" gelten soll - sein Vorschlag ist somit die erste zielgruppenorientierte Konzeption einer negativen Einkommensteuer. Die Konsequenz der graduellen Integration ist das „Überlappen“ des negativen und positiven Einkommensteuerbereichs. Dadurch reduzieren sich die Einführungskosten, die allokativen Wirkungen sind jedoch sehr differenziert $\mathrm{zu}$ betrachten. Tobin et al. (1967) diskutieren auch ausführlich Details der Übergangsprobleme vom Status quo in einem föderativen System sowie Mißbrauchsmöglichkeiten. So wird das Moral hazard-Verhalten der Negativsteuerempfänger herausgearbeitet: das Problem des „underreporting“ des eigenen Einkommens zur Transfermaximierung.

7. Der Rückblick auf die wichtigsten Negativsteuerkonzeptionen hat gezeigt, daß diese theoretisch eleganten Vorschläge Vertreter unterschiedlicher politischer Positionen faszinieren - ein Phänomen, das sich auch in der Bürgergelddiskussion der neunziger Jahre beobachten läßt. Im Jahre 1997 forderten Vertreter aller bedeutenden politischen Parteien die Einführung von Elementen einer Negativsteuer. Die Vorstellungen sind bisher jedoch sehr vage.

8. Das Bürgergeldkonzept von Mitschke liegt seit etwa einem Vierteljahrhundert vor. In den neunziger Jahren standen die möglichen Beschäftigungswirkungen des dualen Integrationsmodells von Mitschke (1994/95) im Mittelpunkt der Bürgergelddiskussion. Im Gegensatz zur bestehenden Literatur wird das Bürgergeldmodell mit dem von Mitschke vorgeschlagenen „Abschmelzungstarif" modelliert. Es wird gezeigt, daß ein solcher Tarif mit einem im Vergleich zum Status quo höheren Grenzsteuersatz oberhalb der Transfergrenze verbunden ist - auch wenn das Bürgergeld haushaltsneutral eingeführt wird. Das duale Integrationsmodell läßt das Steuer- und Sozialversicherungssystem grundsätzlich unangetastet. Die beiden wichtigsten Fehlanreize im Sozialsystem werden dauerhaft beseitigt.

9. Die Modellierung des Bürgergeldkonzepts mit Abschmelzungstarif erlaubt eine statische allokative Analyse des Übergangs vom Status quo zum Bürgergeld. So können die Arbeitsangebotsreaktionen von Sozialhilfe- bzw. Bürgergeldempfängern, Geringverdienern und Besserverdienern theoretisch im Rahmen des Einkommen-Freizeit-Modells abgeleitet werden. Es werden jedoch auch die vorliegenden empirischen Studien herangezogen, um Ein- 
schätzungen der zu erwartenden Reaktionen zu erhalten. Die Analyse der drei Haushaltstypen bestätigt die in der Literatur vorherrschende Ansicht, daß ein Rückgang des aggregierten Arbeitsangebots durch die Einführung eines Bürgergeldes nicht ausgeschlossen werden kann.

10. Die partialanalytischen Einsichten werden durch eine dynamische allokative Analyse ergänzt. Dabei werden die intertemporalen Effekte, die möglichen Folgewirkungen auf die Qualifizierungsbemühungen und Gewohnheiten der Bürgergeldempfänger sowie soziale Normen dargestellt. Auch werden Konsequenzen auf die Lohnstruktur und mögliches Moral hazard-Verhalten betrachtet. Ein Teil der aufgezeigten Wirkungskanäle deutet auf langfristig positive, ein anderer Teil jedoch auf langfristig negative Beschäftigungswirkungen hin. Negative Beschäftigungswirkungen können demnach auch langfristig nicht ausgeschlossen werden.

11. Die fiskalische Kritik am Bürgergeld ist heftig umstritten. Mitschkes behauptete Haushaltsneutralität wird von fast allen vorliegenden Simulationsstudien in Frage gestellt. Der Autor hält den Streit über die Höhe der Einführungskosten für wenig zweckdienlich. Selbst wenn das Bürgergeldkonzept durch entsprechend umfangreiche Kürzungen von Subventionen und Transfers haushaltsneutral eingeführt werden könnte - entscheidend sind die statischen und dynamischen allokativen Wirkungen. Es fällt jedoch auf, daß alle für Deutschland vorliegenden Simulationsstudien die von der Einführung des Bürgergeldes erhofften Arbeitsangebotswirkungen nicht berücksichtigen. Seriöserweise müßten die fiskalischen Entlastungen, die sich bei positiven $\mathrm{Be}-$ schäftigungswirkungen ergeben würden, den Einführungskosten gegengerechnet werden. Eine Simulationsstudie, die Reaktionen des Arbeitsangebots der Haushalte berücksichtigt, liegt dagegen für die Einführung eines Bürgergeldes in Großbritannien vor. Das Ergebnis: Die Beschäftigungseffekte sind nicht eindeutig, eher negativ. Langfristige dynamische Anpassungsreaktionen werden auch bei dieser Analyse nicht betrachtet. Vor diesem Hintergrund erscheint es wenig erfolgversprechend, im Rahmen dieser Arbeit eine Simulationsstudie zum Bürgergeld vorzulegen. Vielmehr wird in Kapitel 5 ein Reformvorschlag entwickelt, der mit minimalen Einführungskosten und einer eindeutigen Verbesserung der Arbeitsanreize gegenüber dem Status quo verbunden ist. Mögliche langfristige Wirkungskanäle sollen in einer verbalen Diskussion identifiziert werden.

12. Schließlich werden die wichtigsten sozial- und verteilungspolitischen, steuersystematischen und politökonomischen Aspekte einer Einführung des Bürgergeldes genannt. Insbesondere politökonomische Erwägungen könnten den erhofften Beschäftigungswirkungen des Bürgergeldkonzepts entgegenstehen. 
Alexander Spermann - 978-3-631-75152-7 Downloaded from PubFactory at 01/11/2019 07:40:14AM via free access 


\section{Kapitel 4: Aktuelle Lohnsubventionsmodelle}

\subsection{Zur Auswahl der Lohnsubventionsmodelle}

In diesem Kapitel werden drei Typen von zielgruppenorientierten Lohnsubventionsmodellen kritisch dargestellt, die sich in der wissenschaftlichen und politischen Diskussion befinden. Zum einen werden Lohnsubventionen an Arbeitnehmer vorgestellt (Kapitel 4.2). Dazu zählen die in den USA und Großbritannien realisierten Negativsteuerkonzeptionen - der „Earned Income Tax Credit" und der „Family Credit" -, die in Deutschland wiederbelebte wissenschaftliche Diskussion über eine „Negative Wage Tax“ sowie die Mitte 1997 aufgekommene Debatte über sogenannte „Kombi-Einkommensmodelle". Zum anderen werden Lohnsubventionen an Arbeitgeber dargestellt (Kapitel 4.3). Dazu zählen bekannte Lohnsubventionsprogramme wie der "Targeted Jobs Tax Credit“ in den USA und die Vielzahl der Zuschußprogramme in Deutschland. In der Diskussion befinden sich die Vorschläge für Stundenlohnsubventionen von Scharpf (1994) für Deutschland und Phelps (1997) für die USA. Besonders interessant ist der Vorschlag, die Arbeitslosenunterstützung in Gutscheine für Arbeitgeber umzuwandeln: das „Benefit-Transfer Program" von Snower $(1994,1997)$. Zum dritten werden Lohnsubventionsmodelle präsentiert, die mit einer Arbeitspflicht verknüpft sind (Kapitel 4.4). Diese sogenannten „Welfare-to-Work"-Programme haben in den USA und Großbritannien, aber auch in Dänemark und Deutschland im Verlauf der neunziger Jahre zunehmend an Bedeutung gewonnen. In diesem Zusammenhang wird auch das von Vaubel (1996) vorgeschlagene „Armutslückenkonzept" diskutiert. Es wird jeweils geprüft, ob die vorgestellten Lohnsubventionsmodelle die Armutsfalle beseitigen können. Außerdem wird diskutiert, ob die vorgestellten Lohnsubventionsmodelle für die Einführung in das deutsche Steuer-, Abgaben- und Transfersystem geeignet sind.

Einige Reformvorschläge fanden nach eingehender Prüfung keine Berücksichtigung. So wird das im Jahre 1990 vorgestellte Modell der „Qualifizierungsgutscheine" von Klodt und Siebert (vgl. Klodt 1990, Klodt 1991, Klodt/Siebert 1991) nicht dargestellt, weil es nicht in die Realität umgesetzt wurde und auch nicht mehr diskuciert wird (vgl. Klodt 1996). Gleiches gilt für den Vorschlag einer „Conditional Negative Income Tax“ von Minford (1984). Ebenso unberücksichtigt bleibt das von Pelzer (1996) vorgeschlagene „Ulmer Modell" - ein Grundsicherungsmodell -, weil es nach dem Kenntnisstand des 
Autors bisher weder in der Wissenschaft noch in der Politik diskutiert wird. In dieser Arbeit findet sich auch keine Auseinandersetzung mit den wenig detaillierten Vorschlägen einer „Beschäftigungshilfe für Langzeitarbeitslose“ von Paqué (1995) und dem Konzept der "Gemeinschaftsarbeit" von Eekhoff (1996).

\subsection{Lohnsubventionen an Arbeitnehmer}

\subsubsection{Der „Earned Income Tax Credit“}

In den USA werden seit 1975 zielgruppenorientierte Transfers an Familien in Form von Steuergutschriften (=,tax credits“ $=$ Negativsteuer) gewährt. Der sogenannte „Earned Income Tax Credit" (EITC) wurde unter der ClintonAdministration in den neunziger Jahren erheblich ausgeweitet. Inzwischen ist dieses Programm das bedeutendste Mittel zur Armutsbekämpfung in den USA. Die Kernidee besteht darin, daß finanzielle Arbeitsanreize für erwerbstätige Geringverdiener durch eine Negativsteuer in Abhängigkeit vom erzielten Arbeitseinkommen geschaffen werden. Diese Variante einer Negativsteuer wirkt wie eine Lohnsubvention, mit der die Aufnahme eines Jobs belohnt wird - der EITC ist demnach ein sogenannter ,in-work benefit“. NichtErwerbstätige erhalten dagegen keine Transfers über das EITC-Programm. Dieser Transfer wurde ursprünglich ausschließlich für geringverdienende Familien konzipiert, seit 1994 sind jedoch auch Einzelpersonen anspruchsberechtigt (vgl. Eissa/Liebman 1996). Der EITC wurde in letzter Zeit als alternatives Konzept für Europa vorgeschlagen (vgl. van der Ploeg 1995) und in Deutschland diskutiert (vgl. Rolle 1997).

Die Funktionsweise des EITC wird im Brutto-/Nettoeinkommen-Diagramm in Abbildung 18 verdeutlicht (vgl. Hoffman/Seidman 1990, Holtzblatt et al. 1994, Bluestone/Ghilarducci 1996, Bird 1996, Walker/Wiseman 1997):

An den Achsen sind Jahreswerte in Dollar abgetragen. Das ausgewählte Zahlenbeispiel gilt für den typischen EITC-Fall, eine Familie mit einem Kind; die Steuersätze und Einkommensgrenzen entsprechen den Plänen für 1996 (vgl. Eissa/Liebman 1996). Beim EITC gelten in verschiedenen Bruttoeinkommensbereichen drei Grenzsteuersätze, so daß sich eine zweifach geknickte Nettoeinkommensgerade ergibt. In der sogenannten "phase-in region“, die in diesem Fall ein Bruttoeinkommen bis zu 6490 \$ im Jahr umfaßt, gilt ein negativer Grenzsteuersatz $t_{1}$ von $34 \%$. Das heißt, daß ein selbstverdienter Dollar das verfügbare Einkommen um 1,34 \$ erhöht - der Nettotransfer beträgt 34 Cents je Dollar. In der sogenannten „constant region“ des EITC beträgt der Grenzsteuersatz $t_{2}$ Null Prozent, so daß ein zusätzlich verdienter Dollar das verfügbare Einkommen auch um einen Dollar erhöht. In diesem Bruttoeinkommensbereich (6490 bis 11900 Dollar) ist der Nettotransfer maximal. Der 
Nettotransfer $(=$ Steuergutschrift $=$ Negativsteuer $)$ wird durch den vertikalen Abstand zwischen der Nettoeinkommensgerade und der $45^{\circ}$-Linie gemessen er beträgt maximal $2206 \$$. In der sogenannten ,phase-out region“ beträgt der Grenzsteuersatz $t_{3}$ 15,98\%. Dadurch entsteht eine Steuerschuld, die mit dem maximalen Transfer von 2206 \$ verrechnet wird. Deshalb sinkt der Nettotransfer kontinuierlich bis zum transferfreien Bruttoeinkommen von $25705 \$$. Bei diesem Bruttoeinkommen schneidet die Nettoeinkommensgerade die $45^{\circ}$ Linie - es wird kein Nettotransfer mehr bezahlt, erst bei höheren Bruttoeinkommen müssen positive Steuern bezahlt werden.

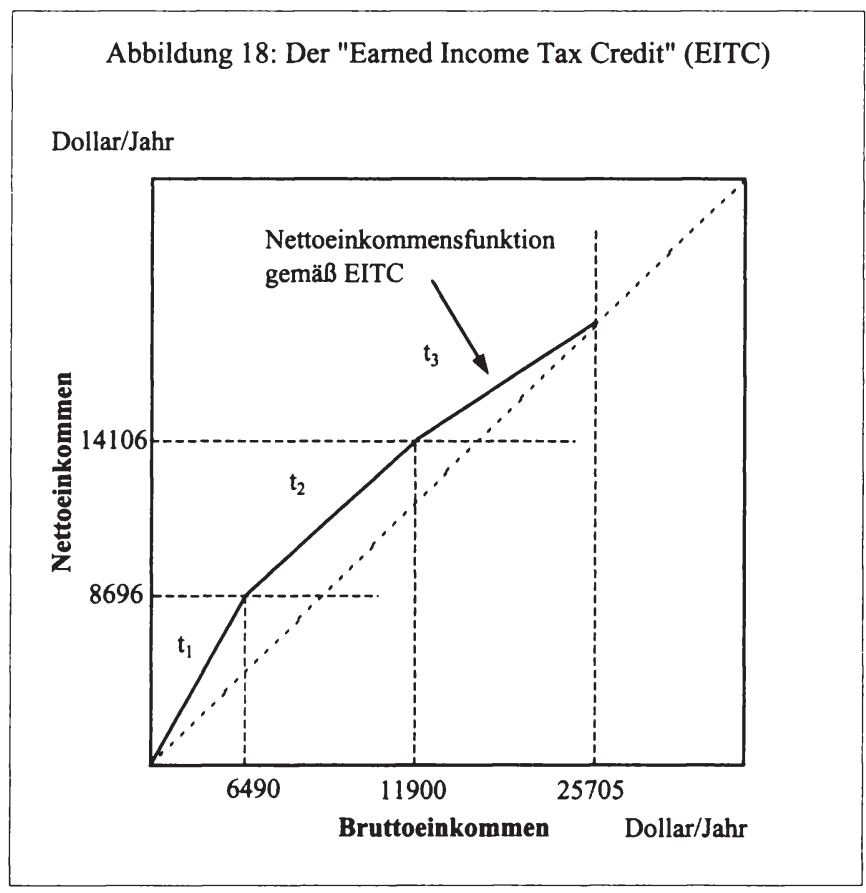

Scholz (1994, S. 78) schätzt auf der Datenbasis von 1990, daß die EITCProgrammausweitung des Jahres 1993 zu folgender Verteilung der Hilfeempfänger auf die unterschiedlichen „regions“ führt: $23 \%$ der anspruchsberechtigten Familien werden mit ihrem Bruttoeinkommen in der phase-in region, $16 \%$ werden in der constant region und $61 \%$ werden in der phase-out region des EITC liegen.

Die üblicherweise in der Literatur gewählte Darstellung des EITC, der in Abbildung 18 gefolgt wurde, verstellt jedoch den Blick auf die Realität. Der Grenzsteuersatz auf Zusatzverdienste in der phase-out region beträgt nur auf den ersten Blick 15,98 \%. Für Bruttoeinkommensbezieher in der phase-out 
region gilt tatsächlich ein Grenzsteuersatz von über $42 \%$, weil der Einkommensteuersatz und der Beitragssatz für die Sozialversicherung addiert werden müssen (vgl. Bluestone/Ghilarducci 1996, S. 24). Anders formuliert: Knapp zwei Drittel der EITC-Empfänger sieht sich mit einem Grenzsteuersatz auf Zusatzverdienste konfrontiert, der höher als der Grenzsteuersatz für Spitzenverdiener in den USA ist! Dickert/Houser/Scholz (1995, S. 24ff.) berücksichtigen bei der Berechnung effektiver Grenzsteuersätze für Niedrigeinkommensbezieher sowohl die Einkommensteuer als auch Sozialversicherungsbeiträge und weitere Transferprogramme (Aid for Families with Dependent Children, AFDC, und Food Stamps). Ihr Ergebnis: Es existieren effektive Grenzsteuersätze auf Zusatzverdienste bis zu $175 \%$ in der phase-out region, aber auch in Teilbereichen der phase-in und constant region, die im wesentlichen auf die hohe Tranferentzugsrate des AFDC-Programms zurückzuführen sind. Der EITC beseitigt nur dann die Armutsfalle, wenn die Wirkungen des AFDC-Programms ausgeklammert werden. An dieser Stelle wird deutlich, daß für eine sachgerechte Problemanalyse eine Gesamtbetrachtung des Steuer-, Abgaben- und Transfersystems nötig ist.

Walker/Wiseman (1997, S. 410f.) weisen jedoch einschränkend darauf hin, daß nur wenige Familien, die AFDC-Leistungen beziehen, eigene Verdienste angeben. Deshalb erhalten in der Mehrzahl der Fälle einkommensschwache Familien den EITC, ohne Barleistungen im Rahmen des AFDC zu erhalten. Dennoch bleibt das grundsätzliche Problem bestehen, daß die Anrechnungsvorschriften für Zusatzverdienste beim Bezug verschiedener Transferleistungen nicht aufeinander abgestimmt sind.

Ein weiteres Detailproblem ist mit der Auszahlungsweise des EITC über das Finanzamt verbunden. Typischerweise erhalten Hilfebezieher ihre Leistung erst 16 Monate nach Antragstellung. Zwar ist es seit 1979 möglich, negative Einkommensteuervorauszahlungen vom Finanzamt zu erhalten, doch nutzen lediglich fünf Prozent der Anspruchsberechtigten diese Option (vgl. Walker/Wiseman 1997).

Im Jahre 1994 nahmen etwa 19 Millionen Personen den EITC in Anspruch, die Kosten beliefen sich auf 26,7 Mrd. \$ (vgl. OECD 1996, S. 47), der Anteil am Bruttosozialprodukt betrug etwa 0,25\% (vgl. Whitehouse 1996, S. 134).

Würde eine Steuergutschrift für Familien im Sinne des EITC in das deutsche Steuerrecht eingeführt, so ergäbe sich ein Gerechtigkeitsproblem. Familien mit Kindern, aber auch Alleinstehende könnten dauerhaft ihre niedrigen Bruttoeinkommen durch den EITC aufstocken - mit der Konsequenz, daß sie ohne zeitliche Befristung über ein wesentlich höheres monatliches Einkommen als Nicht-EITC-Berechtigte verfügten. Je nach Abgrenzung der EITCBruttoeinkommensbereiche könnten sich sehr hohe Einkommensdifferenzen ergeben. Dieser Weg scheint bereits aus diesem Grund wenig realistisch zu sein, so daß die allokativen Wirkungen an dieser Stelle nicht diskutiert werden sollen. 
Dagegen erscheint die Einführung der Teilanrechnung von Zusatzverdiensten im Sinne des EITC in das deutsche Sozialhilferecht realistischer. In diesem Fall würden lediglich die niedrigen Einkommen bedürftiger Haushalte subventioniert. Die Arbeitsanreize für bisher nicht erwerbstätige Hilfeempfänger wären sehr hoch. Erstens bewirkt der negative Grenzsteuersatz der ,phase-in region", daß es nur noch für sehr stark freizeitorientierte Individuen mit sehr steilen Indifferenzkurven nutzenmaximal bleibt, keine Arbeit anzubieten. Negative Grenzsteuersätze haben sich in einem System ohne umfangreiche Grundsicherung - wie in den USA - als beschäftigungswirksam erwiesen; nicht-erwerbstätige Hilfeempfänger erhalten in den USA Lebensmittelmarken (Food Stamps), so daß lediglich das physische Existenzminimum abgesichert ist - einer vierköpfigen Familie stehen demnach etwa 100 \$ je Woche zur Verfügung (vgl. Walker/Wiseman 1997, S. 412). Mehrere empirische Studien zeigen, daß der Zuwachs der Erwerbsquote (labor force participation rate) von Niedriglohnbeziehern die entscheidende Komponente für den positiven gesamtwirtschaftlichen Beschäftigungseffekt des EITC ist. Die Simulationsstudie von Dickert/Houser/Scholz (1995) zeigt am Beispiel der Ausweitung des EITC 1993, daß die Erwerbsquote von Alleinerziehenden um 3,3 Prozentpunkte zunahm. Die Schätzungen von Eissa/Liebman (1996) für die Jahre 1984-86 und 1988-89 ergeben, daß sich die Erwerbsquote alleinerziehender Frauen mit Kindern um 1,4 Prozentpunkte auf $74,5 \%$ relativ zu alleinstehenden Frauen ohne Kindern erhöhte. Die Zunahme war am höchsten bei geringqualifizierten und geringverdienenden Frauen mit Kindern. Die Simulationsstudie von Scholz (1996) kommt zu vergleichbaren Ergebnissen.

Negative Grenzsteuersätze auf Zusatzverdienste sind in einem System mit umfangreicher Grundsicherung - wie in Deutschland - sogar eine attraktivere Option für Hilfeempfänger als Schwarzarbeit. Jede zusätzlich verdiente Mark erhöht nicht nur das verfügbare Einkommen, sondern wäre bei einer phase-in region mit einer "Transferentzugsrate“ von - 34 \% sogar mit einem Zuschuß von 34 Pfennig verbunden.

Zweitens gilt ein Grenzsteuersatz von Null Prozent in der constant region, der einem nicht anzurechnenden Sockel- bzw. Freibetrag für Zusatzverdienste entspricht. In diesem Bruttoeinkommensbereich ist das Anrechnungsverfahren aus finanzieller Sicht ebenso attraktiv wie Schwarzarbeit.

Drittens verbessern sich die Arbeitsanreize für bisher nicht erwerbstätige Hilfeempfänger auch bei der Einführung der phase-out region des EITC in Deutschland. Der Grund: In Deutschland existiert de facto eine Grundsicherung in Form der Sozialhilfe mit weitgehender Vollanrechnung der $\mathrm{Zu}$ satzverdienste, so daß bei einer positiv geneigten Arbeitsangebotskurve der Hilfeempfänger das Arbeitsangebot zunimmt.

Dagegen entsprechen die allokativen Effekte der phase-out region in den USA denen der Einführung einer negativen Einkommensteuer in ein System ohne Grundsicherung. Der Substitutions- und Einkommenseffekt wirken in Rich- 
tung auf ein niedrigeres Arbeitsangebot. Die negativen Arbeitsanreizwirkungen der phase out-region betreffen etwa zwei Drittel der EITC-Empfänger, deren Bruttoeinkommen in diesem Bereich liegen (vgl. Scholz 1994, Browning 1995). Ob diese negativen Arbeitsanreize auch empirisch bedeutsam sind, ist umstritten. Die Studien von Hoffman/Seidman 1990, Dikkert/Houser/Scholz (1995), Browning (1995) und Scholz (1996) bestätigen dieses theoretische Ergebnis, während Eissa/Liebman (1996) den sogenannten „Arbeitsstundeneffekt“ bestreiten.

Die Integration eines EITC-Modells in das deutsche Grundsicherungssystem hätte jedoch einen hohen fiskalischen Preis. Insbesondere die negativen Grenzsteuersätze auf Zusatzverdienste könnten erhebliche Mitnahmeeffekte provozieren. Zum einen könnten sie zum sogenannten „overreporting“ der Hilfeempfänger führen - Hilfeempfänger geben höhere Einkünfte an, um höhere Lohnsubventionen zu erhalten (vgl. Bluestone/Ghilarducci 1996, S. 23f.). Scholz (1994, S. 69) berichtet, daß $30 \%$ der Antragsteller vom EITCBezug ausgeschlossen wurden, weil sie ihre Einkünfte falsch angaben. Deshalb seien erheblich fiskalische Mehrkosten (overpayment) zu befürchten (vgl. Scholz 1996, S. 167). Dagegen zeigt die Untersuchung von Joulfaian/Rider (1996) auf der Basis einer Stichprobe von 3219 EITC-Anspruchsberechtigten im Jahre 1988, daß overreporting für Geringverdiener empirisch nicht signifikant ist. Zum anderen erfordert die Logik des derzeitigen Sozialhilfesystems, daß bisherige Sozialhilfeansprüche aufgestockt werden müßten und zusätzliche Ansprüche auf ergänzende Sozialhilfe für bisher nicht bedürftige erwerbstätige Familien entstehen würden. Der Umfang der fiskalischen Mehrbelastung durch Mitnahmeeffekte könnte - je nach Bruttoeinkommensbereich für die einzelnen „regions“ - sehr hoch werden, auch wenn overreporting keine Rolle spielen sollte. Der zusätzliche Finanzierungsbedarf dürfte kurzfristig wesentlich höher sein als die Einsparungen durch zusätzliche Beschäftigung der Hilfeempfänger. Ob die Einführung des EITC in das deutsche Grundsicherungssystem langfristig mit höherer Beschäftigung und fiskalischen Einsparungen verbunden ist, läßt sich erst nach der Durchführung von Simu-lationsrechnungen à la Duncan/Weeks (1997) mit unterschiedlichen Varianten in bezug auf die Höhe der Anrechnungssätze und der Bruttoeinkommmensbereiche abschätzen.

Würde der EITC als zeitlich unbefristete Lohnsubvention für bedürftige Familien mit Kindern, aber auch für Alleinstehende in das bestehende Sozialhilfesystem integriert, so wären weiterhin die dynamischen allokativen Wirkungen zu betrachten. Es wären negative Rückwirkungen auf die Qualifizierungsbemühungen und Moral hazard-Verhalten der Tarifpartner sowie der Arbeitgeber und Arbeitnehmer zu Lasten des Staates zu erwarten (vgl. Kapitel 3.2.2.2), was wiederum hohe fiskalische Belastungen nach sich ziehen würde. $\mathrm{Da} ß$ die Beschäftigung langfristig wegen der dynamischen allokativen Wirkungen abnimmt, ist nicht auszuschließen. 


\subsubsection{Der „Family Credit“}

In Großbritannien wird seit 1988 eine zielgruppenorientierte Negativsteuer an Familien in Form von Steuergutschriften gewährt: der „Family Credit“. Voraussetzung für den Bezug dieser Steuergutschrift (=Negativsteuer) für Familien ist, daß ein Erwachsener mindestens 16 Stunden je Woche arbeitet - der Family Credit ist demnach ein in-work benefit. Wer weniger als diese Mindeststundenzahl arbeitet, erhält Sozialhilfe. Bruttoeinkommensbereiche mit negativen Grenzsteuersätzen existieren im Gegensatz zum EITC bei diesem Programm nicht. Stattdessen wird ein Bruttoeinkommen in Höhe von 292 Pfund je Monat (73 Pfund je Woche) nicht angerechnet - der Grenzsteuersatz $t_{1}$ beträgt Null Prozent. Darüber liegende Bruttoeinkommen werden mit einem Grenzsteuersatz $t_{2}$ von $70 \%$ belegt (vgl. Duncan/Giles 1996, Whitehouse 1996, OECD 1996).

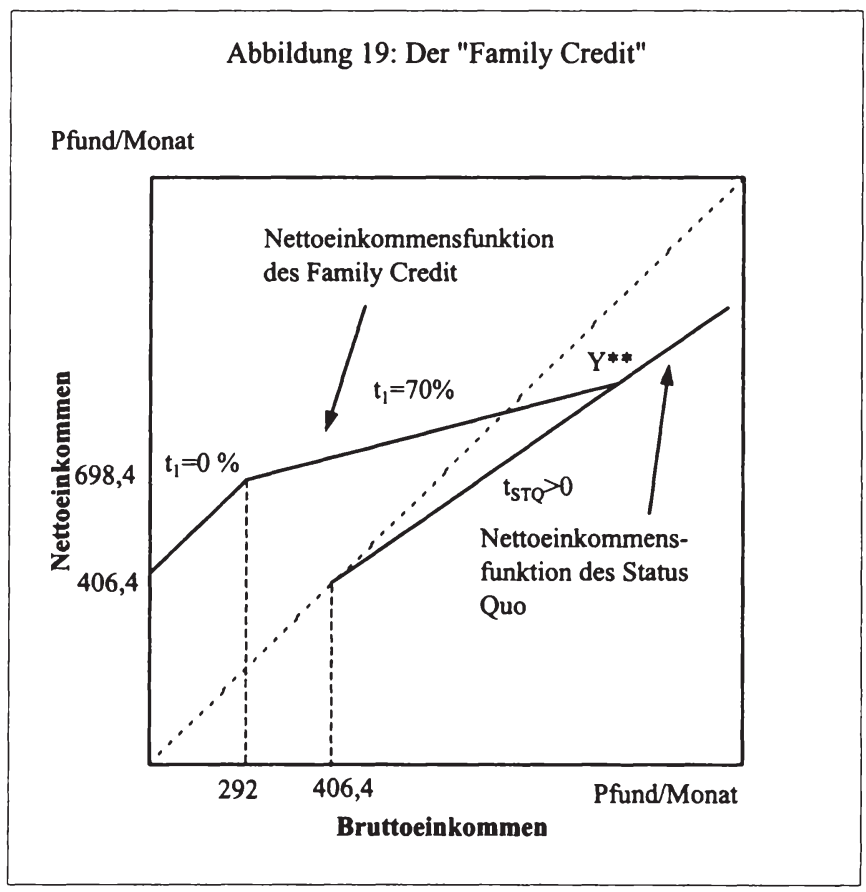

Der Family Credit wird am Beispiel einer Familie mit einem Kind im Brutto-/ Nettoeinkommen-Diagramm in Abbildung 19 dargestellt. An den Achsen sind Monatswerte in Pfund abgetragen. Der Ordinatenabschnitt wird durch den Bedarf der Familie festgelegt, wenn nicht gearbeitet wird. Die Höhe der Steuergutschrift wird für eine dreiköpfige Familie mit 406,4 Pfund/Monat ange- 
nommen; im Jahre 1995/96 betrug der wöchentliche „adult credit“ für Erwachsene 45,1 Pfund, der wöchentliche „credit per child“ schwankte je nach Alter zwischen 11,4 und 32,8 Pfund (vgl. Duncan/Giles 1996). Bruttoeinkommen bis 292 Pfund im Monat bleiben anrechnungsfrei, so daß sich das Nettoeinkommen auf 698,4 Pfund/Monat erhöht. Darüber liegende Bruttoeinkommen werden lediglich zu $70 \%$ angerechnet. Bei einem Bruttoeinkommen von $\mathrm{Y}^{* *}$ mündet die Nettoeinkommensfunktion des Family Credit in die Nettoeinkommensfunktion des Status quo. Zu beachten ist, daß Family Credit-Empfänger auch Steuern zahlen müssen, sobald sie über dem steuerfreien Existenzminimum verdienen. Dadurch ergeben sich in der Realität Grenzsteuersätze von über $80 \%$ auf Zusatzverdienste, sobald die Besteuerung einsetzt (vgl. Duncan/Giles 1996, S. 143). Unter Berücksichtigung von Sozialversicherungsbeiträgen und den Einkommensgrenzen für den Bezug von Wohngeld ergeben sich sogar Grenzsteuersätze bis zu 140 \% (vgl. Walker/Wiseman 1997, S. 406f.). Deshalb wird der Fehlanreiz Armutsfalle durch den Family Credit nur leicht abgeschwächt.

Der über die Sozialämter ausgezahlte Family Credit wurde im Jahre 1994 von etwa 500.000 Familien in Anspruch genommen. Der Family Credit wird in Partnerhaushalten typischerweise an die Frau ausgezahlt, selbst wenn der Mann beschäftigt ist. Die Auszahlung erfolgt jeweils für sechs Monate (vgl. Walker/Wiseman 1997, S. 403f.). Die Kosten betrugen etwa 1,1 Milliarden Pfund (vgl. OECD 1996, S. 47), der Anteil am Bruttosozialprodukt betrug etwa $0,2 \%$ (vgl. Whitehouse 1996, S. 134).

Die Einführung des Family Credit in das deutsche Sozialhilfesystem hätte lediglich marginale Änderungen des Status quo für die Zielgruppe „Familien“ zur Folge. Der Anrechnungssatz auf Zusatzverdienste von Hilfeempfängern wäre weiterhin sehr hoch, Mitnahmeeffekte durch bereits Erwerbstätige sowie durch höhere Ansprüche bisheriger Sozialhilfeempfänger ergeben sich aus der Logik des Systems der ergänzenden Sozialhilfe. Im Gegensatz zum EITC spielt jedoch „overreporting“ keine Rolle, weil kein Einkommensbereich mit negativen Grenzsteuersätzen existiert. Die Beschäftigungswirkungen und fiskalischen Effekte lassen sich mit Hilfe von Simulationsstudien, wie sie Duncan/Giles (1996) für Großbritannien vorgelegt haben, abschätzen.

\subsubsection{Die „Negative Wage Tax“(NWT)}

Eine stundenlohnsatzbezogene Subvention (Negative Wage Tax) an arbeitsfähige Hilfeempfänger wurde von Kesselman (1969) als Alternative zu einer Negativen Einkommensteuer vorgeschlagen und in den siebziger Jahren diskutiert (vgl. Zeckhauser 1971, Browning 1973). Im Zusammenhang mit der Diskussion um den Akerlof et al. (1991)-Lohnsubventionsvorschlag zur Abmilderung der beschäftigungspolitischen Auswirkungen der Wiedervereinigung und der Bürgergelddiskussion der neunziger Jahre wurde dieser Vorschlag von Mackscheidt (1993) und Vierling (1996, 1997) aufgegriffen. In der 
amerikanischen Diskussion wird die NWT von Browning (1995) als praktikable Alternative zum EITC vorgeschlagen.

Im Gegensatz zum Bürgergeld und zum EITC ist die NWT eine Lohnsubvention $\mathrm{S}$, die mit steigendem Stundenlohnsatz $\mathrm{w}$ abnimmt - nicht mit steigendem Einkommen. Es gilt: $S=s\left(W^{*}-w\right)=-t_{\text {NWT }}\left(W^{*}-w\right)$, wobei $s$ ein konstanter Subventionssatz bzw. ein negativer Grenzsteuersatz $-t_{\mathrm{NWT}}$ und $\mathrm{W}^{*}$ der Breakeven-Lohnsatz ist (vgl. Browning 1973, S. 41). Die zentralen Merkmale sind demnach der garantierte Mindestlohnsatz, die degressive Ausgestaltung und der maximal bezuschußte Marktlohnsatz. Vierling $(1996,1997)$ bezeichnet die NWT deshalb als Lohnsatzsubvention.

Die NWT wird - abweichend von der bisherigen Literatur - zunächst im Brutto-/Nettoeinkommen-Diagramm in Abbildung 20 dargestellt. Dazu wird ein konstanter Lohnsatz $\mathrm{w}<\mathrm{W}^{*}$ angenommen und die Arbeitszeit variiert. Bei einer maximalen Arbeitszeit T (z.B. 24 Stunden/Tag) wird das maximale Bruttoeinkommen Y' erzielt.

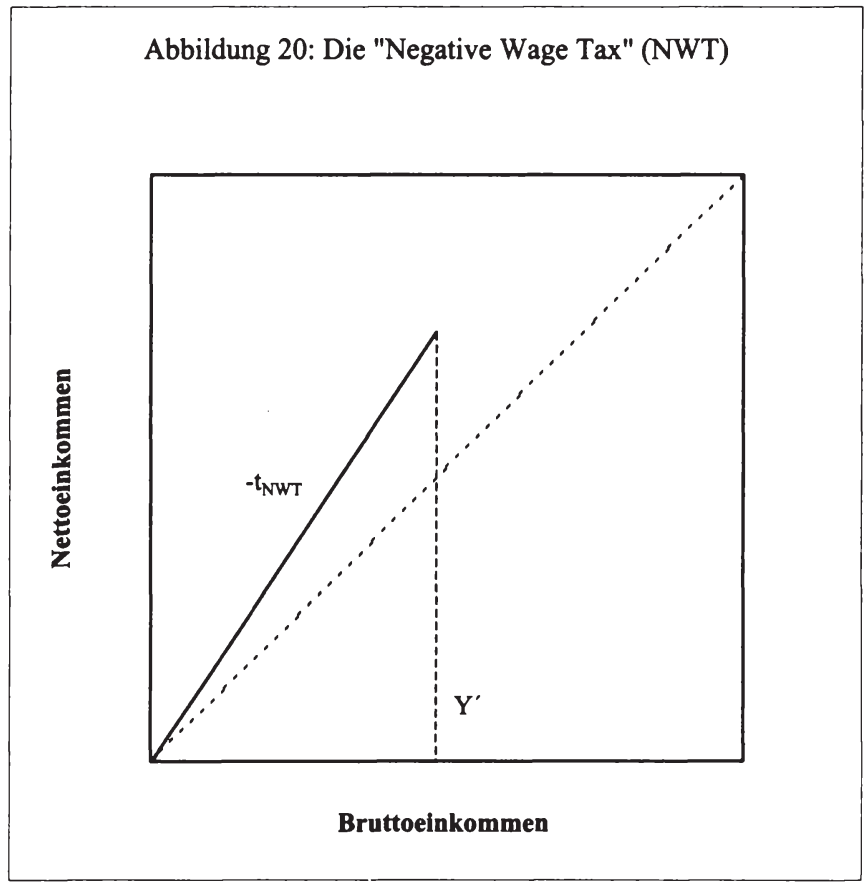

Unter den getroffenen Annahmen ist die NWT auf den ersten Blick identisch mit der „phase-in region“ des EITC - die Nettoeinkommensgerade beginnt im Ursprung, das Nettoeinkommen des NWT-Empfängers steigt gemäß dem negativen Grenzsteuersatz (- $\left.t_{\mathrm{NWT}}\right)$. Abbildung 20 ist aufschlußreich, weil sie 
zum einen deutlich macht, daß die NWT ein in-work benefit ist - nur im Falle eines positiven Bruttoeinkommens wird ein Transfer gewährt. Zum anderen wird der konstante negative Grenzsteuersatz veranschaulicht.

In der Literatur wird der wesentliche Vorteil der NWT gegenüber der Negativen Einkommensteuer im Einkommen-Freizeit-Modell gezeigt (vgl. Kesselman 1969, Boadway/Wildasin 1984, Mackscheidt 1993, Vierling 1996). Auch hier muß - analog zur obigen Darstellung - ein konstanter Lohnsatz w angenommen und die Arbeitszeit variiert werden, wie Abbildung 21 verdeutlicht.

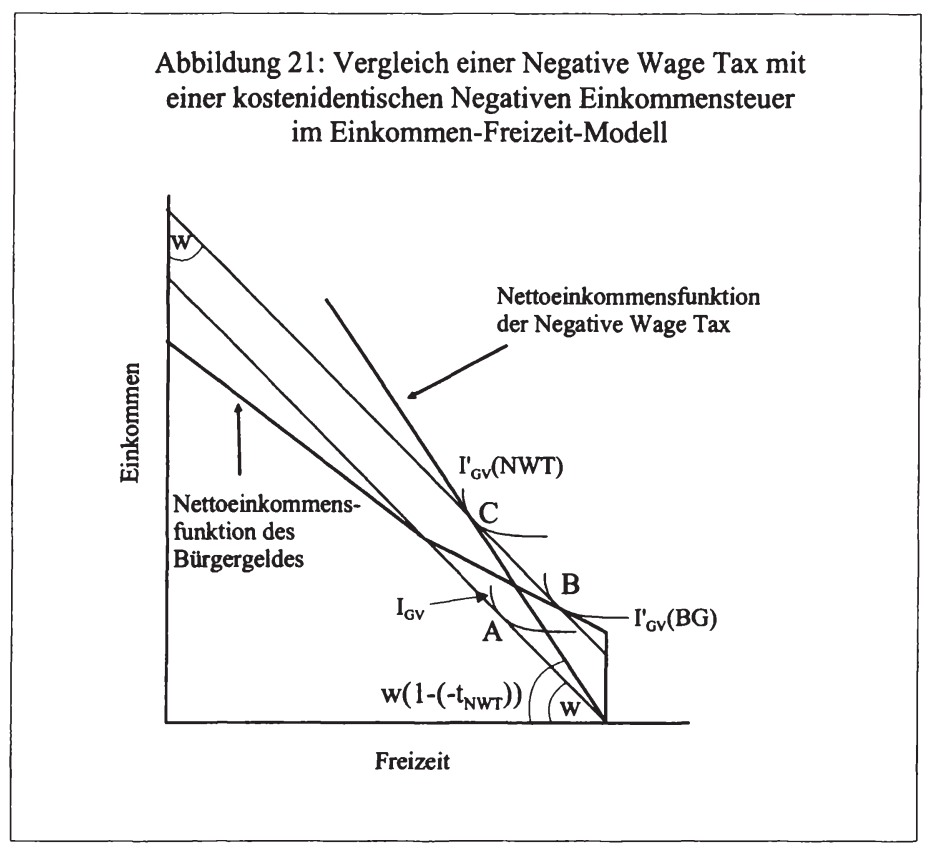

Verglichen werden die Effizienzwirkungen der Einführung einer kostenidentischen Negativen Einkommensteuer mit einer NWT im Vergleich zu einer Situation ohne Grundsicherung. Die Referenzsituation ist demnach nicht der Status quo in Deutschland. Ausgangspunkt sei die Optimallösung für einen Geringverdiener in Punkt A. Die Einführung einer NWT im Vergleich zu einer Negativen Einkommensteuer führt in zwei wesentlichen Punkten zu unterschiedlichen Ergebnissen. Zum einen wirkt der Substitutionseffekt bei der Einführung einer Negativen Einkommensteuer in Richtung weniger Ar- 
beitsangebot, weil der Nettolohnsatz auf w(1- $\left.\mathrm{t}_{\mathrm{BG}}\right)$ sinkt - die neue Optimallösung liegt beim Tangentialpunkt der Indifferenzkurve des Geringverdieners $I_{G V}(B G)$ bei Punkt B (vgl. Kapitel 3.2.2.1). Dagegen wirkt der Substitutionseffekt bei der Einführung einer NWT in Richtung auf ein höheres Arbeitsangebot, weil der Nettolohnsatz auf w(1-(-t $\left.\left.t_{\mathrm{NWT}}\right)\right)$ steigt. Unter der Annahme einer positiv geneigten Arbeitsangebotskurve erhöht sich dann das Arbeitsangebot, weil der Substitutionseffekt den Einkommenseffekt überkompensiert - die neue Optimallösung ist beim Tangentialpunkt der Indifferenzkurve des Geringverdieners $\mathrm{I}_{\mathrm{GV}}(\mathrm{NWT})$ in Punkt $\mathrm{C}$. Zum anderen entfällt bei einer NWT der pauschaltransferbedingte Einkommenseffekt, der bei der Einführung einer Negativen Einkommensteuer in Richtung weniger Arbeitsangebot wirkt (vgl. Kapitel 3.2.2.1). Aus diesen Gründen ist das Arbeitsangebot einer kostenidentischen NWT im Vergleich zu einer Negativen Einkommensteuer höher.

Der Wohlfahrtseffekt ist jedoch nicht eindeutig - die Indifferenzkurve $I_{G V}(N W T)$ muß nicht unbedingt oberhalb der Indifferenzkurve $I_{G V}(B G)$ liegen. Vierling (1996) kommt nach Berücksichtigung aller denkbaren Präferenzen zu dem Ergebnis, daß „weder für die Lohnsubvention noch für die negative Einkommensteuer eine systematische Wohlfahrtsüberlegenheit festgestellt werden kann" (Vierling 1996, S. 172).

Die NWT wird in der Literatur als zeitlich unbefristete Lohnsatzsubvention für Niedriglohnbezieher bei Existenz einer Grundsicherung diskutiert. Damit könnten typische Niedrigeinkommensbezieher, die nicht bedürftig sind, z.B. finanziell abgesicherte Schüler, Studenten und Hausfrauen, die NWT als "windfall profit" mitnehmen. Als Reaktion auf diese Kritik von Jerger/Spermann (1997a) hat Vierling (1997, S. 654) eine Begrenzung der NWT auf bedürftige Niedriglohnbezieher vorgeschlagen. Die Einführung einer zeitlich unbefristeten, zielgruppenorientierten NWT beseitigt demnach die Armutsfalle dauerhaft.

Wenn eine NWT als zeitlich unbefristetes Sonderprogramm für bedürftige Niedriglohnbezieher eingeführt würde, gäbe es jedoch ein gravierendes $\mathrm{Ge}$ rechtigkeitsproblem und Fehlanreize. Nicht-bedürftige Niedriglohnbezieher würden dauerhaft $z$.B. fünf $\mathrm{DM} /$ Stunde weniger als bedürftige Niedriglohnbezieher verdienen. Hinzu kommt, daß für bisher nicht bedürftige Niedriglohnbezieher der Anreiz besteht, selbst bedürftig zu werden, um die NWT „mitzunehmen“. Der Anreiz für bedürftige Niedriglohnbezieher, bedürftig zu bleiben, ist ebenfalls hoch. Schon aus diesen Gründen erscheint die Einführung einer NWT als Sonderprogramm nicht realistisch.

Wenn eine NWT in das deutsche Sozialhilferecht integriert würde, so stellt sich das Gerechtigkeitsproblem und die geschilderte Anpassungsreaktion der Niedriglohnbezieher nicht. Statt dessen würden die Ansprüche bisheriger Hilfeempfänger auf ergänzende Sozialhilfe zunehmen und in großem Umfang neue Anspruchsberechtigte hinzukommen. Die Mitnahmeeffekte sind - analog zum EITC - aufgrund des negativen Grenzsteuersatzes auf Zusatzverdienste 
von Hilfeempfängern zwangsläufig sehr hoch. Hinzu kommt das Problem des overreporting des Stundenlohnsatzes durch die NWT-Bezieher. Auch hier lassen sich nur auf der Basis von Simulationsstudien Aussagen über Beschäftigungswirkungen und fiskalische Effekte treffen.

\subsubsection{Kombi-Einkommensmodelle}

Die Bundesvereinigung der Deutschen Arbeitgeberverbände (BDA) hat Mitte 1997 ein sogenanntes „Kombi-Einkommensmodell“" vorgelegt, das in allen politischen Parteien intensiv diskutiert wird (vgl. Bundesvereinigung der Deutschen Arbeitgeberverbände 1997). Der Begriff Kombi-Einkommen bringt zum Ausdruck, daß erwerbstätige Sozialhilfeempfänger eine Kombination aus Lohn und Sozialhilfe erhalten sollen. Ein Kombi-Einkommen gibt es deshalb im Rahmen des Sozialhilfegesetzes bereits: Sozialhilfe kann ergänzend zum Marktlohn gezahlt werden. Ziel des Vorschlags ist es, einen Niedriglohnsektor in Deutschland zu schaffen - über diesen Weg sollen neue Arbeitsplätze geschaffen werden. Niedrig entlohnte Arbeit soll für Hilfeempfänger durch eine schrittweise Reform des Sozialhilfesystems attraktiver werden. Ausgangspunkt ist ein nach Ansicht des Arbeitgeberverbandes unausgeschöpftes Beschäftigungspotential bei einfachen Tätigkeiten. Die Bundesregierung hat im Dezember 1997 in einem Verordnungsentwurf ein eigenes Kombi-Einkommensmodells vorgelegt (vgl. Deutscher Bundesrat 1997). Die beiden Kombi-Einkommensmodelle zeichnen sich durch im Vergleich zum Status quo großzügigere Sockelbeträge für Familien und geringere Anrechnungssätze für Zusatzverdienste aus. In Abbildung 22 wird exemplarisch das Kombi-Einkommensmodell der CDU/CSU-FDP-Koalition für Verheiratete mit zwei Kindern in einem Brutto-/Nettoeinkommen-Diagramm dargestellt:

Der Sockelbetrag beträgt für diesen Haushaltstyp bei einer sozialversicherungspflichtigen Beschäftigung $30 \%$ vom Regelsatz (bei geringfügigen Beschäftigungen: $15 \%$ vom Regelsatz) zuzüglich $4 \%$ je Kind. Nimmt man ein Sozialhilfeniveau von 3000 DM/Monat und einen monatlichen Regelsatz von 540 DM für das Jahr 1997 an, dann beträgt der anrechnungsfreie Sockelbetrag $205 \mathrm{DM} /$ Monat $\left(\mathrm{t}_{1}=0 \%\right)$. Der Steigerungsbetrag beläuft sich jedoch nur auf $10 \%$ - im Status quo beträgt er $15 \%$ (vgl. Kapitel 2.5.2) -, so daß der Grenzsteuersatz auf Zusatzverdienste $t_{2}$ im Bruttoeinkommensbereich zwischen 205 und 2800 DM/Monat bei $90 \%$ liegt. Die Armutsfalle mit Vollanrechnung der Zusatzverdienste liegt im Bruttoeinkommensbereich zwischen 2800 und 4178 $\mathrm{DM} /$ Monat $\left(\mathrm{t}_{3}=100 \%\right)$.

Trabert et al. (1998) zeigen in einem Vergleich der Absetzungsbeträge für erwerbstätige Sozialhilfeempfänger, daß durch den Vorschlag der CDU/CSUFDP-Koalition die Zuverdienstmöglichkeiten für fast alle Haushaltstypen verbessert werden; lediglich Alleinstehende stellen sich im Vergleich zum Status quo bei der Aufnahme geringfügiger Beschäftigung schlechter. 
Trabert et al. (1998) schätzen die Beschäftigungswirkungen und fiskalischen Effekte der Einführung des Kombi-Einkommensmodells der CDU/CSU-FDPKoalition in Sachsen-Anhalt mit Hilfe eines mikroökonometrischen Modells. Sie verwenden Panel-Daten des Arbeitsmarktmonitors Sachsen-Anhalt von 1990-97 (7121 Individualdatensätze) in Kombination mit aufbereiteten Daten des Sozioökonomischen Panels (SOEP). In einer Tobit-Schätzung finden sie im Einklang mit der Literatur (vgl. Kapitel 3.2.2.1) - einen signifikanten Einfluß des Lohnsatzes auf den Umfang des Arbeitsangebots von Männern und Frauen. Für die empirische Analyse der Arbeitsnachfrage schätzen sie die Lohnelastizität der Arbeitsnachfrage im Verarbeitenden Gewerbe Ostdeutschlands. Die Regression weist eine hohe negative Lohnelastizität aus, die als Ausdruck eines größeren Anteils arbeitsintensiver Fertigung interpretiert wird; der Dienstleistungssektor wird aufgrund fehlender Daten nicht betrachtet.

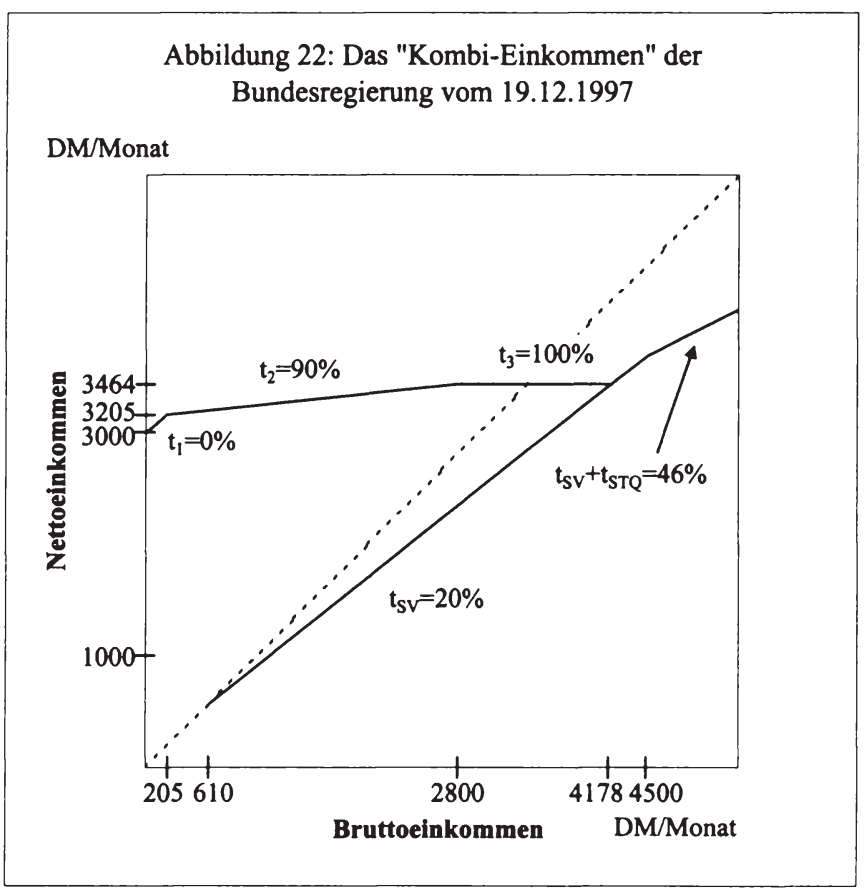

Trabert et al. (1998) unterscheiden drei Gruppen. Für die Gruppe der arbeitslosen Sozialhilfeempfänger ergeben sich rein rechnerisch 540 Personen, die zusätzlich Arbeit anbieten. Bei Berücksichtigung der geschätzten Lohnelastizität der Arbeitsnachfrage finden ungefähr 120 Personen eine Stelle im verarbeitenden Gewerbe, so daß Einsparungen von etwa 1,5 Millionen DM im Jahr 
zu erwarten sind. Für die Gruppe der erwerbstätigen Sozialhilfeempfänger ergibt sich aus der Summe der Mehransprüche an ergänzender Sozialhilfe gegenüber dem Status quo eine Mehrbelastung von etwa zwei Millionen DM im Jahr. Für die Gruppe der „Neueintritte“ bisher nicht anspruchsberechtigter Erwerbstätiger berechnen die Autoren Mehrbelastungen von 4,3 Millionen DM im Jahr. Ihr Fazit: Der Vorschlag der CDU/CSU-FDP-Koalition ist zwar mit positiven Beschäftigungswirkungen verbunden, doch übersteigen die Mehrausgaben durch Mitnahmeeffekte die zu erwartenden Einsparungen. Diese Berechnungen erfüllen jedoch nicht die Anforderungen an Simulationsstudien, wie sie Duncan/Weeks (1997) für Großbritannien vorgelegt haben. Sie können deshalb nur als erste Annäherung verstanden werden.

Unberücksichtigt bleibt auch, daß die Mehrausgaben und Einsparungen asymmetrisch verteilt sind. Zusatzausgaben fallen bei den Kommunen an, Mehreinnahmen aus der Einkommensteuer verteilen sich auf Bund, Länder und Kommunen, und Mehreinnahmen aus abgeführten Abgaben verteilen sich auf die Sozialversicherungsträger.

Ähnliche Ergebnisse wie bei Trabert et al. (1998) finden sich bei Saunders $(1995 a, b)$ für das 1994 von der australischen Regierung vorgeschlagene Kombi-Einkommensmodell. Das Reformvorhaben der australischen Regierung sieht einen im Vergleich zum Status quo geringeren anrechnungsfreien Sockelbetrag und einen $70 \%$-igen Anrechnungssatz auf Zusatzverdienste in einem bestimmten Bruttoeinkommensbereich vor. Saunders legt jedoch keine eigenen Berechnungen $\mathrm{zu}$ den Beschäftigungswirkungen vor, sondern verweist lediglich auf die Schätzungen der Regierung - mit dem Hinweis, daß deren Basis unklar sei (vgl. Saunders 1995a, S. 58). Dementsprechend sind auch seine Überlegungen zu den fiskalischen Effekten den gleichen Kritikpunkten wie die Bürgergeld-Kostenschätzungen ausgesetzt (vgl. Kapitel 3.2.2.2).

\subsection{Lohnsubventionen an Arbeitgeber}

\subsubsection{Traditionelle Lohnsubventionen}

Traditionelle Lohnsubventionen sind Zuschüsse an Arbeitgeber, die häufig vor Wahlen gewährt werden und mit zusätzlichen Staatsausgaben verbunden sind. Ein von Arbeitgebern häufig nachgefragtes Zuschußprogramm ist die „Aktion Beschäftigungshilfen für Langzeitarbeitslose 1989-1994“. Dieses Programm wurde vor der Bundestagswahl 1994 um weitere fünf Jahre verlängert. Im Rahmen der „Aktion Beschäftigungshilfen für Langzeitarbeitslose 1995-1999“ sind auf ein Jahr befristete Lohnkostenzuschüsse an Arbeitgeber bis zur Höhe von $80 \%$ des Arbeitsentgelts im ersten Halbjahr vorgesehen. 
Für den Förderzeitraum stehen Bundesmittel in Höhe von drei Milliarden DM zur Verfügung (vgl. Bundesanstalt für Arbeit 1997).

Die Leistungen im Rahmen dieses Zuschußprogramms sind sehr großzügig, so daß Arbeitgeber hohe Anreize haben, Langzeitarbeitslose einzustellen. Dementsprechend wurden bis Ende 199683.400 Bewilligungen für Lohnkostenzuschüsse ausgesprochen (vgl. Bundesanstalt für Arbeit 1997, S. 22). Diese Zahlen werden von der Bundesregierung als Erfolg gewertet, obwohl wissenschaftliche Programmevaluationen ausstehen. Auf fehlende detaillierte Untersuchungen zur Verbleibswahrscheinlichkeit bezuschußter Langzeitarbeitsloser auf dem privaten Arbeitsmarkt wird zwar in der Literatur hingewiesen (vgl. Bohlen 1993, S. 270) - sie liegen jedoch nach dem Kenntnisstand des Autors bis heute genauso wenig vor wie fiskalische Kosten-NutzenAnalysen für den Gesamtstaat.

Weitere bedeutende Lohnsubventionsprogramme in Deutschland sind die Lohnkostenzuschüsse für ältere Arbeitnehmer nach $\S 97$ AFG, die Einarbeitungszuschüsse nach $\S 49 \mathrm{AFG}$, die Eingliederungszuschüsse nach $\S 54 \mathrm{AFG}$ und die produktiven Lohnkostenzuschüsse nach $\S 249 \mathrm{~h}$ AFG (Ostdeutschland) oder nach $\S 242 \mathrm{~s} \mathrm{AFG}$ (Westdeutschland). Empirische Untersuchungen zu Maßnahme- und Trägerstrukturen liegen lediglich für die Einarbeitungszuschüsse (vgl. Blaschke et al. 1995) und die produktiven Lohnkostenzuschüsse (vgl. Stark/Wolfinger 1995) vor. Systematische, dynamische Untersuchungen $\mathrm{zu}$ den langfristigen Beschäftigungswirkungen und fiskalischen Effekten verschiedener Lohnsubventionsprogramme sind dem Autor nicht bekannt (vgl. OECD 1993, S. 63f. für einen Überblick zu internationalen Studien). Detailliertere Wirkungsanalysen liegen jedoch für die USA vor.

Der „Targeted Jobs Tax Credit“ (TJTC) ist das bedeutendste Programm für Lohnkostenzuschüsse an Arbeitgeber in den USA. Der TJTC wurde 1978 als Ersatz für sein Vorläufermodell „New Jobs Tax Credit“ (NJTC) (vgl. Perloff/Wachter 1979) eingeführt und existierte mit geringfügigen Unterbrechungen bis 1994; derzeit ist unklar, ob der Kongreß das Programm verlängern wird (Stand: Juli 1996). Lohnsubventionen an Arbeitgeber im Sinne des NJTC und TJTC wurden von Haveman (1996a) vorgeschlagen, um schlecht qualifizierte Arbeitnehmer für Firmen attraktiv zu machen.

Die TJTC-Zielgruppe sind ökonomisch benachteiligte Jugendliche im Alter zwischen 18 und 24 Jahren. Der Lohnkostenzuschuß wird in Form eines Gutscheins (=Voucher) gewährt, der vom Programmteilnehmer beim Arbeitgeber vorgelegt werden kann - der Arbeitgeber löst den Gutschein dann bei der Ausgabestelle „Employment Service“ ein. Lohnkostenzuschüsse wurden ursprünglich in Höhe von $50 \%$ im ersten Jahr und in Höhe von $25 \%$ im zweiten Jahr bis zu einem Bruttoeinkommen von 6000 \$/Jahr gewährt. Damit wurde die Förderung von Niedriglohn- und Teilzeitbeschäftigungen weitgehend sichergestellt (vgl. Katz 1996). 
Das TJTC-Programm läßt sich exemplarisch für Arbeitgeber-Lohnsubventionen im Brutto-/Nettoeinkommen-Diagramm in Abbildung 23 darstellen. Dabei ist folgendes zu beachten: Bei den bisherigen Schaubildern war auf der Abszisse das Bruttoeinkommen des Arbeitnehmers abgetragen, das identisch mit den Lohnkosten für die Arbeitgeber war. Die Lohnsubvention treibt einen Keil zwischen diese beiden Größen. In Abbildung 23 sind an der Abszisse die von den Unternehmen getragenen Lohnkosten (=Bruttoeinkommen ohne $\mathrm{Zu}$ schuß) pro Jahr abgetragen.

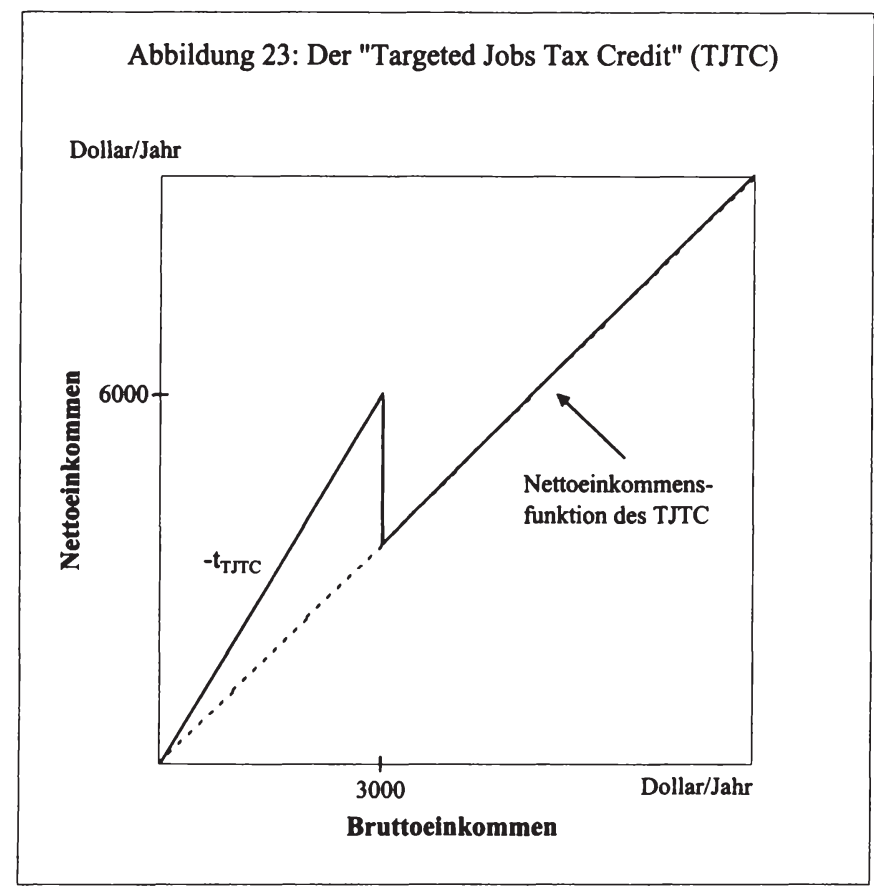

Übernimmt man die ursprünglichen Zahlenwerte für den TJTC im ersten Jahr und abstrahiert von Steuer- und Abgabenzahlungen, so steigt die Nettoeinkommensgerade mit der Steigung $\left(1-\left(-t_{\text {TJTC }}\right)=1,5\right)$ bis zu einem Nettoeinkommen pro Jahr von $6000 \$$ kontinuierlich an. Ein Zahlenbeispiel: Ein ökonomisch benachteiligter Jugendlicher bekommt den Betrag von $6000 \$ / J a h r$ für seine Teilzeittätigkeit in einem Dienstleistungsunternehmen von seinem Arbeitgeber ausgezahlt - sein Nettoeinkommen beträgt demnach $6000 \$ / J a h r$. Er hat diesen Job jedoch nur deshalb erhalten, weil er seinem Arbeitgeber einen Gutschein zur Einlösung geben konnte - der Wert des Gutscheins beträgt $50 \%$ des ausgezahlten Lohns, also $3000 \$ / \mathrm{Jahr}$, und wird durch den vertikalen Abstand zwischen der Nettoeinkommensgeraden und der $45^{\circ}$-Linie ge- 
messen. Die an der Abszisse abgetragenen tatsächlichen Kosten für seinen Arbeitgeber sind nach Einlösung des Gutscheins lediglich 3000 \$/Jahr.

Übersteigt das Nettoeinkommen den Schwellenwert von $6000 \$ / \mathrm{Jahr}$, entfällt der Lohnkostenzuschuß, so daß die Nettoeinkommensgerade mit der $45^{\circ}$-Linie zusammenfällt - wenn Steuern und Abgaben annahmegemäß nicht betrachtet werden.

Die Förderbedingungen des TJTC wurden in den letzten Jahren verschärft. Mitte der achtziger Jahre entfiel der Lohnkostenzuschuß für das zweite Jahr, und der Zuschußsatz für das erste Jahr wurde auf $40 \%$ gekürzt. Seit 1989 haben nur noch Jugendliche zwischen 18 und 22 Jahren Anspruch auf den TJTC. Der reale Wert des maximalen Zuschusses sank im Zeitablauf um 75 \%. Dementsprechend nahm die Zahl der TJTC-Geförderten von 622.000 im Jahre 1985 auf 364.000 im Jahre 1992 ab. Auch sanken die TJTC-Ausgaben von 500 Millionen \$ (in Dollarwerten von 1991) Mitte der achtziger Jahre auf 245 Millionen \$ im Jahre 1991. Der durchschnittliche TJTC-Arbeiter erhielt einen Stundenlohn von fünf Dollar und arbeitete wöchentlich knapp 30 Stunden im Jahre 1992. Die durchschnittliche Dauer eines TJTC-Jobs betrug Anfang der neunziger Jahre sechs Monate (vgl. Katz 1996).

Katz (1996) untersucht die Beschäftigungswirkungen des TJTC für benachteiligte Jugendliche mit Hilfe der Differences-in-Differences-in-Differences (DDD) Schätzmethode. Er nutzt die Begrenzung des TJTC auf Jugendliche zwischen 18 und 22 Jahren im Jahr 1989, um die Beschäftigung benachteiligter Jugendlicher zwischen 23 und 24 Jahren vor und nach der Änderung der Anspruchsberechtigung zu vergleichen. Bei diesem Vergleich bleiben jedoch andere Einflußfaktoren auf die Beschäftigung wie die Konjunkturentwicklung unberücksichtigt. Deshalb ist es zweckmäßig, die Unterschiede in der Beschäftigung vor und nach Änderung der Anspruchsberechtigung zwischen benachteiligten und anderen Jugendlichen im Alter zwischen 23 und 24 Jahren zu vergleichen (differences-in-differences-Schätzung für die Versuchsgruppe). Dabei werden jedoch Einflußfaktoren auf die Beschäftigung der benachteiligten und nicht-benachteiligten Jugendlichen vernachlässigt, die nicht auf die Gewährung des TJTC zurückzuführen sind. Deshalb werden zwei „Placebo-Gruppen“ gebildet, die beide nicht von der Änderung der Anspruchsberechtigung betroffen waren: die 18-22-jährigen benachteiligten Jugendlichen, die im gesamten Untersuchungszeitraum anspruchsberechtigt waren, sowie die 25-29-jährigen benachteiligten Jugendlichen, die nie anspruchsberechtigt waren. Die Veränderung der Beschäftigung der beiden Placebo-Gruppen relativ zu nicht-benachteiligten Jugendlichen des gleichen Alters ergibt eine Schätzung der nicht auf den TJTC zurückzuführenden Einflußfaktoren auf die Beschäftigung der benachteiligten und nicht-benachteiligten Jugendlichen (difference-in-differences Schätzung für die Placebo-Gruppen). Zieht man die difference-in-differences Schätzergebnisse für die Placebo-Gruppen von den difference-in-differences Schätzergebnissen für die Versuchsgruppe $a b$, dann 
ergibt sich der Beschäftigungseffekt des TJTC für die Gruppe der 23-24jährigen benachteiligten Jugendlichen. Schließlich ist noch eine Bereinigung um die Veränderung der experimentellen Gruppe und der Kontrollgruppen (nicht benachteiligte Jugendliche) nötig. Katz (1996) kommt auf der Basis dieser Schätzmethode zum Ergebnis, daß der TJTC geringe positive Beschäftigungseffekte für die benachteiligten Jugendlichen im Untersuchungszeitraum mit sich brachte. Die Kosten für jeden zusätzlichen Job betrugen nach dieser Schätzung etwa 1500 \$ (Basis 1991).

Auffällig ist, daß die Inanspruchnahme (participation rate=take-up rate) des TJTC sehr gering ist. In den achtziger Jahren wurde von den Arbeitgebern für nur etwa zehn Prozent der anspruchsberechtigten Jugendlichen eine Steuergutschrift beantragt (vgl. Bishop/Kang 1991 u. Katz 1996, S. 16). Zwei Gründe gelten als Erklärung dieses Phänomens. Zum einen stellen Informationskosten das Haupthindernis für Arbeitgeber dar: Der mit der Beantragung von Lohnsubventionen verbundene „Papierkrieg“ erhöht die Einstellungskosten für TJTC-Anspruchsberechtigte. Dementsprechend wurde der TJTC vorwiegend von großen Einzelhandels- und Dienstleistungsfirmen in Anspruch genommen, die sogar Personalberatungen mit der Auswahl der subventionierten Arbeitgeber beauftragten (vgl. Lorenz 1995). Zum anderen erklärt sich die geringe Inanspruchnahme des TJTC durch das geringe Interesse der Arbeitnehmer, mit Hilfe von Lohnkostenzuschüssen eingestellt zu werden. Ausschlaggebend könnte die mit der Anspruchsberechtigung auf Lohnsubventionen verbundene Stigmatisierung der Stellensucher sein. Darauf deuten die Ergebnisse eines kontrollierten Experiments in Dayton, Ohio, in den Jahren 1980-81 hin (vgl. Burtless 1985). TJTC-Anspruchsberechtigte wurden zufällig in drei Gruppen eingeteilt. Die erste Gruppe erhielt Gutscheine mit dem Anspruch auf Barauszahlung an potentielle Arbeitgeber, die zweite Gruppe erhielt Gutscheine mit dem Anspruch auf eine Steuergutschrift im Rahmen des TJTC; die Steuergutschrift ist nur bei entsprechend hoher Steuerschuld der Firmen mit einer Barauszahlung identisch, für Firmen ohne Steuerschuld ist eine Steuergutschrift wertlos. Und die dritte Gruppe erhielt keine Lohnkostenzuschüsse. Das überraschende Ergebnis: Arbeitssuchende mit Gutscheinen fanden mit signifikant geringerer Wahrscheinlichkeit einen Job als Arbeitssuchende ohne entsprechende Lohnsubvention! Die Ergebnisse des Experiments von Dayton wurden als Hinweis auf Stigmatisierungseffekte von Lohnsubventionen interpretiert, die die Beschäftigungschancen der Zielgruppe verschlechtern. Ein weiteres Ergebnis des Daytona-Experiments scheint die Ergebnisse von Bishop/Kang (1991) zu unterstützen: Die Arbeitgeber, die Arbeitslose mit Anspruch auf einen Gutschein eingestellt hatten, interessierten sich kaum für die ihnen zustehenden Lohnsubventionen. Nur für gut ein Viertel der eingestellten Arbeitnehmer lösten die Arbeitgeber die Gutscheine ein. Das könnte darauf zurückzuführen sein, daß den Arbeitgebern die Transaktionskosten zu hoch waren. Eine andere Erklärung könnte sein, daß die Ar- 
beitssuchenden ihre Anspruchsberechtigung verschwiegen - dann hätten sie potentielle Stigma-Effekte antizipiert. Das experimentelle Design sah jedoch keine Befragung der Teilnehmer zu dieser Frage vor, so daß lediglich spekuliert werden kann.

Die Beschäftigungswirkungen und fiskalischen Effekte von Lohnsubventionen können darüberhinaus durch Mitnahme-, Substitutions- und Verdrängungseffekte beeinträchtigt werden (vgl. OECD 1993, Bellmann/Jackman 1996). Mitnahmeeffekte (deadweight) entstehen dann, wenn auch ohne die Lohnsubvention ein Beschäftigungsverhältnis entstanden wäre. Substitutionseffekte ergeben sich, wenn subventionierte Arbeitnehmer nicht-subventionierte Arbeitnehmer ersetzen, so daß der Beschäftigungsstand in einer Firma nicht zunimmt (sogenannter „Drehtüreffekt"). Verdrängungseffekte (displacement) treten dann auf, wenn reguläre Beschäftigung an anderer Stelle in der Ökonomie verdrängt wird (crowding-out). Das ist zum Beispiel dann möglich, wenn eine Firma dank subventionierter Arbeitnehmer über geringere Güterpreise einen größeren Marktanteil erzielen kann - mit der Konsequenz, daß Firmen mit nicht-subventionierten Arbeitnehmern Marktanteile verlieren und Beschäftigte entlassen müssen.

Lohnsubventionen sind nach einer Auswertung bestehender Untersuchungen mit hohen Mitnahmeeffekten verbunden - sie betragen bis zu $79 \%$ (vgl. OECD 1993, S. 63f.). Lorenz (1995) weist auf den Einfluß politischer Interessengruppen bei der Gestaltung von Lohnsubventionsprogrammen hin. Mit Hilfe einer detaillierten Untersuchung der Veränderungen in der Implementierung des TJTC zwischen 1979 und 1990 zeigt er die Einflußnahme von Unternehmen auf den politischen Prozeß. Sein Fazit: Interessengruppen verzerrten während der Programmimplementierung kontinuierlich die Struktur des TJTC, so daß er von Unternehmen mit großer Nachfrage nach Geringverdienern lediglich mitgenommen wurde. Das ursprüngliche Ziel des TJTC wurde verfehlt.

Lohnsubventionen an Arbeitgeber sind aber auch mit hohen Substitutionsund Verdrängungseffekten verbunden - sie betragen bis zu $89 \%$ (vgl. OECD 1993, S. 63f., de Koning 1993). Eine hundertprozentige Substitution und Verdrängung bestehender Arbeitsverhältnisse durch subventionierte Arbeitsverhältnisse setzt eine völlig unelastische Arbeitsnachfrage voraus. Die Arbeitsnachfrageelastizität ist jedoch negativ - sowohl in Deutschland (vgl. Trabert et al. 1998) als auch in den USA (vgl. Katz 1996, S. 10) -, so daß positive Beschäftigungseffekte zu erwarten sind.

Ein weiteres, mit der Gewährung von zeitlich befristeten Lohnsubventionen verbundenes Problem sind sogenannte Rotationseffekte (vgl. Bohlen 1993, S. 275). So könnten Lohnsubventionen lediglich vorübergehend zu positiven Beschäftigungseffekten führen, wenn nach Ablauf des Subventionszeitraums die geförderten Arbeitnehmer entlassen werden. $\mathrm{Zu}$ möglichen Rotationseffekten 
liegen nach dem Kenntnisstand des Autors jedoch keine empirischen Untersuchungen vor.

Die Armutsfalle wird durch die vorgestellten Arbeitgeber-Lohnsubventionsmodelle für den Zeitraum der gewährten Lohnsubventionen beseitigt.

\subsubsection{Stundenlohnsubventionen}

Lohnsubventionen für niedrige Stundenlöhne werden in Deutschland von Scharpf (1994) und in den USA von Phelps (1997) vorgeschlagen. Scharpf (1994a,b) plädiert für „Einkommenshilfen für niedrige Erwerbseinkommen“. Kern seines Vorschlages ist ein mit steigendem Stundenlohn abnehmender Lohnkostenzuschuß, der in einem vom Staat zu definierenden NiedriglohnBereich zusätzlich zum Arbeitseinkommen bezahlt werden soll. Die Bemessungsgrundlage Stundenlohn wählt er, um Teilzeitarbeit nicht besonders zu privilegieren. Die Einkommenshilfe soll an die Arbeitgeber fließen. Der Gesamtbetrag aus Einkommenshilfe und Arbeitseinkommen ist steuer- und sozialabgabenpflichtig. Der Arbeitgeber soll Steuern und Sozialabgaben abführen und das Nettoeinkommen an die Niedriglohn-Arbeitnehmer auszahlen. Das Modell von Scharpf läßt sich anhand eines Zahlenbeispiels im Brutto-/ Nettoeinkommen-Diagramm in Abbildung 24 illustrieren. Der Staat legt beispielsweise fest, daß Stundenlöhne zwischen 5 und $15 \mathrm{DM}$ bezuschußt werden sollen. Die Einkommenshilfe könnte zum Beispiel bei einem Stundenlohn von $5 \mathrm{DM}$ ebenfalls $5 \mathrm{DM}$ betragen, so daß sich ein effektiver Stundenlohn von 10 DM ergibt, der nie unterschritten wird. Ein Mindeststundenlohn von 10 DM ist nach Scharpf sinnvoll, weil er dem niedrigsten Tariflohn (1993) entspricht. Die Einkommenshilfen stellen sicher, daß sich mit einem VollzeitNiedriglohn-Job ein Nettoeinkommen über dem Sozialhilfeniveau erzielen läßt. In diesem Zahlenbeispiel erbringt ein Vollzeitjob mit einem 5 DM-Stundenlohn ein Bruttoeinkommen ohne Zuschuß von 800 DM im Monat und ein Bruttoeinkommen mit Zuschuß von 1600 DM im Monat.' Der Gesamtbetrag aus Arbeitseinkommen und Einkommenshilfe von 1600 DM im Monat ist jedoch steuer- und abgabenpflichtig, so daß ein Nettoeinkommen von 1444 DM im Monat verbleibt. Der Einkommenszuschuß sollte nach Scharpf degressiv ausgestaltet sein, also bis zu einem Stundenlohn von 15 DM kontinuierlich abnehmen.

Für Bruttoeinkommen unter $800 \mathrm{DM}$ im Monat sind das Bruttoeinkommen und die Lohnkosten des Arbeitgebers weiterhin identisch: Es gilt der Status quo, der in Abbildung 24 aus Vereinfachungsgründen ohne Absetzbetrag modelliert wurde. Der nicht horizontale Teil der Nettoeinkommensfunktion des Scharpf-Modells beginnt bei Lohnkosten von 800 DM und einem Nettoeinkommen von 1444 DM im Monat; das Bruttoeinkommen mit Zuschuß beträgt

Zur Berechnung des Monatseinkommens wurde eine 40-Stunden-Woche zugrundegelegt und von Urlaubs- und Feiertagen sowie von Sozialabgaben abstrahiert. 
trägt $1600 \mathrm{DM}$ (800 DM Lohnsubvention und $800 \mathrm{DM}$ Lohnkosten) und unterliegt der Steuerpflicht. Die Nettoeinkommensfunktion mündet bei einem Bruttoeinkommen von 2400 DM in die Nettoeinkommensgerade des Status quo. Das zuschußfreie Bruttoeinkommen von $2400 \mathrm{DM}$ ergibt sich bei einem Vollzeitjob, bei dem ein Stundenlohn von 15 DM bezahlt wird; das daraus resultierende Nettoeinkommen beträgt 2036 DM im Monat. Daraus ergibt sich ein „Scharpf-Grenzsteuersatz" $t_{\mathrm{sCH}}$ auf Zusatzverdienste von $63 \%$. Das Problem der Armutsfalle wird demnach dauerhaft abgemildert.

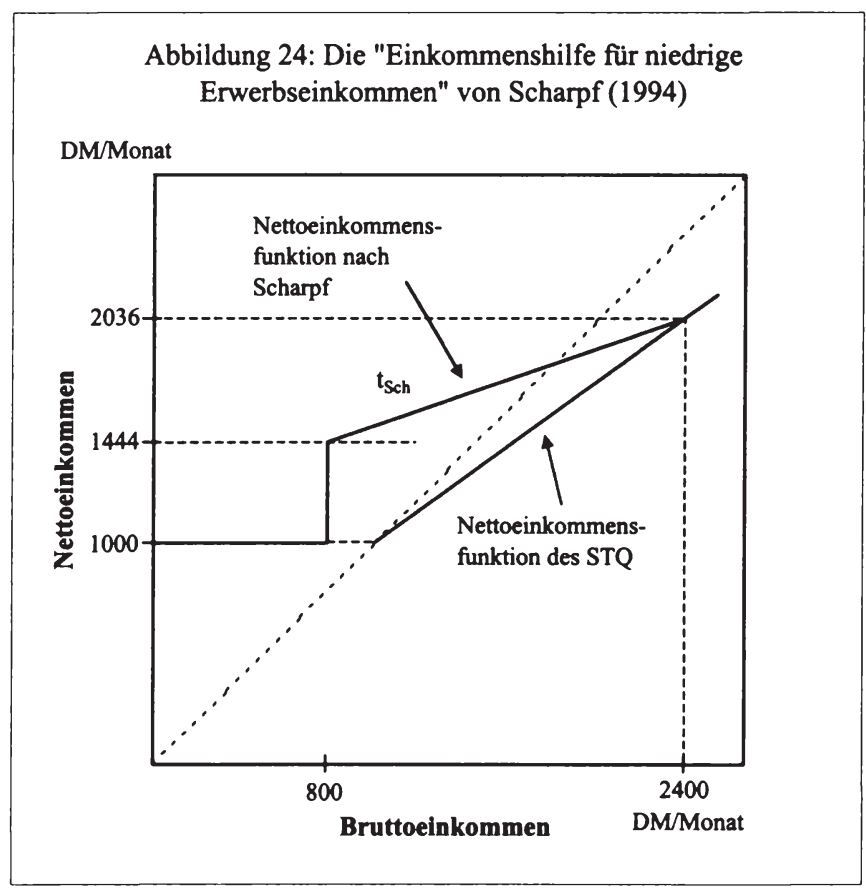

Die Einkommenshilfe wird nicht nur für zusätzliche Beschäftigungsverhältnisse, sondern auch für bereits bestehende Arbeitsverhältnisse bezahlt. Darin sieht Scharpf jedoch keinen Nachteil, sondern eine „unter den Gesichtspunkten der Verteilungsgerechtigkeit und der demokratischen Stabilität gleichermaßen erwünschte Umverteilung zugunsten der untersten Einkommensgruppen" (Scharpf 1994b, S. 35). Deshalb ergibt sich im ungünstigsten Fall eine Mehrbelastung von 6,8 Milliarden DM durch die Einführung des Scharpf-Modells im Jahre 1991. Das wäre dann der Fall, wenn die etwa 6,1 Millionen Beschäftigten, die 1991 zu Stundenlöhnen zwischen 10 und 15 DM beschäftigt wurden, die Einkommenshilfen in Anspruch nehmen würden. 
Phelps (1997a,b) schlägt ebenfalls eine degressive Stundenlohnsubven-tion an alle Niedrigeinkommensbezieher vor. Ein Stundenlohn von 4 \$ soll um $3 \$$ auf $7 \$$ angehoben werden, bei einem Stundenlohn von $12 \$$ soll die Stundenlohnsubvention nur noch $0,03 \$$ betragen. Auch dieser Lohnsubventionsvorschlag mildert das Problem der Armutsfalle dauerhaft ab.

Phelps (1994, 1997a,b) liefert eine allokative Begründung für Stundenlohnsubventionen an Niedrigeinkommensbezieher. Ausgangspunkt ist eine differenzierte Analyse des amerikanischen Wohlfahrtssystems, das Jugendkriminalität und Drogenmißbrauch unterstütze. Kernpunkt sei die fehlende Verknüpfung von Sozialleistungen mit einer Arbeitspflicht. Daraus ergebe sich ein Teufelskreis aus Sittenverfall und weitverbreiteter Arbeitslosigkeit, der die Arbeitsethik unterlaufe - mit der Konsequenz steigender Kriminalität und zunehmenden Drogenmißbrauchs, der wiederum zum Sittenverfall beitrage (vgl. Phelps 1997a, S. 99f.). Dementsprechend können Stundenlohnsubventionen positive externe Effekte in mehreren Bereichen internalisieren, weil die soziale Produktivität arbeitender Hilfeempfänger über ihrer privaten Produktivität liegt. Erstens werden sich die Familien und die Gemeinschaft in den Ghettos vorteilhaft entwickeln. Insbesondere zukünftige Generationen könnten davon profitieren, wenn sie nicht in einer Kultur der Passivität und Entfremdung von der Arbeitswelt aufwachsen würden (community effects). Zweitens werden die Kosten der Gesellschaft für medizinische Versorgung und Kriminalitätsbekämpfung sowie die Ausgaben für bestehende Wohlfahrtsprogramme des Staates zurückgehen, so daß die Ressourcenverschwendung durch Arbeitslosigkeit eingedämmt werden kann. Drittens werden die Einnahmen des Staates aus Steuern und Abgaben zunehmen, wenn Arbeitslose wieder in den Arbeitsmarkt integriert werden können.

Die Einführung von Stundenlohnsubventionen in den USA im Sinne von Phelps sind nach überschlägigen Berechnungen mit etwa $125 \mathrm{Mrd}$. \$ im Jahre 1997 verbunden (vgl. Phelps 1997a, S. 116). Nach Ansicht von Phelps würden sich jedoch bald Einsparungen sowie Mehreinnahmen ergeben, so daß die Einführungskosten überkompensiert werden. Hinzu kämen die externen Nutzen für die Gesellschaft. Deshalb würde dieses Subventionsmodell einen positiven Nettonutzen für die Steuerzahler erzeugen.

Phelps (1997b, S. 240) erwartet von zeitlich unbefristeten, allgemeinen Stundenlohnsatzsubventionen im Vergleich zu europäischen Ländern relativ höhere Nettolohnsätze und geringere Beschäftigungseffekte für die USA - wegen der relativ geringeren Lohnrigidität. Umgekehrt erwartet er für Europa einen relativ höheren Beschäftigungseffekt und relativ geringere Nettolohnsteigerungen - wegen der relativ größeren Lohnrigidität.

Frank (1997) hebt darauf ab, daß der Phelps-Vorschlag - und das gilt auch für den Scharpf-Vorschlag - unnötig teuer sei, weil auch nicht bedürftige Niedrigeinkommensbezieher profitieren: Zur breit gefaßten Zielgruppe zählen auch Personen, die über Vermögen verfügen oder einem gutverdienenden 
Haushalt angehören - auch sie erhalten Stundenlohnsatzsubventionen. Phelps $(1997 a, b)$ kritisiert diese Denkweise, weil Bedürftigkeit und damit Ansprüche an den Wohlfahrtsstaat als zentrales Kriterium herangezogen wird. Statt dessen ist nach seiner Ansicht ein Paradigmenwandel vom Wohlfahrtsdenken zur Arbeitsorientierung nötig. Frank (1997) kritisiert weiterhin, daß Firmen als Reaktion auf eine dauerhafte Subventionierung niedrigentlohnter Tätigkeiten „bad jobs“ zu Lasten besser bezahlter Tätigkeiten schaffen werden. Deshalb hätten Arbeitnehmer keinen Anreiz, in ihre Aus- und Fortbildung zu investieren - Investitionen in Humankapital lohnen sich relativ zum Status quo weniger (vgl. Mortensen 1997).

\subsubsection{Das „,Benefit-Transfer Program “}

Ein Gutscheinsystem für Langzeitarbeitslose wurde von Snower $(1994,1997)$ vorgeschlagen: das „Benefit-Transfer Program“ (BTP). Das BTP sieht vor, daß Langzeitarbeitslosen das Recht eingeräumt wird, einen Teil ihrer Arbeitslosenunterstützung als Gutschein (= Voucher) bei Arbeitgebern einzureichen. Konkret ist an die Umwandlung des zeitlich befristeten Arbeitslosengeldes (unemployment benefit) in Gutscheine gedacht. Die Arbeitgeber können diesen Gutschein beim Staat einlösen - der Gutschein wirkt demnach wie eine Lohnsubvention.

Das BTP unterscheidet sich nach Snower $(1994,1997)$ in mehreren Punkten von traditionellen Lohnsubventionen. Zum einen sind die Gutscheine an die Höhe der Arbeitslosenunterstützung der Langzeitarbeitslosen gekoppelt, so daß die Ausgaben des Staates nie höher als die gezahlte Arbeitslosenunterstützung sein können. Zum anderen nimmt der Wert des Gutscheins mit der Dauer der Arbeitslosigkeit (bis zu einer Höchstgrenze) zu. Zum dritten nimmt der Wert des Gutscheins allmählich ab, je länger ein ehemaliger Langzeitarbeitsloser beschäftigt bleibt. Zwei Arten von Gutscheinen werden unterschieden: „Recruitment voucher“ erhalten Arbeitgeber für die Einstellung von Langzeitarbeitslosen; „Trainingsvoucher“ erhalten Arbeitgeber, die Langzeitarbeitslosen zusätzlich Qualifizierungsmaßnahmen ermöglichen - ihr Wert soll über dem Wert der recruitment voucher liegen.

Das BTP hat nach Snower (1994) mehrere Vorteile. Zum einen wirkt das Programm nicht inflationär, weil die Langzeitarbeitslosenrate geringe Wirkungen auf die Lohninflation hat und die Arbeitskosten durch die Gutscheine reduziert werden. Zum anderen ist das Programm für die Regierung kostenlos, weil die Ausgaben für Gutscheine ohnehin für Arbeitslosenunterstützung ausgegeben worden wären. Zum dritten wirkt das Programm als automatischer Stabilisator: Wenn die Arbeitslosigkeit abnimmt, dann sinken auch die Ausgaben für Arbeitslosenunterstützung und damit der maximale Wert der Gutscheine. Viertens trägt das BTP als Trainingsvoucher dazu bei, daß langfristig Jobs geschaffen werden. 
Orszag/Snower (1996a) erweitern die BTP-Idee auf Zahlungen im Rahmen der Erwerbsunfähigenunterstützung (incapacity benefits). Erwerbsunfähige, die dem Arbeitsmarkt aus gesundheitlichen Gründen nur noch eingeschränkt zur Verfügung stehen, zählen typischerweise nicht zum Arbeitskräftepotential. Sie würden ohne Gutscheine keine Stellenangebote erhalten. Demnach entfallen für diese Personengruppe Mitnahmeeffekte - im Gegensatz zum ursprünglichen BTP für Empfänger von Arbeitslosenunterstützung. Die Autoren zeigen, daß in diesem Fall bei dem Betrag nach positiver Arbeitsnachfrageelastizität immer positive Beschäftigungseffekte durch sich selbstfinanzierende Gutscheine zu erwarten sind.

Orszag/Snower (1996b) analysieren die dynamischen Wirkungen des BTP im Rahmen eines makroökonomischen Modells des Arbeitsmarktes. Dynamische Rückwirkungen verstärken aus zwei Gründen die positiven kurzfristigen Beschäftigungswirkungen. Zum einen ist die Wahrscheinlichkeit von Beschäftigten, einen neuen Job zu erhalten höher als die Wahrscheinlichkeit von Arbeitslosen, eingestellt zu werden. Dementsprechend verbessern sich die langfristigen Beschäftigungschancen, wenn Gutscheine die Einstellungswahrscheinlichkeit der Arbeitslosen erhöhen. Deshalb könnten die langfristigen Beschäftigungseffekte die kurzfristigen übersteigen. Zum anderen entlastet der Abbau der Arbeitslosigkeit das staatliche Budget über geringere Ausgaben für Arbeitslosenunterstützung, so daß ein geringerer Finanzierungsbedarf besteht. Budgetüberschüsse können wiederum für die Finanzierung der Gutscheine verwendet werden. Über diesen Wirkungskanal verstärkt sich ebenfalls der positive Beschäftigungseffekt der Gutscheine. Einschränkend weisen Orszag/Snower (1996b) darauf hin, daß ihr Ergebnis auf einer zentralen Annahme beruht: Gutscheine erhöhen die Einstellungswahrscheinlichkeit auch in der langen Frist.

Snower $(1994,1997)$ kann sich verschiedene Varianten des BTP in der Praxis vorstellen. Im folgenden wird eine vereinfachte Version und auf das deutsche Steuer- und Abgabensystem zugeschnittene Version des Gutscheinmodells im Brutto-/Nettoeinkommen-Diagramm in Abbildung 25 dargestellt. Dabei wird im Hinblick auf die Vergleichbarkeit mit dem in Kapitel 5 diskutierten „Einstiegsgeld" für Langzeitarbeitslose von bedürftigkeitsgeprüften Langzeitarbeitslosen als Zielgruppe ausgegangen. Demnach ist der Bezug der zeitlich unbefristeten Arbeitslosen- und/oder Sozialhilfe Voraussetzung für die Teilnahme am Gutscheinmodell.

Der Wert des Gutscheins wird in Höhe der durchschnittlichen Arbeitslosenund/oder Sozialhilfe von 1000 DM je Monat angenommen. Ein Zahlenbeispiel: Ein Langzeitarbeitsloser erhält einen Job, der ein Bruttoeinkommen von $2000 \mathrm{DM}$ im Monat erbringt. Dieses (in der Abbildung 25 nicht eingetragene) vom Arbeitgeber ausgezahlte Bruttoeinkommen setzt sich aus dem Wert des Gutscheins von $1000 \mathrm{DM} /$ Monat und weiteren vom Arbeitgeber zu tragenden Lohnkosten in Höhe von 1000 DM/Monat zusammen. An der Abszis- 
se sind die Lohnkosten des Arbeitgebers von $1000 \mathrm{DM} / \mathrm{Monat}$, also das Bruttoeinkommen ohne Zuschuß abgetragen. Das Nettoeinkommen des Langzeitarbeitslosen ergibt sich - analog zum Scharpf-Modell - nach Abzug der Steuern und Abgaben; es beträgt $1540 \mathrm{DM}$ im Monat, wenn man in Anlehnung an das deutsche Steuer- und Abgabensystem einen konstanten „SnowerGrenzsteuersatz $z t_{S N}$ von $46 \%$ über dem steuerfreien Existenzminimum annimmt. $\mathrm{Zu}$ beachten ist, daß dieser Grenzsteuersatz nicht von Snower vorgeschlagen wurde - er ergibt sich bei der hier modellierten Implementierung des BTP in das deutsche System. Außerdem soll im Hinblick auf die Vergleichbarkeit mit dem in Kapitel 5 diskutierten Einstiegsgeld angenommen werden, $\mathrm{da} ß$ Transfers nur bis zu einem Bruttoeinkommen ohne Zuschuß von 1000 DM/Monat bezahlt werden.

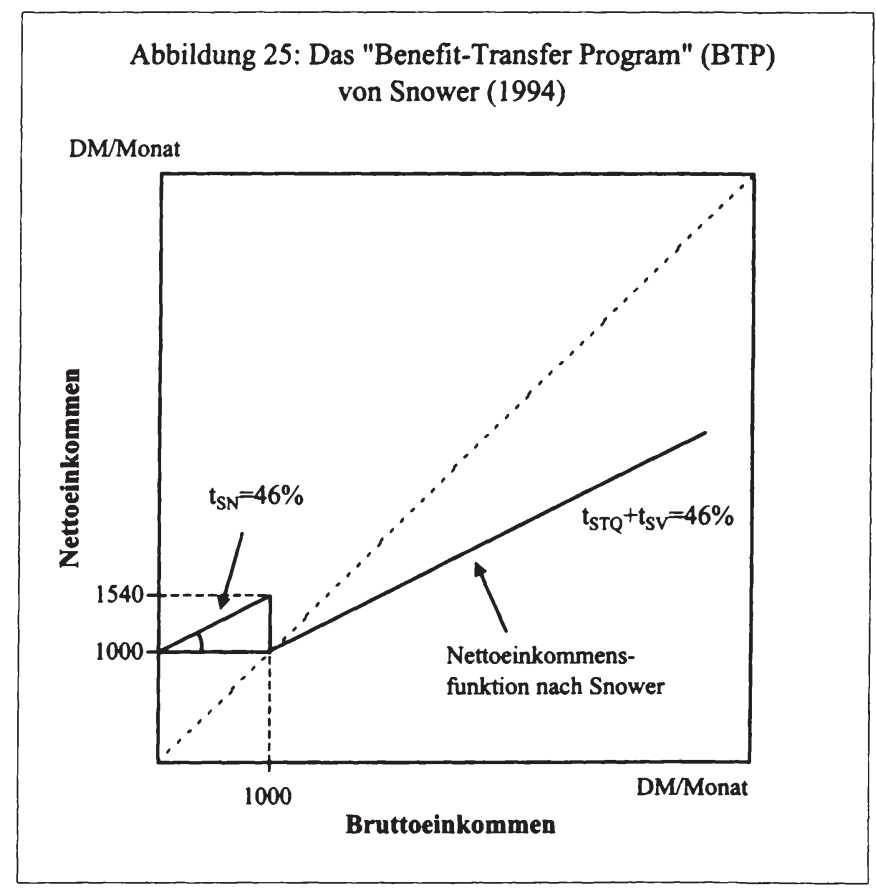

Brunello/Miniaci (1997) untersuchen ein dem BTP-Modell verwandtes Lohnsubventionsprogramm in Italien - die seit 1991 in der Lombardei existierenden sogenannten „Mobility Lists“ (liste di mobilità). Im Oktober 1993 waren 180.000 Arbeitslose in diese Listen eingetragen. Ältere Arbeitnehmer über 39 Jahre erhalten einen im Vergleich zu jüngeren Arbeitnehmern höheren Voucher über einen längeren Zeitraum. Die Autoren untersuchen vor dem Hintergrund der Suchtheorie mit einem neu verfügbaren Datensatz, ob die längere 
Bezugsdauer eines großzügigeren Vouchers die Abgangsrate älterer Arbeitsloser erhöht. Theoretisch wirken zwei Effekte in unterschiedliche Richtungen. Zum einen erhöht sich die Wahrscheinlichkeit, daß ältere Arbeitslose eine Stelle angeboten bekommen, zum anderen erhöht sich der Reservationslohn. Der erste Effekt wirkt in Richtung höherer Abgangsrate, der zweite Effekt wirkt in Richtung auf eine geringere Abgangsrate aus der Arbeitslosigkeit, der Nettoeffekt ist theoretisch unbestimmt. Ihr Ergebnis: Die Abgangsrate älterer Arbeitsloser ist geringer als die jüngerer Arbeitsloser. Diese Untersuchungsergebnisse sprechen jedoch nicht gegen die Implementierung des BTPModells, sondern geben lediglich Auskunft über die Wirkung eines speziell für ältere Arbeitslose vorteilhafter ausgestalteten BTP-Modells. Die empirischen Resultate von Brunello/Miniaci (1997) stehen auch im Einklang mit neueren Untersuchungen zum Zusammenhang zwischen Dauer der Unterstützungsleistung und Dauer der Arbeitslosigkeit (vgl. Steiner 1997 u. Kap. 2.3). Das BTP-Modell wird in mehrfacher Hinsicht kritisiert. Drèze (1997) verweist auf ein fundamentales Problem der Zielgruppenorientierung - jeder Teilnehmer, der nicht zur Zielgruppe gehört, ist gegenüber Anspruchsberechtigten benachteiligt. Einen Mitnahmeeffekt als Folge der Zielgruppenorientierung sieht Coe (1997) darin, daß Kurzzeitarbeitslose ihre Suchintensität verringern könnten. Dabei hätten sie ohne das BTP-Modell bei unveränderten Suchanstrengungen einen Job finden können. Snower (1997) hält dagegen, daß Mitnahmeeffekte minimiert werden können, indem die Jobsuche von Kurzzeitarbeitslosen durch verschärfte Zumutbarkeitsregeln intensiviert werden könnte. Auf diese Weise könnten sie den Anreiz verlieren, in Langzeitarbeitslosigkeit zu investieren (vgl. Snower 1997, S. 190). Eine Zielgruppenorientierung ist unter Kosteneffizienzgesichtspunkten vorteilhaft, weil eine Verringerung der Arbeitslosigkeit mit minimalem staatlichen Budgeteinsatz erreicht werden kann. Aber auch unter Gerechtigkeitsgesichtspunkten ist eine Zielgruppe wichtig: Die Langzeitarbeitslosen sind die Personen, die relativ zu den Kurzzeitarbeitslosen am stärksten von Arbeitslosigkeit betroffen sind. Mitnahmeeffekte könnten jedoch nicht vollständig vermieden werden.

Verdrängungs- und Substitutionseffekte sind nach Snower (1997) zwar ebenfalls nicht zu vermeiden - sie können jedoch grundsätzlich durch Gegenmaßnahmen abgemildert werden. So ließen sich zum Beispiel Firmen, die Arbeitnehmer entlassen, um sie durch subventionierte zu ersetzen, ebenso von der Teilnahme am BTP-Modell ausschließen wie neugegründete Firmen, die lediglich subventionierte Arbeitnehmer beschäftigen. Doch hält Snower diese Gegenmaßnahmen für kontraproduktiv, weil sie die Rolle des BTP-Modells als automatischen Stabilisator schwächen: In der Rezession würden Firmen, die Arbeitnehmer entlassen haben, vom BTP-Modell ausgeschlossen - gerade dann, wenn sie am dringendsten auf kostengünstige Arbeitnehmer angewiesen wären. Deshalb plädiert Snower für „weichere“ Gegenmaßnahmen wie ein Beschwerderecht für substituierte und verdrängte Arbeitnehmer. 
Stigmatisierungseffekte, wie sie in den USA experimentell nachgewiesen wurden (vgl. Kapitel 4.3.1), erwartet Snower (1997, S. 193) bei einer Einführung des BTP-Modells in Europa kaum. Der Grund: In den USA spielt Langzeitarbeitslosigkeit im Gegensatz zu Europa kaum eine Rolle. Langzeitarbeitslosigkeit ist jedoch ein besseres Signal für geringe Produktivität als Nichterwerbstätigkeit: Ein Langzeitarbeitsloser, der sich seit einem Jahr vergeblich um einen Job bemüht, ist wahrscheinlich weniger produktiv als ein Nichterwerbstätiger (z.B. Angehörige der stillen Reserve). Deshalb hat ein europäischer Arbeitgeber mehr Informationen über die Produktivität des Bewerbers als ein amerikanischer Arbeitgeber, der lediglich über die Dauer der Nichterwerbstätigkeit informiert ist. Die Information über die Produktivität von Langzeitarbeitslosen ist ein öffentliches Gut. Dementsprechend ist der zusätzliche Stigmatisierungseffekt von Gutscheinen in Europa geringer als in den USA. Anders formuliert: Langzeitarbeitslose sind bereits durch die Dauer ihrer Arbeitslosigkeit stigmatisiert, der Informationszuwachs durch die Gewährung eines Gutscheins ist für europäische Arbeitgeber geringer als für amerikanische Arbeitgeber.

Das Prinzip des BTP-Modells wird seit 1993 in Ostdeutschland und seit 1995 in Westdeutschland in die Praxis umgesetzt. Im Rahmen der produktiven Lohnkostenzuschüsse-Ost nach $\S 249$ h AFG werden pauschalierte Lohnkostenzuschüsse in Höhe der durchschnittlichen Aufwendungen für Arbeitslosengeld und -hilfe für Tätigkeiten in den Bereichen Umwelt, soziale Dienste, Jugendhilfe, Breitensport, Kulturarbeit und Denkmalpflege an Träger entsprechender Maßnahmen gewährt. Im Jahre 1996 wurden 86.242 Personen in Ostdeutschland und 6.276 Personen in Westdeutschland über produktive Lohnkostenzuschüsse in Beschäftigung gebracht (vgl. Bundesanstalt für Arbeit 1997, S. 24f.). Die meisten Maßnahmen werden von gemeinnützigen Einrichtungen getragen. Das BTP-Modell beseitigt die Armutsfalle für den Zeitraum der Subventionsgewährung.

\subsection{Lohnsubventionen und Arbeitspflicht}

\subsection{1 „Welfare-to-Work"-Programme}

Welfare-to-Work-Programme verknüpfen den Anspruch auf staatliche Transferleistungen mit der Verpflichtung arbeitsfähiger Hilfeempfänger, eine Tätigkeit in der privaten Wirtschaft oder im öffentlichen Sektor anzunehmen. Im Gegensatz zu traditionellen Maßnahmen der aktiven Arbeitsmarktpolitik verpflichtet sich der Staat, den Hilfeempfängern Stellen anzubieten. Im Rahmen von Welfare-to-Work-Programmen wirken demnach staatliche Transfers als Lohnsubventionen für Jobs im privaten oder öffentlichen Sektor. Diese Programme haben sich in den neunziger Jahren zu einem wichtigen Politik- 
instrument insbesondere in den USA und in Großbritannien entwickelt - sie existieren jedoch unter anderen Bezeichnungen auch in Dänemark und Deutschland. Diese vier länderspezifischen Programmvarianten sollen im folgenden kritisch dargestellt werden.

\section{(1) USA}

Bereits zu Beginn der achtziger Jahre wurden in den USA auf Bundesstaatenebene vier soziale Feldexperimente mit verschiedenen Welfare-to-WorkProgrammen für Empfänger von Aid to Families with Dependent Children (AFDC) durchgeführt; die Barauszahlungen von AFDC-Leistungen an Familien werden häufig als „welfare“ bezeichnet (vgl. Blank 1994, S. 183). Da Informationen über die berufliche Entwicklung der Programmteilnehmer in den fünf Jahren nach Programmende ausgewertet werden konnten, ließen sich nicht nur die kurz-, sondern auch die langfristigen Wirkungen abschätzen (vgl. Friedlander/Burtless 1995). Die zentralen Ergebnisse der Programmevaluationen: Mehr Hilfeempfänger nahmen eine Beschäftigung auf oder nahmen eine Beschäftigung früher auf als ohne Programm. Alle Programme waren kosteneffizient, die Einsparungen an Ausgaben für AFDC-Teilnehmer waren größer als die zusätzlichen Ausgaben für die Implementierung der Programme. Die Wahrscheinlichkeit, daß geförderte Hilfeempfänger wieder auf staatliche Transfers angewiesen sind, war nicht höher als für nicht geförderte Hilfeempfänger. Doch wurden auch die Grenzen dieser Programme deutlich. So konnten die Programmteilnehmer bis auf wenige Ausnahmen keine besser bezahlten und sicheren Stellen finden. Auch war der Erfolg bei der Verringerung der Langzeithilfeempfänger sehr eingeschränkt.

Die Erfahrungen mit diesen Feldexperimenten führten im Jahre 1988 zum Family Support Act (FSA), der alle Bundesstaaten zur Einführung von Welfare-to-Work-Programmen verpflichtete. Blank (1994) sieht darin einen Politikwechsel vom Einkommens- zum Arbeitsziel. Der Gouverneur des Bundesstaates Wisconsin, Tommy Thompson, übernahm dabei die Vorreiterrolle. Mitte der achtziger Jahre reduzierte Thompson das Bedürftigkeitsniveau (need standard) und fixierte das nominale Hilfeniveau (assistance standard) des AFDC; die Leistungen für Familien im Rahmen des AFDC werden gemeinsam vom Bund und den Bundesstaaten finanziert, wobei die Bundesstaaten das Unterstützungsniveau festlegen dürfen (vgl. Blank 1994). Die Konsequenz: Zwischen 1986 und 1995 reduzierte sich das reale Niveau staatlicher Unterstützungsleistungen unter Berücksichtigung von Lebensmittelmarken um 14 Prozent (vgl. Wiseman 1996, S. 524). Dadurch vergrößerte sich der Lohnabstand zu unteren Lohngruppen. Die Zahl der AFDC-Hilfeempfänger ging von etwa 100.000 Familien im Jahre 1986 auf etwa 60.000 im Jahre 1996 zurück (vgl. Haveman 1996b).

Im Jahre 1996 beschloß die Clinton-Administration, den Bezug von AFDCLeistungen auf zwei Jahre zu befristen. Hilfeempfänger, die nach Ablauf die- 
ser Frist keine Tätigkeit aufgenommen haben, erhalten keine AFDC-Leistungen mehr; Lebensmittelmarken (Food Stamps) entfallen jedoch nicht (vgl. Wiseman 1996, S. 537). Vor diesem Hintergrund wurde das Programm „Wisconsin Works (W-2)“ in einzelnen Regionen Wisconsins umgesetzt. Es sieht vier Arbeitsmöglichkeiten vor: nicht-subventionierte Stellen im privaten Sektor, subventionierte Stellen im privaten Sektor (trial jobs), Stellen im öffentlichen Sektor (community service jobs) und Übergangsjobs für besonders schwer vermittelbare Personen (transitions). Bis auf nicht-subventionierte Jobs im privaten Sektor sind alle anderen Stellen auf zwei Jahre befristet. Insgesamt darf ein Programmteilnehmer maximal fünf Jahre in verschiedenen subventionierten Programmkomponenten teilnehmen. Verlängerungen sind im Einzelfall in Abhängigkeit von der Lage am lokalen Arbeitsmarkt möglich. Programmteilnehmer mit Stellen im privaten Sektor erhalten zusätzlich zu ihrem Stundenlohn Lohnsubventionen im Rahmen des EITC und Lebensmittelmarken, Programmteilnehmer im öffentlichen Sektor haben keinen Anspruch auf EITC-Zahlungen, erhalten jedoch Lebensmittelmarken. Ziel ist es, die Programmteilnehmer auf eine möglichst hohe Stufe der "SelbsthilfeLeiter" (,self-sufficiency ladder“; Thompson 1997, S. 7) zu bringen. Wisconsin Works gilt als Musterbeispiel für die amerikanische Wohlfahrtsreform. Mit der Einführung von W-2 ist von seiten der Politik die Erwartung verbunden, die Zahl der AFDC-Empfänger weiter zurückzuführen.

Bei der Ausgestaltung der trial jobs ist ein interessanter Punkt festzuhalten: Die Arbeitspflicht für Hilfeempfänger wird in diesem Fall sowohl mit Lohnsubventionen an Arbeitgeber als auch an Arbeitnehmer verknüpft.

W-2 wird durch sogenannte „Job Center“ vor Ort praktisch umgesetzt. Mitarbeiter der Job Center helfen bei der Jobvermittlung, teilen die Hilfeempfänger den unterschiedlichen Arbeitsgelegenheiten gemäß ihrer Fähigkeiten zu, organisieren Kinderbetreuung, medizinische Betreuung und Transportmöglichkeiten, vermitteln Aus- und Fortbildungsmaßnahmen sowie zinsgünstige Darlehen. Die Behörden erwarten hohe Beschäftigungseffekte durch die Einführung von Wisconsin Works. In den ersten sechs Monaten sollen 20.200 Personen nicht-subventionierte Arbeit erhalten. Zum Vergleich: Für 26.800 Personen sollen Stellen im öffentlichen Bereich geschaffen werden (vgl. Wiseman 1996, S. 536). W-2 wird seit September 1997 im gesamten Bundesstaat Wisconsin praktiziert.

Die Erfolgschancen des Programms werden jedoch skeptisch beurteilt. Haveman (1996b,c) weist auf die immensen Kosten des Programms hin - sie werden die Kosten des bestehenden Wohlfahrtssystems, das ersetzt werden soll, kurzfristig sogar überschreiten. Ob langfristig eine fiskalische Kostenentlastung durch geringere Fallzahlen zu erwarten ist, bleibt fraglich. Die Verteilung der Transferempfänger auf die verschiedenen Beschäftigungsmöglichkeiten ist selbst in einer boomenden Ökonomie sehr optimistisch: $\mathrm{Zu}-$ vielen AFDC-Empfängern werden Jobs im privaten Sektor zugeteilt, zuweni- 
gen Hilfeempfängern werden Jobs im öffentlichen Sektor zugewiesen. Die Festlegung des Verteilungsschlüssels ist nicht das Ergebnis wissenschaftlicher Analyse, sondern lediglich eine grobe Schätzung. Aber nicht nur eine Rezession mit deutlich verschlechterten Beschäftigungsmöglichkeiten für $\mathrm{Ge}-$ ringqualifizierte könnte die Kosten erhöhen, sondern auch die Selbstverpflichtung der Kommunen, jedem Hilfeempfänger einen - notfalls auch staatlich finanzierten - Job zu vermitteln. Hinzu kommt, daß Jobs im privaten Sektor lediglich mit geringfügig höheren verfügbaren Einkommen verbunden sind als öffentlich geförderte Jobs: Die Armutsfalle für W-2 Teilnehmer bleibt weiterhin bestehen, weil die Anrechnungsvorschriften anderer Transferprogramme (z.B. Earned Income Tax Credit) nicht gleichzeitig reformiert werden. Auch scheint fraglich, ob für die Benachteiligten noch ein ausreichendes soziales Netz zur Verfügung steht, wenn die Jobgarantie des Staates ausläuft.

\section{(2) Großbritannien}

Das britische Welfare-to-Work-Programm „New Deal“ wurde nach der Wahl der Labour Party im Jahre 1997 realisiert, um die Mitte der neunziger Jahre auf über $40 \%$ gestiegene Langzeitarbeitslosigkeit und die hohe Jugendarbeitslosigkeit zu reduzieren (vgl. OECD 1997c, Walwei/Werner 1997). Mit dem New Deal, der seit Januar 1998 gilt, wird wie in den USA mit den traditionellen Vorstellungen über den Wohlfahrtsstaat gebrochen (vgl. Blair 1996). Das Konzept des New Deal basiert auf dem in der Literatur als „Job Guarantee Scheme“ diskutierten Welfare-to-Work-Konzept von Layard (1997a,b). Das Layard-Konzept, das im folgenden dargestellt wird, unterscheidet sich nur unwesentlich vom New Deal-Programm der britischen Regierung.

Kernziel des Layard-Konzepts ist die Erhöhung der Beschäftigungsfähigkeit (employability) der Arbeitslosen. Dazu dient eine sechsmonatige Beschäftigung (temporary job) im privaten oder öffentlichen Sektor, die Arbeitslosen nach einem Jahr Arbeitslosigkeit angeboten wird. In einem ersten Schritt werden Jugendliche bis zu 25 Jahren in das Welfare-to-Work Programm einbezogen, eine Ausdehnung auf alle Arbeitslosen ist vorgesehen. Langfristig könnten auch Erwerbsunfähige durch die Umwandlung ihrer Transferzahlungen in Lohnsubventionen das Arbeitskräftepotential erhöhen (vgl. Layard 1997a, S. 73).

Der Unterschied zu traditionellen britischen Maßnahmen der aktiven Arbeitsmarktpolitik (vgl. Walwei 1997) und zu anderen Lohnsubventionsvorschlägen für Großbritannien (vgl. Snower 1994, 1997) liegt im Arbeitszwang: Nur wer arbeitet, erhält Lohnsubventionen, wer nicht arbeitet, verliert seine Arbeitslosenunterstützung (vgl. Layard 1997b, S. 338). Der Unterschied zur reinen Arbeitspflicht besteht darin, daß nicht nur für den Erhalt der Unterstützungszahlungen öffentliche Arbeiten zu verrichten sind, sondern in der sechsmonatigen Arbeitsperiode der Marktlohn bezahlt wird. 
Layard $(1997 \mathrm{a}, \mathrm{b})$ betont, daß dieses Programm die Arbeitslosigkeit verringern kann, ohne Inflationsdruck zu erzeugen. Die erhöhte Beschäftigungsfähigkeit der Arbeitslosen nach Abschluß der sechsmonatigen Arbeitsperiode erhöht ihre Einstellungswahrscheinlichkeit. Zusätzliche Stellen werden auch entstehen, weil eine Ausweitung des Arbeitskräftepotentials die Beschäftigung erhöht (people cause jobs). Die Anzahl an Stellen ist nicht festgelegt, sondern positiv mit dem Arbeitskräftepotential korreliert, wie sich empirisch zeigen läßt. Die Vorstellung, daß die Arbeitsnachfrage völlig unelastisch ist und nur durch Veränderungen der aggregierten Nachfrage zunehmen kann, ist ein Trugschluß (lump-of-labour fallacy). Deshalb sind auch keine Substitutionsund Verdrängungseffekte zu erwarten - zumindest nicht im Aggregat. Auf der betrieblichen Ebene können jedoch durchaus nicht subventionierte Arbeitnehmer durch subventionierte Arbeitnehmer ersetzt werden. Als staatliche Gegenmaßnahme könnten Unternehmen, die Arbeitnehmer entlassen, vom Bezug von Lohnsubventionen ausgeschlossen werden. Eine Begrenzung der Lohnsubventionen auf zusätzliche Jobs (Zusätzlichkeitskriterium) ist jedoch kontraproduktiv.

Layard (1997a, S. 66) weist ausdrücklich auf das Problem der Armutsfalle hin. Die hohe Transferentzugsrate kann jedoch nicht wesentlich gesenkt werden, wenn nicht fast die Hälfte aller Familien Anspruch auf den Family Credit haben soll (vgl. Kapitel 4.2.1.2). Als Ergänzung des Welfare-to-Work-Programms sei es aber von Bedeutung, die Transferentzugsrate für Doppelverdiener zu senken. Am wichtigsten dürfte es jedoch sein, die geringe Inanspruchnahme des Family Credit (take-up rate) zu steigern. Deshalb sollten Unternehmen verpflichtet werden, ihre gering bezahlten Arbeitnehmer auf den Family Credit aufmerksam zu machen. Das britische Welfare-to-WorkProgramm verbindet demnach eine Arbeitspflicht für Arbeitslose mit einer vorübergehenden staatlichen Jobgarantie unter Einsatz von Lohnsubventionen an Arbeitgeber sowie ergänzenden Lohnsubventionen an Arbeitnehmer. Layard (1997a) sieht jedoch vor dem Hintergrund der Erfahrungen mit dem Speenhamland System (vgl. Kapitel 3.1) die Gefahr der Absenkung der Löhne durch die Arbeitgeber - mit Verweis auf Lohnsubventionen. Deshalb ist ein gesetzlicher Mindestlohn als ergänzende Maßnahme sinnvoll.

De la Dehesa (1997) kritisiert, daß der Staat letztlich als Arbeitgeber auftreten muß, wenn den vorübergehend Beschäftigten nicht genügend Stellen im privaten Sektor angeboten werden. Der Anreiz ist deshalb besonders groß, weil auf diese Weise das Programm in der Öffentlichkeit als Erfolg dargestellt werden kann. Darüberhinaus werden Arbeitslose Stellen im öffentlichen Sektor bevorzugen - unter der Annahme, daß Stellen im privaten Sektor aus Sicht der Hilfeempfänger unsicherer sind. Deshalb besteht die Gefahr, daß dieses Programm lediglich ein traditionelles Arbeitsbeschaffungsprogramm darstellt. Minford (1997) sieht große Anreize für bisher erwerbstätige Geringverdiener, vorübergehende Beschäftigung aufzunehmen - unter der An- 
nahme, daß sie in den sechs Monaten staatlich garantierter Beschäftigung ein etwa doppelt so hohes Monatsgehalt als bisher erhalten. Dieser Anreiz zum „switching“ bringt die Gefahr umfangreicher Substitutionseffekte mit sich. Dabei unterstellt Minford, daß der Freizeitnutzen während der einjährigen Wartezeit als Arbeitsloser für die betroffenen Individuen höher ist als das durch Langzeitarbeitslosigkeit erworbene Stigma.

\section{(3) Dänemark}

Eine Verschärfung der Arbeitspflicht in Verbindung mit subventionierter Beschäftigung ist ein Element des dänischen Modells zum Abbau von (Langzeit-) Arbeitslosigkeit. Die OECD-standardisierte Arbeitslosenquote in Dänemark ging nach einem historischen Höchststand von $13 \%$ im Jahre 1993 auf $8 \%$ im Jahre 1997 zurück (vgl. OECD 1998); der Anteil der Langzeitarbeitslosen stieg jedoch nach Angaben der OECD zunächst von 25,1\% im Jahre 1993 auf 32,1 \% (1994), um im Jahre 1996 auf 26,5 \% zurückzugehen (vgl. OECD 1996, 1998). Dieser Umschwung am Arbeitsmarkt ist erstaunlich, weil die Arbeitslosigkeit in Dänemark vor allem auf strukturelle Ursachen zurückzuführen ist (vgl. OECD 1997b).

Das „dänische Modell“ besteht aus einer kombinierten Fiskal-, Lohn- und Arbeitsmarktpolitik. Einer expansiven Fiskalpolitik durch Ausgabenerhöhung und Steuersenkung im Jahre 1994 folgte eine Phase der Haushaltskonsolidierung, mit der 1997 ein nahezu ausgeglichenes Budget erreicht werden konnte. Die Fiskalpolitik ging mit einer moderaten Lohnpolitik einher. Einen wesentlichen Beitrag zur Reduzierung der offiziellen Arbeitslosenquote leistete eine Arbeitsmarktpolitik, die auf einen Rückgang des Arbeitsangebots durch Vorruhestandsregelungen und Beurlaubungsprogramme abzielte (vgl. Emmerich 1998, Emmerich/Werner 1998). Der Rückgang der Arbeitslosigkeit zwischen 1994 und 1996 läßt sich nahezu vollständig durch die entsprechenden Programme erklären. Hinzu kamen spezifische Definitionen der Statistik: Jugendliche, die eine besondere Form der Sozialhilfe (,Jugendgarantie“) erhalten, werden nicht mehr in der Arbeitslosenstatistik geführt. Dagegen spielte Teilzeitarbeit für die dänischen Arbeitsmarkterfolge keine bedeutende Rolle: Die Teilzeitquote ist zwar im europäischen Vergleich hoch, war jedoch in den neunziger Jahren leicht rückläufig (vgl. Döhrn et al. 1998).

Die Arbeitsmarktreform fand vor dem institutionellen Hintergrund eines sehr flexiblen Arbeitsmarkts mit hohen steuerfinanzierten Arbeitslosenunterstützungsleistungen statt. In Dänemark existieren zwar tarifliche Regelungen, jedoch kaum gesetzliche Kündigungsschutzregelungen - der Arbeitsmarkt gilt hinter Großbritannien als der am weitesten deregulierte in Europa (vgl. Emmerich 1998). Das Niveau der Arbeitslosenunterstützung ist im europäischen Vergleich sehr hoch und die Dauer der Unterstützungsleistungen gehört zu den längsten in Europa - es werden bis zu $90 \%$ des letzten Nettogehalts bis zu 5 Jahre lang bezahlt. Im Anschluß besteht Anspruch auf die zeitlich unbefri- 
stete Sozialhilfe, die ebenfalls im europäischen Vergleich als großzügig einzuschätzen ist. Dementsprechend ist die Steuer- und Abgabenquote in Dänemark mit etwa $60 \%$ vergleichsweise sehr hoch.

Im Rahmen der „Aktivierung“ von Arbeitslosen wurden die Zumutbarkeitskriterien verschärft. So müssen Arbeitslose, die angebotene Stellen ausschlagen oder durch eigenes Verschulden verlieren, mit einer Minderung des Arbeitslosengeldes rechnen; im Wiederholungsfalle verlieren sie ihre Ansprüche. Bezieher von Arbeitslosengeld können nach einem Jahr, Bezieher von Sozialhilfe können bereits nach 13 Wochen zu öffentlichen Arbeiten herangezogen werden. Diese Maßnahmen trugen dazu bei, daß mehr Arbeitslose eine Arbeit aufnahmen (vgl. Döhrn et al. 1998, S. 25). Von 1998 an besteht für Langzeitarbeitslose, die länger als zwei Jahre arbeitslos sind, das Recht und die Pflicht auf Teilnahme an einer Bildungsmaßnahme oder subventionierten Beschäftigung. Bei geringqualifizierten Arbeitslosen unter 25 Jahren beginnt die Aktivierung bereits nach sechsmonatiger Arbeitslosigkeit. Sogenannte „Pool Jobs“ im öffentlichen Sektor - ähnlich den deutschen Arbeitsbeschaffungsmaßnahmen - werden bis zu drei Jahre zur Verfügung gestellt (vgl. Emmerich/Werner 1998). In diesem Rahmen existiert ein Welfare-to-WorkProgramm in Dänemark.

\section{(4) Deutschland}

In Deutschland existieren Welfare-to-Work-Programme im Rahmen der sogenannten „Hilfe zur Arbeit“. Hinter diesem Begriff verbergen sich verschiedene Arten gemeinnütziger Arbeit, die Kommunen den Sozialhilfeempfängern in verschiedenen Varianten anbieten. Seit 1982 haben diese kommunalen Arbeitsangebote angesichts steigender Sozialhilfeempfängerzahlen stark zugenommen (vgl. Hartmann 1985, S. 23). Zwischen 1993 und 1996 wurden die kommunalen Beschäftigungsangebote um 67 Prozent gesteigert, so da $\beta$ in den neunziger Jahren für etwa 200.000 der geschätzten 700.000 arbeitsfähigen Sozialhilfeempfänger, also etwa 30 Prozent, Stellen existieren (vgl. Fuchs 1997).

Nach $\S 18$ Abs. 2 BSHG besteht in Deutschland grundsätzlich eine Arbeitspflicht für arbeitsfähige Sozialhilfeempfänger. Wer zumutbare Arbeit ablehnt, muß nach $\S 25$ Abs. 2 BSHG mit der Kürzung seines Sozialhilfeanspruchs rechnen, bei mehrfacher Ablehnung kann die Sozialhilfe nach $\S 25$ Abs. 1 BSHG vollständig gestrichen werden. Insofern können Kommunen im bestehenden Rechtsrahmen Arbeitszwang ausüben. Kommunale Welfare-to-WorkProgramme existieren demnach in Deutschland bereits seit Anfang der achtziger Jahre in erheblichem Umfang.

Im Mittelpunkt dieses zweiten Arbeitsmarktes stehen Beschäftigungen im Rahmen der sogenannten „Mehraufwandsentschädigungsvariante“ nach $\S 19$ Abs. 2 BSHG (2. Alternative). Für den angenommenen Mehraufwand bei Ausübung einer gemeinnützigen und zusätzlichen Tätigkeit wird ein Mehr- 
aufwand von etwa drei DM in der Stunde bezahlt. Rund 42 Prozent der Beschäftigungsverhältnisse wurden nach dieser Variante gefördert (vgl. Fuchs 1997, S. 10). Etwa 30 Prozent der Beschäftigten befinden sich in Maßnahmen nach der „Entgeltvariante“ gemäß $§ 19$ Abs. 2 BSHG (1. Alternative). Diese Variante der Hilfe zur Arbeit sieht sozialversicherungspflichtige Arbeitsverhältnisse für Sozialhilfeempfänger mit marktüblicher Entlohnung für einen begrenzten Zeitraum vor, wobei die Kommunen das Entgelt vollständig übernehmen. Diese Arbeitsverhältnisse entsprechen in etwa den britischen temporary jobs. Träger dieser Beschäftigungsmaßnahmen sind insbesondere Kommunen (32\%), freie Träger (27 \%) und Wohlfahrtsverbände (23\%) (vgl. Fuchs 1997).

Im Gegensatz zu den Welfare-to-Work-Programmen in den USA und Großbritannien gibt es in Deutschland keine bundeseinheitliche Verpflichtung, allen (Langzeit)Arbeitslosen eine Arbeitsstelle anzubieten. Auch besteht weiterhin zeitlich unbefristeter Anspruch auf Sozialhilfe bei Bedürftigkeit. Ein radikaler Systemwechsel hat nicht stattgefunden, sondern es werden lediglich die bestehenden Zwangsmaßnahmen im Rahmen des Bundessozialhilfegesetzes verstärkt genutzt. Rosenfeld (1997b, S. 262) bezeichnet deshalb die Hilfe zur Arbeit-Maßnahmen als fakultatives Arbeitszwanginstrument.

Empirische Analysen der Hilfe zur Arbeit-Maßnahmen zeigen, daß zum einen die kommunalen Kosten dieser Maßnahmen kurzfristig höher sind als die Kosten des Status quo (vgl. Rosenfeld 1997b). Vorliegende Kosten-NutzenAnalysen zur Entgeltvariante kommen jedoch in der Regel zum Ergebnis, daß sich spätestens im dritten Jahr Einsparungen für die Kommunen ergeben (vgl. Fuchs 1997). Aus gesamtstaatlicher Sicht ist dieser Einspareffekt allerdings fraglich. Werden Hilfeempfänger im Anschluß an das Beschäftigungsverhältnis nach der Entgeltvariante wieder arbeitslos, so besteht Anspruch auf Arbeitslosengeld. Für den Zeitraum der Zahlung von Arbeitslosengeld sparen zwar die Kommunen Sozialhilfeausgaben, doch die Arbeitslosenversicherung sieht sich Mehrausgaben gegenüber. Der fiskalische Nettoeffekt ist demnach unbestimmt. Einsparungen durch den Verzicht auf Antragstellung potentieller Sozialhilfeempfänger lassen sich quantitativ kaum erfassen. Zwar kann der von den Kommunen ausgeübte Arbeitszwang abschreckend wirken, doch bleiben die Gründe für den Verzicht auf Sozialhilfe meist unklar (vgl. Hartmann 1985, S. 30).

\subsubsection{Das „Armutslückenkonzept" von Vaubel}

Die Absenkung der Sozialhilfe für arbeitsfähige Hilfeempfänger auf das physische Existenzminimum in Kombination mit einer Teilanrechnung von $\mathrm{Zu}-$ satzverdiensten wird von Vaubel (1996) vorgeschlagen. Der entscheidende Punkt seines Modells: Arbeitsfähige Sozialhilfeempfänger werden durch die Absenkung des Sozialhilfeniveaus in bezug auf ihr Nutzenniveau oder ihr verfügbares Gesamteinkommen nicht schlechtergestellt, weil für sie bei normalen 
Präferenzen ein positives Arbeitsangebot nutzenmaximal ist. Voraussetzung ist jedoch, daß ihnen der Zugang zum Arbeitsmarkt über außertarifliche Beschäftigungsverhältnisse ermöglicht wird. Die Kombination aus Kürzung des Transferniveaus und Teilanrechnung von Zusatzverdiensten führt zwar dazu, daß es für arbeitsfähige Hilfeempfänger nutzenmaximal wird zu arbeiten. Dennoch hat das Vaubel-Modell den Charakter eines „Arbeitszwangmodells“, weil arbeitsfähigen Hilfeempfängern eine massive Absenkung des Existenzminimums angedroht wird. Für nicht-arbeitsfähige Hilfeempfänger bleibt der Status quo unverändert.

Das „Vaubel-Modell“ erinnert an das Armutslückenkonzept von Friedman (1962/68), das ebenfalls eine Differenzierung des Existenzminimums vorsah (vgl. Kapitel 3.1.3). Die Armutslücke ist definiert durch die Differenz zwischen dem derzeitigen Existenzminimum und dem physischen Existenzminimum. Sie läßt sich anhand des von Vaubel gewählten Zahlenbeispiels quantifizieren. Das physische Existenzminimum für das Jahr 1994 berechnet er auf der Basis eines Sozialhilfeniveaus, ,das sich in der Vergangenheit ohne jeden Zweifel als menschenwürdig und ausreichend erwiesen hat" (Vaubel 1996, S. 181). So wird der durchschnittliche Eckregelsatz der Jahre 1962-1965 unter Berücksichtigung der Preisentwicklung auf das Jahr 1994 hochgerechnet. Zusammen mit dem Mietzuschuß und den einmaligen Leistungen ergibt sich dann ein Mindesteinkommen für arbeitsfähige Sozialhilfeempfänger von 659 DM/Monat, das „Zweifelsfrei deutlich über dem physischen Existenzminimum liegt" (Vaubel 1996, S. 181). Das durch die Sozialhilfeleistungen festgelegte Existenzminimum betrug im Jahre 1994 dagegen 917 DM/Monat. Die Armutslücke beträgt demnach monatlich $258 \mathrm{DM}$.

Zunächst soll in Anlehnung an Vaubel (1996) in Abbildung 26 gezeigt werden, daß das Armutslückenkonzept eingeführt werden kann, ohne die Sozialhilfeempfänger nutzenmäßig schlechter zu stellen:

Ausgangspunkt ist ein Hilfeempfänger, für den es bei normalen Präferenzen im Status quo nutzenmaximal ist, keine Arbeit anzubieten (Punkt A). Angesichts des gesunkenen Existenzminimums und der Nettolohnsatzerhöhung von $\mathrm{w}\left(1-\mathrm{t}_{\mathrm{STQ}}\right)$ mit $\mathrm{t}_{\mathrm{STQ}}=1$ auf $\mathrm{w}\left(1-\mathrm{t}_{\mathrm{v}}\right)$ mit $\mathrm{t}_{\mathrm{v}}<1$ wird es jedoch durch das Armutslückenkonzept nutzenmaximal Arbeit anzubieten (Punkt B): Der pauschaltransferbedingte Einkommenseffekt und der Substitutionseffekt wirken zusammen in Richtung mehr Arbeit; der klassische Einkommenseffekt existiert in diesem Fall nicht. Bei Individuen mit starker Präferenz für Freizeit ihre Indifferenzkurven verlaufen im Einkommen-Freizeit-Modell sehr steil bleibt es weiterhin nutzenmaximal, keine Arbeit anzubieten. Ihr Nutzenniveau sinkt jedoch, weil sie nur noch das physische Existenzminimum in Höhe von $659 \mathrm{DM} /$ Monat erhalten.

Die Steigung der Nettoeinkommensfunktion des Armutslückenkonzepts und die Höhe des „Vaubel-Grenzsteuersatzes“ $t_{v}$ hängt von der Festlegung des Break-even-Einkommens $\mathrm{Y}^{*}$ ab. Je höher das Break-even-Einkommen ge- 
wählt wird, desto anreizfreundlicher kann der Grenzsteuersatz auf Zusatzverdienste bei gegebener Armutslücke ausfallen.

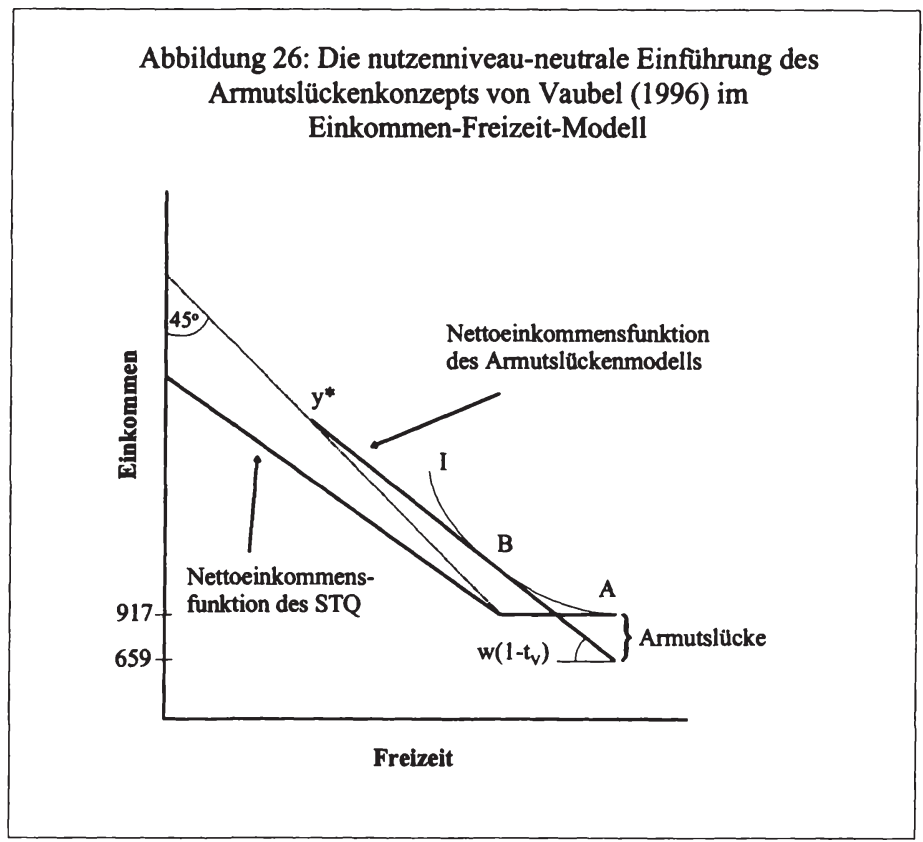

Eine Variante des Armutslückenkonzepts ist die nettoeinkommens-neutrale Einführung - sie wird in Abbildung 27 im Brutto-/Nettoeinkommen-Diagramm dargestellt.

Die Nettoeinkommensfunktion des Armutslückenkonzepts bei unverändertem steuerfreien Existenzminimum beginnt bei einem Nettoeinkommen von 659 DM/Monat, das arbeitsfähigen Hilfeempfängern zusteht. Bei einem Breakeven-Einkommen $\mathrm{Y}^{*}$ von 917 DM im Jahre 1994 mündet die Nettoeinkommensgerade des Armutslückenkonzepts in die Nettoeinkommensgerade des Status quo. Daraus ergibt sich ein Grenzsteuersatz auf Zusatzverdienste $t_{v}$ in Höhe von $71,9 \%$. Das Beispiel ist so gewählt, daß für Hilfeempfänger ein Arbeitsangebot mit einem Bruttoeinkommen in Höhe des steuerfreien Existenzminimums $\mathrm{Y}^{*}$ bei normalen Präferenzen nutzenmaximal ist. Die nettoeinkommens-neutrale Einführung des Armutslückenkonzepts von Vaubel würde demnach zur Einsparung der gesamten Sozialhilfeausgaben für arbeits- 
fähige Hilfeempfänger mit normalen Präferenzen führen. Das (nicht eingezeichnete) Nutzenniveau der Hilfeempfänger würde jedoch im Vergleich zum Status quo erheblich sinken. Für Individuen mit starker Präferenz für Freizeit wäre weiterhin der ausschließliche Bezug von Hilfeleistungen in Höhe von $659 \mathrm{DM} /$ Monat nutzenmaximal. Es ist jedoch zu beachten, daß im deutschen Sozialhilfesystem keine Wahlmöglichkeit für Hilfeempfänger besteht. Wer mehrfach zumutbare Arbeit ablehnt, muß mit der Kürzung der Sozialhilfe rechnen.

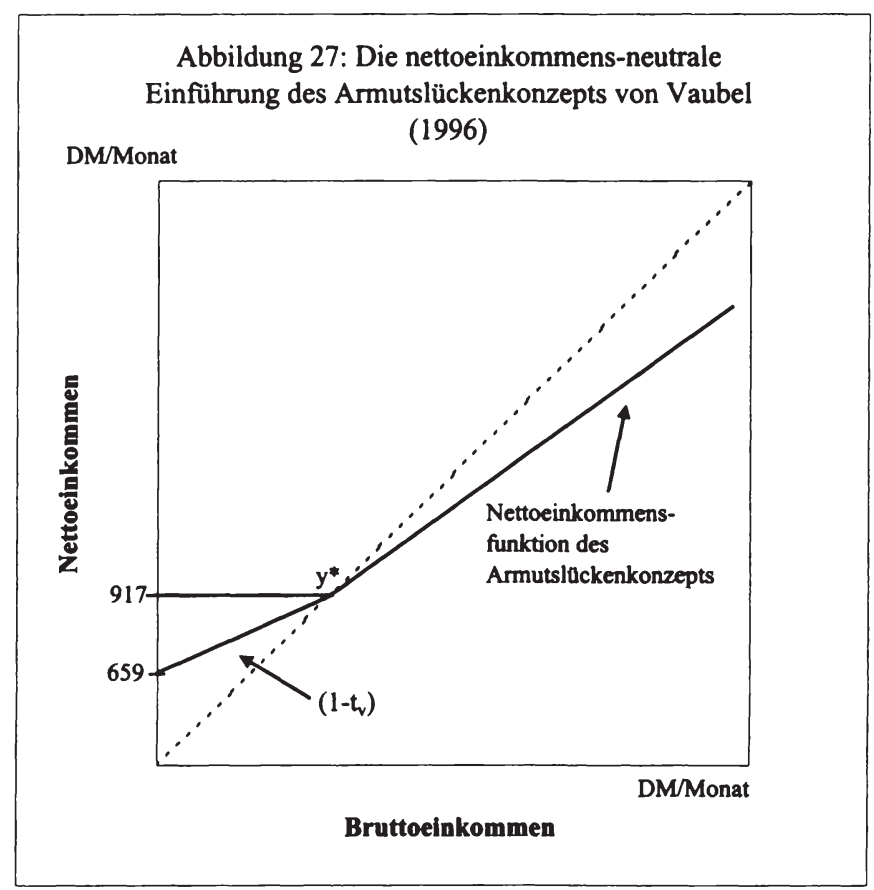

Es bleibt festzuhalten, daß die Armutsfalle durch das Vaubel-Armutslückenmodell durch die Kombination aus Absenkung des Existenzminimums für arbeitsfähige Sozialhilfeempfänger in Verbindung mit einem Grenzsteuersatz auf Zusatzverdienste von über $50 \%$ vollständig und dauerhaft abgemildert wird. Das Vaubel-Modell entspricht annähernd einer second best-Lösung, bei der lediglich eine Grundsicherung für nicht-arbeitsfähige Hilfeempfänger durch verzerrende Steuern finanziert wird.

Angesichts des zunehmenden Drucks auf die Hilfeempfänger bestehen jedoch hohe Anreize für arbeitsfähig eingestufte Hilfeempfänger, ,arbeitsunfähig“ zu werden; für Arbeitsunfähige soll der Status quo unangetastet bleiben. Doch sieht Vaubel (1990, S. 49) ein strenges Prüfverfahren vor, so daß diese Aus- 
weichreaktion zumindest sehr erschwert würde. Das Vaubel-Modell kann als spezielle Variante eines Welfare-to-Work-Programms verstanden werden, das Lohnsubventionen und Arbeitspflicht miteinander verbindet.

\subsection{Zusammenfassung}

In der aktuellen Diskussion befinden sich zahllose Vorschläge, wie Langzeitarbeitslosigkeit durch Lohnsubventionen verringert werden könnte. Die wichtigsten Modelle im In- und Ausland sowie die vielversprechendsten Vorschläge wurden in diesem Kapitel kritisch dargestellt.

Lohnsubventionen an Arbeitnehmer sind in den USA und Großbritannien seit vielen Jahren in der Praxis erprobt. Die Steuergutschriften „Earned Income Tax Credit" in den USA und „Family Credit" in Großbritannien spielen eine wichtige Rolle im sozialen Sicherungssystem dieser beiden Länder. Sie sind als „in-work benefits“ konstruiert, so daß gering entlohnte Arbeit durch Transfers an Arbeitnehmer gefördert wird. Beide Steuergutschriften sind als Familienförderung konzipiert; erst in letzter Zeit wurde der EITC für Alleinstehende geöffnet. Sowohl der Earned Income Tax Credit als auch der Family Credit und die Negative Wage Tax können als spezielle Varianten eines „Kombi-Einkommensmodell“" in das soziale Sicherungssystem in Deutschland eingeführt werden. Die Kombination von Marktlohn und Transfer ist kein neues Systemelement, sondern wird im Rahmen der ergänzenden Sozialhilfe oder Arbeitslosenunterstützung auch in Deutschland seit Jahren praktiziert. Alle in dieser Arbeit diskutierten Varianten von Lohnsubventionen an Arbeitnehmer unterscheiden sich im wesentlichen nur durch die Höhe des Transferanteils am Kombi-Einkommen. Es wurde diskutiert, welche Vor- und Nachteile die Einführung verschiedener Varianten von Kombi-Einkommensmodellen in das deutsche Sozialhilferecht mit sich bringen würde. Dabei stellte sich heraus, daß alle Modellvarianten in unterschiedlichem Umfang unter einem gemeinsamen Problem leiden: Die Einführungskosten werden für den Staat um so höher sein, je höher der Transferanteil am Kombi-Einkommen ausfallt. Hinzu kommt, daß die Kosten und potentiellen Einsparungen asymmetrisch zwischen unterschiedlichen Institutionen des Staates verteilt sein können. Das wird beim Kombi-Einkommensmodell der CDU/CSU-FDPKoalition vom 19.12.1997 deutlich: Die Einführungskosten müssen die Kommunen zahlen, die potentiellen Einsparungen durch höhere Beschäftigung sind eventuell nicht höher als die Einführungskosten und müssen mit Sozialversicherungsträgern und anderen Gebietskörperschaften geteilt werden.

Lohnsubventionen an Arbeitgeber sind ein traditionelles Arbeitsmarktinstrument, das auch in Deutschland weit verbreitet ist. Zur Zeit existieren etwa ein Dutzend unterschiedlicher Lohnsubventionsprogramme für unterschiedli- 
che Zielgruppen. Ob sie zur Erhöhung der Beschäftigung beitragen, ist heftig umstritten. Die Ergebnisse empirischer Studien sind widersprüchlich. Einerseits können positive Beschäftigungseffekte belegt werden, die durch Mitnahme-, Substitutions- und Verdrängungseffekte abgeschwächt werden. Andererseits deuten die Ergebnisse eines Feldexperiments in Dayton, Ohio, darauf hin, daß sich die Beschäftigungschancen von Arbeitslosen durch Lohnsubventionen sogar verschlechtern könnten. Der Grund: Arbeitgeber könnten den Anspruch auf Lohnsubventionen als Zeichen für geringe Produktivität interpretieren, so daß Lohnsubventionen stigmatisierend wirken. Auffällig ist, daß Arbeitgeber-Lohnsubventionen wenig in Anspruch genommen werden. Empirische Untersuchungen zeigen, daß hohe Informationskosten für die Arbeitgeber dafür verantwortlich sind: Der mit der Beantragung von Lohnsubventionen verbundene „Papierkrieg“ wirkt abschreckend.

Allgemeine Stundenlohnsubventionen für Niedriglohnbezieher versprechen Vorteile gegenüber traditionellen Lohnsubventionen, weil sie speziell Niedriglohnbeschäftigung fördern. Doch erscheinen die weitgehend identischen Vorschläge von Scharpf (1994) und Phelps (1994, 1997) aus fiskalischer Sicht unnötig teuer, weil Nicht-Bedürftige subventioniert werden sollen. Dabei ist unklar, ob die Einführungskosten geringer wären als die zu erwartenden Einsparungen durch höhere Beschäftigung - es liegen lediglich überschlägige Kostenberechnungen vor.

Das Benefit-Transfer Program (BTP) sieht vor, daß Langzeitarbeitslose ihre Arbeitslosenunterstützung potentiellen Arbeitgebern für ihre Einstellung als Gutschein anbieten können. Das Prinzip des BTP-Modells wurde bereits in mehreren Ländern erprobt und wird im Rahmen produktiver Lohnkostenzuschüsse auch in Deutschland umgesetzt. Detaillierte Programmevaluationen stehen jedoch noch aus.

Lohnsubventionen und Arbeitspflicht werden in den USA, Großbritannien und Dänemark im Rahmen von Welfare-to-Work-Programmen eng miteinander verknüpft. Welfare-to-Work-Programme stellen einen Bruch mit dem traditionellen Wohlfahrtsverständnis dar: Der Anspruch auf Sozialhilfe wird durch den Anspruch auf Arbeit ersetzt. Aus Sicht des Staates ist damit die Pflicht verbunden, arbeitsfähigen Sozialhilfeempfängern einen Job im privaten Sektor zu vermitteln oder im öffentlichen Sektor zur Verfügung zu stellen. In den achtziger Jahren stellte sich in mehreren Feldexperimenten in den USA heraus, da $ß$ diese Programme die Beschäftigungschancen der Hilfeempfänger erhöhen und damit zu fiskalischen Entlastungen beitragen können. In den neunziger Jahren wurden Welfare-to-Work-Programme in den USA ausgeweitet sowie in Großbritannien und in Dänemark eingeführt. Kritiker weisen jedoch auf die sehr hohen Kosten dieser Programme hin, die um so höher werden, je größer der Anteil der vermittelten Stellen im öffentlichen Sektor ist. Nur detaillierte Programmevaluationen können tieferen Einblick in die 
Wirkungsweise von Welfare-to-Work-Programmen geben - sie bleiben abzuwarten.

Auch in Deutschland besteht eine Arbeitspflicht für Sozialhilfeempfänger. In den neunziger Jahren zogen die Kommunen Sozialhilfeempfänger in zunehmenden Maße zu öffentlichen Arbeiten heran (Hilfe zur Arbeit) - der dabei entstehende Mehraufwand wird mit etwa drei DM/Stunde vergütet. Aber auch sozialversicherungspflichtige Tätigkeiten zum Marktlohn wurden von den Kommunen angeboten. Wenn sich auch Elemente von Welfare-to-Work-Programmen in Deutschland finden, so hat kein radikaler Kurswechsel in der Sozialpolitik stattgefunden. Die Kommunen fordern lediglich die Arbeitspflicht der Sozialhilfeempfänger verstärkt ein, in dem sie Hilfe zur ArbeitMaßnahmen anbieten, also Arbeitspflicht mit Lohnsubventionen kombinieren. Ein weitergehender Vorschlag ist das Armutslückenkonzept von Vaubel. Durch Absenkung des Sozialhilfeniveaus für arbeitsfähige Hilfeempfänger bei gleichzeitiger Verringerung der Transferentzugsrate würde der Druck auf Sozialhilfeempfänger erhöht, eine Tätigkeit aufzunehmen. 


\section{Kapitel 5: Das „Einstiegsgeld“ für Langzeitarbeitslose - ein Vorschlag zur Einführung einer zielgruppenorientierten ne- gativen Einkommensteuer in Deutschland}

\subsection{Zum Aufbau des Kapitels}

In diesem Kapitel wird die Idee einer zeitlich befristeten zielgruppenorientierten negativen Einkommensteuer entwickelt. Dieses Reformmodell wird als „Einstiegsgeld“ für Langzeitarbeitslose bezeichnet (vgl. Spermann 1995, 1996). Das Einstiegsgeld soll Marktlöhne unter dem Existenzminimum aufstocken. Es läßt sich im Rahmen der Sozialhilfe realisieren - dann wird Einstiegsgeld als ergänzende Sozialhilfe über die Sozialämter ausgezahlt. Es läßt sich aber auch im Rahmen des Arbeitsförderungsgesetzes einführen - dann wird das Einstiegsgeld als ergänzende Arbeitslosenhilfe über die Arbeitsämter ausgezahlt. Das Einstiegsgeld ist demnach nicht als Steuergutschrift konzipiert wie das Bürgergeld oder der amerikanische Earned Income Tax Credit eine Auszahlung über das Finanzamt ist nicht vorgesehen. Das Einstiegsgeld ist auch kein neues Subventionsmodell, das zusätzlichen Finanzbedarf erfordert. Einstiegsgeld heißt auch nicht, daß ein zusätzlicher Transfer wie das Erziehungsgeld eingeführt werden soll. Statt dessen werden mit dem Einstiegsgeldvorschlag die Sozial- und Arbeitslosenhilfe als Einkommenssubventionen an Arbeitnehmer eingesetzt. Das ist nicht völlig neu: Bereits im heutigen Transfersystem wirken ergänzend zum Marktlohn gezahlte Sozial- und Arbeitslosenhilfe als Einkommenssubventionen - die Kombination aus Marktlohn und Transfer ist gängige Praxis. Das Einstiegsgeld ist lediglich eine spezielle Variante eines zeitlich befristeten Kombi-Einkommensmodells, das höhere Leistungsanreize für Transferempfänger in das bestehende Transfersystem integriert. Gegenüber den in Kapitel 4.2.4 diskutierten Kombi-Einkommensmodellen unterscheidet sich das Einstiegsgeld jedoch in wesentlichen Punkten. Zum einen sind die Leistungsanreize für Transferempfänger wesentlich höher, so daß positive Beschäftigungseffekte und fiskalische Einsparungen zu erwarten sind. Zum anderen sind die Einführungskosten für den Staat minimal. Im Gegensatz zu Armutslückenkonzepten (vgl. Kapitel 3.1.3 u. 4.4.2) wird beim Einstiegsgeldvorschlag auf eine generelle Absenkung des Existenzminimums für arbeitsfähige Hilfeempfänger verzichtet.

Ziel des Einstiegsgeldvorschlags ist es, Langzeitarbeitslosen den Einstieg in den privaten Arbeitsmarkt zu erleichtern. Dabei wird implizit unterstellt, daß 
Erwerbstätigkeit eine geeignete Möglichkeit zum Erhalt und Aufbau von Humankapital darstellt. Es wird ein leistungsfreundliches Anreizsystem für Transferempfänger vorgeschlagen, das auf die Erhöhung des Arbeitsangebots abzielt. Wenn genügend motivierte Arbeitskräfte ihre Arbeit anbieten, dann werden zusätzliche Jobs entstehen. Diese arbeitsmarktökonomische Grundeinsicht hat sich in mehreren Ländern als empirisch relevant herausgestellt (vgl. Layard 1997b). Die aktuelle Arbeitsmarktpolitik in Deutschland zielt dagegen auf eine Reduzierung des Arbeitsangebots, z.B. durch weitgehende Vorruhestandsregelungen, um die offiziell ausgewiesene Arbeitslosenquote zu senken.

Der Einstiegsgeldvorschlag ist als Ergänzung existierender Maßnahmen der aktiven Arbeitsmarktpolitik des Bundes und der Kommunen gedacht. Das Einstiegsgeld ist ein offenes Konzept, das im Detail von seiten der verantwortlichen Politiker je nach Präferenzen auf Bundes-, Länder- oder kommunaler Ebene variiert werden kann. Die drei zentralen Bausteine des Einstiegsgeldvorschlags sind die leistungsfreundliche Ausgestaltung der Anrechnung von Zusatzverdiensten auf die Sozial- und/oder Arbeitslosenhilfe, die Begrenzung dieser verbesserten Anrechnungsvorschriften auf eine Zielgruppe und die zeitliche Befristung dieser Neuregelung.

In Kapitel 5.2 werden die obligatorischen und fakultativen Bausteine des Einstiegsgeldvorschlags präsentiert und zwei mögliche Varianten dargestellt. In Kapitel 5.3 werden die Beschäftigungswirkungen des Einstiegsgeldes im Vergleich zum Status quo theoretisch abgeleitet. Die grafische Analyse bezieht sich auf das Einkommen-Freizeit-Modell, das kompetitive Arbeitsmarktmodell und das Modell gleichgewichtiger Arbeitslosigkeit. In Kapitel 5.4 wird das Einstiegsgeld ausführlich diskutiert. Dabei wird versucht, sich von den engen partialanalytischen Modellen des vorherigen Kapitels zu lösen und auch längerfristige Wirkungskanäle zu identifizieren. Die ökonomische Diskussion schließt den Vergleich mit den im vierten Kapitel dargestellten Lohnsubventionsmodellen ein. Die Ergebnisse werden in Kapitel 5.5 zusammengefaßt.

\subsection{Bausteine des Einstiegsgeldes}

\subsubsection{Die Zielgruppe}

Als Zielgruppe des Einstiegsgeldes werden bedürftigkeitsgeprüfte Langzeitarbeitslose, die länger als ein Jahr arbeitslos sind, vorgeschlagen. Von zentraler Bedeutung ist nicht das Merkmal Langzeitarbeitslosigkeit, sondern die Begrenzung auf bedürftigkeitsgeprüfte Arbeitslose. Eine Bedürftigkeitsprüfung ist Voraussetzung für den Bezug von Arbeitslosenhilfe (vgl. Stascheit/Turk 1996) und für den Bezug von Sozialhilfe (vgl. Brühl 1996). Damit 
ist sichergestellt, daß Langzeitarbeitslose mit hohem Arbeitslosengeldanspruch, arbeitssuchende Hausfrauen mit gutverdienenden Ehegatten, Rentner mit durchschnittlichem Rentenanspruch, Schüler in Erwerbstätigenhaushalten und Studenten mit finanzieller Absicherung durch Eltern oder Stipendien nicht zur Zielgruppe gehören. Auf diese Weise werden Mitnahmeeffekte minimiert.

Fakultativ ist die Abgrenzung der Zielgruppe. Die offizielle Definition von Langzeitarbeitslosen bezieht sich auf die Dauer der Arbeitslosigkeit von über einem Jahr. Diese Definition ist jedoch willkürlich, so daß sie nicht bindend wirken muß. In die Zielgruppe können zum Beispiel auch jugendliche Arbeitslose aufgenommen werden, die bisher nicht oder nur kurz gearbeitet haben, so daß lediglich Anspruch auf Arbeitslosen- und/oder Sozialhilfe besteht. Die Einbeziehung bedürftigkeitsgeprüfter Jugendlicher in die Zielgruppe ließe sich dadurch rechtfertigen, daß es für diese Gruppe besonders wichtig ist, den Einstieg in den Arbeitsmarkt zu finden, weil sie ihr Berufsleben noch vor sich haben.

Alleinerziehende mit Kindern können ebenfalls in die Zielgruppe einbezogen werden, auch wenn sie nicht über ein Jahr arbeitssuchend sind. Der Anteil der Alleinerziehenden an den Sozialhilfeempfängern ist in den letzten Jahren stark gestiegen. Alleinerziehende sind bei längerem Sozialhilfebezug häufig mehrere Jahre ohne Kontakt zum Arbeitsmarkt. In dieser Zeit sind viele Alleinerziehende nicht als arbeitssuchend beim Arbeitsamt gemeldet. Wenn das Alter der Kinder nach Einschätzung der Sorgeberechtigten eine Teilzeitbeschäftigung erlaubt, kann ihr Einstieg in die Erwerbsarbeit durch das Einstiegsgeld unterstützt werden. Die Einbeziehung dieser Personengruppe läßt sich rechtfertigen, weil derzeit ein sehr hohes Nettoeinkommen aus Teilzeitarbeit erzielt werden muß, um den Sprung über die Armutsfalle zu schaffen (vgl. Kapitel 2).

$\mathrm{Zu}$ überlegen ist auch, ob erwerbstätige Haushaltsangehörige arbeitsloser Hilfeempfänger mit in die Zielgruppe einbezogen werden sollen. Ihr Nettoeinkommen wird derzeit voll mit dem Hilfeanspruch des arbeitslosen Hilfeempfängers verrechnet - mit der Konsequenz, daß sich bei Hilfebezug des Haushaltsvorstands die Erwerbstätigkeit des Partners finanziell nicht mehr lohnt (vgl. Kapitel 2). Die verringerte Anrechnung des Partnereinkommens während des Hilfebezugs des Haushaltsvorstands würde die Leistungsanreize der Partner nicht mehr zerstören.

Als Untergrenze für den Umfang der Zielgruppe kann die Zahl der Arbeitslosenhilfeempfänger gelten: Im Jahre 1996 bezogen 1,1 Millionen Personen Arbeitslosenhilfe, wobei Arbeitslosenhilfeempfänger in der Regel bedürftige Langzeitarbeitslose sind (vgl. Kapitel 2.5.3). Liegt die Arbeitslosenhilfe unter der Bedürftigkeitsgrenze, so kann ergänzende Sozialhilfe beantragt werden Konstellationen, von denen insbesondere Familien mit hohen Wohnkosten in Großstädten betroffen sind, deren quantitative Bedeutung aber aus den beste- 
henden Statistiken nicht zu isolieren ist. Demnach sind lediglich zwei Personengruppen zu addieren: arbeitsfähige Sozialhilfeempfänger, deren Arbeitslosengeld unter der Bedürftigkeitsgrenze liegt, und arbeitsfähige Sozialhilfeempfänger, die ausschließlich Sozialhilfe beziehen. Konkrete Zahlen lassen sich aus den vorliegenden Statistiken nicht errechnen. Je nach dem, ob Jugendliche, Alleinerziehende und Partner ebenfalls in die Zielgruppe einbezogen werden, nimmt der Umfang der Zielgruppe entsprechend zu. Die Zielgruppe umfaßt demnach 1,1 Millionen plus x Personen. Grundsätzlich ist es jedoch möglich, durch detaillierte Untersuchungen auf kommunaler Ebene die Zielgruppe zu quantifizieren.

\subsubsection{Das Anrechnungsverfahren}

Ein weiteres Kernelement des Einstiegsgeldvorschlags ist die Teilanrechnung von Zusatzverdiensten auf die Sozial- und/oder Arbeitslosenhilfe. Dabei ist sowohl der Anrechnungssatz als auch die Bemessungsgrundlage je nach Präferenzen gestaltbar. Entscheidend ist jedoch, daß mindestens die Hälfte des Zusatzverdienstes beim Hilfeempfänger verbleibt, um hohe Leistungsanreize in das Transfersystem zu integrieren.

Jeder Anrechnungssatz des Einstiegsgeldes $t_{\mathrm{EG}}$ unter $100 \%$ ist anreizfördernd. Doch besteht in der finanzwissenschaftlichen Steuerlehre weitgehende Einigkeit, daß Grenzsteuersätze unter $50 \%$ anzustreben sind (vgl. Wissenschaftlicher Beirat beim Bundesministerium der Wirtschaft 1996b, Wissenschaftlicher Beirat beim Bundesministerium der Finanzen 1996). Eine Transferentzugsrate von $100 \%$ im Bereich der Armutsfalle wirkt ökonomisch wie ein Grenzsteuersatz von $100 \%$ auf eigene Verdienste von Transferempfängern. Wieviel letztlich von jeder Mark an Zusatzverdienst unter Berücksichtigung des Steuer-, Abgaben- und Transfersystems beim Hilfeempfänger verbleiben soll, ist nicht wissenschaftlich entscheidbar. Der Vorschlag, die Hälfte oder mehr des Zusatzverdienstes dem Hilfeempfänger zu belassen, ist damit normativ. Es spricht nichts dagegen, die Anrechnungssätze nach Personengruppen zu differenzieren. So könnten zum Beispiel die Zusatzverdienste von Jugendlichen und Alleinerziehenden unterschiedlich angerechnet werden. Die Anrechnungssätze können außerdem nach Dauer der Arbeitslosigkeit oder des Hilfebezugs variiert werden. Auch diese Variationen sind normativ. Sie könnten jedoch wissenschaftlich fundiert werden, wenn unterschiedliche Arbeitsangebotsfunktionen für klar abgrenzbare Personengruppen empirisch feststellbar wären. Die vorliegenden Schätzungen sind jedoch nicht differenziert genug (vgl. Kapitel 3.2.2.1).

Strebt man jedoch bei Reformbemühungen die Zielgröße 50 \% des Zusatzverdienstes an, so ist darauf zu achten, daß die Hälfte des Bruttoverdienstes beim Hilfeempfänger verbleibt. In der Praxis wird derzeit das Nettoeinkommen nach Abzug von Sozialversicherungsbeiträgen und Steuern mit der Sozialhilfe verrechnet (vgl. Kapitel 2.5.2). Eine Absenkung des Anrechnungssat- 
zes auf $50 \%$ des Nettoeinkommens wäre demnach zwar eine Verbesserung der Leistungsanreize gegenüber dem Status quo, doch könnten sich im Einzelfall weiterhin prohibitiv hohe Grenzsteuersätze ergeben, so daß das Ziel einer Arbeitsangebotserhöhung verfehlt würde.

Über eine Variation der Bemessungsgrundlage könnte die Mobilität der Hilfeempfänger gefördert werden. Stellen, die weit vom Wohnort entfernt liegen, könnten finanziell attraktiver werden, wenn Fahrtkosten - analog zum Steuerrecht - vom anzurechnenden Einkommen abgezogen werden dürften. Alleinerziehende hätten höhere Leistungsanreize, wenn darüberhinaus die Kosten der Kinderbetreuung von der Bemessungsgrundlage abgezogen werden dürften. Über weitere Abzüge von der Bemessungsgrundlage im Transfersystem kann mit Blick auf das Steuerrecht reflektiert werden.

Als Bemessungsgrundlage muß jedoch nicht der monatliche Bruttoverdienst gewählt werden. Vor dem Hintergrund der Diskussion zu Stundenlohnsubventionen läßt sich die Teilanrechnung von Zusatzverdiensten auf gering entlohnte Tätigkeiten mit einem Stundenlohn von bis zum Beispiel 15 DM begrenzen. Dadurch ließen sich gezielt niedrig produktive Tätigkeiten fördern. Die Entscheidung für Stundenlohnsubventionen ist mit einer impliziten Einkommensobergrenze für Zusatzverdienste verbunden. Bei einem maximalen Stundenlohn von $15 \mathrm{DM}$, der gefördert werden soll, liegt die implizite Einkommensobergrenze unter der Annahme einer 40-Stunden-Woche bei 2400 DM/Monat - und damit unterhalb der Bedürftigkeitsgrenze einer Familie mit zwei Kindern. Bei einer Teilanrechnung des Bruttoeinkommens könnte eine explizite Einkommensobergrenze eingeführt werden. Dabei bietet sich die Bedürftigkeitsgrenze als Obergrenze an, weil oberhalb der Bedürftigkeitsgrenze im Status quo kein Anspruch auf Transfers mehr besteht.

Ein Sonderproblem stellt die Personengruppe dar, die sowohl Arbeitslosenals auch Sozialhilfe bezieht. Dabei handelt es sich um knapp 170.000 Personen im Jahre 1997 (vgl. Statistisches Bundesamt 1998c, S. 15). Solange die Anrechnungsregeln der Arbeitslosen- und Sozialhilfe nicht synchronisiert sind, kommt es zwangsläufig zum Problem, daß großzügigere Anrechnungsvorschriften in einem Teil des Transfersystems von den relativ restriktiveren Anrechnungsvorschriften im anderen Teil des Transfersystems konterkariert werden. Konkret geht im Jahre 1996 für Arbeitslose der Status Arbeitslosigkeit verloren, wenn sie mehr als 18 Stunden je Woche arbeiten. Damit entfällt der Anspruch auf Arbeitslosenhilfe, so daß ausschließlich die Sozialhilfeträger das Markteinkommen aufstocken müssen. Das kann im Einzelfall dazu führen, daß die Ausgaben für ergänzende Sozialhilfe zunehmen, obwohl Hilfeempfänger mehr als im Status quo arbeiten. Vergleichbare Fälle lassen sich unter Berücksichtigung des Wohngeldes oder anderer Transfers konstruieren. Diese Beispiele machen deutlich, daß bei Veränderungen von Einzelregelungen des Transfersystems das Zusammenspiel mit anderen Transfers und dem Abgabensystem berücksichtigt werden muß. 


\subsubsection{Die zeitliche Befristung}

Das dritte Kernelement des Einstiegsgeldvorschlags ist die zeitliche Befristung des veränderten Anrechnungsverfahrens für Zusatzverdienste der Zielgruppe. Entscheidend ist, daß eine zeitliche Befristung existiert, die Länge des Zeitraums ist jedoch Gestaltungselement.

Analog zu den Überlegungen für eine Differenzierung der Anrechnungssätze läßt sich auch eine Differenzierung der zeitlichen Befristung lediglich normativ einführen. So könnten Jugendliche und Familien mit Kindern unterschiedlich lange gefördert werden. Auch könnte die zeitliche Befristung nach der vorherigen Dauer des Hilfebezugs differenziert werden.

Ein wichtiges Gestaltungselement ist die Kumulation kurzfristiger Beschäftigungsverhältnisse. Die internationalen Erfahrungen mit Tätigkeiten im Niedriglohnbereich und im Teilzeitbereich deuten darauf hin, daß die Zielgruppe häufig nur kurzfristige Beschäftigungen als Einstiegsjobs erhalten wird (vgl. OECD 1996, 1997c). Deshalb erscheint es bedeutsam, daß mehrere kurzfristige Beschäftigungen zu einer maximalen Dauer der Förderung von Zusatzverdiensten der Hilfeempfänger addiert werden dürfen. Dadurch wird vermieden, daß Unterbrechungen der Erwerbstätigkeit von Hilfeempfängern, zum Beispiel nach drei Monaten, wieder in die Armutsfalle des Status quo führen.

\subsubsection{Die Kombination mit Einstiegstarifen}

Die zeitlich befristete Einführung einer Teilanrechnung von Zusatzverdiensten kann mit der zeitlich befristeten Einführung untertariflicher Entlohnung von Langzeitarbeitslosen kombiniert werden. Einstiegstarife wurden zum Beispiel im Jahre 1995 von den Tarifparteien der Chemischen Industrie vereinbart (vgl. IG Chemie 1995). Grundsätzlich ist es jedoch nicht nötig, neue Tarifgruppen $\mathrm{zu}$ vereinbaren solange derzeit nicht besetzte untere Lohngruppen in den jeweiligen Branchen existieren.

Die Kombination mit Einstiegstarifen könnte folgendermaßen aussehen: In dem Maße wie die Entlohnung des Arbeitnehmers gemäß seiner erwarteten Produktivitätssteigerungen zunimmt, kann der Transferanteil (=Einstiegsgeld) am Gesamtverdienst des Arbeitnehmers abnehmen. Das wird dadurch erreicht, daß der Anrechnungssatz auf Zusatzverdienste im Zeitablauf steigt. Aus Arbeitnehmersicht bleibt dann sein Gesamteinkommen im Zeitraum der Förderung konstant. Es ändert sich jedoch die Zusammensetzung seines Gesamteinkommens, genauer seines Kombi-Einkommens aus Marktlohn und Transfer. Ein Pendant dieser Konstruktion findet sich auf dem Kreditmarkt: Eine Annuitätenzahlung bleibt über den Tilgungszeitraum für den Kreditnehmer konstant, doch ändert sich die Kombination aus Zins- und Tilgungszahlungen im Zeitablauf. 


\subsubsection{Administrative Ausgestaltung}

Der Einstiegsgeldvorschlag kann sowohl im Rahmen des Sozialhilferechts als auch des Arbeitsförderungsgesetzes realisiert werden. Kurzfristig ist eine getrennte Einführung in beide Gesetze denkbar. Sozialhilfeempfänger würden dann wie bisher über das Sozialamt ihren Transfer bekommen, Arbeitslosenhilfeempfänger würden über das Arbeitsamt Transfers erhalten. Im Gegensatz zum Vorschlag eines Bürgergeldes und zum amerikanischen EITC spielt das Finanzamt keine Rolle bei der Berechnung und Auszahlung der Transfers. Das Einstiegsgeld ist nicht als Steuergutschrift konzipiert, sondern als monatlich auszuzahlender Transfer. Damit wird vermieden, daß Hilfeempfänger mit Anspruch auf eine jährlich auszuzahlende Steuergutschrift aus Liquiditätsgründen vorübergehend Sozialhilfe beantragen müssen (vgl. Kapitel 4.2.1). Doch haben die Ausführungen in Kapitel 5.2.2 gezeigt, daß Harmonisierungsbedarf existiert, weil eine nicht unerhebliche Zahl von Hilfeempfängern derzeit sowohl Arbeitslosen- als auch Sozialhilfe bezieht. Mittelfristig müßten die Anrechnungsregeln angeglichen werden. Spätestens nach einer Angleichung stellt sich dann die Frage, ob nicht die Integration der beiden Transfers und die verwaltungsmäßige Abwicklung über ein Amt effizienter wäre. Dabei entstehen jedoch erhebliche Detailprobleme, die im wesentlichen auf einen Umstand zurückzuführen sind: die Sozialversicherungsabgaben, die die Bundesanstalt für Arbeit für Arbeitslosenhilfeempfänger an die Rentenund Krankenversicherungsträger überweist. Ein Zahlenbeispiel: Im Jahre 1996 betrug der durchschnittliche monatliche Aufwand je Arbeitslosenhilfeempfänger 1830,15 DM, nach Abzug der Beiträge zur Kranken-, Pflege-, und Rentenversicherung wurden den Arbeitslosenhilfeempfängern durchschnittlich 1015,21 DM ausgezahlt (vgl. Bundesanstalt für Arbeit 1997, S. 58f.). Sozialhilfeempfänger erwerben dagegen keine Sozialversicherungsansprüche. Darin besteht ein wesentlicher Unterschied zwischen Sozial- und Arbeitslosenhilfe. Dementsprechend müßte bei einer verwaltungsmäßigen Integration beim Arbeitsamt die Bundesanstalt für Arbeit die Sozialversicherungsbeiträge für alle arbeitsfähigen Sozialhilfeempfänger übernehmen. Umgekehrt würden die Arbeitslosenhilfeempfänger bei einer verwaltungsmäßigen Integration beim Sozialamt auf den Erwerb von Sozialversicherungsansprüchen verzichten müssen. In diesem Spannungsfeld ist eine mittelfristige Lösung zu suchen.

Die administrative Effizienz ließe sich ebenfalls steigern, indem die derzeit unterschiedlichen Bedürftigkeitsprüfungen als Voraussetzung für den Bezug von Arbeitslosen- und Sozialhilfe harmonisiert werden.

\subsubsection{Das Darlehensmodell}

Eine wichtige Frage stellt sich aufgrund der zeitlichen Befristung des Einstiegsgeldvorschlags: Gilt für Hilfeempfänger, die den Sprung über die Ar- 
mutsfalle nach Ablauf der Förderung noch nicht geschafft haben, wiederum die Armutsfalle des Status quo?

Eine Möglichkeit, besonders schwer vermittelbaren Hilfeempfängern weiterhin Anreize zur Aufnahme von Erwerbstätigkeit zu geben, ist eine spezielle Variante eines Darlehensmodells. Die Grundidee: Hilfeempfänger sollen ihr verfügbares Einkommen nur noch auf Darlehensbasis erhöhen können. Folgendes Zahlenbeispiel soll die Darlehenslösung verdeutlichen (vgl. Abbildung 29 in Kapitel 5.2.7). Die Höhe des Darlehens wird durch den vertikalen Abstand zwischen der Nettoeinkommensfunktion des Einstiegsgeldes und der Nettoeinkommensfunktion des Status quo gemessen - der maximale Darlehensbetrag beträgt für Verheiratete mit zwei Kindern $1666 \mathrm{DM} / \mathrm{Monat}$ (4592 DM/Monat - 2926 DM/Monat). Wenn der monatliche Höchstbetrag gewährt wird, dann könnte das Darlehen bei einer politisch festgelegten maximalen Darlehensobergrenze von 20.000 DM 12 Monate ausgezahlt werden. Eine Kumulation unterschiedlich hoher monatlicher Darlehensbeträge bis zu einer Höchstgrenze erscheint vorteilhaft gegenüber einer zeitlichen Befristung der Darlehensvergabe, weil die Festlegung eines bestimmten Zeitraums kurzzeitige Beschäftigungen diskriminieren würde. Die Rückzahlungskonditionen könnten in Anlehnung an bestehende Regelungen (z.B. BAföG) ausgestaltet werden. Die Transfervergabe auf Darlehensbasis ist kein fundamental neues Element im deutschen Transfersystem - sie wird bereits praktiziert: Die laufende Hilfe zum Lebensunterhalt kann in Sonderfällen und bei vorübergehenden Notlagen als Darlehen nach § 15b BSHG gewährt werden (vgl. Schellhorn et al. 1993, S. 149-153).

Der entscheidende Vorteil des Darlehensmodells ist der Einspareffekt für den Staat gegenüber dem Status quo. Zur Veranschaulichung ist es hilfreich, den oben angesprochenen Grenzfall mit dem maximalen Darlehensbetrag zu betrachten. Einem Verheirateten mit zwei Kindern verbleibt bei einem Bruttoeinkommen von $3505 \mathrm{DM} /$ Monat, nach Abzug von Sozialversicherungsabgaben in Höhe von 579 DM/Monat, ein Nettoeinkommen von 2926 DM/Monat. Bei diesem Bruttoeinkommen wird der maximale Darlehensbetrag von $1666 \mathrm{DM} /$ Monat ausgezahlt, so daß sein Nettoeinkommen nach Transfer auf Darlehensbasis 4592 DM/Monat beträgt. Der entscheidende Punkt: Da der Verheiratete weiterhin arbeitet, kommt es zu Einsparungen des Staates im Vergleich zum Status quo. Konkret nehmen die Sozialversicherungsträger monatlich $579 \mathrm{DM}$ ein, und die Kommunen gewähren statt Transferzahlungen in Höhe von $2580 \mathrm{DM} /$ Monat (2753 DM/Monat - 173 $\mathrm{DM} /$ Monat) für minimal erwerbstätige Hilfeempfänger, die sie im Status quo ausgeben würden, nur noch ein Darlehen von 1666 DM/Monat. Für die Kommunen ergeben sich demnach selbst im Fall der Nicht-Tilgung des Darlehens Einsparungen von 914 DM/Monat (2580 DM/Monat - 1666 DM/Monat) - eine enorme Kostenentlastung gegenüber dem Status quo. Wird das Darlehen vollständig oder zum Teil zu einem späteren Zeitpunkt zurück- 
gezahlt, erhöhen sich die Einsparungen um den Gegenwartswert der Zins- und Tilgungsbeträge.

Die Darlehenslösung nimmt implizit an, daß sich ehemals bedürftigkeitsgeprüfte Langzeitarbeitslose nicht auf dem Kapitalmarkt verschulden können. Das läßt sich auch in der Realität beobachten. Die vorgeschlagene Ausgestaltung der Darlehenslösung eröffnet die Möglichkeit, Erfolgsprämien (z.B. Teilschuldenerlaß) bei vorzeitiger Tilgung zu gewähren. Selbst in dem unwahrscheinlichen Fall, daß alle aufgenommenen Darlehen nie zurückgezahlt werden, spart der Staat im Vergleich zum Status quo enorme Transferbeträge. Vollständige Mitnahmeeffekte sind jedoch nicht zu erwarten.

$\mathrm{Ob}$ ehemals Langzeitarbeitslose das Darlehensangebot annehmen, läßt sich experimentell erforschen. Dagegen spricht, daß sie ein in Zukunft rückzahlbares Darlehen mit der vollständigen Anrechnung gleichsetzen. Andererseits können sie auf Darlehensbasis über ein höheres Einkommen in der Gegenwart verfügen. Die Annahme des Darlehensangebots wird um so wahrscheinlicher, je attraktiver die angebotenen Erfolgsprämien sind. Es liegt im Eigeninteresse der Sozialämter/Arbeitsämter, ihre Darlehensangebote möglichst so auszugestalten, daß Hilfeempfänger sie annehmen - jedes zurückgezahlte Darlehen mit positivem Gegenwartswert vermindert ihre Transferausgaben. Deshalb dürften die Sozialämter/Arbeitsämter attraktive Darlehen mit großzügigen Rückzahlungskonditionen anbieten, die von den Hilfeempfängern auch angenommen werden.

\subsubsection{Zwei mögliche Varianten}

Nach der Darstellung der verschiedenen Bausteine des Einstiegsgeldvorschlags werden zwei mögliche Modellvarianten am Beispiel des Haushaltstyps Verheiratete mit zwei Kindern präsentiert. In Abbildung 28 wird eine Modellvariante mit Einkommensobergrenze, in Abbildung 29 wird das Einstiegsgeld als degressive Einkommenssubvention vorgestellt.

Für Verheiratete mit zwei Kindern ist der Ausgangspunkt die Armutsfalle im Status quo im Bruttoeinkommensbereich zwischen 173 DM und 3505 DM/Monat (vgl. Abbildung 9 in Kapitel 2.5.2). Die Nettoeinkommensfunktion des Einstiegsgeldes für Langzeitarbeitslose beginnt bei einem Wert von 2926 DM im Monat - die Steigung wird bestimmt durch den Grenzsteuersatz des Einstiegsgeldes $t_{\mathrm{EG}}$ von $50 \%$. Zur Überwindung der Armutsfalle ist nur die Teilanrechnung bis zu einem Bruttoeinkommen von $3505 \mathrm{DM} / \mathrm{Monat}$ (Nettoeinkommen: $4592 \mathrm{DM} / \mathrm{Monat}$ ) nötig - hier befindet sich die Bedürftigkeitsgrenze. Die Bedürftigkeitsgrenze ist eine explizite Einkommensobergrenze. Eine implizite Einkommensobergrenze ergibt sich bei einer Teilanrechnung von Zusatzverdiensten bis zu einem bestimmten Stundenlohn, worauf in Kapitel 5.2.2 hingewiesen wurde. Der Vorteil einer Einkommensobergrenze besteht darin, daß Mitnahmeeffekte minimiert werden: Hilfeempfänger, die ein Nettoeinkommen oberhalb der Bedürftigkeitsgrenze bzw. 
einen Stundenlohn oberhalb des maximalen Stundenlohnes erzielen, werden nicht gefördert. Der Nachteil einer Einkommensobergrenze ist jedoch eine anreizfeindliche Sprungstelle in der Nettoeinkommensfunktion der Transferempfänger, wie in Abbildung 28 deutlich wird. Beim Übergang vom Transfersystem in das Steuer- und Abgabensystem entsteht an der Einkommensobergrenze ein unendlich hoher Grenzsteuersatz. Hier wird ein Zielkonflikt in der Ausgestaltung deutlich: Minimierung von Mitnahmeeffekten und hohe Leistungsanreize über den gesamten Tarifverlauf lassen sich nicht gleichzeitig erreichen.

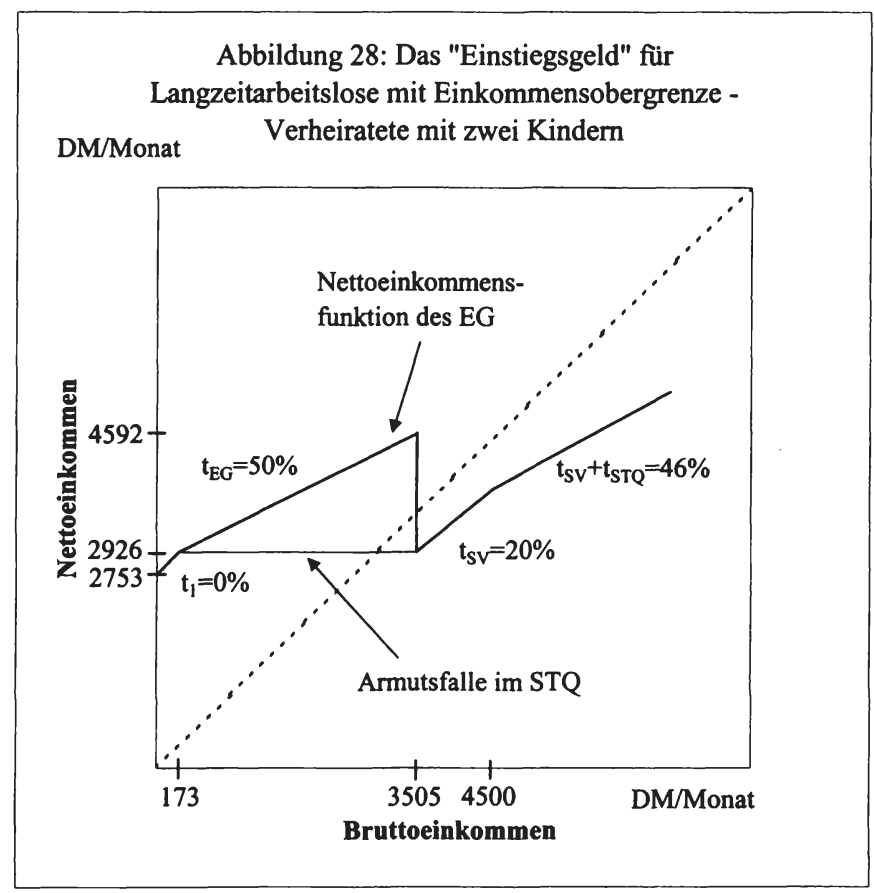

Verzichtet man jedoch auf eine Einkommensobergrenze und nimmt bewußt Mitnahmeeffekte zugunsten eines kontinuierlichen Verlaufs der Nettoeinkommensfunktion des Einstiegsgeldes in Kauf, so müßte das Einstiegsgeld auch an Personen mit sehr hohem Bruttoeinkommen gezahlt werden: Der Schnittpunkt der beiden Nettoeinkommensfunktionen liegt deshalb bei einem sehr hohen Bruttoeinkommen, weil die beiden Funktionen oberhalb des steuerfreien Existenzminimums nahezu parallel verlaufen. Der Verzicht auf eine Einkommensobergrenze hätte um so höhere Mitnahmeeffekte zur Folge je leistungsfreundlicher das Einstiegsgeld und je stärker die Progression des Steuersystems ausgestaltet sind. Deshalb bietet es sich an, die Nettoeinkom- 
mensfunktion des Einstiegsgeldes in höheren Einkommensbereichen abzuflachen, um einen Schnittpunkt $Y^{* *}$ in mittleren Bruttoeinkommensbereichen sicherzustellen. Eine Möglichkeit wäre es, den Anrechnungssatz oberhalb der Einkommensobergrenze zu steigern, wobei sowohl ein konstanter Grenzsteuersatz $0,5<\mathrm{t}_{\mathrm{EG}}<1$ als auch ein variabler Grenzsteuersatz auf Zusatzverdienste realisierbar sind. Vorstellbar ist auch, den Anrechnungssatz mit der Dauer der Gewährung des Einstiegsgeldes ansteigen zu lassen, so daß sich die Nettoeinkommensfunktion im Zeitablauf abflacht. Abbildung 29 spiegelt eine mögliche Variante des Einstiegsgeldes als degressive Einkommenssubvention mit konstantem Anrechnungssatz oberhalb der Bedürftigkeitsgrenze wider. Der Zielkonflikt zwischen möglichst hohen Leistungsanreizen und möglichst geringen Mitnahmeeffekten wäre auf diese Weise zugunsten der Leistungsanreize gelöst.

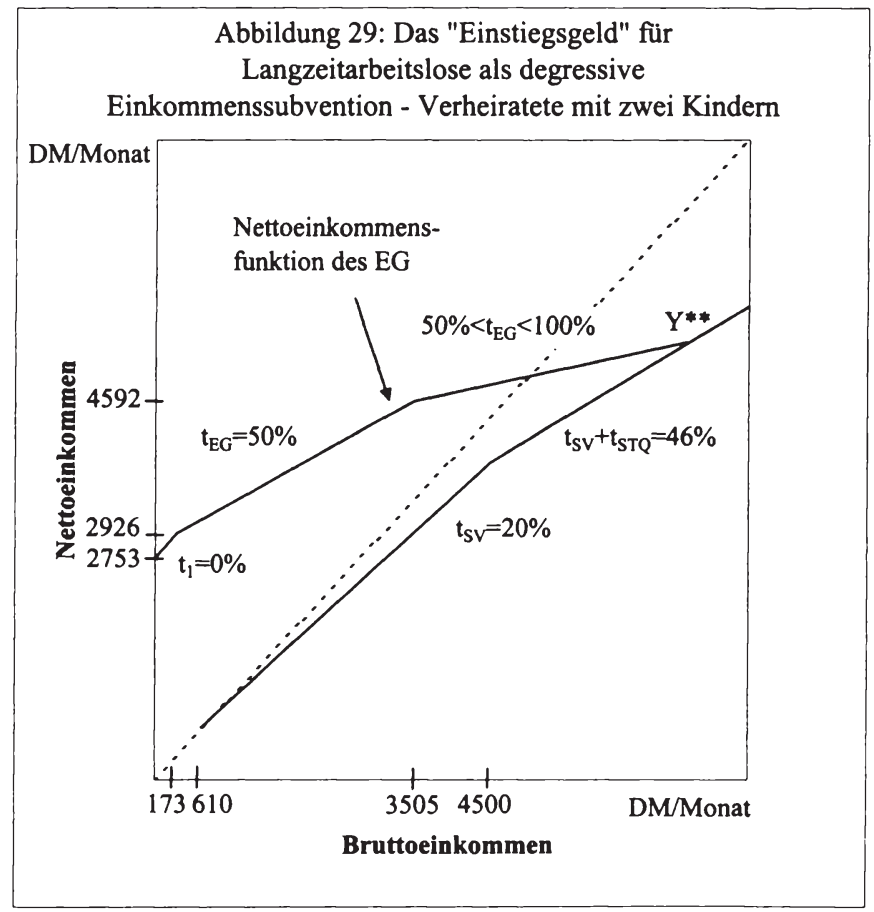

Die Armutsfalle im Arbeitsförderungsgesetz kann ebenfalls durch eine zeitlich befristete Teilanrechnung von Zusatzverdiensten beseitigt werden - in analoger Weise zu obigen Darstellungen, so daß auf weitere Schaubilder ohne Informationsverlust verzichtet werden kann. 


\subsubsection{Langfristige Lösungen}

Es ist nicht auszuschließen, daß besonders schwer vermittelbare Hilfeempfänger selbst im Anschluß an die Darlehenslösung keine Beschäftigung gefunden haben, mit deren Einkommen sie über dem Sozialhilfeniveau liegen. Wenn das derzeitige Existenzminimum unverändert bleiben soll, dann läßt sich die Armutsfalle durch zeitlich unbefristete Kombi-Einkommensmodelle dauerhaft beseitigen. Kombi-Einkommensmodelle sind bei der Einführung um so teurer für den Staat, je höher der Transferanteil am Kombi-Einkommen ist, wie in Kapitel 4.2 ausführlich gezeigt wurde. Nach Auswertung eines Feldexperimentes mit dem zeitlich befristeten Einstiegsgeld ließen sich jedoch die Arbeitsangebotsreaktionen verschiedener Zielgruppen auswerten, so daß ein zeitlich nicht befristetes Kombi-Einkommensmodell mit weniger Unsicherheiten in bezug auf die fiskalische Belastung verbunden wäre. Die dauerhafte Beseitigung der Armutsfalle ohne Einführungskosten ist lediglich bei einer Absenkung des Hilfeniveaus arbeitsfähiger Hilfeempfänger zu erreichen. Armutslückenkonzepte im Sinne von Friedman oder Vaubel weisen dann den Weg.

\subsection{Beschäftigungswirkungen des Einstiegsgeldes im Vergleich zum Sta- tus quo}

\subsubsection{Zur Auswahl des Analyseinstrumentariums}

Welcher theoretische Analyserahmen ist für die Untersuchung der Beschäftigungswirkungen des Einstiegsgeldes im Vergleich zum Status quo und zu anderen Lohnsubventionsmodellen geeignet? Kirchgässner (1996, S. 395) kommt zu der Einschätzung, daß die traditionelle Theorie derzeit nicht in der Lage ist, einfache Vorschläge zum Abbau der bestehenden Massenarbeitslosigkeit zu liefern. Dagegen arbeite die Neue Politische Ökonomie eine Reihe wichtiger Aspekte des Problems der Arbeitslosigkeit heraus: Arbeitslosigkeit werde bewußt erzeugt und duldend hingenommen. Landmann (1996, S. 434) weist jedoch zu Recht darauf hin, daß „die Public-Choice-Literatur, soweit sie sich überhaupt mit der Arbeitslosigkeit befaßt hat, den aktuellen Stand der Beschäftigungstheorie nur wenig rezipiert" zu haben scheint.

Vor diesem Hintergrund wird in der vorliegenden Arbeit nicht nur auf das kompetitive Arbeitsmarktmodell zur Erklärung freiwilliger Arbeitslosigkeit zurückgegriffen, sondern auch das Modell gleichgewichtiger Arbeitslosigkeit zur Untersuchung der Beschäftigungswirkungen herangezogen. Das Modell gleichgewichtiger Arbeitslosigkeit gilt bei allen Vorbehalten als nützliches, theoretisches Referenzmodell zur Erklärung unfreiwilliger Arbeitslosigkeit (vgl. Franz 1996b, S. 4f.), das bereits Eingang in die aktuelle makroökonomi- 
sche Lehrbuchliteratur gefunden hat (vgl. Burda/Wyplosz 1997, Blanchard 1997). Landmann (1996, S. 434) bezeichnet es als „Standard-Analyserahmen, innerhalb dessen sich die aktuelle Beschäftigungsforschung abspielt". Grundsätzlich ist jedoch auch eine politökonomische (vgl. Saint-Paul 1995b, 1996a,b) oder eine suchtheoretische Analyse vorstellbar (vgl. Pissarides 1990, van der Ploeg 1997).

In Kapitel 5.3.2 werden die Arbeitsangebotswirkungen des Einstiegsgeldes im Vergleich zum Status quo zunächst im partialanalytischen Einkommen-Freizeit-Modell abgeleitet. In Kapitel 5.3.3 werden die Voraussetzungen für einen positiven Beschäftigungseffekt im kompetitiven Arbeitsmarktmodell dargestellt. In Kapitel 5.3.4 werden die Beschäftigungswirkungen im modifizierten Modell gleichgewichtiger Arbeitslosigkeit abgeleitet. Die Ableitung der Effekte beschränkt sich jeweils auf grafische Darstellungen.

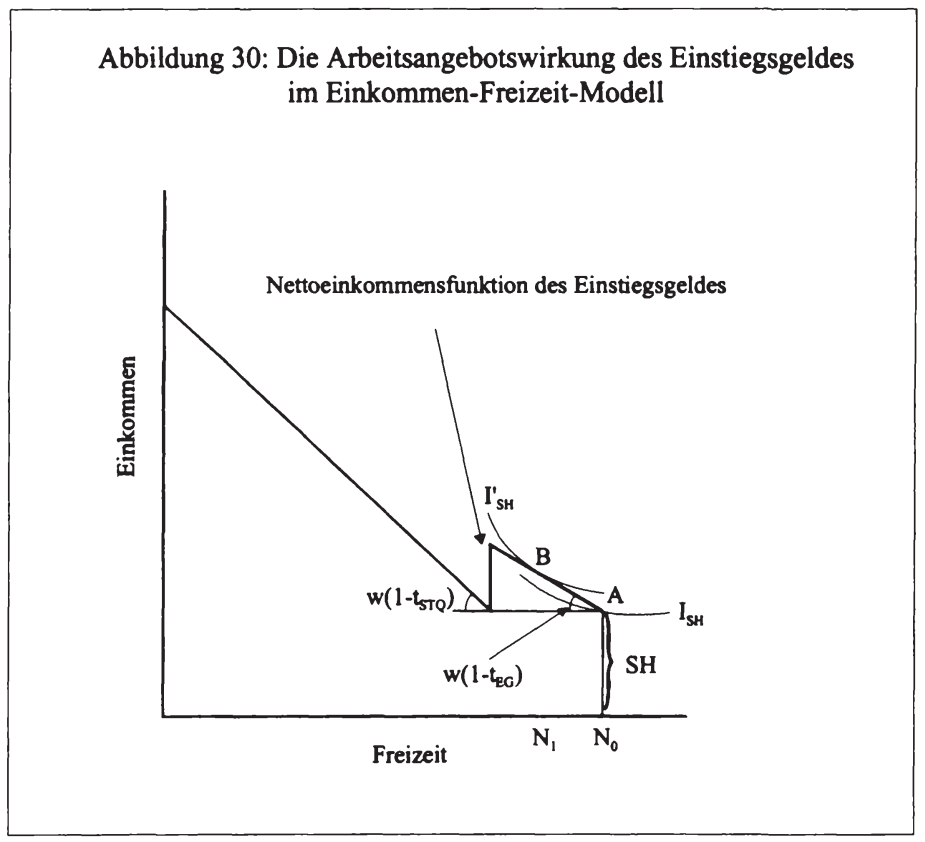

\subsubsection{Das Einstiegsgeld im Einkommen-Freizeit-Modell}

In Abbildung 30 wird exemplarisch die Arbeitsangebotswirkung des Einstiegsgeldes mit Einkommensobergrenze für Sozialhilfeempfänger im partialanalytischen Einkommen-Freizeit-Modell grafisch illustriert. Dabei wird aus Vereinfachungsgründen von Sockel- und Freibeträgen abstrahiert. Im Status quo ist es für Hilfeempfänger nutzenmaximal, keine Arbeit im Bruttoein- 
kommensbereich der Armutsfalle anzubieten (Punkt A), weil die Transferentzugsrate bzw. der Grenzsteuersatz auf Zusatzverdienste $t_{\text {sтQ }}=100 \%$ beträgt, so da $\beta$ der Nettolohnsatz $w\left(1-t_{\text {sтQ }}\right)$ auf Null sinkt. Dementsprechend bieten Sozialhilfeempfänger bei $\mathrm{N}_{0}$ keine Arbeit an.

Durch die Einführung des Einstiegsgeldes für Langzeitarbeitslose sinkt die Transferentzugsrate bzw. der Grenzsteuersatz auf Zusatzverdienste in diesem Bruttoeinkommensbereich auf $t_{\mathrm{EG}}=50 \%$, so daß der Nettolohnsatz $w\left(1-t_{\mathrm{EG}}\right)$ positiv wird. Die Transferempfänger sehen sich nun der Nettoeinkommensfunktion des Einstiegsgeldes gegenüber - verlaufen die Indifferenzkurven nicht zu steil, so bewirkt der Substitutionseffekt, daß ein positives Arbeitsangebot nutzenmaximal ist (Punkt B); der Einkommenseffekt existiert in diesem Fall nicht und die Ecklösung ist nur bei ausgeprägter Präferenz für Freizeit weiterhin nutzenmaximal (vgl. Kapitel 3.2.2.1). Die Indifferenzkurve der Sozialhilfeempfänger $I_{S H}^{\prime}$ liegt oberhalb der ursprünglichen Indifferenzkurve der Sozialhilfeempfänger $I_{S H}$, die Beschäftigung ist auf $N_{1}>0$ gestiegen. Für Erwerbstätige ändert sich der Status quo nicht. Der Arbeitsangebotseffekt des Einstiegsgeldes ist deshalb im Gegensatz zum Bürgergeld im partialanalytischen Einkommen-Freizeit-Modell eindeutig positiv.

\subsubsection{Das Einstiegsgeld im kompetitiven Arbeitsmarktmodell}

Das kompetitive Modell ist zur Erklärung freiwilliger Arbeitslosigkeit geeignet. Freiwillige Arbeitslosigkeit entsteht durch Fehlanreize im Transfersystem, die sich negativ auf das Arbeitsangebot der Transferempfänger auswirken. Dieser Modellrahmen ist relevant für Sektoren des Arbeitsmarktes ohne gewerkschaftlichen Einfluß, z.B. im Bereich haushalts- und personenbezogener Dienstleistungen. Diese Tätigkeiten finden derzeit vor allem in der Schattenwirtschaft statt (vgl. Schneider 1997a,b).

Die Armutsfalle des Transfersystems unterbindet den Arbeitsanreiz für Tätigkeiten, die ein Nettoeinkommen unter dem Hilfeniveau erbringen, wenn für die modelltheoretische Analyse aus Vereinfachungsgründen von Sockel- und Steigerungsbeträgen abgesehen wird. Durch Lohnersatzleistungen und Sozialhilfe entsteht im sozialen Sicherungssystem ein gesellschaftlich definiertes Mindesteinkommen, das staatlich garantiert ist. Das Einkommen aus sozialer Sicherung wirkt wie ein Mindestlohn (vgl. Siebert 1994, S. 148f.). Dieser transfersystembedingte Mindestlohn wird als Mindestlohn I bezeichnet - er ist abhängig vom jeweiligen Haushaltstyp. Bei einem monatlichen Sozialeinkommen von 2753 DM für den Haushaltstyp Verheiratete mit zwei Kindern (vgl. Abbildung 9) errechnet sich unter der Annahme einer monatlichen Arbeitszeit von 160 Stunden ein Mindeststundenlohn von 17,21 DM. Unterhalb dieses Mindeststundenlohns bietet dieser Haushaltstyp im Status quo bei Vollanrechnung von Zusatzverdiensten keine Arbeit an, die Arbeitsangebotsfunktion ist bis zum Mindestlohn I völlig lohnunelastisch. 


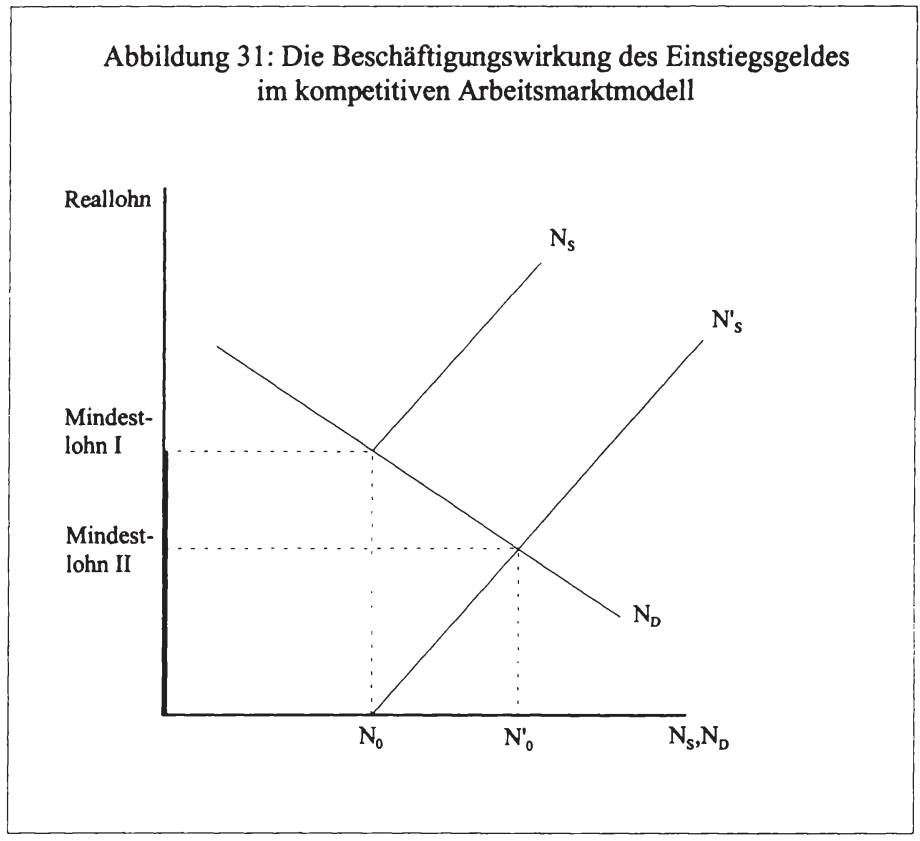

In Abbildung 31 ist an der Abszisse die Menge des Arbeitsangebots $\mathrm{N}_{\mathrm{s}}$ und der Arbeitsnachfrage $N_{D}$ und an der Ordinate der Bruttoreallohn je Arbeitsstunde abgetragen. Der Kapitalstock wird als konstant angenommen. Im Status quo verläuft die Arbeitsangebotsfunktion auf der Ordinate bei Bruttostundenlöhnen bis zum Mindestlohn I. Oberhalb dieses Mindestlohnes springt das aggregierte individuelle Arbeitsangebot auf $\mathrm{N}_{0}$, wenn von einer bestimmten Mindestarbeitszeit je Individuum im Sinne einer diskreten Arbeitsangebotsfunktion ausgegangen wird. Um Mißverständnisse zu vermeiden: Der transfersystembedingte Mindestlohn I variiert von Haushaltstyp zu Haushaltstyp, der Betrag von 17,21 DM ist lediglich ein Durchschnittswert für verheiratete Sozialhilfeempfänger mit zwei Kindern. Empfänger von Arbeitslosenunterstützung, deren Anspruch auf Arbeitslosengeld oder -hilfe unterhalb des Sozialhilfeniveaus liegt, erhalten bei Bedürftigkeit ergänzende Sozialhilfe, so daß der Mindestlohn I für sie ebenfalls relevant ist. Der Mindestlohn I ist jedoch für das Arbeitsangebot nicht-bedürftiger Arbeitnehmer im Niedriglohnsektor irrelevant. So wird zum Beispiel das Arbeitsangebot nicht-bedürftiger geringfügig Beschäftigter (z.B. Hausfrauen, Schüler, Stu- 
denten, Rentner) zwar nicht durch den Mindestlohn I, jedoch nach $§ 102$ AFG mit maximal 18 Stunden/Woche mengenmäßig begrenzt.

Die Einführung der Teilanrechung von Zusatzverdiensten durch eine zielgruppenorientierte negative Einkommensteuer macht Jobs mit Stundenlöhnen unterhalb des Mindestlohns I für Hilfeempfänger finanziell attraktiv: Der Mindestlohn I wird als Beschränkung der Beschäftigung im Niedriglohnsektor zeitlich befristet aufgehoben. Jeder Job mit einem positiven Stundenlohn ist mit einem positiven Arbeitsangebot verbunden. Dementsprechend verschiebt sich durch die Einführung des Einstiegsgeldes die Arbeitsangebotskurve von $\mathrm{N}_{\mathrm{s}}$ auf $\mathrm{N}_{\mathrm{s}}^{\prime}$ nach unten, so daß die Beschäftigung von $\mathrm{N}_{0}$ auf $\mathrm{N}_{0}^{\prime}$ zunehmen kann; aus Vereinfachungsgründen wird nicht zwischen verschiedenen Varianten des Einstiegsgeldes unterschieden, so daß von einer detaillierteren Analyse des Verlaufs der Arbeitsangebotsfunktion an dieser Stelle abgesehen wird (vgl. Jerger/Spermann 1996, S. 125 für die Diskussion einer Variante). Die Erhöhung des Arbeitsangebots könnte dennoch wirkungslos verpuffen, wenn ein gesetzlicher Mindeststundenlohn II oberhalb des Gleichgewichtslohns liegen würde. In Abbildung 31 ist ein Mindestlohn II eingetragen, der mit dem Gleichgewichtslohn zusammenfällt, so daß keine freiwillige Arbeitslosigkeit auftritt. Liegt der Mindestlohn II jedoch oberhalb des Gleichgewichtslohns, so wird ein Teil der Beschäftigungsausweitung unterbunden, und es entsteht in Höhe des Arbeitsangebotsüberschusses freiwillige Arbeitslosigkeit. In Deutschland existiert jedoch kein gesetzlicher Mindeststundenlohn, der einen Mindestpreis für Arbeit festlegen würde. Tarifpolitische Regelungen, die wie Mindestlöhne wirken, wenn sie für allgemeinverbindlich erklärt werden, spielen im kompetitiven Teil des Niedriglohnsektors keine Rolle. Ein Mindestlohn II kann im nicht-gewerkschaftlich bestimmten Teil des Niedriglohnsektors dennoch existieren. Dafür sprechen zum einen Effizienzlohnüberlegungen der Arbeitgeber, um Drückebergerei (shirking) von Arbeitnehmern zu verhindern (vgl. Shapiro/Stiglitz 1984), und zum anderen die mögliche Anpassungsreaktion der Arbeitnehmer, um unfaires Verhalten von Arbeitgebern durch reziprokes Verhalten zu bestrafen (vgl. Fehr et al. 1993, 1997). Empirische Untersuchungen auf der Basis von Laborexperimenten haben gezeigt, daß Arbeitgeber aus Fairneßüberlegungen einen Lohn oberhalb des gleichgewichtigen Reallohnes zahlen können (vgl. Fehr et al. 1993, Fehr et al. 1998). Der Mindestlohn II kann somit auch als Effizienz- oder Fairneßlohn interpretiert werden. So läßt sich festhalten, daß die Abmilderung institutioneller Fehlanreize über eine Erhöhung des Arbeitsangebots von Transferempfängern die Beschäftigung erhöht und die freiwillige Arbeitslosigkeit verringert, wenn die Arbeitsnachfrage elastisch ist und der Mindestlohn II unterhalb des Mindestlohns I liegt.

In Jerger/Spermann $(1996,1997 b)$ werden die Beschäftigungswirkungen des Einstiegsgeldes in einem formalisierten kompetitiven Zwei-Sektoren-Modell abgeleitet. Dazu wird das exogene gesamtwirtschaftliche Arbeitskräftepoten- 
tial auf zwei Gruppen aufgeteilt: den Niedriglohn- und den Hochlohnsektor. Im Hochlohnsektor wird aus Vereinfachungsgründen Vollbeschäftigung angenommen, Arbeitslosigkeit ist lediglich im Niedriglohnsektor möglich. Das Arbeitsangebot wird durch das Transfersystem beeinflußt. Da die Arbeitsnachfrage vom Bruttolohn abhängig ist, wird das Arbeitsangebot in Abhängigkeit vom Bruttolohn ausgedrückt, damit das Arbeitsmarktgleichgewicht als Schnittpunkt der Arbeitsangebots- und Arbeitsnachfragefunktion zu bestimmen ist. Es zeigt sich, daß der Übergang vom Status quo mit Armutsfalle zum Einstiegsgeld kurzfristig die Beschäftigung im Niedriglohnsektor erhöht. Im langfristigen Gleichgewicht müssen sich die Ströme zwischen den beiden Sektoren entsprechen. Der Strom vom Niedrig- zum Hochlohnsektor hängt annahmegemäß von der Beschäftigung im Niedriglohnsektor ab. Erhöht sich die Beschäftigung im Niedriglohnsektor, so wird der Niedriglohnsektor für ein gegebenes Arbeitskräftepotential langfristig kleiner. Die langfristige Wirkung verstärkt demnach die kurzfristige Wirkung.

In Segmenten des Arbeitsmarktes mit Gewerkschaftseinfluß ist der Erklärungsgehalt des kompetitiven Modells jedoch unbefriedigend. Deshalb werden im folgenden Kapitel die Beschäftigungswirkungen des Einstiegsgeldes als Arbeitnehmer-Lohnsubvention im Modell gleichgewichtiger Arbeitslosigkeit abgeleitet.

\subsubsection{Das Einstiegsgeld im modifizierten Modell gleichgewichtiger Arbeitslo- sigkeit}

Das Modell gleichgewichtiger Arbeitslosigkeit bzw. Wage Setting - Price Setting-Modell (WS-PS-Modell) - beide Begriffe werden hier synonym gebraucht - ist ein makroökonomisches Arbeitsmarktmodell. Dieses Modell wurde in den achtziger Jahren an der London School of Economics entwickelt. Im Gegensatz zum kompetitiven Modell kann das WS-PS-Modell zum einen ein Arbeitsmarktgleichgewicht bei gleichgewichtiger Arbeitslosigkeit bzw. unfreiwilliger Arbeitslosigkeit erklären. Zum anderen wird auch das empirische Phänomen einer im Reallohn-Beschäftigungsraum positiv geneigten Lohnkurve (vgl. Blanchflower/Oswald 1994, 1995) theoretisch erklärt. Eine ausführliche Beschreibung des Modells, das inzwischen in die makroökonomische Lehrbuchliteratur eingegangen ist (vgl. Burda/Wyplosz 1997, Blanchard 1997), findet sich in Carlin/Soskice (1990), Fehr (1990), Layard et al. (1991), Booth (1995) und Michaelis (1998). Das Modell gleichgewichtiger Arbeitslosigkeit wird für die Fragestellung leicht modifiziert. Zum einen wird das Modell als Einsektorenmodell interpretiert - es wird ausschließlich der von den Tarifpartnern bestimmte Teil des Niedriglohnsektors betrachtet, Rückkoppelungen auf andere Sektoren bleiben unberücksichtigt (vgl. Sørensen 1997 für ein Mehrsektorenmodell). Zum anderen wird Langzeitarbeitslosigkeit durch eine veränderte Interpretation der PS-Kurve in das Modell eingeführt. 
In Abbildung 32 ist die Beschäftigung an der Abszisse und der Reallohn an der Ordinate abgetragen. Bei vollkommener Konkurrenz auf dem Gütermarkt ist die PS-Kurve mit der Arbeitsnachfragekurve identisch. Die Firmen verhalten sich als „Preisnehmer“. Bei unvollkommener Konkurrenz auf dem Gütermarkt verhalten sich die Firmen als „Preissetzer“ - die PS-Kurve spiegelt das Preissetzungsverhalten der Firmen wider: Die Firmen setzen ihre Preise als Aufschlag auf die Grenzkosten. Je höher die Marktmacht, desto höher ist der Preisaufschlag. Bei konstanten Skalenerträgen verläuft die PSKurve horizontal. In Abbildung 32 wird der Kapitalstock als konstant angenommen - bei abnehmenden Grenzerträgen der Arbeit ist die PS-Kurve dann negativ geneigt. Die negativ geneigte PS-Kurve verläuft um so näher am Ursprung, je höher der Preisaufschlag ausfällt. Um Langzeitarbeitslosigkeit zu erfassen, wird das WS-PS-Modell folgendermaßen erweitert (vgl. Snower 1997). Nach der Humankapitaltheorie wird angenommen, daß Langzeitarbeitslose mit der Dauer der Arbeitslosigkeit einen Teil ihres Humankapitals verlieren: Ihre Ausbildung verliert an Wert (Dequalifikation), und es treten typische Arbeitsentwöhnungseffekte wie fehlende Pünktlichkeit und Verläßlichkeit sowie Entmutigungseffekte auf (vgl. Franz 1996b). Der einfachste Weg, diese Effekte in das WS-PS-Modell zu integrieren, ist die Annahme fallender Grenzprodukte der Arbeit je Arbeitslosen bei zunehmender Dauer der Arbeitslosigkeit. Dazu nimmt man an, daß alle Arbeitslosen gemäß der Dauer ihrer Arbeitslosigkeit an der horizontalen Achse geordnet sind. Damit sind implizit heterogene Arbeitnehmer unterstellt, deren Produktivität mit der Dauer der Arbeitslosigkeit abnimmt. Deshalb ist die PS-Kurve nicht nur aufgrund abnehmender Grenzerträge der Arbeit negativ geneigt. Hinzu kommt der Effekt, daß bei zunehmender Beschäftigung immer mehr Arbeitslose mit zunehmender vorausgegangener Arbeitslosigkeitsdauer beschäftigt werden. Deshalb liegt die „PS-Kurve der Arbeitslosen“ PS $_{\mathrm{AL}}$ im modifizierten WS-PSModell in Abbildung 32 rechts vom Arbeitsmarktgleichgewicht in Punkt A unterhalb der ursprünglichen PS-Kurve.

Die Innovation im Modell gleichgewichtiger Arbeitslosigkeit ist die Lohnsetzungskurve (WS-Kurve). Im Gegensatz zum kompetitiven Arbeitsmarkt verhalten sich die Arbeitnehmer nicht als „Lohnnehmer", sondern dank der gewerkschaftlichen Macht als „Lohnsetzer“. Im Extremfall eines Monopolgewerkschaftsmodells setzt die Monopolgewerkschaft den Lohn und die Unternehmen wählen dann die für sie gewinnmaximale Beschäftigung. Im sogenannten „Right-to-manage (RTM)“ Modell setzen die Tarifpartner den ausgehandelten Lohn, die Firmen nehmen diesen Lohn als gegeben an und wählen die gewinnmaximale Beschäftigung. Im Modell effizienter Kontrakte verhandeln die Tarifpartner sowohl über die Löhne als auch über die Beschäftigung. Welches dieser kollektiven Lohnverhandlungsmodelle für Deutschland am besten geeignet ist - darüber findet sich in der Literatur nach Goerke/Holler (1997, S. 212) keine eindeutige Antwort. Weitgehende Einigkeit besteht je- 
doch darin, daß das Monopolgewerkschaftsmodell zwar als Referenzmodell dienen kann, jedoch für Deutschland realitätsfern ist (vgl. Franz 1996a, S. 11). Dagegen sind implizite Vereinbarungen über Reallöhne und Beschäftigung in der Realität durchaus beobachtbar (vgl. Goerke/Holler 1997, S. 212 u. Michaelis 1998, S. 96ff.), doch scheint es kaum explizite effiziente Kontrakte zu geben (vgl. Oswald 1993, S. 92f. u. Franz 1997, S. 166). Deshalb erscheint ein RTM-Modell als kollektives Lohnverhandlungsmodell zur mikroökonomischen Fundierung der WS-Kurve für den von den Tarifpartnern bestimmten Niedriglohnsektor relativ am besten geeignet.

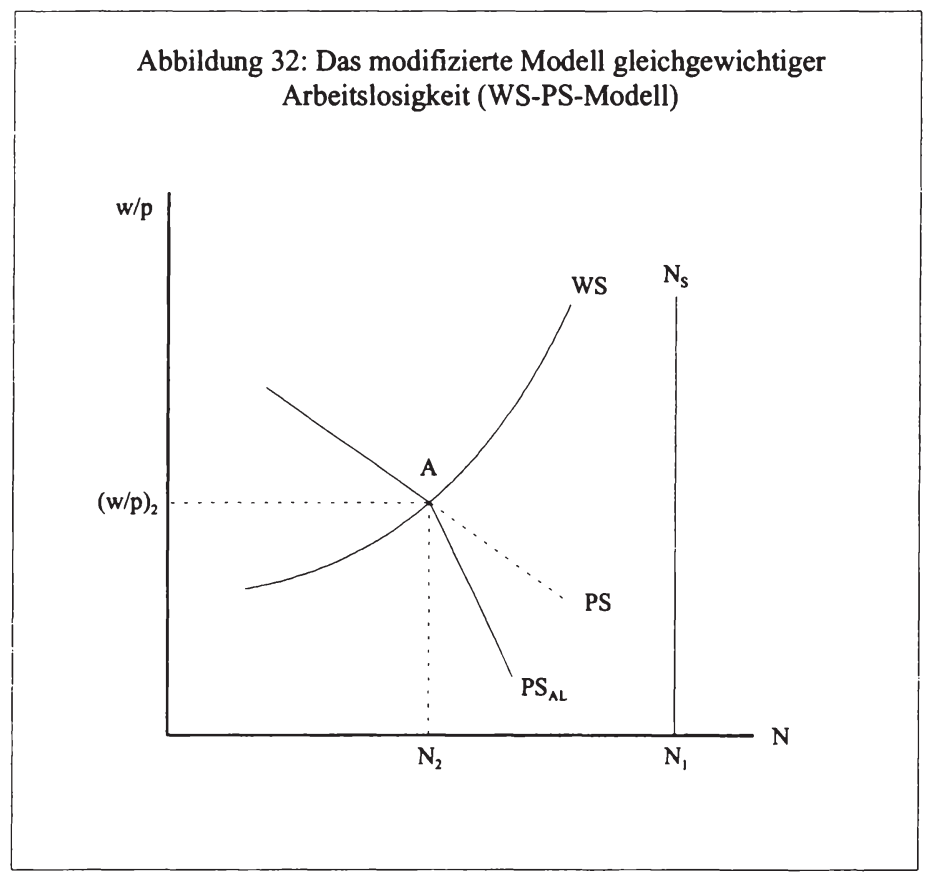

Im Rahmen eines RTM-Modells ist die Annahme der Gewinnmaximierung als Zielsetzung der Unternehmen üblich. Dagegen ist die Frage, ob die Gewerkschaften neben dem Lohn- auch ein Beschäftigungsziel verfolgen, in der Literatur strittig. Unterstellt man Gewerkschaften mit einem Reallohn- und Beschäftigungsziel, so gehen beide Ziele als Argumente mit einem positiven Vorzeichen in die gewerkschaftliche Nutzenfunktion ein. Dementsprechend ist die gewerkschaftliche Indifferenzkurve im Arbeitsmarktdiagramm negativ geneigt (vgl. Burda/Wyplosz 1997, S. 146ff.). Die gewerkschaftliche Indifferenzkurve verläuft steil bei hoher Gewichtung des Beschäftigungsziels relativ zum Reallohnziel (Jobs-first-Präferenzen). Die gewerkschaftliche Indiffe- 
renzkurve verläuft flach bei hoher Gewichtung des Reallohnziels relativ zum Beschäftigungsziel (Hard-line-Präferenzen). Die Gewerkschaft maximiert ihren Nutzen gegeben die gewinnmaximale Arbeitsnachfrage des Unternehmens. Die optimale Reallohn-Beschäftigungs-Kombination liegt dann beim Tangentialpunkt der gewerkschaftlichen Indifferenzkurve mit der Arbeitsnachfragefunktion. Im Optimum ist die Grenzrate der Substitution zwischen Reallohn und Beschäftigung gleich der Steigung der Arbeitsnachfragefunktion. Dementsprechend ergibt sich bei Jobs-first-Präferenzen im Optimum eine relativ zu Hard-line-Präferenzen höhere Beschäftigung und ein relativ geringerer Reallohn. Dagegen gehen Layard et al. $(1991,1994)$ von horizontalen gewerkschaftlichen Indifferenzkurven im relevanten Bereich aus. Dabei unterstellen sie, daß die Gewerkschaften indifferent gegenüber einer höheren Beschäftigung als die aktuelle sind. Sie nehmen jedoch nicht an, daß die Gewerkschaften ausschließlich reallohnorientiert sind - gegen Beschäftigungsabbau sind sie nicht indifferent, so daß die gewerkschaftlichen Indifferenzkurven im Tangentialpunkt geknickt sind (vgl. Oswald 1985 u. Layard 1990). Ob diese Annahme für Deutschland relevant ist, erscheint jedoch fraglich (vgl. Michaelis 1998, S. 52ff. für eine ausführliche Diskussion).

In die gewerkschaftliche Nutzenfunktion geht der Reallohn als Argument ein, während in Tarifverträgen die Nominallöhne fixiert werden. Dieses Vorgehen erscheint jedoch gerechtfertigt. Carlin/Soskice (1990, S. 138ff.) weisen darauf hin, daß erwartete Preisveränderungen während der Laufzeit der Tarifverträge in die Lohnverhandlungen eingehen. Werden höhere Inflationsraten erwartet, dann steigt der von den Gewerkschaften geforderte Nominallohn. Michaelis (1998, S. 75) macht auf die Unterscheidung zwischen partialanalytischer Ebene und allgemeinem Gleichgewicht aufmerksam. Bei Lohnverhandlungen zwischen Firmen und Firmengewerkschaften ist das Preisniveau exogen. Verhandlungen über den Nominallohn sind deshalb identisch mit Verhandlungen über den Reallohn.

Umstritten ist auch, welche Spezifikation der Nutzenfunktion am besten geeignet ist. Als gewerkschaftliche Nutzenfunktion wird in der Literatur häufig eine utilitaristische Nutzenfunktion gewählt (vgl. Pissarides 1998); es finden sich aber auch Spezifikationen vom Stone-Geary Typ oder der Funktion des erwarteten Nutzens eines repräsentativen Gewerkschaftsmitglieds (vgl. Goerke/Holler 1997 für einen Überblick).

Die Verhandlungen zwischen Gewerkschaften und Firmen werden üblicherweise als sequentielles Spiel aufgefaßt. Unter der Annahme eines konstanten Kapitalstocks verhandeln die Unternehmen und Gewerkschaften in einer Stufe über die Entlohnung je Beschäftigten, und in einer zweiten Stufe entscheidet das Unternehmen über die Beschäftigung. Zur Bestimmung des optimalen Lohnsatzes muß das mit der Verhandlungsmacht der Tarifpartner gewichtete Nash-Produkt unter der Nebenbedingung der gewinnmaximalen Arbeitsnachfrage maximiert werden. Die Idee des Nash-Produkts besteht darin, daß nut- 
zenmaximierende Gewerkschaften und gewinnmaximierende Unternehmen sich durch Verhandlungen besser stellen können. Kommt es zu keinem Verhandlungsergebnis, so erhalten die Gewerkschaftsmitglieder kein Lohneinkommen, sondern lediglich ein exogenes Alternativeinkommen (z.B. Streikeinkommen, Arbeitslosenunterstützung). Die nicht-kooperative Lösung führt für die Unternehmen zu Null-Profiten, weil keine Produktion stattfindet.

Die kooperative Lösung und damit der Lohnsatz, der das Nash-Produkt maximiert, hängt entscheidend von der Verhandlungsmacht der Tarifpartner ab. Bei maximaler Verhandlungsmacht der Gewerkschaften geht das RTMModell in ein Monopolgewerkschaftsmodell über, bei maximaler Verhandlungsmacht der Firmen ergibt sich das kompetitive Arbeitsmarktmodell als Grenzfall des RTM-Modells. Je größer die Verhandlungsmacht der Gewerkschaften, desto größer ist der in den Tarifverhandlungen durchgesetzte Aufschlag auf das Alternativeinkommen. Je geringer die Verhandlungsmacht der Gewerkschaften, desto mehr nähert sich der vereinbarte Lohnsatz dem Alternativeinkommen an. Der Aufschlag auf das exogene Alternativeinkommen hängt darüber hinaus von der Produktionstechnologie, der Wettbewerbsintensität auf dem Gütermarkt und der Risikoaversion der Gewerkschaften ab (vgl. Michaelis 1998, S. 81 u. Pissarides 1998, S. 162ff.).

In mehreren empirischen Studien wird für Deutschland ein relativ hoher Zentralisierungsgrad der Lohnverhandlungen festgestellt (vgl. Berthold/Fehn 1996, S. 59 für einen Überblick). Die institutionelle Ausgestaltung der Lohnverhandlungen wird in RTM-Modellen stark vereinfacht modelliert. So verhandeln Firmen und Gewerkschaften annahmegemäß auf dezentralisierter Ebene. Dabei wird implizit unterstellt, daß zentralisierte Lohnverhandlungen zur Vollbeschäftigung führen (vgl. Pissarides 1998, S. 162). Die Intuition für diese Implikation ist folgende: Wenn lediglich eine Gewerkschaft mit einem Arbeitgeber verhandeln würde, gäbe es keine Beschäftigungschance für entlassene Arbeitnehmer bei anderen Unternehmen. Dadurch ist die Verhandlungsposition der Gewerkschaft im Vergleich zu dezentralen Verhandlungen geschwächt, so daß das Verhandlungsergebnis Vollbeschäftigung ist (vgl. Layard et al. 1994, S. 43).

Bei der Beschreibung des Nash-Maximierungsproblems wurde darauf hingewiesen, daß das Alternativeinkommen der Gewerkschaftsmitglieder auf partialanalytischer Ebene exogen ist. Auf gesamtwirtschaftlicher Ebene wird das Alternativeinkommen jedoch endogen, weil es von der Höhe der Beschäftigung abhängt. Im allgemeinen Gleichgewicht setzt sich das Alternativeinkommen des Gewerkschaftsmitglieds aus der Summe zweier Komponenten zusammen - dem outside wage und dem Nichtarbeitseinkommen. Die erste Komponente ist der Lohnsatz, den der Arbeitnehmer bei anderen Unternehmen erzielen würde, multipliziert mit der Wahrscheinlichkeit, eine Stelle auBerhalb seines Unternehmens zu erhalten - diese Wahrscheinlichkeit läßt sich durch die Beschäftigungsrate approximieren. Die zweite Komponente ist das 
Nichtarbeitseinkommen (z.B. Streikeinkommen, Arbeitslosenunterstützung), multipliziert mit der Wahrscheinlichkeit, arbeitslos zu sein - diese Gegenwahrscheinlichkeit läßt sich durch die Arbeitslosenrate approximieren. Dadurch wird eine Verbindung zwischen der Arbeitslosen- bzw. Beschäftigtenrate und dem Alternativeinkommen hergestellt (vgl. Michaelis 1998, S. $61 \mathrm{ff}$. u. 202ff.). Nimmt man aus Vereinfachungsgründen weiterhin an, daß alle dezentral verhandelnden Firmen und Gewerkschaften den gleichen Lohn aushandeln, unterstellt man demnach eine Vielzahl identischer Paare von Firmen und Gewerkschaften (Symmetrieannahme), so ergibt sich die WS-Kurve; die WS-Kurve wird auch kollektive Arbeitsangebotskurve genannt.

Die WS-Kurve ist im Reallohn-Beschäftigungs-Raum positiv geneigt. Intuitiv läßt sich die positive Steigung dadurch begründen, daß ein höheres Beschäftigungsniveau die Verhandlungsmacht der Gewerkschaft erhöht - mit der Konsequenz, daß sie im Verhandlungsprozeß höhere Reallöhne durchsetzen kann. Bei Jobs-first-Präferenzen ergibt sich eine positiv geneigte, flache WS-Kurve. Die Intuition ist naheliegend: Es sind nur geringe Reallohnsteigerungen nötig, um ein höheres kollektives Arbeitsangebot zu bewirken. Bei Hard-line-Präferenzen sind dagegen hohe Reallohnsteigerungen notwendig, um ein höheres kollektives Arbeitsangebot zu bewirken - die positiv geneigte WS-Kurve verläuft in diesem Fall steil. Im Grenzfall ausschließlicher Reallohnorientierung der Gewerkschaften mit horizontalen Indifferenzkurven verläuft die WSKurve dementsprechend vertikal.

Das allgemeine Arbeitsmarktgleichgewicht wird beim Schnittpunkt der WSund PS-Kurve bestimmt (Punkt A in Abbildung 32). Gegeben, daß Unternehmen die Güterpreise und die Tarifpartner die Löhne gesetzt haben, ergibt sich demnach ein Arbeitsmarktgleichgewicht bei einem Beschäftigungsniveau $\mathrm{N}_{2}$ und einem Reallohn (w/p) $)_{2}$. Da das Modell keine Nichtlinearität enthält, ist das Gleichgewicht eindeutig bestimmt (vgl. Michaelis 1998, S. 213). Das aggregierte individuelle Arbeitsangebot $\mathrm{N}_{\mathrm{S}}$ wird als exogen gegeben angenommen. Die resultierende Arbeitslosigkeit $\left(\mathrm{N}_{1}-\mathrm{N}_{2}\right)$ ist unfreiwillig aus Sicht der Individuen, aber freiwillig aus Sicht der Gewerkschaften.

Das Arbeitsmarktgleichgewicht bringt die Ansprüche der Preissetzer und Lohnsetzer an das zu verteilende Sozialprodukt in Einklang. Das ist bei genau einer Arbeitslosenrate, bei der die Inflationsrate konstant ist, möglich: Das Arbeitsmarktgleichgewicht ist mit der sogenannten „natürlichen Arbeitslosenrate“ oder ,inflationsstabilen Arbeitslosenrate“ (= Non-Accelerating Inflation $R$ ate of Unemployment $=$ NAIRU) verbunden. Die gleichgewichtige Arbeitslosenrate räumt demnach nicht den Markt, sondern es existiert unfreiwillige Arbeitslosigkeit in Höhe der NAIRU in dem Sinne, daß arbeitswillige Arbeitnehmer bei den gegebenen Reallöhnen keine Stellen erhalten (vgl. Carlin/Soskice 1990, S. 137). Der Begriff natürliche Arbeitslosenrate ist jedoch unglücklich gewählt, weil die NAIRU keineswegs eine Naturkonstante darstellt (vgl. zur aktuellen NAIRU-Diskussion: Stiglitz 1997, Gordon 1997, 
Blanchard/Katz 1997, Galbraith 1997). Ganz im Gegenteil: Die NAIRU ist durch wirtschaftspolitische Maßnahmen beeinflußbar. Blanchard (1997) schlägt deshalb den Begriff ,strukturelle Arbeitslosenrate“ vor.

Der Unterschied zwischen dem Modell gleichgewichtiger Arbeitslosigkeit und dem kompetitiven Arbeitsmarktmodell läßt sich folgendermaßen zusammenfassen (vgl. Blanchard 1986). Im kompetitiven Arbeitsmarktmodell wird das Arbeitsmarktgleichgewicht durch den Schnittpunkt der Arbeitsnachfrageund Arbeitsangebotskurve bestimmt. Im WS-PS-Modell wird Marktmacht zugelassen. Marktmacht der Gewerkschaften ermöglicht die Durchsetzung relativ zum kompetitiven Ergebnis höherer Reallöhne im Verhandlungsprozeß mit den Unternehmen. Intuitiv erlaubt die Lohnsetzungsmacht die Verschiebung der Arbeitsangebotskurve nach oben im Beschäftigungs-Reallohn-Raum - die WS-Kurve oder kollektive Arbeitsangebotskurve liegt oberhalb der aggregierten individuellen Arbeitsangebotskurve. Im Extremfall einer Monopolgewerkschaft setzt ausschließlich die Gewerkschaft den Lohn. Marktmacht der Unternehmen ermöglicht die Durchsetzung höherer Güterpreise relativ zum kompetitiven Ergebnis. Intuitiv erlaubt die Preissetzungsmacht die Verschiebung der Arbeitsnachfragekurve nach unten im Beschäftigungs-Reallohn-Raum - die PS-Kurve liegt unterhalb der Arbeitsnachfragekurve. Im Extremfall eines Monopolunternehmens bestimmt ein Unternehmen den Güterpreis. Da die WS-Kurve den Aufschlag der Löhne auf die Preise, und die PSKurve den der Preise auf die Löhne beschreibt, kann das Arbeitsmarktgleichgewicht als das Ergebnis eines „battle of the mark-ups“ (Layard/Nickell 1986, S. S146) interpretiert werden, sobald Marktmacht im Güter- und Arbeitsmarkt zugelassen wird. Wenn die unterschiedlichen Aufschläge nicht konsistent sind, dann ist strukturelle Arbeitslosigkeit langfristig der zentrale Ausgleichsmechanismus im „Kampf“ der Arbeitgeber und Arbeitnehmer um die höchsten Preis- bzw. Lohnaufschläge.

Nachdem die wesentlichen Modellkomponenten erläutert wurden, kann die Beschäftigungswirkung des Einstiegsgeldes grafisch illustriert werden. Grundsätzlich gilt, daß eine Lohnsubvention wie eine Steuer einen Keil zwischen den Produzenten- und Konsumentenreallohn treibt. Bei einer Auszahlung einer Lohnsubvention an die Arbeitnehmer läuft der Transmissionskanal über die WS-Kurve: In die gewerkschaftliche Nutzenfunktion geht der Konsumentenreallohn als Bestimmungsgrund ein (vgl. Bean 1994, S. 579). In Abbildung 33 treibt das Einstiegsgeld als Arbeitnehmer-Lohnsubvention einen Keil $\mathrm{s}$ zwischen den an der Ordinate abgetragenen Produzentenreallohn $w^{\mathrm{p}} / \mathrm{p}$ und den Konsumentenreallohn wc/p. Die Begründung: Die Gewerkschaften können für die Gruppe der Langzeitarbeitslosen niedrigere Produzenten-Reallöhne akzeptieren - es ist für sie nutzenmaximal, relativ zu einer Situation ohne Einstiegsgeld einen geringeren Aufschlag für die Gruppe der Langzeitarbeitslosen zu verhandeln, weil die Arbeitnehmer-Lohnsubvention Einstiegsgeld den für die Gewerkschaften relevanten Konsumenten-Reallohn der Langzeitar- 
beitslosen erhöht. Demnach verschiebt sich die WS-Kurve in Abbildung 33 nach rechts von WS zu WS ${ }_{\mathrm{AL}}$, wenn die Gewerkschaften untertarifliche Entlohnung von Langzeitarbeitslosen akzeptieren (vgl. Fehr 1990). Zeitlich befristete Einstiegstarife für Langzeitarbeitslose wurden zum Beispiel in der chemischen Industrie vereinbart (vgl. IG Chemie 1995). Abstrahiert man von dynamischen Aspekten, so steigt die Beschäftigung von $\mathrm{N}_{2}$ auf $\mathrm{N}_{3}$ um die zusätzlich beschäftigten Langzeitarbeitslosen, die unfreiwillige Arbeitslosigkeit reduziert sich auf $\mathrm{N}_{1}-\mathrm{N}_{3}$.

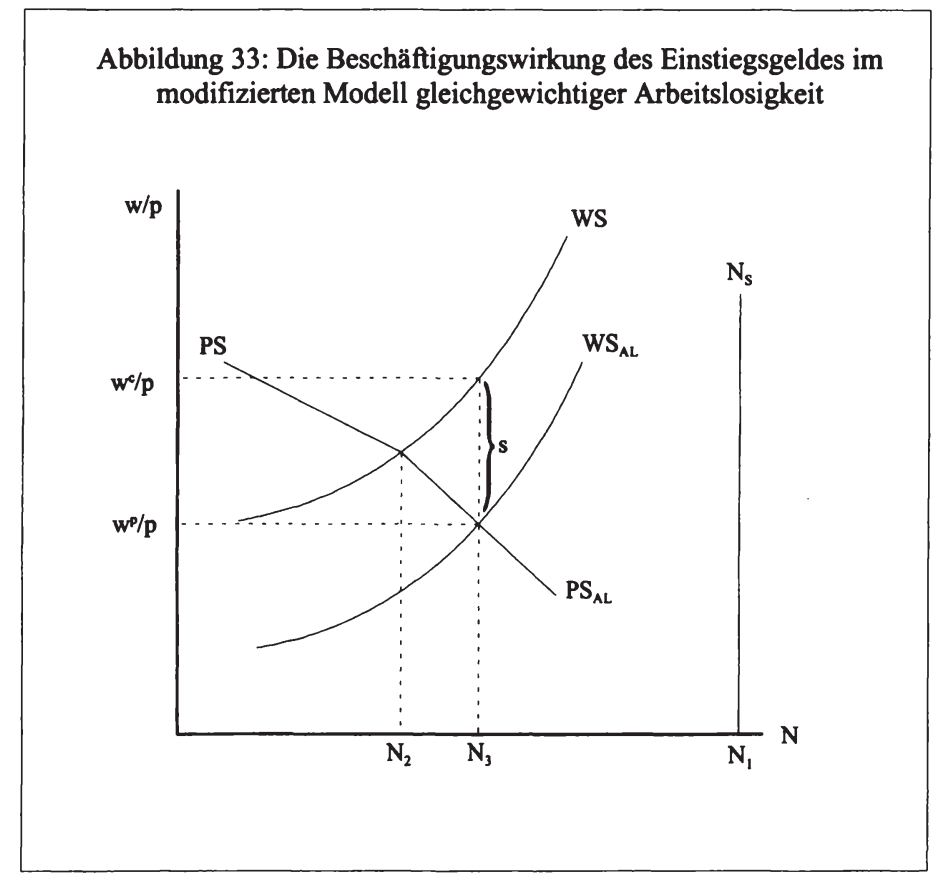

Bei dieser Argumentationskette wird implizit die Standardannahme der makroökonomischen Literatur zu Lohnsubventionen unterstellt: Das Budget des Staates ist ausgeglichen und wird durch verzerrende Produzentensteuern finanziert (vgl. Layard et al. 1991, Fehr 1990 u. Orszag/Snower 1996a für eine Kritik). Durch diese Annahme der „ex ante-Neutralität“ bleiben Rückkoppelungen auf das Arbeitsmarktgleichgewicht unberücksichtigt. Es wird demnach davon abstrahiert, daß es im Fall fiskalischer Einsparungen zu den positiven Beschäftigungseffekt verstärkenden Rückkoppelungen kommen kann. Welche Voraussetzungen für fiskalische Einsparungen erfüllt sein müssen, wird in Kapitel 5.4.1 ausführlich diskutiert. 
Das Modell gleichgewichtiger Arbeitslosigkeit ist zwar ein mikrofundietes, makroökonomisches allgemeines Gleichgewichtsmodell. Es bleibt jedoch ein Partialmodell in dem Sinne, daß weder verschiedene Arten von Kapital noch dynamische Anpassungsreaktionen modelliert sind. Deshalb sollen im folgenden Kapitel die ökonomischen Wirkungen des Einstiegsgeldes über diesen engen Blickwinkel hinaus diskutiert werden.

\subsection{Diskussion des Einstiegsgeldes}

\subsubsection{Vergleich mit dem Status quo}

In der wissenschaftlichen Auseinandersetzung um Lohnsubventionsmodelle wie das Einstiegsgeld werden eine Vielzahl von Problemen diskutiert. Im Mittelpunkt der Kritik am Einstiegsgeld steht zum einen die Befürchtung, daß Mitnahme-, Substitutions- und Verdrängungseffekte die im vorherigen Kapitel abgeleiteten positiven Beschäftigungseffekte zerstören und - im schlimmsten Fall - sogar zu fiskalischen Mehrbelastungen führen könnten. Zum anderen wird die grundsätzliche Zielrichtung des Einstiegsgeldes, höhere Beschäftigung durch Arbeitsangebotsanreize erzielen zu wollen, in Frage gestellt. Insbesondere wird darauf verwiesen, $\mathrm{da} \beta$ in Zeiten hoher struktureller Arbeitslosigkeit in einer Europäischen Union mit Freizügigkeit für Arbeitnehmer und zunehmender Billiglohnkonkurrenz aus Transformations- und Entwicklungsländern eine Erhöhung des Arbeitsangebots zu mehr Arbeitslosigkeit führen könnte. Zum dritten wird auf mögliche Ungerechtigkeiten, die sich aus dem gespaltenen Steuer- und Abgabensystem einerseits und dem Transfertarif andererseits ergeben könnten, hingewiesen. In diesem Kapitel werden die vorgebrachten Argumente systematisch aufbereitet und reflektiert. Dabei wird zunächst auf die Arbeitsangebots- und Arbeitsnachfrageentscheidungen auf mikroökonomischer Ebene eingegangen, bevor die Voraussetzungen für eine Erhöhung der Beschäftigung im Niedriglohnsektor diskutiert werden. Mögliche Wirkungen auf die intertemporalen Entscheidungen der Arbeitnehmer und Arbeitgeber sowie Gerechtigkeitsaspekte schließen die Diskussion ab.

\section{(1) Arbeitsangebotsentscheidung}

Ein grundsätzlicher Einwand gegen die Verbesserung von Arbeitsanreizen besteht darin, daß mit einer solchen Forderung implizit unterstellt wird, Langzeitarbeitslose seien arbeitsscheu. Doch das ist nicht der zentrale Punkt. Bereits in den vierziger Jahren wies Lady Rhys-Williams darauf hin, daß institutionelle Fehlregelungen die Untätigkeit von Arbeitslosen regelrecht erzwingen. Wenn die Annahme von gering entlohnten Vollzeitjobs und durchschnittlich entlohnten Teilzeitjobs insbesondere für Alleinerziehende und Familien mit mehreren Kindern das verfügbare Einkommen kaum erhöht, dann 
kann die in der Regel vorhandene Arbeitsmotivation zerstört werden. Die Beseitigung der Armutsfalle anzustreben heißt nicht, die derzeit Langzeitarbeitslosen zu verunglimpfen. Statt dessen wird auf Fehlanreize im Sozialsystem hingewiesen, die die Aufnahme der Erwerbstätigkeit erschweren und zur Verlängerung der Arbeitslosigkeitsdauer beitragen.

Die Verbesserung der Arbeitsanreize der Transferempfänger durch das Einstiegsgeld verändert den Relativpreis zwischen regulärer Arbeit und Schwarzarbeit. Schwarzarbeit wird relativ unattraktiver, weil im Vergleich zum Status quo die Transferentzugsrate sinkt. Insofern bestehen Anreize für risikoaverse Individuen, illegale Tätigkeiten selbst aufzudecken. Die Umwandlung von Tätigkeiten der Schattenwirtschaft ist um so wahrscheinlicher, je geringer der Anrechnungssatz auf Zusatzverdienste legaler Tätigkeiten und je höher die Aufdeckungswahrscheinlichkeit illegaler Tätigkeiten ist. Dennoch bleibt festzuhalten: Schwarzarbeit bleibt unter finanziellen Gesichtspunkten die attraktivere Option für Transferempfänger.

Durch eine zielgruppenorientierte negative Einkommensteuer entstehen im Gegensatz zu einer allgemeinen negativen Einkommensteuer keine direkten negativen Wirkungen auf den Nettolohn der Erwerbstätigen. Der zusätzliche Finanzierungsbedarf ist bei der Einführung im Vergleich zum Status quo minimal. $\mathrm{Zu}$ beachten sind jedoch Mitnahmeeffekte als Konsequenz der Zielgruppenorientierung, die zusätzlichen Finanzierungsbedarf nach sich ziehen könnten. Zum einen ist ein Moral hazard der geringverdienenden Erwerbstätigen nicht auszuschließen. Für diese Gruppe könnte es eine überlegenswerte Option sein, ihren Job aufzugeben, um Mitglied der geförderten Zielgruppe zu werden. Card et al. (1998) sprechen von einem sogenannten „,new applicant effect". In diesem Fall würden aus bisherigen Steuerzahlern zusätzliche Transferempfänger (Mitnahmeeffekt I). Dieser Fehlanreiz ist jedoch nur auf den ersten Blick von großer Bedeutung. Um Einstiegsgeldempfänger werden zu können, müßten Geringverdiener ihren Job kündigen. Im Fall der Eigenkündigung wird nach $\S 119$ a AFG erst nach einer Sperrzeit von 12 Wochen Arbeitslosengeld für durchschnittlich ein Jahr gezahlt. Je nach Höhe des aktuellen Nettoeinkommens und Familienstandes kann die absolute Höhe des Einkommensverlustes während der Wartezeit von mindestens einem Jahr erheblich sein. Nach Ablauf des Arbeitslosengeldes muß eine Bedürftigkeitsprüfung ,bestanden“ werden. Erst danach besteht Anspruch auf das zeitlich befristete Einstiegsgeld. Ob nach dem Erwerb des Status „,bedürftigkeitsgeprüfter Langzeitarbeitsloser“ sofort eine Stelle angetreten werden kann, ist unklar. Für die Dauer der Stellensuche müssen noch höhere Einkommenseinbußen als während der einjährigen Wartezeit hingenommen werden, weil die Arbeitslosen- und/oder Sozialhilfe unter dem Niveau des Arbeitslosengeldes liegt. Insgesamt betrachtet erscheint Arbeitnehmer-Moral hazard wenig wahrscheinlich. Es könnte lediglich für nicht-vermögende Haushalte mit Nettoeinkommen knapp über der Bedürftigkeitsgrenze in Frage kommen - aber nicht 
wegen der Einführung des Einstiegsgeldes, sondern wegen des geringen Lohnabstands zur Sozialhilfe. Auch ohne Einstiegsgeld könnte ein Geringverdiener zwischen Erwerbstätigkeit und Sozialhilfebezug abwägen, wenn die Arbeitspflicht bei Sozialhilfebezug in der entsprechenden Kommune nur de jure besteht. Das Arbeitnehmer-Moral hazard kann demnach durch eine engere Verknüpfung von Hilfebezug und Arbeitspflicht auch für Geringverdiener und durch niedrigere Steuern und Abgaben auf Niedrigeinkommen weitgehend ausgeschlossen werden.

Problematischer ist jedoch der Personenkreis, der derzeit trotz Voll-erwerbstätigkeit ergänzende Sozialhilfe bezieht. Die Struktur und die Arbeitsmotive von Erwerbstätigen, die ergänzende Sozialhilfe als aufstockenden Transfer erhalten, sind kaum bekannt. Es ist jedoch davon auszugehen, daß ein erheblicher Teil der Geringverdiener die existierenden Anrechnungsvorschriften nicht genau kennt. Der Staat dürfte in diesem Fall der besserinformierte ,agent", die häufig geringqualifizierten Hilfeempfänger dürften dagegen die über institutionelle Detailfragen schlecht informierten „principals“ sein. Bei vollkommener Information über die Armutsfalle wäre es demnach für erwerbstätige Sozialhilfeempfänger bereits jetzt ökonomisch rational, geringfügig oder Teilzeit statt Vollzeit zu arbeiten, weil das gleiche Einkommen nach Transfer erzielt werden würde (vgl. zum Beispiel Abbildung 9 in Kapitel 2.5.2). Dieses Moral hazard-Verhalten bereits bedürftiger Erwerbstätiger wäre mit der Mitnahme staatlicher Transfers verbunden (Mitnahmeeffekt II). Die Ursache für diesen Mitnahmeeffekt ist die Armutsfalle. Wenn immer mehr Personen bei unverändertem Status quo zu Beziehern ergänzender Sozialhilfe werden, dürfte die derzeit offensichtlich existierende asymmetrische Information zwischen Anspruchsberechtigten allmählich abgebaut werden. Es ist nicht auszuschließen, daß die Einführung des Einstiegsgeldes als Katalysator zum Abbau der asymmetrischen Information wirken könnte. Daraus kann jedoch kein Argument gegen das Einstiegsgeld abgeleitet werden, sondern lediglich für die Beseitigung der Armutsfalle.

Auch das Moral hazard-Verhalten von Kurzzeitarbeitslosen läßt sich nicht ausschließen. Kurzzeitarbeitslose haben den Anreiz, zur Zielgruppe „Langzeitarbeitslose" zu gehören, weil dann ihre Zusatzverdienste weniger angerechnet werden. Dadurch könnte sich ihre Suchintensität verringern, oder sie könnten sogar warten, bis sie die Anspruchsvoraussetzungen des Einstiegsgeldes erfüllen. In diesem Zeitraum würden sie staatliche Transfers mitnehmen (Mitnahmeeffekt III). Card et al. (1998) sprechen vom sogenannten ,delayed exit effect". Dieses Verhalten ist jedoch nur für wenige Personen wahrscheinlich. Kurzzeitarbeitslose beziehen in der Regel Arbeitslosengeld und sind nicht bedürftigkeitsgeprüft. Der Verzicht auf intensive Stellensuche ist mit Einkommensverzicht während der Wartezeit verbunden, weil eventuell eine gut bezahlte Stelle bei entsprechenden Anstrengungen gefunden worden wäre. Ist die Wahrscheinlichkeit, einen Job mit Nettoeinkommen oberhalb der 
Armutsfalle zu finden, gering, und die Wahrscheinlichkeit, die Bedürftigkeitsprüfung zu bestehen, hoch, dann könnte der Erwerb des Status „,bedürftigkeitsgeprüfter Langzeitarbeitsloser" jedoch ökonomisch rational sein. Kurzzeitarbeitslose mit eigenem Vermögen oder vermögendem Ehepartner sowie guten Vermittlungschancen in den Arbeitsmarkt haben jedoch nur einen geringen ökonomischen Anreiz, länger als bisher arbeitslos zu bleiben. Dennoch ist zu überlegen, ob nicht bestimmten bedürftigen Problemgruppen, die mit hoher Wahrscheinlichkeit langzeitarbeitslos werden, sofort oder bereits nach wenigen Monaten die Teilanrechnung von Zusatzverdiensten anzubieten ist, um unerwünschtes Moral hazard-Verhalten von Kurzzeitarbeitslosen zu minimieren. Zur Erinnerung: Für die Abgrenzung der Zielgruppe ist das Kriterium der Bedürftigkeit und nicht die Dauer des Hilfebezugs entscheidend (vgl. Kapitel 5.2.1).

Der Mitnahmeeffekt III ist in einem Feldexperiment mit zielgruppenorientierten Arbeitnehmer-Lohnsubventionen in Kanada empirisch getestet worden. Das kanadische Self-Sufficiency Project (SSP) ist ein soziales Feldexperiment in zwei unterschiedlichen Regionen Kanadas. Dabei wird Langzeitsozialhilfeempfängern eine großzügige Lohnsubvention angeboten für den Fall, daß sie eine Vollzeittätigkeit finden und nicht mehr auf Sozialhilfe angewiesen sind. Die Stichprobe des Experiments beträgt 3.315 Alleinerziehende, die zufällig entweder der Programmgruppe oder der Kontrollgruppe zugeordnet wurden. Die Autoren fanden lediglich einen sehr geringen „delayed exit effect" der Programmgruppe relativ zur Kontrollgruppe.

\section{(2) Arbeitsnachfrageentscheidung}

Lohnsubventionen an Arbeitnehmer können wie Lohnsubventionen an Arbeitgeber nicht nur zu Mitnahmeeffekten, sondern auch zu Substitutions- und Verdrängungseffekten führen. Deshalb befürchtet zum Beispiel Werner (1998, S. 606), daß die Subventionierung bestimmter Zielgruppen per saldo das Beschäftigungsniveau kaum erhöhen wird.

Substitutionseffekte sind wie Mitnahmeeffekte nicht vollständig zu vermeiden. Der „Drehtüreffekt“ - subventionierte Beschäftigte rein, nicht-subventionierte Beschäftigte raus - kann auf Firmenebene nicht ausgeschlossen werden. Gleiches gilt für Verdrängungseffekte durch crowding-out von nicht-subventionierten Arbeitnehmern in anderen Firmen oder Märkten (vgl. Kapitel 4.3.1). Vollständige Substitutionseffekte sind jedoch nicht zu erwarten. Zum einen sind Langzeitarbeitslose oder Langzeithilfeempfänger nach längerer Abwesenheit vom Arbeitsmarkt nicht als vollständige Substitute für Erwerbstätige mit betriebsspezifischem Know-how im industriellen Sektor anzusehen. Arbeitgeber werden nicht zuverlässige und erfahrene Mitarbeiter durch kostengünstigere Langzeitarbeitslose ersetzen. Das ist selbst bei sehr einfachen Tätigkeiten mit geringen Anlernzeiten, z.B. in der automatischen Fertigung nicht zu erwarten, weil Sekundärtugenden, wie Pünktlichkeit, eine 
große Rolle spielen. Langzeitarbeitslose zeichnen sich durch eine geringere Produktivität aus, weshalb sie erst durch untertarifliche Einstiegstarife für Arbeitgeber interessant werden. Zum anderen bestehen insbesondere im Bereich haushalts- und personengebundener Dienstleistungen zum Teil enge persönliche Beziehungen zwischen Arbeitgeber und Arbeitnehmer, die durch kurzfristige Kostenvorteile kaum aufgewogen werden können. Neben den im industriellen Bereich wichtigen Sekundärtugenden kommt in diesem Sektor das persönliche Vertrauensverhältnis als wichtige Voraussetzung für ein Arbeitsverhältnis hinzu, werden doch zum Beispiel das eigene Kind oder die Großeltern betreut oder die Privatwohnung gesäubert. Die Grenzen für Substitutionseffekte sind insbesondere in diesem Sektor sehr eng.

Auch Verdrängungseffekte sind wenig wahrscheinlich. Kapitalintensive Unternehmen im industriellen Sektor werden durch subventionierte Arbeitnehmer ihre Güterpreise kaum signifikant senken können. Lediglich lohnintensive Unternehmen könnten durch einen hohen Anteil subventionierter Arbeitnehmer ihren Konkurrenten über geringere Güterpreise Marktanteile abnehmen - mit der Konsequenz, daß die Konkurrenzunternehmen ihre nichtsubventionierten Arbeitnehmer entlassen müßten. Diese Argumentationskette setzt jedoch voraus, daß die subventionierten Arbeitnehmer eine gleich hohe Arbeitsproduktivität haben wie nicht-subventionierte Kollegen. Genau das ist nicht zu erwarten, weil doch die Lohnsubventionen wegen dieses Produktivitätsnachteils gezahlt werden. Layard et al. (1994, S. 95) verneinen sogar arbeitsnachfragebedingte Substitutions- und Verdrängungseffekte auf gesamtwirtschaftlicher Ebene, weil diesen Effekten die Vorstellung einer begrenzten Arbeitsnachfrage zugrundeliegt. Empirische Untersuchungen für Westdeutschland kommen zu dem Schluß, daß die Arbeitsnachfrageelastizität in den meisten Sektoren negativ ist, so daß vollständige Substitutions- und Mitnahmeeffekte ausgeschlossen werden können (vgl. Franz 1996b u. Fitzenberger/Franz 1997).

\section{(3) Arbeitsmarktwirkungen}

Der bisherigen Diskussion lag die Vorstellung zugrunde, daß sich ein höheres Arbeitsangebot seine Arbeitsnachfrage selbst schafft. Ob das Say'sche Theorem auf dem Arbeitsmarkt Gültigkeit besitzt, bezweifelt Solow (1998, S. 5). Weder sei die Anzahl der Jobs konstant bzw. die Arbeitsnachfrage vollkommen unelastisch, noch reagiere sie eins zu eins auf zusätzliches Arbeitsangebot bzw. ist die Arbeitsnachfrage vollkommen elastisch. Außerdem hat die bisherige Diskussion gezeigt, daß Mitnahme-, Substitutions- und Verdrängungseffekte nicht vollständig vermieden werden können. So stellt sich die Frage, unter welchen Voraussetzungen es zu negativen Beschäftigungswirkungen und fiskalischen Mehrbelastungen kommen könnte (,Worst caseSzenario“). Wenn ein Rückgang der Beschäftigung nicht zu erwarten ist, so 
stellt sich die Frage, um wieviel die Beschäftigung im besten Fall zunehmen könnte („Best case-Szenario“).

„Worst case-Szenario": Unter welchen Voraussetzungen könnte die Beschäftigung durch die Einführung eines zeitlich befristeten Einstiegsgeldes zurückgehen? Unter welchen Voraussetzungen könnte die fiskalische Belastung zunehmen? Unter den völlig unrealistischen Annahmen vollständiger Substitution und Verdrängung bestehender Arbeitsverhältnisse, also einer völlig unelastischen Arbeitsnachfrage, resultieren über die Mitnahmeeffekte IIII Einnahmenausfälle und zusätzliche Transferausgaben für den Staat. Bei gegebenen Staatsausgaben entsteht ein zusätzlicher Finanzierungsbedarf, der durch die Erhöhung verzerrender Steuern gedeckt werden muß. Dadurch erhöht sich im kompetitiven Arbeitsmarktmodell bzw. im Modell gleichgewichtiger Arbeitslosigkeit der Steuerkeil zwischen Brutto- und Nettolohn, so daß in diesem Fall negative Beschäftigungseffekte zu erwarten sind. Dieses Szenario ist jedoch unrealistisch.

Wie realistisch ist dagegen das Moral hazard-Verhalten der Arbeitgeber (Moral hazard I), das bereits das Speenhamland-System des 18. Jahrhunderts zerstörte (vgl. Kapitel 3)? Danach könnten die Arbeitgeber mit Verweis auf Lohnsubventionen die Löhne senken, so daß das System für den Staat unbezahlbar wird. Diese Gefahr, die von seiten der Gewerkschaften als „Lohndrückerei“" bezeichnet wird, besteht bereits im derzeitigen System. Arbeitgeber können mit Verweis auf die Sozialhilfe die Löhne nach unten drücken, weil der geringere Lohn durch ergänzende Sozialhilfe aufgestockt werden kann. Bei vollständiger Information über die Armutsfalle müßten gewinnmaximierende Arbeitgeber die Löhne bereits soweit wie möglich abgesenkt haben. In einem System mit Armutsfalle existiert demnach keine immanente Bremse gegen Lohndrückerei, weil es bei einer Transferentzugsrate von 100 $\%$ für den Arbeitnehmer irrelevant ist, aus welchen Komponenten sich sein verfügbares Einkommen zusammensetzt. Ihn interessiert lediglich der Nettolohn nach Transfer. Das Einstiegsgeld implementiert eine Bremse gegen dieses Moral hazard-Verhalten der Arbeitgeber. Bei einer Teilanrechnung von Zusatzverdiensten liegt es im Eigeninteresse der Arbeitnehmer, sich gegen eine Lohnsenkung zu wehren, weil in diesem Fall ihr verfügbares Einkommen sinken würde; die Nettoeinkommensfunktion des Einstiegsgeldes ist positiv geneigt, so daß bei sinkendem Bruttoeinkommen zwar der Transferanteil zunimmt, aber das Nettoeinkommen sinkt! Inwieweit das Eigeninteresse der Arbeitnehmer, Lohnabsenkung zu verhindern, in konkrete Verhandlungsmacht umgesetzt werden kann, ist jedoch eine offene Frage.

Wie realistisch ist das Moral hazard-Verhalten der Tarifpartner zu Lasten der Allgemeinheit (Moral hazard II)? Im Zuge der Wiedervereinigung vereinbarten die Tarifpartner weit über der Arbeitsproduktivität liegende Tariflöhne. Ursache für die Verhaltensreaktion der Tarifpartner war die Existenz der Arbeitslosenversicherung und der Sozialhilfe - die sozialen Sicherungssysteme 
federten die daraus zwangsläufig resultierende Arbeitslosigkeit für die Betroffenen finanziell ab. Die Einführung des Einstiegsgeldes verschärft das Moral hazard-Verhalten der Tarifpartner nicht, weil die verbesserte Teilanrechung der Zusatzverdienste lediglich für Bedürftige gilt. Könnten jedoch alle Arbeitslosen von den verbesserten Leistungsanreizen profitieren, so ist nicht ausgeschlossen, daß angesichts der relativ höheren Wiederbeschäftigungswahrscheinlichkeit von Arbeitslosen ,alle Dämme bei den Tarifverhandlungen brechen" (Sinn/Sinn 1992, S. 185).

Vereinbarungen der Tarifpartner über eine Tariflohnsenkung sind kein Moral hazard-Verhalten oder eine Art „Lohndumping“, sondern die durch Lohnsubventionen erwünschte Verhaltensreaktion: Einstiegstarife für Langzeitarbeitslose ermöglichen eine höhere Beschäftigung. In einer ökonometrischen Analyse für Westdeutschland kommen Fitzenberger/Franz (1997) zum Ergebnis, daß mit einer größeren Lohnspreizung die Lastverteilung des Beschäftigungsrisikos zwischen den einzelnen Qualifikationsgruppen bei gegebenem Output, Kapitaleinsatz und technischem Fortschritt durch eine Erhöhung der Beschäftigung von gering qualifizierten Arbeitnehmern angeglichen werden kann.

„Best-case Szenario“: Wieviele neue Jobs könnten in Deutschland entstehen? Nach den Berechnungen von Klös (1997b) vom Institut der Deutschen Wirtschaft (IW) fehlen auf dem deutschen Arbeitsmarkt 4,6 bis 9,5 Millionen Dienstleistungs-Arbeitsplätze. Der Autor stützt sich bei der Berechnung der sogenannten „Dienstleistungslücke“ auf internationale Vergleiche der relativen Beschäftigungsdichte. Nach Berechnungen von Haisken-De New et al. (1996, 1997) vom Deutschen Instituts für Wirtschaftsforschung (DIW) auf der Basis von Haushaltsbefragungen ist dagegen der Dienstleistungssektor in Deutschland ähnlich gut entwickelt wie in den USA - eine Dienstleistungslücke gibt es nach Ansicht des DIW nicht. Die Frage, ob zusätzliche Jobs in großem Umfang insbesondere im Dienstleistungssektor entstehen werden, ist demnach empirisch unklar.

So ist der Frage, ob es ein bisher wenig genutztes, weil sowohl für Arbeitnehmer und Arbeitgeber nicht rentables Beschäftigungspotential im Bereich haushalts- und personengebundener Dienstleistungen geben könnte, auf theoretischer Ebene nachzugehen. Welche Argumente sprechen für die Ausweitung der Beschäftigung im Niedriglohn-Dienstleistungssektor? Welche Hindernisse stellen sich der Auslagerung einfacher Dienstleistungen aus den privaten Haushalten (outsourcing) in den Weg? Im Vergleich zu den USA ist Deutschland zweifellos ein Land, in dem Service noch kleingeschrieben wird. Die Kultur des Dienens und Bedientwerdens ist noch wenig ausgeprägt. Der Kunde ist zwar theoretisch König, aber in der Praxis wird er häufig als potentieller Zahlungsverweigerer behandelt. Die Akzeptanz der Arbeitsteilung als Quelle der Wohlfahrt von Nationen ist insbesondere in Familien noch wenig ausgeprägt. Die im internationalen Vergleich geringe Beschäftigungsrate von 
qualifizierten Frauen spiegelt die häufig verbreitete Grundeinstellung wider, $\mathrm{da} ß$ an sich auslagerbare Dienstleistungen bevorzugt in Eigenarbeit erledigt werden. So werden einfache Dienstleistungen im Haushalt (z.B. Waschen, Putzen, Kochen, Einkaufen, Gartenarbeiten) sowie zeitintensive Betreuungsaufgaben (z.B. Kinderbetreuung, Pflege älterer Personen) auch von hochqualifizierten Frauen erledigt. Aus ökonomischer Sicht sind diese Verhaltensweisen ineffizient, wenn das eigene erzielbare Nettoeinkommen die Kosten der ausgelagerten Dienstleistungen übersteigt. Demnach gibt es unter der Annahme ökonomischer Rationalität im Entscheidungsprozeß zwei Ansatzpunkte für die Erklärung, weshalb einfache Dienstleistungen nicht nachgefragt werden: Entweder ist kein entsprechend hohes Nettoeinkommen erzielbar, oder die Dienstleistungen sind zu teuer. In der Realität dürfte eine Kombination dieser beiden Gründe relevant sein.

Nehmen hochqualifizierte Zweitverdiener eine Ganztagsbeschäftigung an, so wird ihr Nettoeinkommen hoch genug sein für eine positive Arbeitsnachfrage bei gegebenen Preisen für haushalts- und personengebundene Dienstleistungen. So nehmen hochqualifizierte Doppelverdiener häufig einfache Dienstleistungen in Anspruch. Weshalb könnte das erzielbare Nettoeinkommen von hochqualifizierten Zweitverdienern jedoch zu gering sein? Wird eine geringfügige oder eine Teilzeitbeschäftigung angenommen, so sinkt häufig nicht nur das monatliche Bruttoeinkommen, sondern auch der Bruttostundenlohn relativ zu einer Ganztagsbeschäftigung: Teilzeit- und geringfügig Beschäftigte müssen in der Regel Gehaltsabschläge im Vergleich zu einer Ganztagstätigkeit hinnehmen (vgl. Schwarze 1998), oder sie erhalten nur Jobs unter ihrem Qualifikationsniveau. Bei langen An- und Abfahrtszeiten zur Arbeitsstelle sowie eventuell anfallenden An- und Abfahrtswegen zu Betreuungseinrichtungen verringert sich die finanzielle Attraktivität eigener Verdienste weiter. Dagegen müssen private Haushalte als Arbeitgeber die Bruttokosten zahlen. Der Vergleich zwischen eigenem Nettostundenlohn und zu zahlendem Bruttostundenlohn führt bei den derzeitigen Preisen für reguläre einfache Dienstleistungen häufig zur ökonomisch effizienten Entscheidung: Eigenarbeit statt Fremdbezug von Dienstleistungen. Kann jedoch die Dienstleistung unter Umgehung der Steuer- und Abgabenpflicht bezogen werden, lohnt es sich für relativ mehr Haushalte, Dienstleistungen nachzufragen. Zur Vermeidung von Steuer- und Abgabenpflicht ist der Arbeitsmarkt für einfache Dienstleistungen in Deutschland deshalb häufig innerfamiliär bzw. im Rahmen von Nachbarschaftshilfe bzw. als Schwarzmarkt organisiert. Dementsprechend hat der Umfang der Schattenwirtschaft (vgl. Schneider 1997a,b) und der geringfügigen Beschäftigungen (vgl. Schupp et al. 1997) in den neunziger Jahren angesichts steigender Steuer- und Abgabenbelastung in Deutschland zugenommen. Im Rahmen des Jahressteuergesetzes 1997 (Bundesgesetzblatt 1996, S. 2065) wurden die steuerlichen Anreize für private Haushalte verbessert, um eine höhere Arbeitsnachfrage nach sozialversicherungspflichtigen Beschäftigungs- 
verhältnissen im Dienstleistungssektor zu bewirken. So wurde der Sonderausgabenabzug für private Haushalte von 12.000 DM auf 18.000 DM pro Jahr erhöht, wenn sie eine sozialversicherungspflichtige Beschäftigung anbieten. Dabei muß der Arbeitgeber die gesamten Sozialversicherungsbeiträge direkt übernehmen. Das Meldeverfahren bei der Sozialversicherung wurde durch die Einführung sogenannter Haushaltsschecks vereinfacht. Die Möglichkeit des Sonderausgabenabzugs ist auch nicht mehr auf Familien mit zwei und mehr Kindern begrenzt, sondern steht auch Ein-Kind-Haushalten offen. Die Steuerersparnis durch die Abzugsmöglichkeit soll die Mehrkosten gegenüber Schwarzarbeit in der Regel ausgleichen. Finanzielle Belastungen durch Urlaub, Lohnfortzahlung oder Feiertage werden jedoch nicht ausgeglichen. Nach Berechnungen von Emmerich (1997) vom Institut für Arbeitsmarkt- und Berufsforschung (IAB) besteht erst ab einem Grenzsteuersatz von $40 \%$ der Anreiz, Haushaltshilfen sozialversicherungspflichtig zu beschäftigen, so daß lediglich etwa 500-600.000 Haushalte als potentielle Arbeitgeber in Betracht kommen. Doch nur für einen Bruchteil dieser Haushalte sind Teilzeit- oder Vollzeit-Haushaltshilfen bei gegebenen Bruttolöhnen interessant: Der durchschnittliche Zeitbedarf privater Haushalte liegt bei den derzeitigen Bruttokosten lediglich bei etwa 5 Stunden/Woche.

Weshalb könnten die Bruttokosten für einfache Dienstleistungen zu hoch bleiben, so daß zusätzliche Arbeitsnachfrage unterbunden wird? Der wesentliche Grund für die hohen Bruttokosten für einfache Dienstleistungen in Deutschland ist der Abgaben- und Steuerkeil. Dementsprechend bevorzugen potentielle Arbeitgeber abgaben- und steuerfreie Beschäftigungsverhältnisse. Sozialabgaben lassen sich durch geringfügige Beschäftigungsverhältnisse vermeiden und die von den Arbeitgebern im Regelfall gezahlten Pauschalsteuern können auf die Löhne der geringfügig Beschäftigten rückgewälzt werden (vgl. Schwarze 1998). Dementsprechend existiert in Deutschland ein umfangreicher Arbeitsmarkt für geringfügige Beschäftigungsverhältnisse. Auch Arbeitsverhältnisse auf selbständiger, freiberuflicher oder Werkvertragsbasis entbinden Arbeitgeber von der Sozialabgaben- und Steuerpflicht, so daß auch diese Beschäftigungsverhältnisse in bedeutendem Umfang existieren. Nach Schätzungen von Dietrich (1996) sind etwa 938.000 Erwerbstätige in die Grauzone von selbständiger und abhängiger Erwerbstätigkeit einzuordnen. Dagegen ist ein regulärer Arbeitsmarkt für sozialversicherungspflichtige Teilzeit- und Ganztagsbeschäftigungsverhältnisse bei einfachen Dienstleistungen wenig ausgeprägt. Am 30. Juni 1997 waren lediglich 34.159 Arbeitnehmer sozialversicherungspflichtig in privaten Haushalten in Gesamtdeutschland beschäftigt (vgl. Bundesanstalt für Arbeit 1997a). Werden zur Vermittlung sozialversicherungspflichtiger Beschäftigungsverhältnisse noch Dienstleistungsagenturen eingesetzt, steigen die Bruttokosten um den Gewinnanteil der Agenturen. So sind Bruttokosten von weit über $30 \mathrm{DM} / S t u n d e$ für Haushaltshilfen in größeren Städten üblich. 
Kann sich eine größere Arbeitsnachfrage bei gegebenen Bruttokosten für einfache Dienstleistungen in der Zukunft dennoch entwickeln? Dafür spricht sowohl die demographische Entwicklung als auch die Erodierung der Familienbande. Vorliegende Bevölkerungsprognosen weisen bei gegebener Geburtenrate und gegebener medizinischer Versorgung darauf hin, daß der Anteil der älteren Menschen an der Gesamtbevölkerung in den nächsten Jahrzehnten zunehmen wird (vgl. Raffelhüschen/Walliser 1997). Daraus resultiert ein höherer Bedarf nicht nur an Pflegedienstleistungen, sondern auch an Haushaltsdienstleistungen (z.B. Einkaufsservice). Auch ist zu erwarten, daß völlig neue Dienstleistungen für ältere Menschen entstehen werden. Die Nachfrage nach Dienstleistungen wird auch durch die Entwicklung zur Single-Gesellschaft gefördert. Für kinderlose Singles ist der Fremdbezug von Dienstleistungen häufig kostengünstiger als Eigenerstellung. Im Rentenalter können sie nicht auf Versorgung im Rahmen des Familienverbandes zählen, so daß Dienstleistungen auf dem Arbeitsmarkt nachgefragt werden müssen. Aber auch in den Familien könnte die Nachfrage nach einfachen Dienstleistungen zunehmen, wenn das Qualifikationsniveau und damit die Verdienstchancen von Frauen als potentielle Zweitverdiener sich weiterhin erhöhen. Dadurch steigen die Opportunitätskosten der Eigenerstellung einfacher Dienstleistungen, so daß die Wahrscheinlichkeit des Fremdbezugs zunimmt.

Gegen eine in der Zukunft erhöhte Arbeitsnachfrage bei gegebenen Bruttokosten spricht die von den Tarifpartnern beschlossene Verringerung der Arbeitszeit zugunsten der Freizeit. Arbeitszeitverkürzung ohne vollen Lohnausgleich senkt den Stundenlohn, so daß die Opportunitätskosten der Freizeit sinken. Eigenarbeit wird dadurch relativ zum Fremdbezug von Dienstleistungen kostengünstiger. Außerdem sind der Auslagerung haushalts- und personengebundener Dienstleistungen Grenzen gesetzt, die ihre Ursache zum einen in der Privat- und Intimsphäre der Menschen haben. Zum anderen ist die Voraussetzung für den Fremdbezug von Dienstleistungen, die bisher im Familien-, Freundes- und Bekanntenkreis erbracht wurden, Vertrauen. Der Aufbau von Vertrauen benötigt jedoch Zeit und erfordert deshalb langfristige Arbeitsverhältnisse, die eventuell nicht im Eigeninteresse der Beschäftigten sind. Weiterhin sprechen Fairneß- und Effizienzlohnüberlegungen der Arbeitgeber gegen eine Absenkung der Löhne (vgl. Mindestlohn II in Abbildung 31), so daß die Beschäftigungsausweitung im Niedriglohnsektor arbeitsnachfrageseitig begrenzt wird.

\section{(4) Intertemporale Entscheidungen der Arbeitnehmer}

Die bisherige Diskussion der Beschäftigungswirkungen hat lediglich kurzfristige Entscheidungen der Arbeitnehmer berücksichtigt. Zeitlich unbefristete Lohnsubventionsmodelle werden jedoch auch wegen ihrer negativen Effekte auf die Qualifizierungsbemühungen der Arbeitnehmer kritisiert (vgl. Siebert 1994, 1995, 1996). Sie vermindern den Anreiz zur Humankapitalbildung, 
weil die Aufstockung geringer Löhne den Lohnabstand zwischen Niedriglohn- und Hochlohnsektor verringert. So stellt sich die Frage: Vermindert die Einführung einer zielgruppenorientierten negativen Einkommensteuer den Anreiz von Transferempfängern, ihre Qualifikation zu verbessern? Auf den ersten Blick könnte dieser Eindruck entstehen, weil Einstiegsgeldempfänger zusätzlich zu ihrem Arbeitsverdienst einen Teil ihres bisherigen Sozialhilfeanspruchs als Einstiegsgeld erhalten, so daß sie sich finanziell besser stellen als nicht erwerbstätige Sozialhilfeempfänger. Würde eine Lohnsubvention an alle Niedrigeinkommensbezieher ohne zeitliche Befristung gewährt, wäre der Anreiz für Investitionen in das eigene Humankapital tatsächlich relativ geringer als im Status quo. Das Einstiegsgeld ist jedoch zeitlich befristet und lediglich für eine Zielgruppe vorgesehen.

Fehlanreize in bezug auf die Humankapitalbildung existieren im Status quo durch den geringen Lohnabstand zwischen Sozialhilfe und unteren Nettoeinkommen. Das Einstiegsgeld erhöht den Lohnabstand nicht, verringert ihn aber auch nicht. Negative Qualifizierungsanreize bestehen jedoch auch durch die Armutsfalle. Zusatzverdienste aus geringfügiger und Teilzeitbeschäftigung lohnen sich im Status quo kaum, so daß Qualifizierung durch training-on-thejob weitgehend unterbleibt. Dieser Qualifizierungsfehlanreiz wird durch das Einstiegsgeld vermindert. Da Qualifikation nicht nur durch formale Abschlüsse, sondern auch durch betriebsspezifisches know-how erworben wird, erhöhen sich die Chancen auf eine besserbezahlte Beschäftigung in der Zukunft. Niedriglohnbeschäftigung erhöht die Wiederbeschäftigungswahrscheinlichkeit - die Bewerbung aus dem Job heraus ist erfolgversprechender als die Bewerbung aus der Arbeitslosigkeit. Der Einstiegsgeldvorschlag fördert demnach eine langfristige Höherqualifikation. Staatliche Qualifizierungsmaßnahmen, die auf den Erwerb formaler Bildungsabschlüsse abzielen, sind kein Element des Einstiegsgeldkonzepts, stehen jedoch in einer komplementären Beziehung.

Eine weitere intertemporale Entscheidung der Arbeitnehmer ist die Frage nach der Ersparnisbildung. Erhöht das Einstiegsgeld den Anreiz zum Sparen? Aus der Versicherungsökonomik ist bekannt, daß für risikoscheue Individuen mit niedrigem Einkommen wegen der Existenz von Sozialhilfe eine Nichtversicherung ökonomisch rational ist (vgl. Buchholz/Wiegard 1992). Im Schadensfall „Langzeitarbeitslosigkeit“ verlassen sich die Individuen auf die steuerfinanzierte Arbeitslosen- und/oder Sozialhilfe, statt in ausreichendem Maße Eigenvorsorge durch entsprechende Versicherungsnachfrage zu treffen. $\mathrm{Ob}$ die Möglichkeit einer zeitlich befristeten, leistungsfreundlichen Ausgestaltung des Transfersystems in das Erwartungsnutzenkalkül von Niedrigeinkommensbeziehern eingeht, ist letztlich eine empirische Frage, die im Rahmen von Feldexperimenten untersucht werden muß. 
(5) Intertemporale Entscheidungen der Arbeitgeber

Die Arbeitsnachfragewirkungen wurden bisher unter der Annahme eines konstanten Kapitalstocks diskutiert. Die zusätzliche Einstellung von Arbeitnehmern wird durch Lohnsubventionen für Arbeitgeber gewinnmaximal (vgl. Abbildung 31). Die Auszahlung an Arbeitnehmer bewirkt, daß ein höheres Arbeitsangebot nutzenmaximal ist, so daß die Bruttoreallöhne sinken können. Die Beschäftigungsausweitung findet entlang einer Arbeitsnachfragekurve statt. Die durchschnittliche Arbeitsproduktivität sinkt entlang der Arbeitsnachfragekurve, weil Arbeitnehmer mit geringerer Grenzproduktivität eingestellt werden.

Zeitlich unbefristete Lohnsubventionen wie der amerikanische EITC werden wegen negativer Effekte auf die Produktivität kritisiert. So verändert eine Lohnsubvention den relativen Preis zwischen Arbeit und Kapital - das Lohn-/ Zins-Verhältnis -, so daß sich der Anreiz für die Arbeitgeber vermindert, in neue Technologien und Kapital zu investieren (vgl. Bluestone/Ghilarducci 1996, S. 24). Dieses Produktivitätsargument gegen Lohnsubventionen bedarf einer detaillierteren Analyse.

In der kurzen Frist sinkt die Arbeitsproduktivität durch die Einführung von Arbeitnehmer-Lohnsubventionen wie den EITC und das Einstiegsgeld. Doch die Wirkungskette ist damit noch nicht abgeschlossen. Bei erhöhter Beschäftigung steigt auch der Output. Unter der Annahme komplementärer Produktionsfaktoren ist die Grenzproduktivität des Kapitals positiv mit der Arbeitsmenge korreliert, so daß die Ausweitung der Investitionstätigkeit für die Unternehmen gewinnmaximal ist. Zusätzliche Investitionen verschieben die Arbeitsnachfragekurve nach oben, so daß die Beschäftigung und der Output erneut zunehmen (vgl. Jerger 1993 für eine dynamische Analyse). Eine Betrachtung der Beschäftigungswirkungen mit endogener Kapitalstockanpassung macht deutlich, daß das ursprüngliche Reallohnniveau im Niedriglohnsektor durch beschäftigungsinduzierte Investitionen wieder erreicht werden kann. Lohnsubventionen führen demnach lediglich vorübergehend zu geringerer Arbeitsproduktivität und geringeren Reallöhnen. Langfristig steigt die Arbeitsproduktivität durch zusätzliche Investitionen. Höhere Reallöhne werden möglich, weil die Kapitalausstattung der Volkswirtschaft zugenommen hat. Wie wirkt sich die Einführung des Einstiegsgeldes im Vergleich zu zeitlich unbefristeten Lohnsubventionen auf die Investitionsentscheidung von Arbeitgebern aus? Das Einstiegsgeld ist im Gegensatz zum EITC eine zeitlich befristete Lohnsubvention. Legt man ein dynamisches Investitionsmodell mit dem Entscheidungskriterium Kapitalwert zugrunde, so wird deutlich, daß sich bei einer zeitlich unbefristeten Lohnsubvention relativ mehr Investitionen mit längerer Laufzeit für die Arbeitgeber lohnen. Das Einstiegsgeld beeinflußt die Investitionsentscheidung der Arbeitgeber positiv, jedoch weniger stark als eine zeitlich unbefristete Lohnsubvention. 
Der Einstiegsgeldvorschlag führt demnach über mehr Beschäftigung und mehr Investitionen zu höherer Arbeitsproduktivität. Damit steht der Vorschlag im Gegensatz zum Transformationsweg in Ostdeutschland, der über weniger Beschäftigung zu höherer Arbeitsproduktivität führte. In Ostdeutschland wurden in den Tarifverhandlungen 1991 Reallohnsteigerungen weit oberhalb der zu erwarteten Steigerungen der Arbeitsproduktivität durch technologisch bedingte Produktivitätssprünge vereinbart. Hohe Löhne wurden auch mit dem Verweis auf ihre Wirkung als „Produktivitätspeitsche“ vereinbart. Diese Peitsche wirkte auch: $\mathrm{Zu}$ einem großen Teil ist die hohe Arbeitsproduktivität in Ostdeutschland auf einen Rückgang der Beschäftigung zurückzuführen. Angesichts der hohen Reallöhne war ein Abbau der Beschäftigung für die Unternehmen gewinnmaximal. Nur in modernen Industrieanlagen mit hoher Kapitalproduktivität und entsprechend hoher Arbeitsproduktivität konnten die hohen Reallöhne von den Arbeitnehmern erwirtschaftet werden. Der in Ostdeutschland realisierte Transformationsweg kommt einer sogenannten „HighTech-Hochlohnstrategie" sehr nahe (vgl. Sinn/Sinn 1992). Hohe Tariflöhne und hohe Kapitalsubventionen führten zu einer stark kapitalintensiven Produktionsstruktur mit hoher Arbeitsproduktivität. Die Kehrseite der hohen Arbeitsproduktivität in Ostdeutschland ist jedoch die hohe Arbeitslosigkeit (vgl. Sinn 1995). Dagegen fördert der Einstiegsgeldvorschlag arbeitsintensive Produktionsprozesse und Dienstleistungen, was angesichts hoher und langandauernder Arbeitslosigkeit sinnvoll erscheint.

\section{(6) Gerechtigkeitsaspekte}

Gegen zielgruppenorientierte Lohnsubventionsmodelle wie das Einstiegsgeld wird eingewandt, daß die bevorzugte Behandlung einer Zielgruppe gegen den Grundsatz der horizontalen Gerechtigkeit verstößt, weil ein „erwerbstätiger Sozialhilfeempfänger zusammen mit der Sozialhilfe ein höheres Nettoeinkommen realisieren könnte als ein nichtsozialhilfeberechtigter Erwerbstätiger mit einem gleich hohen Nettoerwerbseinkommen" (Rosenfeld 1997, S. 252). Das Gerechtigkeitsproblem ist kein spezifisches Problem des EinstiegsgeldVorschlags, sondern ein Grundproblem jedes Transfers an eine Zielgruppe. Haushalte, die Erziehungsgeld oder Wohngeld erhalten, stellen sich finanziell besser als Haushalte, die keinen Anspruch auf diese Transfers haben. Voraussetzung für die Gewährung dieser Transfers ist jedoch die Unterschreitung bestimmter Einkommensgrenzen. Sowohl Erziehungs- als auch Wohngeld wird lediglich an einkommensschwache Haushalte gezahlt. Es ist deshalb nicht auszuschließen, daß Transferempfänger sich finanziell besser stellen als Haushalte, deren Nettoeinkommen knapp über den Einkommensgrenzen liegt. Das Gerechtigkeitsproblem beim Vergleich von Sozialhilfeempfängern und Erwerbstätigen tritt allerdings nicht beim Wohngeld auf, weil dieser Transfer voll auf die Sozialhilfe angerechnet wird. Eine Erhöhung des Wohngelds vermindert den Sozialhilfeanspruch, so daß sich das verfügbare Einkommen 
von Sozialhilfeempfängern nicht verändert. Das Erziehungsgeld wird dagegen nicht auf die Sozialhilfe angerechnet, sondern als zusätzlicher Transfer gewährt, so daß exakt die oben angesprochene Ungleichbehandlung resultiert. Das Einstiegsgeld wird wie das Erziehungsgeld zeitlich befristet nur an Bedürftige gezahlt. Im Gegensatz zum Erziehungsgeld erfordert die Einführung des Einstiegsgelds jedoch keine zusätzlichen Finanzierungsmittel des Staates. Hier offenbart sich ein Zielkonflikt zwischen Effizienz und Gerechtigkeit. Je höhere Leistungsanreize für bedürftige Langzeithilfeempfänger in das bestehende Transfersystem ohne Absenkung des Grundsicherungsniveaus eingebaut werden, desto größer wird das horizontale Gerechtigkeitsproblem. Im Hinblick auf möglichen sozialen Konfliktstoff zwischen bedürftigen Langzeitarbeitslosen und nicht-bedürftigen Geringverdienern ist dieser Aspekt von Bedeutung. Die verschiedenen Bausteine des Einstiegsgelds ermöglichen jedoch die Abmilderung des horizontalen Gerechtigkeitsproblems. Neben der degressiven Ausgestaltung können die Anteile an Markt- und Transfereinkommen auch im Zeitablauf variabel gestaltet werden. Durch eine entsprechende Austarierung von im Zeitablauf zunehmenden Einstiegstarifen (Marktlohn) und abnehmendem Einstiegsgeld (Transfer) läßt sich das Gerechtigkeitsproblem minimieren. Werden geringere Hilfeniveaus für arbeitsfähige Hilfeempfänger akzeptiert und Armutslückenkonzepte eingeführt, so verschwindet dieses Gerechtigkeitsproblem.

Bei der Einführung des Erziehungsgelds fand angesichts der familienpolitischen Zielsetzung - Förderung einkommensschwacher Familien - keine öffentliche Diskussion über horizontale Gerechtigkeit statt. Bei einer arbeitsmarktpolitischen Zielsetzung - Förderung bedürftiger Langzeitarbeitsloser ist diese Diskussion jedoch zu erwarten. Als Indizien können stark emotional geführte innerbetriebliche Auseinandersetzungen dienen, wenn Zeitarbeiter einen höheren Nettostundenlohn als die Stammbelegschaft erhalten - auch wenn sie keine Sozialversicherungsansprüche erwerben. Auch Aushilfskräfte (z.B. Schüler und Studenten) können nach Lohnsteuerjahresausgleich einen höheren Nettostundenlohn erhalten als die Stammbelegschaft - wenn sie nur wenige Monate im Jahr arbeiten. Andererseits könnten vorübergehend unterschiedlich hohe verfügbare Einkommen nach Transfer aus drei Gründen für Geringverdiener akzeptabel sein. Zum einen ist die Hürde für den Bezug von Einstiegsgeld sehr hoch: Um von der verbesserten Teilanrechnung profitieren zu können, müssen Hilfeempfänger in der Regel ein Jahr lang arbeitslos sein und eine Bedürftigkeitsprüfung bestehen. Mitnahmeeffekte werden durch diese Maßnahmen minimiert. Zum anderen dürfte es für Geringverdiener nachvollziehbar sein, daß es auch für sie vorteilhaft ist, wenn Langzeitarbeitslose arbeiten - ansonsten müssen sie höhere Sozialhilfe- und Arbeitslosenhilfezahlungen mitfinanzieren. Zum dritten dürften auch Geringverdiener daran interessiert sein, daß Langzeitarbeitslose eine Chance erhalten, ihren Beitrag 
zur Einsparung von Staatsausgaben zu leisten - das Angebot an Altruismus ist begrenzt (vgl. Solow 1998).

\subsubsection{Vergleich mit Lohnsubventionen an Arbeitnehmer}

Das Einstiegsgeld unterscheidet sich von Lohnsubventionen an Arbeitnehmer (vgl. Kapitel 4.2) in einer Hinsicht fundamental und in mehreren Punkten in Detailfragen. Das entscheidende Merkmal des Einstiegsgeldes ist die zeitlich befristete Spaltung des Steuer- und Abgabensystems auf der einen Seite und des Transfertarifs auf der anderen Seite. Für steuer- und abgabenpflichtige Erwerbstätige und Transferempfänger, die nicht zur Zielgruppe gehören, gelten weiterhin die Regelungen des Status quo. Das Transfersystem wird lediglich für eine Zielgruppe zeitlich befristet leistungsfreundlich ausgestaltet. Daraus resultiert der entscheidende Vorteil des Einstiegsgeldes gegenüber Lohnsubventionsmodellen an Arbeitnehmer: die minimalen Einführungskosten. Das Einstiegsgeld unterscheidet sich jedoch auch in der Abgrenzung der Zielgruppe, der Art des Anrechnungsverfahrens und der administrativen Ausgestaltung von anderen Lohnsubventionsmodellen an Arbeitnehmer.

\section{(1) Zielgruppen}

Die Zielgruppe des amerikanischen Earned Income Tax Credit (EITC) und des britischen Family Credit (FC) sind einkommensschwache Familien; seit 1994 können jedoch auch Einzelpersonen Steuergutschriften im Rahmen des EITC erhalten. Die Zielgruppe der Negative Wage Tax (NWT) sind dagegen bedürftige Niedriglohnbezieher. Hilfeempfänger, die Teilzeit arbeiten, jedoch Stundenlöhne oberhalb des maximal bezuschußten Stundenlohns erzielen, werden nicht gefördert. Kombi-Einkommensmodelle im Rahmen der Sozialhilfe sehen - wie der Einstiegsgeldvorschlag - als Zielgruppe arbeitsfähige Sozialhilfeempfänger vor. Voraussetzung für die Förderung ist eine Bedürftigkeitsprüfung. Darüber hinaus können Arbeitslosenhilfeempfänger, jugendliche Kurzzeitarbeitslose und alleinerziehende Langzeitsozialhilfeempfänger ebenfalls in die Zielgruppe des Einstiegsgeldes einbezogen werden.

\section{(2) Anrechnungsverfahren}

Der EITC und der FC sind als ,in-work benefits“ konzipiert. Erwerbstätige, aber einkommensschwache Familien erhalten eine jährliche Gutschrift, die mit ihren eigenen Einkünften verrechnet wird. Ist die Gutschrift höher als das Nettoeinkommen der Familien, dann wird ein Transfer gezahlt. Würde ein Anrechnungsverfahren im Sinne des EITC in das deutsche Sozialhilferecht integriert, so wären ein negativer Grenzsteuersatz von $34 \%$ im Bruttoeinkommensbereich der „phase-in region“, ein Grenzsteuersatz von Null Prozent in der „,constant region“ und ein positiver Grenzsteuersatz von etwa $16 \%$ in der „phase-out region“ die Folge. Die Leistungsanreize für Hilfeempfänger wären im Bereich der phase-in region sogar höher als bei Schwarzarbeit, weil - ausgehend vom Sozialhilfeniveau - jede zusätzlich verdiente Mark mit 34 
Pfennig Zuschuß aufgestockt würde. Auch in den beiden anderen Bruttoeinkommensbereichen wäre das Transfersystem sehr leistungsfreundlich ausgestaltet. Der Preis für diese geringen Anrechnungssätze wären jedoch sehr hohe zusätzliche Transferausgaben (vgl. Kapitel 4.2.1).

Das Anrechnungsverfahren des FC entspricht oberhalb des anrechnungsfreien Sockelbetrags der Teilanrechnung von Zusatzverdiensten der phase-out region - allerdings mit der hohen Transferentzugsrate von $70 \%$. Kombi-Einkommensmodelle sehen ebenfalls hohe Anrechnungssätze zwischen 70 und $100 \%$ je nach Einkommensbereich vor. Hinzu kommt, daß das Nettoeinkommen die Bemessungsgrundlage darstellt, so daß sich unter Berücksichtigung der Steuer- und Abgabenbelastung noch höhere Grenzsteuersätze auf Zusatzverdienste ergeben können. Die Leistungsanreize für Hilfeempfänger sind demnach insbesondere in höheren Bruttoeinkommensbereichen sehr gering.

Die NWT entspricht bei einem konstanten Lohnsatz der phase-in region des EITC. Bei steigendem Lohnsatz geht der Subventionssatz jedoch zurück, so daß sich eine degressive Lohnsubvention ergibt. Auch das Einstiegsgeld läßt sich prinzipiell als degressive Lohnsubvention ausgestalten. Die Modellvariante 2 (vgl. Abbildung 29) sieht eine Transferentzugsrate von höchstens $50 \%$ bis zur Bedürftigkeitsgrenze bzw. Einkommensobergrenze vor, oberhalb dieser Grenze führt die degressive Ausgestaltung jedoch zu Transferentzugsraten von über $50 \%$. Dabei ist jedoch eine degressive Einkommenssubvention unterstellt.

\section{(3) Administrative Ausgestaltung}

Whitehouse (1996) sieht in der administrativen Ausgestaltung von ,in-work benefits" eine zentrale politische Frage. Sollen Lohnsubventionen an Einkommensschwache wie beim amerikanischen EITC über das Finanzamt oder wie beim britischen FC über das Sozialamt ausgezahlt werden? Bei der Einführung einer NWT, eines Kombi-Einkommensmodells oder des Einstiegsgeldes in das Sozialhilfesystem wären ebenfalls die Sozialämter für die Auszahlung der Transfers zuständig. Das Einstiegsgeld für Arbeitslosenhilfeempfänger soll über die Arbeitsämter ausgezahlt werden. Es geht demnach um die grundsätzliche Frage, ob Lohnsubventionen über das Steuer- oder das Transfersystem abgewickelt werden sollen.

Der Einstiegsgeldvorschlag sieht im Gegensatz zum EITC eine Auszahlung über das Transfersystem vor. Auf diese Weise werden Mitnahmeeffekte minimiert, weil zum einen die Bedürftigkeitsprüfung nicht nur eine Einkommensprüfung, sondern auch eine Vermögensprüfung umfaßt - im Gegensatz zur Finanzamtslösung. Zum anderen ist der Haushalt und nicht das Individuum Grundlage für die Berechnung des Transferanspruchs - mit der Konsequenz, daß zum Beispiel Transferzahlungen an geringfügig beschäftigte Frauen gutverdienender Ehepartner vermieden werden können. Ein weiterer Vorteil ist die monatliche Auszahlung von Transfers - im Gegensatz zur jährlichen Aus- 
zahlung einer Steuergutschrift. Zwar ist es grundsätzlich möglich, auch Steuergutschriften als negative Einkommensteuervorauszahlung in kürzeren Abständen auszuzahlen. Doch ist diese Option wenig transparent und mit Blick auf mögliche Rückforderungen des Finanzamtes auch wenig attraktiv für Geringverdiener, wie Untersuchungen des EITC gezeigt haben (vgl. Alstott 1994 u. Whitehouse 1996, S. 135).

Ein Nachteil einer Auszahlung über das Transfersystem sind die relativ höheren administrativen Kosten je Fall. Die höheren Kosten entstehen zum einen durch den Aufwand für die umfangreiche Bedürftigkeitsprüfung der Haushalte. Zum anderen müssen Fälle doppelt bearbeitet werden, wenn sowohl Steuern gezahlt werden als auch Anspruch auf Transfers besteht. Zum Beispiel zahlen in Großbritannien $45 \%$ der Bezieher des FC gleichzeitig Lohnsteuern (vgl. Whitehouse 1996, S. 137). Weiterhin treten bei einer Auszahlung über das Transfersystem Stigma-Effekte auf, die sich negativ auf die Inanspruchnahme (take-up rate) der Lohnsubventionen auswirken. So läßt sich empirisch für das amerikanische Steuer- und Transfersystem belegen, daß die Inanspruchnahme des EITC mit 60-80\% über der Inanspruchnahme bedürftigkeitsgeprüfter Transfers liegt.

Welche der beiden grundsätzlichen Auszahlungsformen unter dem Gesichtspunkt der administrativen Kosteneffizienz vorteilhafter ist, läßt sich ohne weitere Informationen über die Kosten der Verwaltungsleistungen nicht beurteilen.

\subsubsection{Vergleich mit Lohnsubventionen an Arbeitgeber}

Der Vergleich zwischen Arbeitnehmer-Lohnsubventionen und ArbeitgeberLohnsubventionen wird exemplarisch für den Vergleich zwischen dem Einstiegsgeld und dem Benefit Transfer-Program (BTP) dargestellt. Alle wesentlichen Argumente ergeben sich aus dem Vergleich dieser beiden zielgruppenorientierten Lohnsubventionsmodelle. Einstiegsgeld und BTP lassen sich völlig analog konzipieren, so daß sich die beiden Lohnsubventionsmodelle nur noch durch die Art der Auszahlung unterscheiden. Aus Vereinfachungsgründen wird von sämtlichen dynamischen Aspekten der beiden Lohnsubventionsmodelle abstrahiert. Sowohl im kompetitiven als auch im Modell gleichgewichtiger Arbeitslosigkeit treiben beide Lohnsubventionsmodelle einen Keil zwischen den Produzenten- und Konsumentenlohn. In Abbildung 34 ist exemplarisch das Modell gleichgewichtiger Arbeitslosigkeit wiedergegeben. Durch eine zielgruppenorientierte Arbeitgeber-Lohnsubvention wird die Preissetzungskurve $\mathrm{PS}_{\mathrm{AL}}$ nach oben auf $\mathrm{PS}_{\mathrm{AL}}{ }_{\mathrm{AL}}$ verschoben, so daß sich die Beschäftigung von $\mathrm{N}_{2}$ auf $\mathrm{N}_{3}$ erhöht (vgl. Snower 1997).

$\mathrm{Zu}$ beachten ist, daß auf dem Arbeitsmarkt der Konsumentenlohn beobachtbar ist. Durch eine zielgruppenorientierte Arbeitnehmer-Lohnsubvention verhandeln die Tarifpartner niedrigere Einstiegstarife für Langzeitarbeitslose, so daß sich die $W_{\mathrm{AL}}-$ Kurve ergibt. Dadurch steigt die Beschäftigung ebenfalls von 
$\mathrm{N}_{2}$ auf $\mathrm{N}_{3}$ (vgl. Kapitel 5.3.4), wobei auf dem Arbeitsmarkt der Produzentenlohn beobachtbar ist. So läßt sich festhalten: In einer Coase-Welt ohne Transaktionskosten und asymmetrischer Information spielt es keine Rolle, ob zielgruppenorientierte Lohnsubventionen an Arbeitnehmer oder Arbeitgeber ausgezahlt werden - es ergibt sich der gleiche Beschäftigungseffekt.

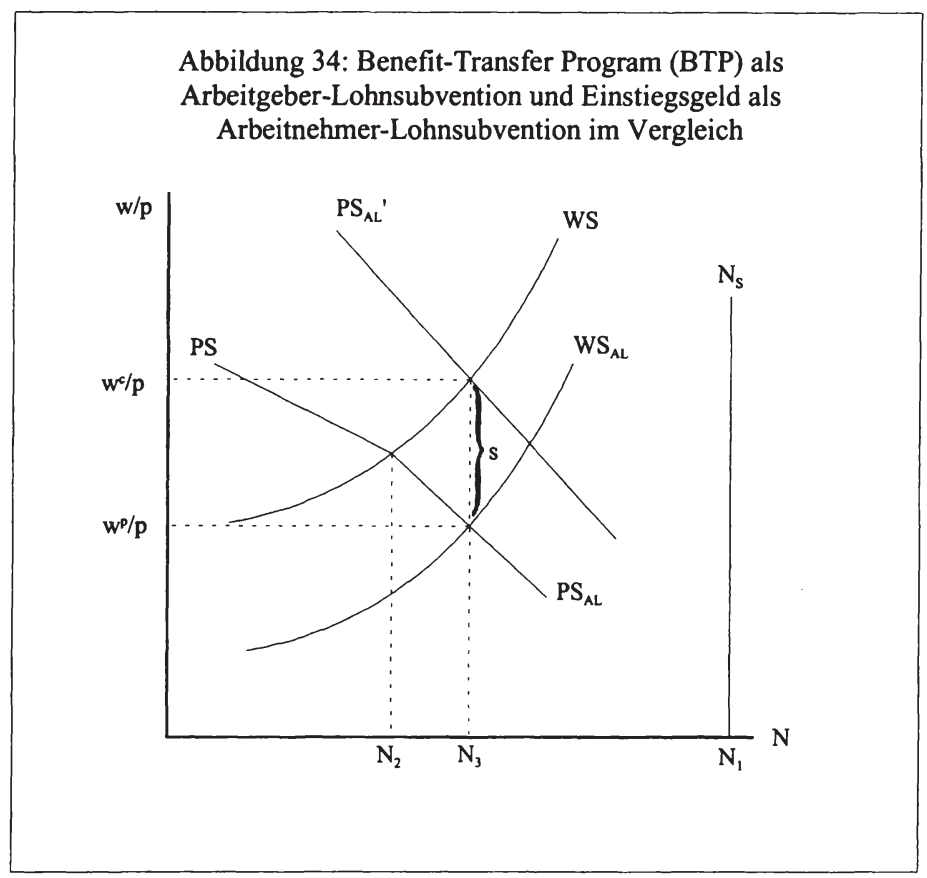

Sobald die realitätsfernen Annahmen einer Coase-Welt aufgegeben werden, ergeben sich jedoch wesentliche Unterschiede zwischen den Auszahlungsformen. Hinweise auf die Vorteilhaftigkeit einer Auszahlung an Arbeitnehmer gibt die Untersuchung von Woodbury/Spiegelman (1987). Die Autoren analysieren zwei kontrollierte Feldexperimente mit zufällig ausgewählten Empfängern von Arbeitslosenunterstützung im US-Bundesstaat Illinois 1984/85. In einem der Experimente wurde den Arbeitslosen ein 500 Dollar-Bonus zur Auszahlung an den Arbeitgeber in Aussicht gestellt, wenn sie innerhalb von 11 Wochen eine Stelle für den Zeitraum von mindestens vier Monaten fänden (Employer Bonus Experiment). In dem anderen Experiment wurde den Arbeitslosen eine gleich hohe Bonuszahlung als Arbeitnehmer-Lohnsubvention angeboten, wenn sie eine Stelle für den gleichen Zeitraum fänden (Claimant Bonus Experiment). Es stellte sich heraus, daß der Beschäftigungseffekt der 
Arbeitnehmer-Lohnsubventionen höher als der Beschäftigungseffekt der Arbeitgeber-Lohnsubventionen war. Woodbury/Spiegelman (1987) berichten zwar dieses Ergebnis, geben jedoch keine Erklärung für die unterschiedlichen Wirkungen. Die folgende Diskussion bezieht sich zwar auf den Vergleich zwischen Einstiegsgeld und BTP - sie könnte jedoch auch einige Hinweise zur Interpretation des Illinois-Experiments geben.

\section{(1) Einstellungskosten}

Die Erfahrungen in den USA mit dem Targeted Jobs Tax Credit (TJTC) - dem wichtigsten Arbeitgeber-Lohnsubventionsprogramm in den USA - belegen die geringe Attraktivität von Arbeitgeber-Lohnsubventionen aufgrund zusätzlicher Einstellungskosten. Bishop/Kang (1991) untersuchten die Ursachen für die geringe Partizipationsrate des TJTC und fanden heraus, daß Informationskosten das Haupthindernis darstellten (vgl. Kapitel 4.3.1). In Deutschland existieren derzeit etwa ein Dutzend unterschiedlicher Lohnsubventionsprogramme für benachteiligte Arbeitslose. Diese Subventionsprogramme unterscheiden sich in vielfacher Hinsicht - unterschiedliche Behörden sind für die Bearbeitung der Anträge zuständig, die Zielgruppen sind unterschiedlich abgegrenzt, die Höhe und die Dauer der Lohnsubventionen differieren von Programm zu Programm. Deshalb ist es für Unternehmen zeit- und damit kostenintensiv, sich über diese Programmvielfalt zu informieren. Die Einstellungsentscheidung wird komplizierter, weil nicht nur der geeignete Bewerber, sondern auch das für ihn vorteilhafteste Subventionsprogramm gefunden werden muß. Insbesondere für Freiberufler, Einzelunternehmer und kleine Firmen, aber auch private Haushalte als potentielle Arbeitgeber können die Informationskosten prohibitiv hoch sein.

Einstellungskosten sind bei der Auszahlung über die Arbeitnehmer geringer, weil die Arbeitgeber lediglich den Produzentenlohn bezahlen und sich nicht um die Beschaffung der Lohnsubventionen kümmern müssen. Statt dessen berichten die Arbeitnehmer den Behörden ihr Einkommen, damit es um den Transferbetrag aufgestockt werden kann. Zwar existieren weiterhin Informationskosten, doch werden sie von den Arbeitnehmern getragen, so daß die Entstehung von Stellen nicht behindert wird. Die gesamten Informationskosten sind sogar geringer, wenn Langzeitarbeitslose mehrere Jobs mit geringem Einkommen ausüben. In diesem Fall, der im Niedriglohnsektor nicht selten zu beobachten ist, müssen die Arbeitnehmer am Ende des Monats lediglich die Summe ihrer Einkünfte dem Sozial- oder Arbeitsamt melden, um ergänzend Sozial- oder Arbeitslosenhilfe zu erhalten. Dagegen fallen bei ArbeitgeberLohnsubventionen bei jedem einzelnen Arbeitgeber, bei dem der Arbeitnehmer beschäftigt ist, Informationskosten an.

\section{(2) Entlassungskosten}

Im Fall von zeitlich befristeten Arbeitgeber-Lohnsubventionen liegt die Entscheidung, den subventionierten Arbeitnehmer nach Ablauf der Förderung zu 
entlassen, beim Arbeitgeber. Bei Entlassung kann es zu sogenannten Rotationseffekten kommen, wenn Arbeitgeber die entlassenen Arbeitnehmer durch subventionierte Kräfte ersetzen. Dieses Problem kann durch die Auszahlung an Arbeitnehmer abgemildert werden, weil nach Ablauf des Subventionszeitraums sich die Kostensituation für den Arbeitgeber nicht ändert - der Arbeitgeber zahlt stets den Produzentenlohn. Die Entscheidung, nach Ablauf der Förderung weiterzuarbeiten, liegt in diesem Fall ausschließlich beim Arbeitnehmer. Der Unterschied zwischen den Auszahlungsformen würde sich jedoch auflösen, wenn sich die Vertragspartner darauf einigen würden, daß die Arbeitnehmer nach Ablauf des Subventionszeitraums den geringeren Produzentenlohn erhalten.

\section{(3) Verwaltungskosten}

Zielgruppenorientierte Programme haben den finanziellen Vorteil, daß ihre gesamten Kosten häufig relativ gering sind, die Kosten je Teilnehmer sind jedoch tendenziell höher als bei allgemeinen Hilfeprogrammen mit Barauszahlung von Transfers. Das liegt daran, daß Ausgaben bei der Durchführung und Überwachung anfallen, wenn bestimmte Dienstleistungen für eine Zielgruppe angeboten werden und bestimmte Verhaltensweisen von den Programmteilnehmern erwartet werden (vgl. Blank 1997). Aber sowohl das BTP als auch das Einstiegsgeld erfordern lediglich minimale zusätzliche Verwaltungskosten, weil die Teilnehmer der Zielgruppe bereits auf ihre Bedürftigkeit geprüft wurden. Der einzige Unterschied zur derzeitigen Praxis besteht darin, daß die Berechnungsweise des Einstiegsgeldes und das BTP in bestehende Software-Pakete eingearbeitet werden müßte. Die Berechnungsweise ist den Sachbearbeitern der Ämter grundsätzlich vertraut, so daß keine kostenintensive Ausbildung nötig ist. Statt dessen bedarf es lediglich einer kurzen Fortbildung für die Mitarbeiter. Außerdem fallen keine Überwachungskosten an, weil es im Eigeninteresse der Hilfeempfänger liegt, einen Job in der privaten Wirtschaft zu suchen. Welche Stelle die Hilfeempfänger annehmen und welche Tätigkeiten sie ausüben, ist für die Behörde bedeutungslos. Einzig der Monatslohn oder der Stundenlohn (bei einer Ausgestaltung des Einstiegsgeldes als Stundenlohnsubvention) der Hilfeempfänger sind die relevanten Informationen für die Ämter. Die gesamtstaatlichen Überwachungskosten könnten sogar sinken, wenn Hilfeempfänger und Arbeitgeber bisherige Beschäftigungsverhältnisse in der Schattenwirtschaft in reguläre Stellen umwandeln. Das könnte für risikoaverse Individuen um so interessanter werden, je höher die Aufdeckungswahrscheinlichkeit illegaler Tätigkeiten dank moderner Informationstechnologien und Datenabgleich zwischen Behörden in der Zukunft wird.

Arbeitgeber-Lohnsubventionen unterscheiden sich jedoch in bezug auf die gesamten Verwaltungskosten von Arbeitnehmer-Lohnsubventionen, wenn Hilfeempfänger mehrere Jobs annehmen. In diesem Fall entstehen Verwal- 
tungskosten für jeden eingelösten Gutschein der Arbeitgeber. Dagegen ist nur ein Verwaltungsvorgang notwendig, wenn die Arbeitnehmer die Summe ihrer monatlichen Einkünfte aus mehreren Jobs dem Sozial- oder Arbeitsamt mitteilen.

\section{(4) Stigmatisierungseffekte und asymmetrische Information}

Die Ergebnisse des kontrollierten Experiments in Dayton, Ohio, in den Jahren 1980-81 mit TJTC-Anspruchsberechtigten verdeutlichten die Bedeutung von Stigmatisierungseffekten von Arbeitgeber-Lohnsubventionen: Arbeitssuchende mit Gutscheinen fanden mit signifikant geringerer Wahrscheinlichkeit einen Job als Arbeitssuchende ohne entsprechende Lohnsubvention (vgl. Burtless 1985 u. Kapitel 4.3.1).

Die Auszahlung der Lohnsubvention an den Arbeitnehmer verhindert, daß Arbeitgeber den Status des Bewerbers sofort erkennen. Arbeitnehmer-Lohnsubventionen erlauben es Hilfeempfängern, ihren Status zu verheimlichen, um potentielle Stigmatisierungseffekte zu vermeiden. Mitglieder der Zielgruppe handeln als besserinformierte Agenten, während Arbeitgeber die schlechter informierten Prinzipale im Arbeitsmarkt sind. Zweifellos könnten die Arbeitgeber das Problem der asymmetrischen Information lösen, wenn sie nur entsprechend hohe Informationskosten aufwenden würden. Aber diese Informationskosten dürften im Vergleich zu den Entlassungskosten im Niedriglohnsektor relativ hoch sein. Deshalb dürften Arbeitnehmer-Lohnsubventionen besser geeignet sein, das Stigmatisierungsproblem zu lösen als ArbeitgeberLohnsubventionen.

Um dieses Argument zu verdeutlichen, ist folgendes Beispiel hilfreich: Ein 45-jähriger Langzeitarbeitsloser, der seinen qualifizierten Job in der Metallindustrie verloren hat, muß nach zahlreichen Bewerbungen erkennen, daß er in seinem Alter in seinem angestammten Beruf keine Chance mehr auf eine dauerhafte Anstellung hat. Deshalb bewirbt er sich für Stellen als Gärtner bei privaten Haushalten. Um potentielle Stigmatisierungseffekte zu vermeiden, wird er sich zum Beispiel als Selbständiger ausgeben und - wenn nötig - auf Empfehlungsschreiben von Bekannten verweisen, bei denen er bereits Gartenarbeiten verrichtete. Ein analoges Beispiel ließe sich für Haushaltshilfen, Kinder- und Altenbetreuer und zahlreiche andere Tätigkeiten im Bereich haushalts- oder personengebundener Dienstleistungen anführen.

Weshalb sollten Arbeitgeber auf formale Qualifikationen und detailliertere Informationen bestehen? Wenn der Bewerber einen vertrauenswürdigen und zuverlässigen Eindruck hinterläßt, gibt es für den Arbeitgeber keinen Anlaß, Zeit und Geld zu investieren, um das Problem der asymmetrischen Information zu lösen. Oder deutlicher: Für die Auswahl von Bewerbern im Niedriglohnsektor sind Assessment Center angesichts der geringen Einarbeitungszeit der Arbeitnehmer kostenineffizient. Deshalb werden Arbeitgeber motivierten Bewerbern in der Regel eine Chance geben, ihre Eignung unter Be- 
weis zu stellen. Das Risiko ist für den Arbeitgeber gering, weil die Entlassungskosten in diesem Segment des Arbeitsmarktes gering sind. Wenn sich die Arbeitnehmer jedoch bewähren, dann werden ihre Löhne bei Produktivitätssteigerungen im Zeitablauf zunehmen.

\section{(5) Eintrittseffekte und asymmetrische Information}

Asymmetrische Information zwischen dem Staat und den besser informierten Individuen ist die Ursache für sogenannte „Eintrittseffekte“ (entry effects) von Nichtanspruchsberechtigten in die geförderte Zielgruppe. Bei der Diskussion des Einstiegsgeldes im Vergleich zum Status quo wurde unterschieden zwischen dem Moral hazard der Erwerbstätigen (new applicant effect) und dem Moral hazard der Kurzzeitarbeitslosen (delayed exit effect) als Folge der Zielgruppenorientierung des Einstiegsgeldes (vgl. Kapitel 5.4.1). Beide Teileffekte können auch für das Benefit-Transfer Program nicht ausgeschlossen werden. Das Moral hazard der Erwerbstätigen dürfte jedoch aufgrund der hohen Hürden gegen Mitnahmeeffekte zu vernachlässigen sein, das Moral hazard der Kurzzeitarbeitslosen hat sich zumindest in einem Feldexperiment in Kanada als gering erwiesen (vgl. Card et al. 1998). Die Art der Auszahlung von Lohnsubventionen spielt demnach im Hinblick auf Eintrittseffekte keine Rolle.

\subsubsection{Welfare-to-Work und Einstiegsgeld}

Gegen zeitlich unbefristete Lohnsubventionsmodelle wie das Kombi-Einkommen wird eingewandt, daß sie langfristig die Leistungsmentalität der Bevölkerung untergraben, wenn es zum Beispiel in zwanzig Jahren als fast normal gilt, Bezieher von Kombi-Einkommen zu sein. Damit ist die Frage nach den Wirkungen auf Gewohnheiten und soziale Normen angesprochen, die bereits Gegenstand der Diskussion des Bürgergeldes war (vgl. Lindbeck 1995, 1997 u. Kapitel 3.2.2.1).

Welfare-to-Work-Programme, die Sozialhilfe durch Arbeit vollständig ersetzen, bewegen sich im Spannungsfeld zweier sozialer Normen. Einerseits soll die Selbsthilfe gestärkt werden, wobei die Trennlinie zum Sozialdarwinismus (survival of the fittest) besonders dann kaum erkennbar ist, wenn Sozialhilfe zeitlich begrenzt wird. Andererseits ist zur Kenntnis zu nehmen, daß Altruismus in jeder Gesellschaft begrenzt ist. Das tatsächliche Problem ist nach Solow (1998, S. 42), daß Sozialhilfe beide Normen unterhöhlt. Vor diesem Hintergrund regt er eine „faire“ Version (Gutman 1998, S. IX) von Welfare-to-Work an, um ein vernünftiges Gleichgewicht zwischen diesen beiden Normen zu erreichen. Selbsthilfe darf nicht überbeansprucht werden. So dürfen zum Beispiel Mütter ihre Kinder nicht vernachlässigen müssen, um ihrer Arbeitspflicht nachzukommen. Aber auch der Altruismus der Steuerzahler darf nicht durch Moral hazard-Verhalten und Betrugsverhalten der Transferempfänger überbeansprucht werden. Faire Welfare-to-Work-Programme 
sind für alle Beteiligten ein Gewinn. Transferempfänger gewinnen durch Erwerbsarbeit Selbstachtung und den Respekt der Gesellschaft, ohne Einkommen zu verlieren, und der Altruismus der Steuerzahler wird bewahrt.

Zum Vergleich der Effizienz- und Verteilungswirkungen von Welfare-toWork-Programmen und einer allgemeinen negativen Einkommensteuer liegt eine Simulationsstudie vor (vgl. Fortin et al. 1993). Grundlage ist ein statisches Simulationsmodell für eine kleine, offene Volkswirtschaft. Die Autoren kommen zu der Schlußfolgerung - und nur dieses Teilergebnis ist in diesem Zusammenhang interessant -, daß eine Kombination einer allgemeinen negativen Einkommensteuer in Verbindung mit einer Arbeitspflicht die soziale Wohlfahrt maximieren könnte. Diese Modellergebnisse sind jedoch mit groBer Zurückhaltung zu beurteilen, weil sie keine dynamischen Aspekte berücksichtigen (vgl. Fehr/Wiegard 1996 für einen Überblick zu dynamischen Modellen). Die Diskussion des Bürgergeldes hat jedoch gezeigt, daß nicht nur statische, sondern auch dynamische allokative Aspekte von großer Bedeutung für die Beurteilung sind.

Wie ist das Verhältnis von Welfare-to-Work-Programmen und einer zielgruppenorientierten negativen Einkommensteuer einzuschätzen? Eine dynamische Wohlfahrtsanalyse unter Berücksichtigung von Effizienz- und Verteilungseffekten kann hier nicht vorgelegt worden. An dieser Stelle läßt sich lediglich auf den komplementären Charakter von Einstiegsgeld und Welfare-to-WorkProgrammen verweisen. Eine zielgruppenorientierte negative Einkommensteuer kann als zusätzliches Instrument im Rahmen eines Welfare-to-WorkProgramms angeboten werden. Vor dem Hintergrund der derzeit in Deutschland von den Kommunen praktizierten Hilfe zur Arbeit-Programmen (vgl. Kapitel 4.4.1) ist jedoch ein wichtiger Vorteil des Einstiegsgeld-Vorschlags hervorzuheben. Da Hilfeempfänger im Rahmen der Mehraufwandsentschädigungsvariante lediglich einen Stundenlohn von etwa 3 DM je Stunde zusätzlich zur Sozialhilfe erhalten, lohnen sich aus finanzieller Sicht bereits Jobs ab einem Stundenlohn von 6 DM, wenn beim Einstiegsgeldvorschlag eine Transferentzugsrate von $50 \%$ und gleiches Grenzleid der Arbeit unterstellt wird. So entsteht ein zusätzlicher Anreiz für Hilfeempfänger, sich selbst Jobs im privaten Sektor zu suchen oder Tätigkeiten in der Schattenwirtschaft offen zu legen, um ihrer Arbeitspflicht nachzukommen. Die Verknüpfung von Einstiegsgeld mit der verstärkten Einforderung der Arbeitspflicht von Hilfeempfängern hätte weiterhin den Vorteil, daß arbeitsfähige Hilfeempfänger mit hoher Präferenz für Freizeit durch Kürzung bzw. Streichung der Hilfeleistungen systematisch diskriminiert würden. Auch der Mitnahmeeffekt I - das Moral hazard der geringverdienenden Erwerbstätigen (vgl. Kapitel 5.4.1) ließe sich auf diese Weise weiter minimieren. Arbeitspflicht und Arbeitsanreiz stehen demnach in einem komplementären Verhältnis zueinander. Durch die konsequente Anwendung bestehender Gesetze könnte der Ausgleich der angespro- 
chenen sozialen Normen auch ohne die Einführung von Welfare-to-WorkProgrammen gelingen.

Die Entscheidung für Welfare-to-Work-Programme nach amerikanischem Vorbild könnten sogar teurer sein als der Status quo, weil Kommunen in großem Umfang Stellen für arbeitsfähige Sozialhilfeempfänger schaffen müßten (vgl. Kapitel 4.4.1). Deshalb erscheint es auch aus fiskalischer Sicht sinnvoll, das Potential für zusätzliche Beschäftigung im Niedriglohnsektor zunächst durch die experimentelle Einführung eines Einstiegsgeldes in verschiedenen lokalen Arbeitsmärkten auszuloten. Die möglichen Kosten eines Welfare-toWork-Programms ließen sich dann besser abschätzen.

\subsection{Zusammenfassung}

In diesem Kapitel wurde die Konzeption einer zielgruppenorientierten negativen Einkommensteuer („Einstiegsgeld“ für Langzeitarbeitslose) dargestellt. Der Einstiegsgeldvorschlag sieht die zeitlich befristete Kombination von Markteinkommen und Transfer für eine Zielgruppe vor. Diese Konstruktion erlaubt die Einführung hoher Leistungsanreize in das Transfersystem, so daß die Armutsfalle für einen bestimmten Zeitraum für eine Zielgruppe beseitigt wird. Der Lohnabstand bleibt in dem Sinne gewahrt, daß erwerbstätige Hilfeempfänger stets über ein höheres Einkommen verfügen als Nicht-Erwerbstätige. Das Einstiegsgeld ist aus fiskalischer Sicht attraktiv, weil die Einführungskosten für den Staat minimal sind.

Die Konzeption des Einstiegsgeldes wurde in acht Bausteinen präsentiert (Kapitel 5.2). Obligatorische Kernelemente sind das Kriterium der Bedürftigkeit für die Abgrenzung der Zielgruppe, die leistungsfreundliche Anrechnung von Zusatzverdiensten von Transferempfängern und die zeitliche Befristung dieser Regelung. Die Kombination mit zeitlich befristeten Einstiegstarifen ist für die Einführung im gewerkschaftlich bestimmten Segment des Niedriglohnsektors von Bedeutung. Die administrative Abwicklung ist im Rahmen bestehender Institutionen möglich. Die Anrechnungsregeln für Arbeitslosenhilfe- und Sozialhilfeempfänger müßten jedoch harmonisiert werden, um hohe Leistungsanreize für Hilfeempfänger zu gewährleisten, die beide staatliche Leistungen beziehen. Eine harmonisierte Bedürftigkeitsprüfung für die Arbeitslosen- und Sozialhilfe könnte darüber hinaus die administrative Effizienz erhöhen. Die Laufzeit des Einstiegsgeldes könnte durch die Gewährung eines rückzahlbaren staatlichen Darlehens verlängert werden. Die Vergabe von Sozialhilfe auf Darlehensbasis ist kein vollständig neues Instrument. Die vorgeschlagene Darlehenslösung ist jedoch so ausgestaltet, daß die Sozialhilfeträger auch dann fiskalisch entlastet werden, wenn die maximale Darlehenssumme nicht zurückgezahlt wird. Als eine mögliche Variante wird das Einstiegsgeld mit impliziter und expliziter Einkommensobergrenze am Bei- 
spiel von Verheirateten mit zwei Kindern dargestellt. Der Vorteil dieser Lösung ist die Minimierung von Mitnahmeeffekten, der Nachteil besteht jedoch in einer anreizfeindlichen Sprungstelle in der Nettoeinkommensfunktion. Die Ausgestaltung des Einstiegsgeldes als degressive Lohnsubvention vermeidet diese Sprungstelle, ist jedoch weniger gegen Mitnahmeeffekte abgeschirmt. Im Zeitablauf veränderliche und nach Personengruppen differenzierte Anrechnungssätze sind weitere Variationsmöglichkeiten für die Ausgestaltung des Einstiegsgeldes. Das Einstiegsgeld ist auch unter Berücksichtigung der Darlehenslösung zeitlich befristet. Langfristige Lösungen könnten die in Kapitel 4 diskutierten Kombi-Einkommensmodelle oder Armutslückenkonzepte sein.

Die Beschäftigungswirkungen des Einstiegsgeldes werden in verschiedenen theoretischen Analyserahmen untersucht (Kapitel 5.3). Die Arbeitsangebotswirkung ist im Gegensatz zum Bürgergeld im Einkommen-Freizeit-Modell positiv. Bei der Analyse der Beschäftigungswirkungen wird zwischen einem kompetitiven und einem gewerkschaftlich bestimmten Segment des Niedriglohnsektors unterschieden. Die Beschäftigungswirkung im kompetitiven Modell ist positiv, weil der durch das Sozialhilfesystem festgelegte Mindestlohn I aufgehoben wird. Die Beschäftigungsausweitung wird jedoch durch einen Mindestlohn II begrenzt, der aus Fairneß- und Effizienzlohnüberlegungen der Arbeitgeber resultiert. Die Beschäftigungswirkung im Modell gleichgewichtiger Arbeitslosigkeit ist ebenfalls positiv, weil es für die Gewerkschaften nutzenmaximal ist, niedrigere Einstiegstarife für Langzeitarbeitslose zu vereinbaren. Die gewählten Analyserahmen sind jedoch Partialmodelle, die den komplexen Wirkungszusammenhängen zwischen Sozialpolitik und Arbeitsmarkt nur zum Teil gerecht werden können.

Die breite ökonomische Diskussion des Einstiegsgeldes im Vergleich zum Status quo ist in sechs Unterpunkte gegliedert (Kapitel 5.4). Erstens wird die Arbeitsangebotsentscheidung vor dem Hintergrund möglicher Mitnahmeeffekte untersucht. Dabei werden drei mögliche Mitnahmeeffekte von Erwerbstätigen, bedürftigen Erwerbstätigen und Kurzzeitarbeitslosen herausgearbeitet. Zweitens wird die Arbeitsnachfrageentscheidung der Arbeitgeber im Hinblick auf mögliche Substitutions- und Verdrängungseffekte untersucht. Drittens werden die Arbeitsmarktwirkungen unter Berücksichtigung von Mitnahmeeffekten einerseits und Substitutions- und Verdrängungseffekten andererseits diskutiert. Im Rahmen eines „Worst Case-Szenarios“ wird mögliches Moral hazard-Verhalten der Arbeitgeber und der Tarifpartner diskutiert. Es zeigt sich, daß ein Rückgang der Beschäftigung und eine Erhöhung der fiskalischen Belastung des Staates durch die Ausgestaltung des Einstiegsgeldvorschlags weitgehend ausgeschlossen werden kann. Im Rahmen eines „Best Case-Szenarios" wird diskutiert, unter welchen Voraussetzungen sich die Arbeitsnachfrage nach personen- und haushaltsgebundenen Dienstleistungen in der Zukunft erhöhen könnte. Viertens werden die intertemporalen Entschei- 
dungen der Arbeitnehmer diskutiert. Es zeigt sich, daß Fehlanreize auf die Humankapitalbildung und die Ersparnisbildung durch die Einführung eines Einstiegsgeldes unwahrscheinlich sind. Fünftens wird die intertemporale Investitionsentscheidung der Arbeitgeber untersucht. Unter der Annahme komplementärer Produktionsfaktoren fördert die Einführung des Einstiegsgeldes zusätzliche Investitionen. Im Gegensatz zur Transformationsstrategie in Ostdeutschland werden somit arbeitsintensive Produktionsprozesse und Dienstleistungen gefördert sowie eine höhere Arbeitsproduktivität durch mehr Beschäftigung und mehr Investitionen erreicht. Sechstens wird das Problem der horizontalen Gerechtigkeit hinterfragt. Dieses Problem entsteht durch die zeitlich befristete Bevorzugung der Zielgruppe, so daß Mitglieder der Zielgruppe kurzfristig über ein höheres Einkommen nach Transfer verfügen als Geringverdiener. Bei genauerer Betrachtung stellt sich heraus, daß dieses $\mathrm{Ge}-$ rechtigkeitsproblem ein Grundproblem jedes Transfers an eine Zielgruppe ist und in gleicher Weise beim Erziehungsgeld für einkommensschwache Familien existiert. Es werden Argumente vorgetragen, weshalb die Ungleichbehandlung von Transferempfängern und Erwerbstätigen zwar in der politischen Diskussion bedeutsam sein dürfte, doch von Geringverdienern angesichts hoher Langzeitarbeitslosigkeit und Langzeitsozialhilfebezug vorübergehend akzeptiert werden könnte.

Der Vergleich mit anderen Lohnsubventionen an Arbeitnehmer verdeutlicht die Unterschiede zwischen den einzelnen Modellen in bezug auf die Abgrenzung der Zielgruppen, das Anrechnungsverfahren und die administrative Ausgestaltung.

Der Vergleich mit anderen Lohnsubventionen an Arbeitgeber wird auf eine Gegenüberstellung zwischen Einstiegsgeld und Benefit-Transfer Program reduziert. Beide Reformvorschläge sind im Hinblick auf ihre Beschäftigungswirkungen in einer Coase-Welt ohne Transaktionskosten und asymmetrischer Information identisch. Doch in der Praxis zeigen sich erhebliche Unterschiede. Unter Berücksichtigung von Einstellungs-, Entlassungs- und Verwaltungskosten sowie Stigmatisierungs- und Eintrittseffekten wird die Hypothese abgeleitet, daß eine Auszahlung an Arbeitnehmer kosteneffizienter als eine Auszahlung an Arbeitgeber ist.

Schließlich wird das Verhältnis zwischen Einstiegsgeld und Welfare-toWork-Programmen angesprochen. Es zeigt sich, daß die konsequente Anwendung bestehender Gesetze in Deutschland in Kombination mit dem Einstiegsgeld zur Bewahrung wichtiger sozialer Normen ausreichend sein dürfte. Die Einführung eines Welfare-to-Work-Programms erscheint zum jetzigen Zeitpunkt aus fiskalischer Sicht mit erheblichen Unsicherheiten verbunden, so daß erst zusätzliche Informationen über die Wirkungsweise von Lohnsubventionsmodellen aus der Durchführung von Feldexperimenten abgewartet werden sollten. 


\section{Kapitel 6: Schlußfolgerungen}

An dieser Stelle sollen nicht die einzelnen Kapitel zusammengefaßt werden Zusammenfassungen der Ergebnisse finden sich jeweils am Ende der Kapitel 2 bis 5 . Statt dessen werden die wichtigsten Schlußfolgerungen für die aktuelle wirtschafts- und sozialpolitische Diskussion herausgearbeitet und der zukünftige Forschungsbedarf skizziert.

Hohe Arbeitslosigkeit und Langzeitarbeitslosigkeit haben zur Krise des Sozial- und Wohlfahrtsstaates europäischer Prägung beigetragen. Institutionelle Regelungen des Sozialstaates, die in Zeiten der Vollbeschäftigung weitgehend unschädlich waren, tragen inzwischen wesentlich zur Verlängerung der Langzeitarbeitslosigkeit und des Langzeitsozialhilfebezugs bei. Jeder zweite Arbeitslose in Deutschland ist inzwischen länger als ein Jahr arbeitslos, jeder zweite Sozialhilfeempfänger erhält seit über einem Jahr Sozialhilfe.

Die Reaktion der Wirtschafts- und Tarifpolitik auf die hohe strukturelle Arbeitslosigkeit in Deutschland sind zum einen kleine Schritte in Richtung Flexibilisierung der Güter- und Arbeitsmärkte. Im Mittelpunkt stehen jedoch Maßnahmen zur Reduzierung des Arbeitsangebots durch Arbeitszeitverkürzung und Vorruhestandsregelungen. Die offizielle Arbeitslosenquote wird vermindert, indem die Zahl der statistisch erfaßten Stellensucher reduziert wird. Die Verringerung des Arbeitsangebots als Reaktion auf einen Rückgang der Arbeitsnachfrage ist auf den ersten Blick naheliegend. Doch liegt diesem Denken zugrunde, daß die Zahl der Stellen festgelegt ist und nur durch keynesianische Nachfragepolitik erhöht werden kann. Doch die Zahl der Stellen ist kein fester „Arbeitskuchen“, der auf möglichst viele Personen verteilt werden muß. Der Kuchen, also die Beschäftigung, kann wachsen, je mehr Menschen Stellen suchen. Diese arbeitsmarktökonomische Grunderkenntnis ist zum Beispiel in den USA aber auch in Israel empirisch bestätigt worden.

Die Verringerung des Arbeitsangebots in Kombination mit in dieser Arbeit ausführlich beschriebenen institutionellen Fehlanreizen des Sozialstaates könnte die Finanzierungsgrundlage des Wohlfahrtsstaates noch mehr gefährden. So kommen die Vereinbarungen zum Vorruhestand einer expliziten Aufforderung an ältere Arbeitnehmer zu Langzeitarbeitslosigkeit und Langzeitsozialleistungsbezug gleich. Auch die im internationalen Vergleich hohen Sozialhilfeleistungen sind in Verbindung mit der Armutsfalle eine Einladung zum Langzeitsozialhilfebezug. Eine solche Arbeitsmarkt- und Sozialpolitik trägt zur Aushöhlung der Arbeitsnorm bei. Ein Teufelskreislauf bahnt sich an: Je weniger Menschen arbeiten, desto höher ist die Last des Sozialstaats für den Einzelnen, desto geringer sind die Leistungsanreize, desto weniger Men- 
schen arbeiten... - ein Umdenken in der Arbeitsmarkt- und Sozialpolitik erscheint deshalb dringend nötig, um die wichtigen Vorteile des Wohlfahrtsstaates auch in der Zukunft erhalten zu können.

\section{Erhöhung statt Reduzierung des Arbeitsangebots}

Die Arbeitsmarktpolitik müßte mehr Arbeit fördern, auch durch eine leistungsfreundliche Ausgestaltung des Sozialsystems. Höhere Leistungsanreize können am einfachsten durch eine massive Absenkung und zeitliche Befristung der Arbeitslosenunterstützung und der Sozialhilfe erzielt werden. Dieser „amerikanische Weg“ dürfte mit großer Wahrscheinlichkeit das Problem der Langzeitarbeitslosigkeit und des Langzeitsozialhilfebezugs weitgehend beseitigen. Doch der Preis des Erfolgs wäre hoch. Die Vorteile des Sozialstaats müßten zum Teil aufgegeben werden. Das Gut Sicherheit könnte nur noch in geringerem Umfang produziert werden, soziale Konflikte und steigende Kriminalität dürften die Folge sein. Dieser Weg erscheint deshalb nicht anstrebenswert. In dieser Arbeit wird eine Alternative zu einer Strategie des Sozialabbaus aufgezeigt.

Kürzung und Streichung von Sozialhilfe ist nach der bestehenden Gesetzeslage in Deutschland bei mehrfacher Ablehnung zumutbarer Arbeit durch arbeitsfähige Sozialhilfeempfänger möglich. In den neunziger Jahren wurde das Vollzugsdefizit in diesem Bereich angesichts steigender Sozialhilfeempfängerzahlen von den Kommunen abgebaut. Diese Maßnahmen sind sinnvoll, um die Selbsthilfe der Transferempfänger und den Altruismus der Steuerzahler zu stärken. Die Arbeitspflicht trägt zur Bewahrung der finanziellen Grundlagen des Wohlfahrtsstaats bei.

Kerngedanke einer Alternative zum amerikanischen Weg sind die Kombination von Arbeitspflicht und Arbeitsanreizen für Transferempfänger. „Das Steuer- und Transfersystem muß so gestaltet sein, daß es durch einen stetig degressiven Anstieg des verfügbaren Einkommens noch Leistungsanreize beinhaltet" (Siegel/Schneider 1994, S. 603). Das gilt selbstverständlich auch für das Sozialversicherungssystem, das ebenfalls Anreizprobleme kennt (vgl. Fuest/Huber 1998). Eine leistungsfreundliche Ausgestaltung des Steuer-, Transfer- und Abgabensystems führt im besten Fall zu einem höherem Arbeitsangebot - und steht damit diametral im Gegensatz zur derzeitigen Arbeitsmarkt- und Sozialpolitik.

Ob die Arbeitspflicht verschärft werden sollte, wie Sinn (1998) als Ergänzung zu Kombilohnmodellen vorschlägt, oder ob im Rahmen von Welfare-toWork-Programmen Sozialhilfe durch Arbeitsangebote ersetzt werden sollte, sind zusätzliche Diskussionspunkte. Auch eine Armutsdiskussion steht auf der Tagesordnung, wenn man sich die Rolle der Sozialhilfe als Grundsicherung für immer mehr Menschen bewußt macht. Solow (1998) geht davon aus, daß insbesondere für Geringqualifizierte mit Familien in einer globalisierten Welt mit schnellem technologischen Wandel Nettoeinkommen oberhalb des Exi- 
stenzminimums immer schwerer erzielbar sein dürften. Vor allem für Alleinerziehende mit Kindern ist es schwierig, einer verschärften Arbeitspflicht ohne Vernachlässigung der Kinder nachzukommen (vgl. Blank 1996). Deshalb könnte es sein, daß in der Zukunft - noch mehr als bisher - niedrige Einkommen zumindest in bestimmten Lebensphasen über einen längeren Zeitraum durch staatliche Transfers aufgestockt werden müssen. Entsteht damit eine große Gruppe von arbeitenden Armen (working poor)? Sind Haushalte, die mit Hilfe ergänzender Transfers über ein Einkommen oberhalb des Existenzminimums verfügen, wirklich arm? In diesen Diskussionen ist viel Sensibilität gefragt.

Eine Arbeitsmarkt- und Sozialpolitik, die auf eine Erhöhung des Arbeitsangebots durch den Abbau institutioneller Fehlanreize setzt, ist Teil einer Flexibilisierungsstrategie der Güter- und Arbeitsmärkte zum Abbau struktureller Arbeitslosigkeit (vgl. OECD 1997a,b). Über diesen Weg dürfte sich das hohe friedensstiftende soziale Sicherungsniveau in Deutschland ohne Sozialabbau erhalten lassen.

\section{Widerstände gegen einen Niedriglohnsektor in Deutschland}

Gegen die Erhöhung des Arbeitsangebots durch eine Teilanrechnung von $\mathrm{Zu}$ satzverdiensten von Transferempfängern ist Widerstand zu erwarten. Die Gewerkschaften wehren sich nicht nur gegen Sozialabbau, sondern auch gegen den Ausbau des Niedriglohnsektors in Deutschland. Der gewerkschaftlich Widerstand war bereits in Ostdeutschland erfolgreich. Der „Tiger in der Wohnstube" (Sinn 1995, S. 34) wurde durch hohe Tarifabschlüsse für Ostdeutschland zusammen mit den Arbeitgeberverbänden erfolgreich verhindert. Interessanterweise begrüßen Gewerkschaften einen Niedriglohnsektor, wenn er versteckt eingeführt wird. So werden Lohnsubventionen für Langzeitarbeitslose an Arbeitgeber unterstützt, obwohl die effektiv von den Arbeitgebern gezahlten Bruttokosten zum Teil weit unter den Tariflöhnen liegen. Da aber unverändert hohe Konsumentenlöhne gezahlt werden, wird der tatsächlich gezahlte Produzentenlohn verschleiert. Insofern existiert bereits ein gewerkschaftlich akzeptierter Niedriglohnsektor. Auch zeitlich befristete Einstiegstarife für Langzeitarbeitslose werden zumindest von einigen Teilgewerkschaften (z.B. IG Chemie) unterstützt. Weshalb wehren sich dann Gewerkschaften mit Vehemenz gegen mehr Beschäftigung im Niedriglohnsektor in Deutschland? Die gängigen Argumente, daß mehr Beschäftigung durch sinkende Reallöhne und zunehmende Lohnungleichheit erkauft werden müssen, vermögen nicht zu überzeugen. Im Hintergrund könnte vielleicht die Angst vor Machtverlust stehen. Würde eine Ausweitung der Beschäftigung im Niedriglohnsektor unterstützt, so ist zu erwarten, da $\beta$ vor allem im Bereich der personen- und haushaltsgebundenen Dienstleistungen neue Stellen entstehen. Die Position der Gewerkschaften würde geschwächt, weil der gewerkschaftlich bestimmte Teil des Niedriglohnsektors im Vergleich zum nicht-ta- 
riflich bestimmten Teil an Gewicht verlieren würde. Aus theoretischer Sicht verlagert sich damit die Lohnfindung im Niedriglohnsektor vom Modell gleichgewichtiger Arbeitslosigkeit zum kompetitiven Modell, also von einem Modell mit Marktmacht zu einem Modell ohne Marktmacht der Gewerkschaften. Das kann nicht im Eigeninteresse der Gewerkschaften liegen. An ein Umdenken bei den Gewerkschaften zu appellieren, ist vor diesem Hintergrund wenig erfolgversprechend.

So stellt sich die Frage, wie die gesellschaftliche Akzeptanz zusätzlicher Beschäftigung im Niedriglohnsektor gesteigert werden könnte. Billigjobs, McJobs, Handlangertätigkeiten, Rückkehr der Dienstboten (vgl. Sitte 1997), Dienstmädchenprivileg - unsere Sprache und insbesondere die Berichterstattung in den Medien ist voller Denunziationen zusätzlicher Beschäftigungschancen für Geringqualifizierte. Statt dessen wird Langzeitarbeitslosigkeit und Langzeitsozialhilfebezug in seiner Dimension unterschätzt. Auch wird wenig realisiert, daß bereits ein umfangreicher Niedriglohnsektor in Deutschland existiert. Geringfügige Beschäftigung, Scheinselbständigkeit, Zeitarbeit, Tätigkeiten in der Schattenwirtschaft - alle diese Beschäftigungsformen sind Anpassungsreaktionen der Arbeitgeber und Arbeitnehmer auf Arbeitsmarktregulierungen. Durch neue Regulierungen werden lediglich neue Anpassungsreaktionen provoziert - die zugrundeliegenden strukturellen Probleme bleiben ungelöst.

Um die gesellschaftliche Akzeptanz der Beschäftigung im Niedriglohnsektor zu heben, könnte eine Diskussion eines gesetzlichen Mindestlohnes hilfreich sein. Die Diskussion der möglichen Beschäftigungsausweitung hat gezeigt, daß Fairneß- und Effizienzüberlegungen bereits Mindestlöhne im kompetitiven Sektor implizieren. So könnte ein gesetzlicher Mindestlohn in Höhe des Fairneßlohnes unschädlich sein. Allerdings dürfte ein bundeseinheitlich geregelter Mindestlohn in einzelnen Regionen oberhalb des Fairneßlohns liegen. Insofern bedeutet eine gesetzliche Vorgabe eine Beschränkung der Beschäftigungschancen im Niedriglohnsektor. Wenn jedoch die Alternative ist, daß ein breiter legaler Niedriglohnsektor weiterhin gesellschaftlich geächtet wird, könnte die Diskussion um einen gesetzlichen Mindestlohn die Beschäftigungsausweitung im Niedriglohnsektor erst ermöglichen. Hinzu kommt, daß neuere empirische Untersuchungen die Schädlichkeit des Mindestlohns für die Beschäftigung in Frage gestellt haben (vgl. Card/Krueger 1995, 1998), so daß dieses Tabuthema für Ökonomen in neuem Licht behandelt werden könnte (vgl. OECD 1998, S. $31 \mathrm{ff}$.).

\section{Offene Fragen und Forschungsbedarf}

Die Analyse verschiedener Varianten von Arbeitnehmer-Lohnsubventionen bedarf noch tiefergehender theoretischer und empirischer Analysen. Simulationsergebnisse auf der Basis berechenbarer allgemeiner Gleichgewichtsmodelle mit verschiedenen Sektoren und struktureller Arbeitslosigkeit liegen be- 
reits für Dänemark (vgl. Sørensen 1997) und die Niederlanden (vgl. Bovenberg et al. 1998) vor. Sørensen (1997, S. 251) kommt zum Ergebnis, daß Lohnsubventionen an Sektoren, die unmittelbar mit der Eigenproduktion von Haushalten und der Schattenwirtschaft konkurrieren, zu nicht vernachlässigbaren Beschäftigungs- und Wohlfahrtsgewinnen führen, auch wenn deren Finanzierung zusätzliche Verzerrungen verursacht. Bovenberg et al. (1998, S. 31) kommen zu dem Schluß, daß zielgruppenorientierte Arbeitnehmer-Lohnsubventionen wie der EITC der effizienteste Weg sind, um strukturelle Arbeitslosigkeit zu vermindern. Eine entsprechende Simulationsstudie mit verschiedenen Kombi-Einkommensmodellen für Deutschland steht noch aus.

Auch die Untersuchung verschiedener Varianten von Arbeitnehmer-Lohnsubventionen in suchtheoretischen Modellen steht noch am Anfang. Erste Analysen deuten darauf hin, daß positive Beschäftigungseffekte zu erwarten sind, jedoch die Lohnungleichheit zwischen Gering- und Hochqualifizierten zunehmen dürfte (vgl. van der Ploeg 1997, S. 323f.). Die Wirkungen von Kombi-Einkommensmodellen auf das Wirtschaftswachstum sind ebenfalls weitgehend unerforscht. In einer ersten Annäherung kann für die Einführung eines zeitlich befristeten Einstiegsgeldes mit positiven Wachstumsimpulsen gerechnet werden, weil die Wachstumsdeterminanten Beschäftigung, Kapital und Humankapital angeregt werden. Die Beschäftigungswirkungen von Arbeitnehmer-Lohnsubventionen in der offenen Volkswirtschaft stellen ein weiteres Forschungsfeld dar.

\section{Mut zu Feldexperimenten}

Doch tiefergehende theoretische und empirische Analysen müssen angesichts der Komplexität der Zusammenhänge durch zeitlich befristete Feldexperimente ergänzt werden. Gerade wegen der Begrenztheit der vorliegenden Analysen und den zahlreichen aufgezeigten Unsicherheiten und Unwägbarkeiten ist es erforderlich, Informationen über die Wirkungsweise von Lohnsubventionsmodellen in Deutschland experimentell zu testen. Zeitlich befristete Feldexperimente können mit der Arbeitslosenhilfe auf Bundesebene und mit der Sozialhilfe auf Länder- und Kommunalebene durchgeführt werden. Feldexperimente in Deutschland sind nötig, um zusätzliche Informationen über die Wirkungsweise von Kombi-Einkommensmodellen zu erhalten. Feldexperimente können einen Teil der fehlenden Informationen generieren. In der Region Aachen wird derzeit ein Negativsteuerkonzept als Modellversuch getestet (vgl. Klös 1997c). Die Ausgestaltung des Modellversuchs wird jedoch nicht in der Art und Weise wissenschaftlich begleitet, daß wissenschaftlich verwertbare Ergebnisse zu erwarten sind. Vorbildlich ist in dieser Hinsicht die Konzeption und Auswertung eines Feldexperiments mit ArbeitnehmerLohnsubventionen in Kanada (vgl. Card/Robins 1996, Card et al. 1998).

Die Ergebnisse von Feldexperimenten sollten abgewartet werden, bevor über zeitlich unbefristete Kombi-Einkommensmodelle entschieden wird. Vor der 
Einführung eines wie auch immer ausgestalteten Kombi-Einkommensmodells ohne zeitliche Befristung oder gar einer allgemeinen negativen Einkommensteuer ist beim derzeitigen Wissensstand dringend abzuraten. In dieser Arbeit wurden zahlreiche Wirkungskanäle, Unsicherheiten und Rückkoppelungen mit unüberschaubaren Konsequenzen aufgezeigt, die im schlimmsten Fall den Kollaps des sozialen Sicherungssystems bewirken könnten.

Statt dessen muß ein mühsamer Weg beschritten werden, will man die Möglichkeiten für höhere Beschäftigung für Geringqualifizierte ausloten. Ein erstes Feldexperiment mit einer zielgruppenorientierten negativen Einkommensteuer ist in Deutschland für das Jahr 1999 vorgesehen. Das baden-württembergische Sozialministerium hat im Mai 1998 die Einführung eines Einstiegsgeldes für langzeitarbeitslose Sozialhilfeempfänger in den Stadt- und Landkreisen angeregt (vgl. Sozialministerium Baden-Württemberg 1998). Geplant sind zeitlich befristete Modellversuche in neun Kreisen, darunter in Freiburg und Mannheim. Die Kommunen sind an der Einführung des Einstiegsgeldes im Gegensatz zu zeitlich unbefristeten Kombi-Einkommensmodellen interessiert, weil die Einführungskosten für sie minimal sind. Außerdem kann das Einstiegsgeld als komplementäres zusätzliches Instrument der kommunalen Sozialpolitik eingesetzt werden. Eine wissenschaftliche Evaluation der Modellversuche durch das Institut für Angewandte Wirtschaftsforschung (IAW) in Tübingen ist vorgesehen.

Erst nach vielen Modellversuchen in verschiedenen Regionen mit zielgruppenorientierten Arbeitnehmer- und Arbeitgeberlohnsubventionen, also mit dem Einstiegsgeld und dem Benefit-Transfer Program, die detailliert evaluiert werden müssen, läßt sich in mehreren Jahren qualifiziert beurteilen, ob und welche Art von Lohnsubventionen für die soziale Abfederung des schnellen Strukturwandels in der Informationsgesellschaft und des internationalen Standortwettbewerbs am besten geeignet sind. Dabei ist eine engere Verknüpfung mit der Arbeitspflicht und der glaubwürdigen Androhung von Hilfekürzung und -entzug im Einklang mit bestehenden Gesetzen durchaus sinnvoll. Die Kombination aus Anreiz (carrot) und Sanktion (stick) hilft vielleicht am ehesten, um soziale Normen nicht weiter erodieren zu lassen.

Es ist keine Zeit zu verlieren. Die Probleme der Langzeitarbeitslosigkeit und des Langzeithilfebezugs werden durch Nichtstun mit großer Wahrscheinlichkeit zunehmen. Keynesianische Programme zum Abbau konjunktureller Arbeitslosigkeit werden die strukturellen Arbeitsmarktprobleme in Deutschland ebensowenig lösen wie die Abschottung gegen Zuwanderung aus dem Ausland. 


\section{Literaturverzeichnis}

Akerlof, George A. u. A.K. Rose u. J.L. Yellen u. H. Hessenius (1991): East Germany in from the Cold: The Economic Aftermath of Currency Union, Brookings Papers on Economic Activity, Band 1, 1-101.

Alstott, Anne L. (1994): The Earned Income Tax Credit and Some Fundamental Institutional Dilemmas of Tax-Transfer Integration, National Tax Journal, 47, 609-619.

Amt für Statistik und Einwohnerwesen der Stadt Freiburg im Breisgau (Hrsg.) (1991): Sozialhilfebericht 1990, Beiträge zur Statistik der Stadt Freiburg im Breisgau, Freiburg.

Amt für Statistik und Einwohnerwesen der Stadt Freiburg im Breisgau (Hrsg.) (1997): Sozialhilfebericht 1996, Beiträge zur Statistik der Stadt Freiburg im Breisgau, Freiburg.

Amtliche Nachrichten der Bundesanstalt für Arbeit, Nürnberg.

Anderson, Patricia M. u. Bruce D. Meyer (1997): Unemployment Insurance Takeup Rates and the After-Tax Value of Benefits, Quarterly Journal of Economics, 112, 913-937.

Andreß, Hans-Jürgen (1994): Steigende Sozialhilfezahlen. Wer bleibt, wer geht und wie sollte die Sozialverwaltung darauf reagieren, in: Zwick, Michael M. (Hrsg.), Einmal arm, immer arm?, Neue Befunde zur Armut in Deutschland, Frankfurt, 75-105.

Andreß, Hans-Jürgen u. Wolfgang Strengmann-Kuhn (1997): Warum arbeiten, wenn der Staat zahlt? Über das Arbeitsangebot unterer Einkommensschichten, Zeitschrift für Sozialreform, 43, 505- 525.

Ashenfelter, Orley C. (1986): Discussion, in: Munnell, Alicia H. (Hrsg.) Lessons from the Income Maintenance Experiments, Federal Reserve Bank of Boston and the Brookings Institution, 53-55.

Atkinson, Anthony Barnes (1969): Poverty in Britain and the Reform of Social Security, Cambridge

Atkinson, Anthony B. (1989): The Cost of Social Dividend and Tax Schemes, in: Atkinson, Anthony B. (Hrsg.), Poverty and Social Security, New York, 309-326.

Atkinson, Anthony Barnes (1995): Public Economics in Action, Oxford.

Atkinson, Anthony Barnes u. Joseph E. Stiglitz (1980): Lectures on Public Economics, London. 
Atkinson, Anthony B. u. John Micklewright (1991): Unemployment Compensation and Labor Market Transitions: A Critical Review, Journal of Economic Literature, 29, 1679-1727.

Atkinson, Anthony B. u. H. Sutherland (1991): Basic Income Schemes and the Lessons from Public Economics, in: Arrow, Kenneth J. (Hrsg.), Issues in Contemporary Economics, Volume 1, Markets and Welfare, London, 22-38.

Bäcker, Gerhard (1993): Angriff auf den Kernbestand des Sozialstaates (Zu den Vorschlägen von Fritz W. Scharpf zur ,Subventionierung von niedrigen Erwerbseinkommen"), Gewerkschaftliche Monatshefte, 44, 644647.

Bäcker, Gerhard u. Thomas Ebert (1996): Defizit und Reformbedarf in ausgewählten Bereichen der sozialen Sicherung, in: Ministerium für Arbeit, Gesundheit und Soziales des Landes Nordrhein-Westfalen (Hrsg.), Zukunft des Sozialstaates, Düsseldorf.

Bäcker, Gerhard u. Walter Hanesch (1997): Kombi-Lohn: Kein Schlüssel zum Abbau der Arbeitslosigkeit!, WSI-Mitteilungen, 50, 701-712.

Bäcker, Gerhard u. Johannes Steffen (1995a): Marktradikaler Umbau mittels Sozialpolitik, „Arbeitsanreizverstärkung“ über Negativsteuer und Pflichtarbeit, in: Schmitthenner, Horst (Hrsg.), Der „schlanke“ Staat, Hamburg, 39-53.

Bäcker, Gerhard u. Johannes Steffen (1995b): Lohnt es sich noch zu arbeiten?, WSI-Mitteilungen, 48, 3-11.

Bean, Charles (1994): European Unemployment: A Survey, Journal of Economic Literature, 32, 573-619.

Beck, Martin (1992): Sozialhilfeempfänger 1990, Wirtschaft und Statistik, 299-310.

Beck, Ulrich (1997): Was ist Globalisierung?, Frankfurt.

Beck, Ulrich (Hrsg.)(1998): Politik der Globalisierung, Frankfurt.

Becker, Irene (1995): Das Bürgergeld als alternatives Grundsicherungssystem: Darstellung und kritische Würdigung einiger empirischer Kostenschätzungen, Finanzarchiv, N.F., 52, Heft 3, 306-338.

Bellmann, Lutz u. Richard Jackman (1996): Aggregate Impact Analysis, in: Schmid, Günter u. Jacqueline O'Reilly u. Klaus Schömann (Hg.), International Handbook of Labour Market Policy and Evaluation, 143-162.

Berthold, Norbert (1991): Ansätze einer ökonomischen Theorie der Sozialpolitik, Normative und positive Aspekte, Jahrbuch für Sozialwissenschaft, 42, 145-178. 
Berthold, Norbert (1997): Der Sozialstaat im Zeitalter der Globalisierung, Tübingen.

Berthold, Norbert u. Rainer Fehn (1996): Evolution von Lohnverhandlungssystemen - Macht oder ökonomisches Gesetz?, in: Zohlnhöfer, Werner (Hrsg.), Die Tarifautonomie auf dem Prüfstand, Schriften des Vereins für Socialpolitik, Band 244, 57-94.

Beveridge, W.H. (1943): Der Beveridge-Plan, Sozialversicherung und verwandte Leistungen, Zürich.

Bird, Edward J. (1996): Repairing the Safety Net: Is the EITC the Right Patch?, Journal of Policy Analysis and Management, 15, 1-31.

Bishop, John H. u. Suk Kang (1991): Applying for Entitlements: Employers and the Targeted Jobs Tax Credit, Journal of Policy Analysis and Management, 10, 24-45.

Blair, Tony (1996): New Britain, My Vision of a Young Country, London.

Blanchard, Olivier J. (1986): The Wage-Price Spiral, Quarterly Journal of Economics, 101, 543-565.

Blanchard, Olivier (1997): Macroeconomics, New Jersey.

Blanchard, Olivier u. Lawrence F. Katz (1997): What We Know and Do Not Know About the Natural Rate of Unemployment, Journal of Economic Perspectives, 11, 51-72.

Blanchflower, David G. u. Andrew J. Oswald (1994): The Wage Curve, Cambridge.

Blanchflower, David G. U. Andrew J. Oswald (1995): An Introduction to the Wage Curve, Journal of Economic Perspectives, 9, 153-167.

Blank, Rebecca M. (1994): Policy Watch, Proposals for Time-Limited Welfare, Journal of Economic Perspectives, 8, 183-193.

Blank, Rebecca M. (1996): Labor Markets and Public Assistance Programs, NBER Reporter, Fall, 11-13.

Blank, Rebecca M. (1997): It takes a Nation, A New Agenda for Fighting Poverty, Princeton.

Blaschke, Dieter u. Christian Brinkmann u. Elisabeth Nagel (1995): Einarbeitungszuschüsse - Befunde und Perspektiven, IAB Werkstattbericht Nr. 2 vom 30.1.1995, Nürnberg.

Bluestone, Barry u. Teresa Ghilarducci (1996): Making Work Pay, Public Policy Brief Nr. 28, The Jerome Levy Economics Institute of Bard College. 
Blundell, Richard (1992): Labour Supply and Taxation: A Survey, Fiscal Studies, 13, 15-40.

Boadway, Robin W. u. David E. Wildasin (1984): Public Sector Economics, 2. Auflage, Boston.

Bogai, Dieter u. Doris Hess u. Helmut Schröder u. Menno Smid (1994): Binnenstruktur der Langzeitarbeitslosigkeit älterer Männer und Frauen, Mitteilungen aus der Arbeitsmarkt- und Berufsforschung Nr. 2/94, 7393.

Bohlen, Christoph (1993): Zur Theorie und Empirie von Lohnsubventionen, Sozialpolitische Schriften, Heft 62, Berlin.

Booker, H.S. (1946): Lady Rhys-Williams' Proposals for the Amalgamation of Direct Taxation with Social Insurance, The Economic Journal, 56, 230-243.

Booth, Alison L. (1995): The Economics of the Trade Union, Cambridge.

Boss, Alfred (1994): Explizite und implizite Besteuerung geringer Arbeitseinkommen - Aspekte der Armutsfalle in der Bundesrepublik Deutschland, Kieler Arbeitspapiere Nr. 643, Institut für Weltwirtschaft, Kiel.

Boss, Alfred (1996): Leistungshemmende Besteuerung geringer Arbeitseinkommen, in: Siebert, Horst (Hrsg.), Sozialpolitik auf dem Prüfstand, Leitlinien für Reformen, Tübingen, 119-167.

Bovenberg, A. Lans u. Johan J. Graafland u. Ruud A. de Mooij (1998): Tax Reform and the Dutch Labor Market: An Applied General Equilibrium Approach, NBER Working Paper 6693, Cambridge.

Breuer, Wilhelm u. Dietrich Engels (1993): Der Abstand zwischen dem Leistungsniveau der Hilfe zum Lebensunterhalt nach dem BSHG und den verfügbaren Arbeitnehmereinkommen unterer Lohn- und Gehaltsgruppen im Juli 1992, Gutachten des Otto-Blume-Instituts für Sozialforschung und Gesellschaftspolitik im Auftrag des Bundesministeriums für Familie und Senioren, Köln.

Browning, Edgar K. (1973): Alternative Programs for Income Redistribution: The NIT and the NWT, American Economic Review, Papers and Proceedings, 63, 38-49.

Browning, Edgar K. (1995): Effects of the Earned Income Tax Credit on Income and Welfare, National Tax Journal, 48, 23-43.

Brühl, Albrecht (1996): Mein Recht auf Sozialhilfe, 13. Auflage, München.

Brunello, Giorgio u. Raffaele Miniaci (1997): Benefit Transfers in Italy: An empirical Study of Mobility Lists in the Milan Area, Oxford Bulletin of Economics and Statistics, 59, 329-347. 
Buchholz, Wolfgang u. Wolfgang Wiegard (1992): Allokative Überlegungen zur Reform der Pflegevorsorge, Jahrbücher für Nationalökonomie und Statistik, 209, 441-457.

Bundesanstalt für Arbeit (Hrsg.) (1997): Geschäftsbericht 1996, Nürnberg.

Bundesministerium für Familie, Senioren, Frauen und Jugend (Hrsg.) (1993a): Bericht der Bundesregierung zur Frage der Einhaltung des Lohnabstandsgebotes nach $\S 22$ Abs. 3 BSHG, Bonn.

Bundesministerium für Familie, Senioren, Frauen und Jugend (1993b): Pressemitteilung vom 29.12.1993.

Bundesministerium für Familie und Senioren (Hrsg.) (1996): Erziehungsgeld, Erziehungsurlaub, Bonn.

Bundesvereinigung der Deutschen Arbeitgeberverbände (1997): Kombi-Einkommen: Für eine verbesserte Verzahnung von Arbeitsmarkt und Transfersystemen, Internes BDA-Diskussionspapier v. 26.6.1997.

Burda, Michael (1988): ,Wait Unemployment' in Europe, Economic Policy, 3, 393-425.

Burda, Michael u. Charles Wyplosz (1997): Macroeconomics, 2nd edition, Oxford.

Burtless, Gary (1985): Are Targeted Wage Subsidies Harmful? Evidence from a Wage Voucher Experiment, Industrial and Labor Relations Review, 39, 105-114.

Burtless, Gary (1986): The Work Response to a Guaranteed Income: A Survey of Experimental Evidence, in: Munnell, Alicia H. (Hrsg.) Lessons from the Income Maintenance Experiments, Federal Reserve Bank of Boston and the Brookings Institution, 22-52.

Callan, Tim u. Holly Sutherland (1997): The impact of comparable policies in European countries: Microsimulation approaches, European Economic Review, 41, 627-633.

Card, David u. Alan B. Krueger (1995): Myth and Measurement: The New Economics of the Minimum Wage, Princeton.

Card, David u. Alan B. Krueger (1998): A Reanalysis of the Effect of the New Jersey Minimum Wage Increase on the Fast-Food Industry with Representative Payroll Data, NBER Working Paper 6386, Cambridge.

Card, David u. Philip K. Robins (1996): Do Financial Incentives Encourage Welfare Recipients to Work? Evidence from a Randomized Evaluation of the Self-Sufficiency Project, NBER Working Paper No. 5701.

Card, David u. Philip K. Robins u. Winston Lin (1998): Would Financial Incentives for Leaving Welfare lead some People to Stay on Welfare 
longer? An Experimental Evaluation of 'Entry Effects' in the SelfSufficiency Project, NBER Working Paper Nr. 6449.

Carlin, Wendy u. David Soskice (1990): Macroeconomics and the Wage Bargain, New York.

Coe, David T. (1997): Discussion, in: Snower, Dennis J. u. Guillermo de la Dehesa (Hg.), Unemployment Policy, Government Options for the Labour Market, 199-202.

Cramer, Ulrich u. Werner Karr u. Helmut Rudolph (1986): Über den richtigen Umgang mit der Arbeitslosen-Statistik, Mitteilungen aus der Arbeitsmarkt- und Berufsforschung, 19, 409-421.

De Koning, Jaap (1993): Measuring the Placement Effects of Two WageSubsidy Schemes for the Long-Term Unemployed, Empirical Economics, 18, 447-468.

De la Dehesa, Guillermo (1997): Discussion, in: Snower, Dennis J. u. Guillermo de la Dehesa (Hg.), Unemployment Policy, Government Options for the Labour Market, 349-351.

Deutsche Bundesbank (Hrsg.) (1996a): Monatsbericht Februar 1996, Frankfurt, 48, 61-66.

Deutsche Bundesbank (1996b): Die Ausgaben für Sozialhilfe seit Mitte der achtziger Jahre, in: Monatsbericht April 1996, 48, 35-52.

Deutscher Bundesrat (1997): Bundesratsdrucksache 1039/97 v. 19.12.1997.

Deutscher Bundestag (1995): Bundestagsdrucksache Nr. 13/1143 v. 18.4.1995.

Deutscher Paritätischer Wohlfahrtsverband (1992): Bedarfsorientierte Grundsicherung, Blätter der Wohlfahrtspflege, 72-78.

Deutscher Paritätischer Wohlfahrtsverband (1993): Bedarfsorientierte Grundsicherung, Blätter der Wohlfahrtspflege, 245-250.

Deutsches Institut für Wirtschaftsforschung (1997): Hohe Fluktuation in der Stillen Reserve, DIW-Wochenbericht, 64, 921-928.

Diamond, Peter A. (1968): Negative Taxes and the Poverty Problem - A Review Article, National Tax Journal, 21, 288-303.

Dichmann, Werner (1995): Einführung einer negativen Einkommensteuer als integriertes Steuer-Transfer-System oder als Stückwerk-Sozialtechnik, List Forum für Wirtschafts- und Finanzpolitik, 21, 65-89.

Dickert, Stacy u. Scott Houser u. John Karl Scholz (1995): The Earned Income Tax Credit and Transfer Programs: A Study of Labor Market and 
Program Participation, in: Poterba, James M. (Hrsg.), Tax Policy and the Economy, 9, 1-43.

Dietrich, Hans (1996): Empirische Befunde zur „Scheinselbständigkeit“, IAB Werkstattbericht Nr. 7 v. 25.11.1996.

Döhrn, Roland u. Ullrich Heilemann u. Günter Schäfer (1998): Ein dänisches „Beschäftigungswunder"?, Erfahrungen und Lehren für Deutschland, Institut für Arbeitsmarkt- und Berufsforschung (IAB), Workshop: Strategien für mehr Beschäftigung und weniger Arbeitslosigkeit: Internationale Erfahrungen und ihre Übertragbarkeit in Deutschland, 23.4.1998.

Dreger, Christian u. Wolfram Kempe u. Jürgen Kolb u. Lioba Trabert (1998): Was bringt ein Kombilohn?, Mitteilungen aus der Arbeitsmarkt- und Berufsforschung, 31, 705-714.

Drèze, Jacques H. (1997): Discussion, in: Snower, Dennis J. u. Guillermo de la Dehesa (Hg.), Unemployment Policy, Government Options for the Labour Market, 202-205.

Duncan, Alan u. Christopher Giles (1996): Labour Supply Incentives and Recent Family Credit Reforms, The Economic Journal, 106, 142-155.

Duncan, Alan u. Melvyn Weeks (1997): Behavioural tax microsimulation with finite hours choices, European Economic Review, 41, 619-626.

Eekhoff, Johann (1996): Beschäftigung und soziale Sicherung, Tübingen.

Eissa, Nada u. Jeffrey B. Liebman (1996): Labour Supply Responses to the Earned Income Tax Credit, Quarterly Journal of Economics, 111, 605637.

Emmerich, Knut (1997): Wann rechnet sich die Haushaltshilfe?, Eine Einschätzung möglicher Arbeitsmarktwirkungen der Steuerförderung und des Haushaltsscheck-Verfahrens, IAB-Kurzbericht Nr. 4 vom 5.8.1997.

Emmerich, Knut (1998): Dänemark: Arbeitsmarktflexibilität bei hoher Sozialer Sicherung, Wirtschaftsdienst, 78, 401-406.

Emmerich, Knut u. Heinz Werner (1998): Erstaunlicher Umschwung am Arbeitsmarkt, IAB Kurzbericht Nr. 13 v. 28.5.1998.

Engels, Wolfram u. Joachim Mitschke u. B. Starkloff (1973): Staatsbürgersteuer, Wiesbaden.

Erbe, Rainer (1995): Konsumsteuer und Bürgergeld: umverteilungs- oder beschäftigungsorientiert?, Wirtschaftsdienst, 75, 386-390.

Erbe, Rainer u. Susanne Erbe (1993): Sozialhilfe auf dem Prüfstand, Wirtschaftsdienst, 73, 588-596. 
Expertenkommission Wohnungspolitik (1995): Wohnungspolitik auf dem Prüfstand, Tübingen.

Experten-Kommission „Alternative Steuer-Transfer-Systeme“ (1996): Probleme einer Integration von Einkommensbesteuerung und steuerfinanzierten Sozialleistungen, Schriftenreihe des Bundesministeriums der Finanzen, Heft 59, Bonn.

Falk, Rüdiger u. Hans-Peter Klös (1997): Einfacharbeitsplätze als Ansatzpunkte einer kommunalen Beschäftigungspolitik zur Integration von Benachteiligten, Mitteilungen aus der Arbeitsmarkt- und Berufsforschung, 30, 412-423.

Feenstra, Robert C. u. Tracy R. Lewis (1994): Trade adjustment assistance and Pareto gains from trade, Journal of International Economics, 36, 201-222.

Feenstra, Robert C. (1998): New technology and trade: a threat to low-skilled workers?, Swedish Economic Policy Review, 5, 137-160.

Feist, Holger (1997): Das Bürgergeld: ein praktikabler Vorschlag für ein neues Steuer-Transfer-System?, Serie Steuerlehre und Finanzwissenschaft, DSWR, 26, 134-138.

Fehr, Ernst (1990): Fiscal Incentives in a Model of Equilibrium Unemployment, Journal of Institutional and Theoretical Economics, 146, 617-639.

Fehr Ernst u. Georg Kirchsteiger u. Arno Riedl (1993): Does Fairness prevent Market Clearing? An Experimental Investigation, Quarterly Journal of Economics, 108, 437-460.

Fehr, Ernst u. Simon Gächter u. Georg Kirchsteiger (1996): Reciprocal Fairness and Noncompensating Wage Differentials, Journal of Institutional and Theoretical Economics (JITE), 152, 608-640.

Fehr, Ernst u. Simon Gächter u. Georg Kirchsteiger (1997): Reciprocity as a Contract Enforcement Device: Experimental Evidence, Econometrica, $65,833-860$.

Fehr, Ernst u. Georg Kirchsteiger u. Arno Riedl (1998): Gift Exchange and reciprocity in competitive experimental markets, European Economic Review, 42, 1-34.

Fehr, Hans u. Wolfgang Wiegard (1996): Numerische Gleichgewichtsmodelle: Grundstruktur, Anwendungen und Erkenntnisgehalt, in: Ökonomie und Gesellschaft, Jahrbuch 13, Experimente in der Ökonomie, Frankfurt, 296-339. 
Fitzenberger, Bernd (1997): Außenhandel, technischer Fortschritt und Arbeitsmarkt in Westdeutschland von 1975 bis 1990, Mitteilungen aus der Arbeitsmarkt- und Berufsforschung, 30, 642-691.

Fitzenberger, Bernd u. Wolfgang Franz (1997): Flexibilität der qualifikatorischen Lohnstruktur und Lastverteilung der Arbeitslosigkeit: Eine ökonometrische Analyse für Westdeutschland, ZEW Discussion Paper No. 97-32.

Forrester, Vivienne (1997): Der Terror der Ökonomie, Frankfurt.

Fortin, Bernard u. Michel Truchon u. Louis Beauséjour (1993): On reforming the welfare system: Workfare meets the negative income tax, Journal of Public Economics, 51, 119-151.

Frank, Jeff (1997): Discussion, in: Snower, Dennis J. u. Guillermo de la Dehesa (Hg.), Unemployment Policy, Government Options for the Labour Market, 244-247.

Franz, Wolfgang (1995): Ursachen der Arbeitslosigkeit, in: Franz, Wolfgang u. Viktor Steiner, Der westdeutsche Arbeitsmarkt im strukturellen Anpassungsprozeß, Baden-Baden, 9-27.

Franz, Wolfgang (1996a): Theoretische Ansätze zur Erklärung der Arbeitslosigkeit: Wo stehen wir 1995?, in: Gahlen, Bernhard u. Helmut Hesse u. Hans Jürgen Ramser (Hg.), Arbeitslosigkeit und Möglichkeiten ihrer Überwindung, Wirtschaftswissenschaftliches Seminar Ottobeuren, Band 25, Tübingen, 3-45.

Franz, Wolfgang (1996b): Arbeitsmarktökonomik, 3. Auflage, Berlin.

Franz, Wolfgang (1997): Arbeitsmärkte, in: von Hagen, Jürgen u. Paul J.J. Welfens u. Axel Börsch-Supan (Hg.), Springers Handbuch der Volkswirtschaftslehre 2, Wirtschaftspolitik und Weltwirtschaft, Berlin, 135176.

Frick, Joachim u. Felix Büchel u. Wolfgang Voges (1996): Sozialhilfe als Integrationshilfe für Zuwanderer in Westdeutschland, DIW-Wochenbericht, 63, 767-775.

Friedländer, Daniel u. Gary Burtless (1995): Five Years After, The LongTerm Effects of Welfare-to-Work Programs, New York.

Friedman, Milton (1962): Capitalism and Freedom, Chicago.

Friedman, Milton (1968a): The Case for the Negative Income Tax, in: Melvin Laird (Hrsg.): Republican Papers, 202-220.

Friedman, Milton (1968b): Negative Income Tax - I, Newsweek, 72, 16.9.1968, 53. 
Friedman, Milton (1968c): Negative Income Tax - II, Newsweek, 72, 7.10.1968, 48 .

Friedman, Milton (1971): Kapitalismus und Freiheit, Stuttgart.

Fuchs, Ludwig (1994): Kommunale Beschäftigungsförderung, Ergebnisse einer Umfrage über Hilfen zur Arbeit nach BSHG und Arbeitsbeschaffungsmaßnahmen nach AFG, 2. Auflage, hrsg. v. Deutschen Städtetag, Köln.

Fuchs, Ludwig (1997): Kommunale Beschäftigungsförderung, Ergebnisse einer Umfrage von 1997 über Hilfen zur Arbeit nach BSHG und Arbeitsbeschaffungsmaßnahmen nach AFG, hrsg. v. Deutschen Städtetag, Köln.

Fuest, Winfried (1995): Negative Einkommensteuer, WiSt, 25, 365-368.

Fuest, Clemens u. Bernd Huber (1998): Eine beschäftigungsfreundliche Reform der 620-DM-Arbeitsverhältnisse, Wirtschaftsdienst, 78, 645-651.

Gagel, Alexander (1995): Arbeitsförderungsgesetz, Bd. 1, Kommentar §§ 1133, München.

Galbraith, James K. (1997): Time to Ditch the NAIRU, Journal of Economic Perspectives, 11, 93-108.

Gern, Klaus-Jürgen (1995): Das Einkommen- und Transfersystem der Bundesrepublik Deutschland, Kieler Arbeitspapiere Nr. 718, Kiel.

Gern, Klaus-Jürgen (1996a): Ein Modell zur Simulation des deutschen SteuerTransfer-Systems, Kieler Arbeitspapiere 725, Institut für Weltwirtschaft, Kiel.

Gern, Klaus-Jürgen (1996b): Das „Bürgergeld“ - ein sinnvolles Konzept?, Abschlußbericht zum Forschungsauftrag der Friedrich-NaumannStiftung.

Gern, Klaus-Jürgen (1999): Auswirkungen verschiedener Varianten einer negativen Einkommensteuer in Deutschland, Eine Simulationsstudie, Kieler Studien 294, Tübingen.

Goerke, Laszlo u. Manfred J. Holler (1997): Arbeitsmarktmodelle, Berlin.

Gordon, Robert J. (1997): The Time-Varying NAIRU and its Implications for Economic Policy, Journal of Economic Perspectives, 11, 11-32.

Green, Christopher (1967): Negative Taxes and the Poverty Problem, Washington.

Gutman, Amy (1998): Introduction, in: Gutman, Amy (Hrsg.), Work and Welfare, Princeton, S. VII-XV. 
Hackenberg, Helga u. Gert Wagner (1996): Kommunale Beschäftigungsförderung im Spannungsfeld von Innovation, Mißbrauchsrhetorik und Reform der Sozialhilfe, WSI-Mitteilungen, 49, 774-782.

Hackenberg, Helga u. Gert Wagner (1997): Arbeitsanreize und Arbeitshemmnisse für Sozialhilfeempfänger, Wirtschaftsdienst, 97, 220-226.

Hackenberg, Helga u. Stefan Sell (1997): Die „Negative Einkommensteuer“ als beschäftigungspolitisches Instrument - oder: Über die Einseitigkeit modelltheoretischer Annahmen, Sozialer Fortschritt, 46, 86-90.

Hague, D.C. (1953): Taxation and Incentive by Lady Rhys-Williams (Book Review), Economica, 20, 377-378.

Haisken-De New, John u. Gustav A. Horn u. Jürgen Schupp u. Gert Wagner (1996): Keine Dienstleistungslücke in Deutschland, DIW-Wochenbericht 14/96, 63, 221-226.

Haisken-De New, John u. Gustav A. Horn u. Jürgen Schupp u. Gert Wagner (1997): Rückstand beim Anteil der Dienstleistungstätigkeiten aufgeholt, DIW-Wochenbericht 34/97, 64, 613-617.

Hartmann, Helmut (1985): Die Praxis der Hilfe zur Arbeit nach dem Bundessozialhilfegesetz, Eine empirische Untersuchung über den Arbeitseinsatz von Sozialhilfeempfängern gemäß $\S \S 18 \mathrm{ff}$. Bundessozialhilfegesetz, hrsg. v. Hans-Böckler-Stiftung, Graue Reihe Nr. 20, Köln.

Hauser, Richard (1995a): Armutspolitik unter veränderten ökonomischen und politischen Rahmenbedingungen, in: Hanesch, Walter (Hrsg.), Sozialpolitische Strategien gegen Armut, Opladen, 112-140.

Hauser, Richard (1995b): Die Diskussion um die Reform der Sozialhilfe, Wirtschaftsdienst, 75, 429-433.

Hauser, Richard (1996): Ziele und Möglichkeiten einer Sozialen Grundsicherung, Schriftenreihe „Dialog Sozial“, Baden-Baden.

Hausman, Jerry (1985): Taxes and Labor Supply, in: Auerbach, Alan u. Martin Feldstein (Hg.), Handbook of Public Economics, Bd. 1, 213-263.

Haveman, Robert (1996a): Reducing Poverty while Increasing Employment: A Primer on Alternative Strategies, and a Blueprint, OECD Economic Studies, 26, 7-42.

Haveman, Robert (1996b): From welfare to work: Problems and pitfalls, Focus, 18, Special Issue, 21-24.

Haveman, Robert (1996c): Implementing W-2: A few questions, in: Focus, 18, Special Issue, 72-73.

Hayek, Friedrich August von (1996a): Die verhängnisvolle Anmaßung: Die Irrtümer des Sozialismus (übersetzt von Monika Streissler), Tübingen. 
Hayek, Friedrich August von (1996b): Die Anmaßung von Wissen, Neue Freiburger Studien, Wolfgang Kerber (Hrsg.), Wirtschaftswissenschaftliche und wirtschaftsrechtliche Untersuchungen 32, Tübingen.

Heckman, James J. (1993a): What Has Been Learned About Labor Supply in the Past Twenty Years?, American Economic Review, P. u. P., 83, 116121.

Hoffman, Saul D. u. Laurence S. Seidman (1990): The Earned Income Tax Credit, Kalamazoo.

Hoffmann, Ulrich u. Martin Beck (1994): Die neue Sozialhilfe- und Asylbewerberleistungsstatistik, Wirtschaft und Statistik, 116-127.

Holtzblatt, Janet u. Janet McCubbin u. Robert Gillette (1994): Promoting Work Through the EITC, National Tax Journal, 47, 591-607.

Hüther, Michael (1990): Integrierte Steuer-Transfer-Systeme für die Bundesrepublik Deutschland, Normative Konzeption und empirische Analyse, Volkswirtschaftliche Schriften, Heft 400, Berlin.

Hüther, Michael (1997): Das Bürgergeld - doch finanzierbar!, Gutachten über vorliegende Berechnungen zu den fiskalischen Auswirkungen der Einführung eines Bürgergeldes im Auftrag der Friedrich-Ebert-Stiftung, Bonn.

Hubert, Franz (1996): Zur Reform des Wohngeldes, Zeitschrift für Wirtschafts- und Sozialwissenschaften (ZWS), 116, 503-529.

Hunt, Jennifer (1995): The Effect of Unemployment Compensation on Unemployment Duration in Germany, Journal of Labor Economics, 13, 88-120.

IG Chemie (Hrsg.) (1995): Pressedienst v. 9.3.1995.

Institut für Arbeitsmarkt- und Berufsforschung (Hrsg.) (1997): Zahlen-Fibel. Ergebnisse der Arbeitsmarkt- und Berufsforschung in Tabellen, Nürnberg.

Jerger, Jürgen (1993): Beschäftigung und Kapitalbildung, Eine theoretische Analyse für die Bundesrepublik Deutschland 1961-1989, Freiburg.

Jerger, Jürgen u. Alexander Spermann (1996): Lösungsansätze zur Beseitigung von Fehlanreizen für Langzeitarbeitslose, in: Steiner, Viktor u. Klaus F. Zimmermann (Hg.), Soziale Sicherung und Arbeitsmarkt Empirische Analyse und Reformansätze, ZEW-Wirtschaftsanalysen, Band 4, Baden-Baden, 109-134.

Jerger, Jürgen u. Alexander Spermann (1997a): Wege aus der Arbeitslosenfalle - ein Vergleich alternativer Lösungskonzepte, Zeitschrift für Wirtschaftspolitik, 46, 51-73. 
Jerger, Jürgen u. Alexander Spermann (1997b): Promoting Low-Wage Employment: The Case for a Targeted Negative Income Tax, Jahrbuch für Wirtschaftswissenschaften (Revue of Economics), 48, 269-287.

Jerger, Jürgen u. Alexander Spermann (1998): Altenatives to Subsidize LowWage Employment, in: Addison, John T. u. Paul J.J. Welfens (Hg.), Labor Markets and Social Security, Berlin, 49-68.

Joulfaian, David u. Mark Rider (1996): Tax Evasion in the Presence of Negative Income Tax Rates, National Tax Journal, 49, 553-570.

Kaltenborn, Bruno (1995): Modelle der Grundsicherung: Ein systematischer Vergleich, Schriftenreihe des ZEW, Band 4, Baden-Baden.

Kaltenborn, Bruno (1997): Fiskalische Nettokosten der BündnisGrünen Grundsicherung, Bonn, mimeo.

Kaltenborn, Bruno (1998): Von der Sozialhilfe zu einer zukunftsfähigen Grundsicherung, 2. Aufl., Baden-Baden.

Karr, Werner (1997a): Die konzeptionelle Untererfassung der Langzeitarbeitslosigkeit, Mitteilungen aus der Arbeitsmarkt- und Berufsforschung, 30, 37-46.

Karr, Werner (1997b): Die Erfassung der Langzeitarbeitslosigkeit - Ein kaum beachtetes Meßproblem, IAB Kurzbericht Nr. 5 v. 7.8.1997.

Katz, Lawrence F. (1996): Wage Subsidies for the Disadvantaged, NBER Working Paper No. 5679.

Katz, Lawrence F. u. Bruce D. Meyer (1990): The Impact of the Potential Duration of Unemployment Benefits on the Duration of Unemployment, Journal of Public Economics, 41, 45-72.

Kesselman, Jonathan (1969): Labor-Supply Effects of Income, Income-Work, and Wage Subsidies, Journal of Human Resources, 4, 275-292.

Kesselman, Jonathan R. u. Irwin Garfinkel (1978): Professor Friedman, Meet Lady Rhys-Williams: NIT vs. CIT, Journal of Public Economics, 10, 179-216.

Killingsworth, Mark R. (1983): Labour supply, Cambridge University Press.

Kirchgässner, Gebhardt (1996): Bewußt erzeugte und duldend hingenommene Arbeitslosigkeit: Zum Problem der Arbeitslosigkeit aus der Sicht der Neuen Politischen Ökonomie, in: Gahlen, Bernhard u. Helmut Hesse u. Hans-Jürgen Ramser (Hg.), Arbeitslosigkeit und Möglichkeiten ihrer Überwindung, Wirtschaftswissenschaftliches Seminar Ottobeuren, Band 25, Tübingen, 395-432.

Klodt, Henning (1990): Arbeitsmarktpolitik in der DDR: Vorschläge für ein Qualifizierungsprogramm, Die Weltwirtschaft, 78-90. 
Klodt, Henning (1991): Wirtschaftsförderung für die neuen Bundesländer: Qualifizierungsgutscheine als Alternative, Die Weltwirtschaft, 78-90.

Klodt, Henning (1996): Lohnkostenzuschüsse: Ökonomische Effizienz und gesellschaftliche Akzeptanz, Kieler Arbeitspapiere Nr. 715, Kiel.

Klodt, Henning u. Horst Siebert (1991): Qualifizierungsgutscheine: Eintrittskarten in den Arbeitsmarkt, Kieler Diskussionsbeiträge 175, Institut für Weltwirtschaft, Kiel.

Klös, Hans-Peter (1997a): Dienstleistungslücke und Niedriglohnsektor in Deutschland, iw-Trends 3/97.

Klös, Hans-Peter (1997b): Der Beitrag von Einfacharbeitsplätzen zur Verringerung der Sockelarbeitslosigkeit, in: Montada, Leo (Hrsg.), Beschäftigungspolitik zwischen Effizienz und Gerechtigkeit, Frankfurt, 127-152.

Klös, Hans-Peter (1997c): Einfach-Arbeitsplätze, Stiefkinder des Arbeitsmarktes, Kurzfassung eines Gutachtens des Instituts der deutschen Wirtschaft Köln im Auftrag des Kreises Aachen, Köln.

Krause-Junk, Gerold (1996): Probleme einer Integration von Einkommensbesteuerung und steuerfinanzierten Sozialleistungen, Anmerkungen zum Gutachten der Experten-Kommission, Wirtschaftsdienst, 76, 345-349.

Krause-Junk, Gerold (1997): Bürgergeld, Jahrbücher für Nationalökonomie und Statistik, 216, 549-560.

Kress, Ulrike (1994): Die negative Einkommensteuer: Arbeitsmarktwirkungen und sozialpolitische Bedeutung, Mitteilungen aus der Arbeitsmarkt- und Berufsforschung, 27, 246-254.

Krugman, Paul (1994): Europe Jobless, America Penniless?, Foreign Policy, 95, 19-34.

Krupp, Hans-Jürgen (1995): „Bürgergeld“ oder zielorientierte soziale Sicherung?, Hamburger Jahrbuch für Wirtschafts- und Gesellschaftspolitik, 40, 291-313.

Lambert, Sue (1995): Social Policy: Poverty Traps and Alternative Income Support Systems, Working Paper Nr. 134, Perth.

Lampert, Heinz (1995): Die Sozialstaatskritik auf dem Prüfstand, Wirtschaftsdienst, 75, 504-512.

Landmann, Oliver (1996): Korreferat zum Referat G. Kirchgässner, in: Gahlen, Bernhard u. Helmut Hesse u. Hans Jürgen Ramser (Hg.), Arbeitslosigkeit und Möglichkeiten ihrer Überwindung, Wirtschaftswissenschaftliches Seminar Ottobeuren, Band 25, Tübingen, 433-437. 
Landmann, Oliver u. Michael Pflüger (1996): Arbeitsmärkte im Spannungsfeld von Globalisierung und technologischem Wandel, in: Külp, Bernhard (Hrsg.), Arbeitsmarkt und Arbeitslosigkeit, Schriftenreihe des Instituts für Allgemeine Wirtschaftsforschung der Albert-LudwigsUniversität Freiburg i. Br., Band 56, Freiburg.

Layard, Richard (1990): Lay-Offs by Seniority and Equilibrium Employment, Economics Letters, 32, 295-298.

Layard, Richard (1994): Vermeidung von Langzeit-Arbeitslosigkeit, in: Alfred Herrhausen Gesellschaft für internationalen Dialog, Arbeit der Zukunft - Zukunft der Arbeit, Stuttgart.

Layard, Richard (1997a): What Labour can do, London.

Layard, Richard (1997b): Preventing long-term unemployment, in: Snower, Dennis J. u. Guillermo de la Dehesa (Hg.), Unemployment Policy, Government Options for the Labour Market, 333-349.

Layard, Richard u. Stephen Nickell (1986): Unemployment in Britain, Economica, 53 (Supplement), 121-159.

Layard, Richard u. Stephen Nickell u. Richard Jackman (1991): Unemployment, Oxford University Press.

Layard, Richard u. Stephen Nickell u. Richard Jackman (1994): The Unemployment Crisis, Oxford.

Leibfried, Stephan u. Lutz Leisering u. Petra Buhr u. Monika Ludwig u. Eva Mädje u. Thomas Olk u. Wolfgang Voges u. Michael Zwick (1995): Zeit der Armut, edition Suhrkamp, Neue Folge Band 923, Frankfurt.

Liefmann-Keil, Elisabeth (1961): Ökonomische Theorie der Sozialpolitik, Berlin u.a.

Lindbeck, Assar (1995): Welfare State Disincentives with Endogenous Habits and Norms, Scandinavian Journal of Economics, 97, 477-494.

Lindbeck, Assar (1997): Incentives and Social Norms in Household Behavior, American Economic Review, P.P., 87, 370-377.

Lorenz, Edward C. (1995): TJTC and the Promise and Reality of Redistributive Vouchering and Tax Credit Policy, Journal of Policy Analysis and Management, 14, 270-290.

Lücke, Matthias (1997): Auswirkungen des Außenhandels mit Niedriglohnländern auf den Arbeitsmarkt in Deutschland und Großbritannien, in: Rüdiger Pohl u. Hilmar Schneider (Hg.), Wandeln oder weichen Herausforderungen der wirtschaftlichen Integration in Deutschland, Halle, 63-88. 
Mackscheidt, Klaus (1993): Die Transferaktivität der Bundesanstalt für Arbeit nach der Deutschen Einigung - Dynamik und Effizienz, in: Karl-Heinrich Hansmeyer (Hrsg.): „Finanzierungsprobleme der deutschen Einheit II. Aufbau und Finanzierung der sozialen Sicherung", Schriften des Vereins für Socialpolitik, Band 229/II, Berlin, 113- 153.

Martin, Hans-Peter u. Harald Schumann (1996): Die Globalisierungsfalle, Hamburg.

Mc Kinsey Global Institute (Hrsg.) (1997): Removing Barriers to Growth and Employment in France and Germany, Frankfurt.

Meade, James Edward (1948): Planning and the Price Mechanism, London.

Meade, James Edward (1972): Poverty in the Welfare State, Oxford Economic Papers, 24, 289-326.

Meinhardt, Volker u. Dieter Teichmann u. Gert Wagner (1994): „Bürgergeld“: Kein sozial- und arbeitsmarktpolitischer deus ex machina, WSI Mitteilungen, 47, 624-635.

Meinhardt, Volker u. Dagmar Svindland u. Dieter Teichmann u. Gert Wagner (1996): Auswirkungen der Einführung eins Bürgergeldes - Neue Berechnungen des DIW, DIW-Wochenbericht, 63, 533-543.

Meltzer, Allan H. u. Scott F. Richard (1985): A positive theory of in-kind transfers and the negative income tax, Public Choice, 47, 231-265.

Metze, Ingolf (1982): Negative Einkommensteuer, in: Handwörterbuch der Wirtschaftswissenschaft, Bd. 9, 788-799.

Meyer, Dirk (1999): Wettbewerbliche Neuorientierung der Freien Wohlfahrtspflege, Volkswirtschaftliche Schriften, Heft 486, Berlin.

Michaelis, Jochen u. Alexander Spermann (1991): Investivlohn, Sozialpakt für den Aufschwung, Gewinnbeteiligung - Lösungen für Ostdeutschland, Wirtschaftsdienst, 71, 614-622.

Michaelis, Jochen (1998): Zur Ökonomie von Entlohnungssystemen, Schriften zur angewandten Wirtschaftsforschung, 78, Tübingen.

Minford, Patrick (1984): State Expenditure: A Study in Waste, Supplement to economic affairs, April-June, i-xix.

Minford, Patrick (1997): Discussion, in: Snower, Dennis J. u. Guillermo de la Dehesa (Hg.), Unemployment Policy, Government Options for the Labour Market, 351-356.

Mitschke, Joachim (1985): Steuer- und Transferordnung aus einem Guß, Entwurf einer Neugestaltung der direkten Steuern und Sozialtransfers in der Bundesrepublik Deutschland, Schriften zur Ordnungspolitik, Bd. 2, 
hrsg. v. Frankfurter Institut für wirtschaftspolitische Forschung, BadenBaden.

Mitschke, Joachim (1994a): Integration von Steuer- und Sozialleistungssystem - Chancen und Hürden, Steuer und Wirtschaft, 71, 153-162.

Mitschke, Joachim (1994b): Bürgersteuer und Bürgergeld als beschäftigungsund sozialpolitische Chance, Statement und Thesen zum Expertengespräch „Bürgersteuer/Bürgergeld“ in der Staatskanzlei Rheinland-Pfalz am 3. Mai 1994, Mainz.

Mitschke, Joachim (1994c): Bürgergeld als beschäftigungs- und sozialpolitische Chance, Diskussionsvorlage zu einer Schrift des Kronberger Kreises (unveröffentliches Manuskript vom 20.4.1994).

Mitschke, Joachim (1995a): Steuer- und Sozialpolitik für mehr reguläre Beschäftigung, Wirtschaftsdienst, 75, 75-84.

Mitschke, Joachim (1995b): Stellungnahme zum Manuskript „Das Bürgergeld als alternatives Grundsicherungssystem: Darstellung und kritische Würdigung einiger empirischer Kostenschätzungen" von Frau Irene Becker, unveröffentlichtes Manuskript vom 25.10.1995, Frankfurt.

Mitschke, Joachim (1996): Anmerkungen zum Gutachten des Deutschen Instituts für Wirtschaftsforschung vom Dezember 1995 „Fiskalische Auswirkungen der Einführung eines Bürgergelds“, unveröffentlichtes Manuskript v. 15.2.1996, Frankfurt

Moffitt, Robert (1992): Incentive Effects of the U.S. Welfare System: A Review, Journal of Economic Literature, 30, 1-61.

Mortensen, Dale T. (1997): Discussion, in: Snower, Dennis J. u. Guillermo de la Dehesa (Hg.), Unemployment Policy, Government Options for the Labour Market, 247-249.

Neuhäuser, Jenny (1995): Sozialhilfeempfänger 1993, Wirtschaft und Statistik, 704-718.

Neuhäuser, Jenny (1997): Sozialhilfe und Leistungen an Asylbewerber 1995, Wirtschaft und Statistik, 331- 341.

OECD (1987): Who are the Unemployed? Measurement Isssues and their Policy Implications, Employment Outlook, September, 125-141.

OECD (1993): Employment Outlook, Paris.

OECD (1994a): The OECD Jobs Study. Evidence and Explanations, Part I: Labour Market Trends and Underlying Forces of Change, Paris.

OECD (1994b): The OECD Jobs Study. Evidence and Explanations, Part II: The Adjustment Potential of the Labour Market, Paris. 
OECD (1996): Employment Outlook, Paris.

OECD (1997a): OECD Economic Surveys, Germany 1997, Paris.

OECD (1997b): Implementing the OECD Jobs Strategy, Lessons from Member Countries' Experience, Paris.

OECD (1997c): Employment Outlook, Paris.

OECD (1997d): Making Work Pay, Paris

OECD (1998): Employment Outlook, Paris.

Orszag, J. Michael u. Dennis J. Snower (1996a): A Macro Theory of Employment Vouchers, CEPR Discussion Paper Nr. 1367.

Orszag, J. Michael u. Dennis J. Snower (1996b): Incapacity Benefits versus Benefit Transfers, CEPR Discussion Paper No. 1471.

Oswald, Andrew J. (1985): The Economic Theory of Trade Unions: An Introductory Survey, Scandinavian Journal of Economics, 87, 160-193.

Oswald, Andrew J. (1993): Efficient Contracts are on the Labour Demand Curve: Theory and Facts, Labour Economics, 1, 85-113.

Otten, Albert (1977): Die Negative Einkommensteuer als sozialpolitische Alternative: Diskussionsstand und Erfahrungen in den USA und eine Analyse für die Bundesrepublik Deutschland, Europäische Hochschulschriften, Frankfurt.

Pahlke, Jürgen (1976): Wirkungen negativer Einkommensteuern auf das individuelle Arbeitsangebot, Jahrbücher für Nationalökonomie und Statistik, 190, 219-234.

Paqué, Karl-Heinz (1995): Beschäftigungshilfe statt Arbeitslosenhilfe - Ein Reformvorschlag zur Senkung struktureller Arbeitslosigkeit, in: Beihefte der Konjunkturpolitik, Heft 43, Wege aus der Arbeitslosigkeit, Berlin, 81-99.

Paqué, Karl-Heinz (1997): Auswirkungen des Außenhandels mit Niedriglohnländern auf den Arbeitsmarkt in Deutschland und Großbritannien (Koreferat zu Matthias Lücke), in: Rüdiger Pohl u. Hilmar Schneider (Hg.), Wandeln oder weichen - Herausforderungen der wirtschaftlichen Integration in Deutschland, Halle, 89-93.

Parker, Hermione (1989): Instead of the Dole, London.

Peacock, Alan T. (1952): The Economics of National Insurance, Edinburgh.

Pelzer, Helmut (1996): Bürgergeld - Vergleich zweier Modelle, Zeitschrift für Sozialreform, 42, 595-613. 
Pencavel, John (1986): Labour Supply of Men: A Survey, in: Ashenfelter, Orley u. Richard Layard (Hg.), Handbook of Labour Economics, Amsterdam, 1, 3-102.

Perloff, Jeffrey M. u. Michael L. Wachter (1979): The New Jobs Tax Credit: An Evaluation of the 1977-78 Wage Subsidy Program, American Economic Review, P.P., 69, 173-179.

Phelps, Edmund S. (1994): Low-Wage Employment Subsidies versus the Welfare State, American Economic Review, Papers and Proceedings, 84, 54-58.

Phelps, Edmund S. (1997a): Rewarding Work: How to Restore Participation and Self-Support to Free Enterprise, Cambridge.

Phelps, Edmund S. (1997b): Wage subsidy programmes: alternative designs, in: Snower, Dennis J. u. Guillermo de la Dehesa (Hg.), Unemployment Policy, Government Options for the Labour Market, 206-244.

Pissarides, Christopher A. (1990): Equilibrium Unemployment Theory, London.

Pissarides, Christopher A. (1998): The impact of employment tax cuts on unemployment and wages; The role of unemployment benefits and tax structure, European Economic Review, 42, 155-183.

Polanyi, Karl (1995): The Great Transformation, Politische und ökonomische Ursprünge von Gesellschaften und Wirtschaftssystemen, 3. Auflage, suhrkamp Taschenbuch wissenschaft 260, Baden-Baden.

Prinz, Aloys (1989): Wie beeinflussen Grundeinkommenssysteme das Arbeitsangebot?, Konjunkturpolitik, 35, 110-128.

Raffelhüschen, Bernd u. Jan Walliser (1997): Was hinterlassen wir zukünftigen Generationen? Ergebnisse der Generationenbilanzierung, in: Knappe, Eckhard u. Albrecht Winkler (Hg.), Sozialstaat im Umbruch, Trierer Schriften zu Sozialpolitik und Sozialverwaltung, Band 17, Frankfurt, 65-89.

Rifkin, Jeremy (1995): The End of Work, New York.

Rhys-Williams, Lady Juliet E. (1943): Something to look forward to, London.

Rhys-Williams, Lady Juliet E. (1953): Taxation and Incentives, London.

Robins, Philip K. (1985): A Comparison of the Labour Supply Findings From the Four Negative Income Tax Experiments, The Journal of Human Resources, 20, 567-582.

Rodrik, Dani (1997): Has Globalization Gone Too Far?, Washington. 
Rolle, Carsten (1997): „US-Kombi-Einkommen“ - ein Beispiel für Deutschland, Arbeitgeber, 19/49, 608-613.

Rosen, Harvey S. (1995): Public Finance, 4. Aufl., Chicago.

Rosenfeld, Martin (1997): Arbeit statt/und Sozialhilfe, Alternativen für einen institutionellen Neubau der sozialen Grundsicherung in Deutschland, Jahrbuch für Wirtschaftswissenschaften, 49, 241-268.

Rudolph, Helmut (1992): Struktur und Dynamik der Langzeitarbeitslosigkeit in der Bundesrepublik Deutschland 1980-1990, in: Brinkmann, Christian u. Karen Schober (Hg.), Erwerbsarbeit und Arbeitslosigkeit im Zeichen des Strukturwandels, Beiträge zur Arbeitsmarkt- und Berufsforschung, BeitrAB 163, Nürnberg, 147-188.

Sachverständigenrat zur Begutachtung der gesamtwirtschaftlichen Entwicklung (1995): Den Aufschwung sichern - Arbeitsplätze schaffen, Jahresgutachten 1994/95, Stuttgart.

Saint-Paul, Gilles (1995a): The High Unemployment Trap, Quarterly Journal of Economics, 110, 527-550.

Saint-Paul, Gilles (1995b): Some political aspects of unemployment, European Economic Review, 39, 575-582.

Saint-Paul, Gilles (1996a): Understanding Labour Market Institutions: A Political Economy Perspective, CEPR Nr. 1438, London.

Saint-Paul, Gilles (1996b): Dual Labor Markets, Cambridge.

Saunders, Peter (1995a): Improving Work Incentives in a Means-Tested Welfare System: The 1994 Australian Social Security Reforms, Fiscal Studies, 16, 45-70.

Saunders, Peter (1995b): A correction to 'Improving Work Incentives in a Means-Tested Welfare System: The 1994 Australian Social Security Reforms', Fiscal Studies, 16, 126.

Scharpf, Fritz W. (1994a): Für eine Subventionierung niedriger Erwerbseinkommen, Wirtschaftsdienst, 74, 111-114.

Scharpf, Fritz W. (1994b): Nicht Arbeislosigkeit, sondern Beschäftigung fördern, in: Heinz-Werner Meyer (Hrsg.), Sozial gerecht teilen ökologisch umsteuern?, Beiträge zur Reformdiskussion im Deutschen Gewerkschaftsbund und in seinen Gewerkschaften, Band 2, Köln, 24-42.

Schellhorn, W. u. H. Jirasek u. P. Seipp (1993): Das Bundes-sozialhilfegesetz, Kommentar, 14. Aufl., Neuwied.

Scherf, Wolfgang (1994): Die negative Einkommensteuer: Ein problematisches Konzept der Steuer- und Sozialpolitik, Wirtschaftsdienst, 74, 114-118. 
Schildbach, Stephan (1997): Bürgergeldmodell zur integrierten Grundsicherung, WiSt, 27, 21-28.

Schmidt, Klaus M. (1971): Negative Einkommensteuern als Mittel der Armutsbekämpfung, Freiburg i. Br.

Schneider, Friedrich (1997a): Empirical Results of the Size of the Shadow Economy of 15 OECD Countries over Time, mimeo, Linz.

Schneider, Friedrich (1997b): Der Umfang der Schattenwirtschaft in Österreich und Deutschland in den neunziger Jahren, mimeo, Linz.

Scholz, John Karl (1994): The Earned Income Tax Credit: Participation, Compliance and Antipoverty Effectiveness, National Tax Journal, 47, 63-85.

Scholz, John Karl (1996): In-Work Benefits in the United States: The Earned Income Tax Credit, The Economic Journal, 106, 156-169.

Schumpeter, Joseph A. (1961): Konjunkturzyklen, Göttingen.

Schupp, Jürgen u. Johannes Schwarze u. Gert Wagner (1997): Erwerbsstatistik unterschätzt Beschäftigung um 2 Millionen Personen, DIWWochenbericht v. 18.9.1997, 64, 689-694.

Schwarze, Johannes (1998): Wer trägt die pauschale Lohnsteuer bei geringfügiger Beschäftigung? Eine Analyse der Stundenlöhne erwerbstätiger Frauen, in: Galler, H.P. und G. Wagner (Hg.): Empirische Forschung und wirtschaftspolitische Beratung, Frankfurt, erscheint demnächst.

Seehofer, Horst (1995): Eckpunkte für eine Reform der Sozialhilfe, Wirtschaftsdienst, 75, 231-233.

Seffen, Achim (1992): Zur Kritik an der Sozialhilfe in der alten Bundesrepublik, Beiträge zur Wirtschafts- und Sozialpolitik Nr. 195, Institut der deutschen Wirtschaft, Köln.

Semrau, Peter (1990): Entwicklung der Einkommensarmut, in: Döring, Diether u. Walter Hanesch u. Ernst-Ulrich Huster (Hg.), Armut im Wohlstand, 111-128.

Sesselmeier, Werner/Klopfleisch, Roland/Setzer, Martin (1996): Mehr Beschäftigung durch eine negative Einkommensteuer: Zur beschäftigungspolitischen Effektivität und Effizienz eines integrierten Steuer- und Transfersystems, Sozialökonomische Schriften Bd. 10, Frankfurt am Main: Lang.

Shapiro, Carl u. Stiglitz, Joseph E. (1984): Equilibrium Unemployment as a Worker Discipline Device, American Economic Review, 74, 433-444.

Siebert, Horst (1994): Geht den Deutschen die Arbeit aus? Wege zu mehr Beschäftigung, München. 
Siebert, Horst (1995): Geht den Deutschen die Arbeit aus? Wege zu mehr Beschäftigung, Aktualisierte Auflage, München.

Siebert, Horst (1996): Hundert Punkte für mehr Beschäftigung, Kieler Diskussionsbeiträge Nr. 264, Kiel.

Siebert, Horst u. Frank Stähler (1995): Sozialtransfer und Arbeitsangebot, Zeitschrift für Wirtschafts- und Sozialwissenschaften (ZWS), 115, 377392.

Siegel, Theodor u. Dieter Schneider (1994): Existenzminimum und Familienlastenausgleich: Ein Problem der Reform des Einkommensteuerrechts, Deutsches Steuerrecht (DStR), 32, 597-604.

Sinn, Hans-Werner u. Gerlinde Sinn (1992): Kaltstart, 2. Auflage, Tübingen.

Sinn, Hans-Werner (1994): A Theory of the Welfare State, Scandinavian Journal of Economics, 97, 495-526.

Sinn, Hans-Werner (1995): Schlingerkurs: Lohnpolitik und Investitionsförderung in den neuen Bundesländern, Schriften des Vereins für Socialpolitik, Band 239, Berlin.

Sinn, Hans-Werner (1998): Sozialstaat im Wandel, Vortrag bei der Jahrestagung des Vereins für Socialpolitik, unveröffentlichtes Manuskript, Rostock.

Sitte, Ralf (1997): Rückkehr der Dienstboten?, Der begrenzte Nutzen von Lohnsubventionen bei einfachen Dienstleistungen, Sozialer Fortschritt, 46, 183-188.

Snower, Dennis J. (1994): Converting Unemployment Benefits into Employment Subsidies, American Economic Review, Papers and Proceedings, 84, 65-70.

Snower, Dennis J. (1997): The Simple Economics of Benefit Transfers, in: Snower, Dennis J. u. Guillermo de la Dehesa (Hg.), Unemployment Policy, Government Options for the Labour Market, 163-198.

Solow, Robert M. (1998): Guess Who Likes Welfare (Lecture 1), Guess Who Pays for Workfare (Lecture 2), in: Gutman, Amy (Hrsg.), Work and Welfare, Princeton, S. 3-43.

Sørensen, Peter Birch (1997): Public finance solutions to the European unemployment problem?, Economic Policy, 25, 223-264 (including comments by Vidar Christiansen and Juan J. Dolado).

Sozialministerium Baden-Württemberg (1998): Pressemitteilung vom 12.5.1998, Stuttgart.

Spermann, Alexander (1994): Das Bürgergeld - ein sozial- und beschäftigungspolitisches Wundermittel?, Sozialer Fortschritt, 43, 105-111. 
Spermann, Alexander (1995): Das „Einstiegsgeld“ für Langzeitarbeitslose ein Weg aus der Armutsfalle, in: Prosi, Gerhard u. Christian Watrin, Gesundung der Staatsfinanzen - Wege aus der blockierten Gesellschaft, VII. Internationaler Kongreß Junge Wissenschaft und Wirtschaft, Veröffentlichung der Hanns Martin Schleyer-Stiftung, Band 45, Köln, 179-188.

Spermann, Alexander (1996): Das „Einstiegsgeld“ für Langzeitarbeitslose, Wirtschaftsdienst, 76, 240-246.

Spermann, Alexander (1997): Die BündnisGrüne Grundsicherung: Sozialpolitischer Fortschritt, aber beschäftigungspolitische Gefahr, in: Bündnis90/Die Grünen (Hrsg.), Bedarfsorientierte Grundsicherung, Dokumentation der gleichnamigen Anhörung am 25.4.1997, 50-53.

Spermann, Alexander (1999): Fighting Long-term Unemployment with Targeted Employment Subsidies: Benefit Transfer Programme (BTP) versus Targeted Negative Income Tax (TNIT), Jahrbücher für Nationalökonomie und Statistik, 218, 647-657.

Stark, Birgit u. Claudia Wolfinger (1995): Lohnkostenzuschüsse nach $\S 249 \mathrm{~h}$ AFG, IAB-Werkstattbericht Nr. 11 vom 18.12.1995, Nürnberg.

Stascheit, Ulrich u. Elwine Turk (1996): Leitfaden für Arbeitslose: Der Rechtsratgeber zum AFG, 13. Auflage, Frankfurt am Main.

Statistisches Bundesamt (1997a): Statistik der Sozialhilfe, Empfänger(innen) von laufender Hilfe zum Lebensunterhalt am 31.12.1995, Arbeitsunterlage, Wiesbaden.

Statistisches Bundesamt (1997b): Statistik der Sozialhilfe, Empfänger(innen) von Hilfe in besonderen Lebenslagen, Arbeitsunterlage, Wiesbaden.

Statistisches Bundesamt (1997c): Statistik der Sozialhilfe, Ausgaben und Einnahmen 1995, Arbeitsunterlage, Wiesbaden.

Statistisches Bundesamt (1997d): Asylbewerberstatistik, Empfänger und Empfängerinnen von Leistungen nach dem Asylbewerberleistungsgesetz am 31.12.1995, Arbeitsunterlage, Wiesbaden.

Statistisches Bundesamt (1997e): Mitteilung vom 11.6.1997.

Statistisches Bundesamt (1997f): Mitteilung vom 5.8.1997.

Statistisches Bundesamt (1997g): Mitteilung vom 17.6.1997.

Statistisches Bundesamt (1998a): Statistik der Sozialhilfe, Empfänger(innen) von laufender Hilfe zum Lebensunterhalt am 31.12.1996, Arbeitsunterlage, Wiesbaden.

Statistisches Bundesamt (1998b): Statistik der Sozialhilfe, Ausgaben und Einnahmen 1996, Arbeitsunterlage, Wiesbaden. 
Statistisches Bundesamt (1998c): Statistik der Sozialhilfe, Empfänger(innen) von laufender Hilfe zum Lebensunterhalt am 31.12.1997, Arbeitsunterlage, Wiesbaden.

Steiner, Viktor (1994): Labour Market Transitions and the Persistence of Unemployment - West Germany 1983-1992, Zentrum für Europäische Wirtschaftsforschung Discussion Paper No. 94-20.

Steiner, Viktor (1997): Extended Benefit-Entitlement Periods and the Duration of Unemployment in West Germany, ZEW Discussion Paper No. 97-14.

Steiner, Viktor u. Bruno Kaltenborn (1995): Arbeitsmarktdynamik, Langzeitarbeitslosigkeit und der Beitrag der Arbeitsmarktpolitik. Eine Strukturanalyse der westdeutschen Arbeitsmarktentwicklung seit 1980, in: ZEWWirtschaftsanalysen, Band 3, Baden-Baden, 29-64.

Stiglitz, Joseph E. (1997): Reflections on the Natural Rate Hypothesis, Journal of Economic Perspectives, 11, 3-10.

Thompson, Tommy G. (1997): Wisconsin Works W-2, mimeo.

Thurow, Lester C. (1996): The Future of Capitalism, London.

Tobin, James (1965): On Improving the Economic Status of the Negro, Daedalus, Journal of the American Academy of Arts and Sciences, 94, 878-898.

Tobin, James u. Joseph A. Pechman u. Peter M. Mieszkowski (1967): Is a Negative Income Tax Practical?, The Yale Journal, 77, 1-27.

Trabert, Lioba u. Christian Dreger u. Wolfram Kempe u. Jürgen Kolb (1998): Gutachten des Instituts für Wirtschaftsforschung Halle (IWH), in: Ministerium für Arbeit, Frauen, Gesundheit und Soziales des Landes Sachsen-Anhalt (Hrsg.), Forschungsbeiträge zum Arbeitsmarkt in Sachsen-Anhalt, Band 12, Kombilohn in Sachsen-Anhalt, Magdeburg.

Van Almsick, Josef (1981): Die negative Einkommenssteuer: Finanztheoretische Struktur, Arbeitsangebotswirkungen und sozialpolitische Konzeption, Volkswirtschaftliche Schriften, Heft 307, Berlin.

Van der Ploeg, Frederick (1995): Public Finance and Unemployment in Europe, Paper presented at the Lisbon-Congress of the Institute of Public Finance.

Van der Ploeg, Frederick (1997): The Political Economy of a Consensus Society: Experience from Behind the Dykes, The Economic and Social Review, 28, 307-332.

Van Suntum, Ulrich (1997): Zum Verhältnis von Arbeitsmarkt und Sozialpolitik, in: Hartwig, Karl-Hans (Hrsg.), Alternativen der sozialen Siche- 
rung - Umbau des Sozialstaates, Gespräche der List Gesellschaft, Band 17, Baden-Baden, 87-99.

Vaubel, Roland (1990): Sozialpolitik für mündige Bürger: Optionen für eine Reform, Baden-Baden.

Vaubel, Roland (1996): Aktuelle Möglichkeiten der Einkommenssicherung über eine negative Einkommensteuer, in: Siebert, Horst (Hrsg.), Sozialpolitik auf dem Prüfstand, Leitlinien für Reformen, Tübingen, 169-195.

Velling, Johannes (1994): Wie hoch ist die Arbeitslosigkeit in Deutschland wirklich?, ZEW-Newsletter Nr. 2, 9-14.

Vierling, Michael (1996): Lohnsubvention und negative Einkommensteuer, Wirkungen auf Arbeitsangebot und Wohlfahrt, Finanzwissenschaftliche Forschungsarbeiten, Neue Folge, Band 65, Berlin.

Vierling, Michael (1997): Subventionierung des Lohnsatzes anstelle des Einkommens, Wirtschaftsdienst, 77, 647-654.

Walker, Robert u. Michael Wiseman (1997): The Possibility of a British Earned Income Tax Credit, Fiscal Studies, 18, 401-425.

Walwei, Ulrich u. Heinz Werner (1997): Beschäftigungsinitiativen in Deutschland, IAB Werkstattbericht Nr. 2 v. 10.2.1997.

Weeber, Joachim (1992): Vermindert die bestehende Sozialhilfe das Arbeitsangebot?, Konjunkturpolitik, 38, 55-68.

Werner, Heinz (1998): Auf dem Weg zu mehr Beschäftigung: Erfahrungen anderer Länder, Wirtschaftsdienst, 78, 601-608.

Whitehouse, Edward (1996): Designing and Implementing In-Work Benefits, The Economic Journal, 106, 130-141.

Winkelmann, Liliana u. Rainer Winkelmann (1995): Happiness and Unemployment: A Panel Data Analysis for Germany, Konjunkturpolitik, 41, 293-307.

Winkelmann, Liliana u. Rainer Winkelmann (1998): Why Are the Unemployed So Unhappy? Evidence from Panel Data, Economica, 65, 115.

Winter-Ebmer, Rudolf (1998): Potential Unemployment Benefit Duration and Spell Length: Lessons from a Quasi-Experiment in Austria, Oxford Bulletin of Economics and Statistics, 60, 33-45.

Wiseman, Michael (1996): State Strategies for Welfare Reform: The Wisconsin Story, Journal of Policy Analysis and Management, 15, 515546. 
Wissenschaftlicher Beirat beim Bundesministerium der Finanzen (1996): Zur

Reform des Einkommensteuertarifs, Schriftenreihe des Bundesministeriums der Finanzen, Heft 60, Bonn.

Wissenschaftlicher Beirat beim Bundesministerium der Wirtschaft (1996a): Gutachten zur Langzeitarbeitslosigkeit, Tübingen.

Wissenschaftlicher Beirat beim Bundesministerium der Wirtschaft (1996b): Anstehende große Steuerreform, Studienreihe des BMWI Nr. 94, Bonn.

Woodbury, Stephan A. u. Robert G. Spiegelman (1987): Bonuses to Workers and Employers to Reduce Unemployment: Randomized Trials in Illinois, American Economic Review, 77, 513-530.

Zeckhauser, Richard J. (1971): Optimal Mechanisms for Income Transfer, American Economic Review, Papers and Proceedings, 61, 324-334.

Zimmermann, Klaus F. (1993): Labour Responses to Taxes and Benefits in Germany, in: Atkinson, A.B. u. G.V. Morgensen (Hg.), Welfare and Work Incentives, A North European Perspective (Clarendon Press, Oxford), 192-240.

Zwick, Michael M. (Hrsg.) (1994): Einmal arm, immer arm?, Neue Befunde zur Armut in Deutschland, Frankfurt. 
Periodika/Tageszeitungen:

Mediendienst der Bundesvereinigung der Deutschen Arbeitgeberverbände (BDA)

Presse- und Informationsdienst der Bundesregierung, Sozialpolitische Umschau

Frankfurter Allgemeine Zeitung

Süddeutsche Zeitung

Gesetze und Richtlinien:

Arbeitsförderungsgesetz (AFG) vom 25. Juni 1969 (BGBl. I S. 582), zuletzt geändert durch Art. 11 des Gesetzes vom 24.3.1997 (BGBl. I S. 594).

Arbeitslosenrecht (mit den aktuellen Änderungen aus dem ArbeitsförderungsReformgesetz - AFRG), Synoptischer Abdruck des alten und neuen AFG, mit dem neuen Sozialgesetzbuch (SGB) Drittes Buch III - Arbeitsförderung und den geänderten Vorschriften des Fünften Buches Sozialgesetzbuch (SGB V), Baden-Baden 1997.

Bundessozialhilfegesetz (BSHG) in der Fassung der Bekanntmachung vom 23. März 1994 (BGBl. I S. 646, ber. S. 2975), zuletzt geändert durch Gesetz v. 6.8.1998 (BGBl. I S. 2005).

Gesetz zur Umsetzung des Föderalen Konsolidierungsprogramms (FKPG) vom 23.6.1993

Sozialgesetzbuch (SGB) III v. 24. März 1997, Bundesgesetzblatt Teil I, S. 594, zuletzt geändert durch Gesetz vom 16.12.1997 (BGBL.I S. 2998).

Sozialgesetzbuch (SGB) VI v. 18.12.1989.

Sozialhilferichtlinien des Landes Baden-Württemberg (1997): 40. Ergänzungslieferung v. Februar 1997. 


\section{FINANZWISSENSCHAFTLICHE SCHRIFTEN}

Band 1 Werner Steden: Finanzpolitik und Einkommensverteilung. Ein Wachstums- und Konjunkturmodell der Bundesrepublik Deutschland. 1979.

Band 2 Rainer Hagemann: Kommunale Finanzplanung im föderativen Staat. 1976.

Band 3 Klaus Scherer: Maßstäbe zur Beurteilung von konjunkturellen Wirkungen des öffentlichen Haushalts. 1977.

Band 4 Brita Steinbach: "Formula Flexibility" - Kritische Analyse und Vergleich mit diskretionärer Konjunkturpolitik. 1977.

Band 5 Hans-Georg Petersen: Personelle Einkommensbesteuerung und Inflation. Eine theoretisch-empirische Analyse der Lohn- und veranlagten Einkommensteuer in der Bundesrepublik Deutschland. 1977.

Band 6 Friedemann Tetsch: Raumwirkungen des Finanzsystems der Bundesrepublik Deutschland. Eine Untersuchung der Auswirkungen der Finanzreform von 1969 auf die Einnahmenposition der untergeordneten Gebietskörperschaften und ihrer regionalpolitischen Zieladäquanz. 1978.

Band 7 Wilhelm Pfähler: Normative Theorie der fiskalischen Besteuerung. Ein methodologischer und theoretischer Beitrag zur Integration der normativen Besteuerungstheorie in der Wohlfahrtstheorie. 1978.

Band 8 Wolfgang Wiegard: Optimale Schattenpreise und Produktionsprogramme für öffentliche Unternehmen. Second-Best Modelle im finanzwirtschaftlichen Staatsbereich. 1978.

Band 9 Hans P. Fischer: Die Finanzierung des Umweltschutzes im Rahmen einer rationalen Umweltpolitik. 1978.

Band 10 Rainer Paulenz: Der Einsatz finanzpolitischer Instrumente in der Forschungs- und Entwicklungspolitik. 1978.

Band 11 Hans-Joachim Hauser: Verteilungswirkungen der Staatsverschuldung. Eine kreislauftheoretische Inzidenzbetrachtung. 1979.

Band 12 Gunnar Schwarting: Kommunale Investitionen. Theoretische und empirische Untersuchungen der Bestimmungsgründe kommunaler Investitionstätigkeit in NordrheinWestfalen 1965-1972. 1979.

Band 13 Hans-Joachim Conrad: Stadt-Umland-Wanderung und Finanzwirtschaft der Kernstädte. Amerikanische Erfahrungen, grundsätzliche Zusammenhänge und eine Fallstudie für das Ballungsgebiet Frankfurt am Main. 1980.

Band 14 Cay Folkers: Vermögensverteilung und staatliche Aktivität. Zur Theorie distributiver Prozesse im Interventionsstaat. 1981.

Band 15 Helmut Fischer: US-amerikanische Exportförderung durch die DISC-Gesetzgebung. 1981.

Band 16 Günter Ott: Einkommensumverteilungen in der gesetzlichen Krankenversicherung. Eine quantitative Analyse. 1981.

Band 17 Johann Hermann von Oehsen: Optimale Besteuerung. (Optimal Taxation). 1982.

Band 18 Richard Kössler: Sozialversicherungsprinzip und Staatszuschüsse in der gesetzlichen Rentenversicherung. 1982.

Band 19 Hinrich Steffen: Zum Handlungs- und Entscheidungsspielraum der kommunalen Investitionspolitik in der Bundesrepublik Deutschland. 1983.

Band 20 Manfred Scheuer: Wirkungen einer Auslandsverschuldung des Staates bei flexiblen Wechselkursen. 1983. 
Band 21 Christian Schiller: Staatsausgaben und crowding-out-Effekte. Zur Effizienz einer Finanzpolitik keynesianischer Provenienz. 1983.

Band 22 Hannelore Weck: Schattenwirtschaft: Eine Möglichkeit zur Einschränkung der öffentlichen Verwaltung? Eine ökonomische Analyse. 1983.

Band 23 Wolfgang Schmitt: Steuern als Mittel der Einkommenspolitik. Eine Ergänzung der Stabilitätspolitik? 1984.

Band 24 Wolfgang Laux: Erhöhung staatswirtschaftlicher Effizienz durch budgetäre Selbstbeschränkung? Zur Idee einer verfassungsmäßig verankerten Ausgabengrenze. 1984.

Band 25 Brita Steinbach-van der Veen: Steuerinzidenz. Methodologische Grundlagen und empirisch-statistische Probleme von Länderstudien. 1985.

Band 26 Albert Peters: Ökonomische Kriterien für eine Aufgabenverteilung in der Marktwirtschaft. Eine deskriptive und normative Betrachtung für den Allokationsbereich. 1985.

Band 27 Achim Zeidler: Möglichkeiten zur Fortsetzung der Gemeindefinanzreform. Eine theoretische und empirische Analyse. 1985.

Band 28 Peter Bartsch: Zur Theorie der längerfristigen Wirkungen 'expansiver' Fiskalpolitik. Eine dynamische Analyse unter besonderer Berücksichtigung der staatlichen Budgetbeschränkung und ausgewählter Möglichkeiten der öffentlichen Defizitfinanzierung. 1986.

Band 29 Konrad Beiwinkel: Wehrgerechtigkeit als finanzpolitisches Verteilungsproblem. Möglichkeiten einer Kompensation von Wehrungerechtigkeit durch monetäre Transfers. 1986.

Band 30 Wolfgang Kitterer: Eftizienz- und Verteilungswirkungen des Steuersystems. 1986.

Band 31 Heinz Dieter Hessler: Theorie und Politik der Personalsteuern. Eine Kritik ihrer Einkommens- und Vermögensbegriffe mit Blick auf die Leistungsfähigkeitstheorie. 1994.

Band 32 Wolfgang Schert: Die beschăftigungspolitische und fiskalische Problematik der Arbeitgeberbeiträge zur Rentenversicherung. Eine Auseinandersetzung mit der Kritik an der lohnbezogenen Beitragsbemessung. 1987.

Band 33 Andreas Mästle: Die Steuerunion. Probleme der Harmonisierung spezifischer Gütersteuem. 1987.

Band 34 Günter Ott: Internationale Verteilungswirkungen im Finanzausgleich der Europäischen Gemeinschaften. 1987.

Band 35 Heinz Haller: Zur Frage der zweckmåßigen Gestalt gemeindlicher Steuern. Ein Diskussionsbeitrag zur Gemeindesteuerreform. 1987.

Band 36 Thomas Kuhn: Schlüsselzuweisungen und fiskalische Ungleichheit. Eine theoretische Analyse der Verteilung von Schlūsselzuweisungen an Kommunen. 1988.

Band 37 Walter Hahn: Steuerpolitische Willensbildungsprozesse in der Europäischen Gemeinschaft. Das Beispiel der Umsatzssteuer-Harmonisierung. 1988.

Band 38 Ulrike Hardt: Kommunale Finanzkraft. Die Problematik einer objektiven Bestimmung kommunaler Einnahmemöglichkeiten in der gemeindlichen Haushaltsplanung und im kommunalen Finanzausgleich. 1988.

Band 39 Jochen Michaelis: Optimale Finanzpolitik im Modell überlappender Generationen. 1989.

Band 40 Bernd Raffelhüschen: Anreizwirkungen der sozialen Alterssicherung. Eine dynamische Simulationsanalyse. 1989.

Band 41 Berend Diekmann: Die Anleihe- und Darlehenstransaktionen der Europäischen Gemeinschaften. 1990.

Band 42 Helmut Kaiser: Konsumnachfrage, Arbeitsangebot und optimale Haushaltsbesteuerung. Theoretische Ergebnisse und mikroökonometrische Simulation für die Bundesrepublik Deutschland. 1990. 
Band 43 Rüdiger von Kleist: Das Gramm-Rudman-Hollings-Gesetz. Ein gescheiterter Versuch der Haushaltskonsolidierung. 1991.

Band 44 Rolf Hagedorn: Steuerhinterziehung und Finanzpolitik. Ein theoretischer Beitrag unter besonderer Berücksichtigung der Hinterziehung von Zinserträgen. 1991.

Band 45 Cornelia S. Behrens: Intertemporale Verteilungswirkungen in der gesetzlichen Krankenversicherung der Bundesrepublik Deutschland. 1991.

Band 46 Peter Saile: Ein ökonomischer Ansatz der Theorie der intermediären Finanzgewalten Die Kirchen als Parafisci. 1992.

Band 47 Peter Gottfried: Die verdeckten Effizienzwirkungen der Umsatzsteuer. Eine empirische allgemeine Gleichgewichtsanalyse. 1992.

Band 48 Andreas Burger: Umweltorientierte Beschäftigungsprogramme. Eine Effizienzanalyse am Beispiel des "Sondervermögens Arbeit und Umwelt". 1992.

Band 49 Jeanette Malchow: Die Zuordnung verteilungspolitischer Kompetenzen in der Europäischen Gemeinschaft. Eine Untersuchung aufgrund einer Fortentwicklung der ökonomischen Theorie des Föderalismus. 1992.

Band 50 Barbara Seidel: Die Einbindung der Bundesrepublik Deutschland in die Europäischen Gemeinschaften als Problem des Finanzausgleichs. 1992.

Band 51 Ralph Wiechers: Markt und Macht im Rundfunk. Zur Stellung der öffentlich-rechtlichen Rundfunkanstalten im dualen Rundfunksystem der Bundesrepublik Deutschland. 1992.

Band 52 Klaus Eckhardt: Probleme einer Umweltpolitik mit Abgaben. 1993.

Band 53 Oliver Schwarzkopf: Die Problematik unterschiedlicher Körperschaftsteuersysteme innerhalb der EG. 1993.

Band 54 Thorsten Giersch: Bergson-Wohlfahrtsfunktion und normative Ökonomie. 1993.

Band 55 Li-Fang Chou: Selbstbeteiligung bei Arzneimitteln aus ordnungspolitischer Sicht. Das Beispiel der Bundesrepublik Deutschland. 1993.

Band 56 Harald Schlee: Einkommensteuerliche Behandlung von Transferzahlungen. Zur Neuordnung der Familienbesteuerung sowie der Besteuerung von Versicherungsleistungen und Sozialtransfers. 1994.

Band 57 Alexander Spermann: Kommunales Krisenmanagement. Reaktionen baden-württembergischer Stadtkreise auf steigende Sozialhilfekosten und Einnahmenausfälle (198092). 1993.

Band 58 Otto Roloff / Sibylle Brander / Ingo Barens / Claudia Wesselbaum: Direktinvestitionen und internationale Steuerkonkurrenz. 1994.

Band 59 Claudia Wesselbaum-Neugebauer: Internationale Steuerbelastungsvergleiche. 1994.

Band 60 Stephanie Miera: Kommunales Finanzsystem und Bevölkerungsentwicklung. Eine Analyse des kommunalen Finanzsystems vor dem Hintergrund der sich abzeichnenden Bevölkerungsentwicklung am Beispiel Niedersachsens unter besonderer Berücksichtigung des Landkreises Wolfenbüttel und seiner Gemeinden. 1994.

Band 61 Wolfgang Schert: Die Bedeutung des kaldorianischen Verteilungsmechanismus für die gesamtwirtschaftlichen Wirkungen der staatlichen Neuverschuldung. 1994.

Band 62 Rainer Volk: Vergleich der Vergünstigungseffekte der verschiedenen investitionsfördernden Maßnahmen. 1994.

Band 63 Hans-Georg Napp: Kommunale Finanzautonomie und inre Bedeutung für eine effiziente lokale Finanzwirtschaft. 1994. 2., unverănderte Auflage 1994.

Band 64 Bernd Rahmann / Uwe Steinborn / Günter Vornholz: Empirische Analyse der Autonomie lokaler Finanzwirtschaften in der Europäischen Gemeinschaft. 1994. 
Band 65 Carsten Kühl: Strategien zur Finanzierung der Altlastensanierung. 1994.

Band 66 Stephan Boll: Intergenerationale Umverteilungswirkungen der Fiskalpolitik in der Bundesrepublik Deutschland. Ein Ansatz mit Hilfe des Generational Accounting. 1994.

Band 67 Karl Justus Bernhard Neumärker: Finanzverfassung und Staatsgewalt in der Demokratie. Ein Beitrag zur konstitutionellen Finanztheorie. 1995.

Band 68 Christian Haslbeck: Zentrale versus dezentrale Internalisierung externer Effekte bei unvollständiger Information. 1995.

Band 69 Regina Müller: Horizontale oder vertikale Transfers zur Durchsetzung eines horizontalen Finanzausgleichs. 1995.

Band 70 Christian Hockenjos: Öffentliche Sporttörderung in der Bundesrepublik Deutschland. Darstellung und finanztheoretische Analyse. 1995.

Band 71 Manfred Rosenstock: Die Kontrolle und Harmonisierung nationaler Beihilfen durch die Kommission der Europäischen Gemeinschaften. 1995.

Band 72 Christian Rüsch: Wohnungsbau- und Wohneigentumspolitik im Rahmen der Einkommensteuer. Eine Analyse unter steuersystematischen, verteilungspolitischen und fiskalischen Aspekten. 1996.

Band 73 Stephan Winters: Die kollektive Vorsorge für den Pflegefall im Alter. Eine Untersuchung am Beispiel der gesetzlichen Pflegeversicherung in den Niederlanden. 1996.

Band 74 Knut Blind: Allokationsineffizienzen auf Sicherheitsmärkten: Ursachen und Lösungsmöglichkeiten. Fallstudie: Informationssicherheit in Kommunikationssystemen. 1996.

Band 75 Barbara Petrick-Rump: Ökonomische Wirkungen von Steueramnestien. Untersuchung konkreter Erfahrungen ausgewählter Länder mit dem Einsatz von Steueramnestien anhand eines effizienten Steueramnestieprogramms. 1996.

Band 76 Georg Hirte: Effizienzwirkungen von Finanzausgleichsregelungen. Eine Empirische Allgemeine Gleichgewichtsanalyse für die Bundesrepublik Deutschland. 1996.

Band 77 Ulrike Kirchhoft: Die rheinland-pfälzischen Gemeinden im System des Finanzausgleichs. 1996.

Band 78 Kerstin Keil: Der soziale Mietwohnungsbau: Măngel und Alternativen. 1996.

Band 79 Bernhard Manzke: Kinderlastenausgleich versus verstärkte Einwanderung. Alternative Ansätze zur langfristigen Sicherung der Gesetzlichen Rentenversicherung. 1997.

Band 80 Hariolf M. Wenzler: Institutionenökonomik und öffentliche Finanzkontrolle. Eine Analyse am Beispiel der Europäischen Union. 1997.

Band 81 Joachim Nagel: Supply-Side Policy in den USA. Eine theoretische und empirische Analyse der angebotsorientierten Wirtschaftspolitik Reagans unter besonderer Berücksichtigung steuerlicher Aspekte. 1997.

Band 82 Heinz Lampert: Krise und Reform des Sozialstaates. 1997.

Band 83 Monika Hanswillemenke / Bernd Rahmann: Zwischen Reformen und Verantwortung für Vollbeschättigung. Die Finanz- und Haushaltspolitik der sozial-liberalen Koalition von 1969 bis 1982. 1997.

Band 84 Berthold Fürst: Die Maastrichter Budgetkriterien im Konflikt mit der Verschuldungsautonomie der deutschen Gebietskörperschaften. 1997.

Band 85 Burkhard Pahnke: Einkommensorientierte Förderung des sozialen Mietwohnungsbaues. Bestandsaufnahme und Kritik. 1998.

Band 86 Judith Safford: Staatsverschuldung im Vereinigten Königreich. Die öffentliche Verschuldung unter der Konservativen Regierung von 1979-1994. Ursachen und Auswirkungen. 1998. 
Band 87 Ralf Oberheide: Die Bekämpfung der Steuerumgehung. 1998.

Band 88 Achim Truger: Die neue Finanzwissenschaft zwischen Realitätsferne und Irrelevanz der Annahmen. Eine methodologische Analyse potentieller Verteidigungsstrategien der neuen Finanzwissenschaft gegen den Vorwurf der Realitätsferne ihres entscheidungstheoretischen Fundamentes. 1998.

Band 89 Karin Bickel: Familienbezogene Elemente im System der gesetzlichen Rentenversicherung. Unter besonderer Berücksichtigung von Ein-Eltern-Familien. 1999.

Band 90 Wolfgang Scherf: Schlüsselzuweisungen und Kreisumlage. Die Problematik der Finanzierung der Landkreise am Beispiel des kommunalen Finanzausgleichs von RheinlandPfalz. 1998.

Band 91 Sandra Ehmann: Familienpolitik in Frankreich und Deutschland - ein Vergleich. 1999.

Band 92 Hendrik Suermann: Einkommensteuerliche Behandlung von Währungsgewinnen und -verlusten. Eine finanzwissenschaftliche Analyse des Steuerrechts in den USA und in Deutschland. 1999.

Band 93 Rolf Bösinger: Die Neuordnung des bundesstaatlichen Finanzausgleichs 1995. Eine theoretische und empirische Analyse unter Berücksichtigung von allokationstheoretischen und polit-ökonomischen Gesichtspunkten. 1999.

Band 94 Ulrich Ermschel: Finanzwirtschaftliche Konsequenzen beim Übergang auf das Ursprungslandprinzip im Europäischen Binnenmarkt. Eine Untersuchung am Beispiel des unvollkommenen oligopolistischen Neufahrzeugmarktes. 1999.

Band 95 Ute Hansen: Überwälzte Leistungen der Administration. Eine empirische und theoretische Analyse. 2000.

Band 96 Hans-Werner Seiler: Zur Durchsetzung der Einmalbesteuerung deutscher Körperschaftsgewinne. Strategien zur Vermeidung der im deutschen Körperschaftsteuersystem angelegten Benachteiligung ausländischer Anteilseigner. Eine finanzwissenschaftliche Analyse. 2000.

Band 97 Steffen Meyer: Zwischenstaatliche Finanzzuweisungen im zusammenwachsenden Europa. Zur Gestaltung eines Finanzausgleichs für die Europäische Union. 2000.

Band 98 Marion Hübner: Ökodumping? Umweltpolitik in internationalen Oligopolmärkten. 2000.

Band 99 Christhart Bork: Steuern, Transfers und private Haushalte. Eine mikroanalytische Simulationsstudie der Aufkommens- und Verteilungswirkungen. 2000.

Band 100 Norbert Eichler: Die Probleme des Gemeindefinanzausgleichs im Kooperativen Föderalismus. Eine ökonomische Analyse am Beispiel des Bundeslandes Nordrhein-Westfalen. 2000.

Band 101 Wolfgang Schert: Der Länderfinanzausgleich in Deutschland. Ungelöste Probleme und Ansatzpunkte einer Reform. 2000.

Band 102 Stefan Dietrich Josten: Staatsverschuldung, intertemporale Allokation und Wirtschaftswachstum. Eine theoretische Analyse staatlicher Verschuldungspolitik in Modellen exogenen und endogenen Wachstums. 2000.

Band 103 Axel Breitbach: Steuerhinterziehung und Schattenwirtschaft aus gesamtwirtschaftlicher Sicht. 2000.

Band 104 Alexander Spermann: Negative Einkommensteuer, Lohnsubventionen und Langzeitarbeitslosigkeit. 2001.

Band 105 Michael Broer: Der kommunale Finanzausgleich in Hessen. Historische Darstellung und ökonomische Analyse unter besonderer Berücksichtigung der Schlüsselzuweisungen. 2001. 


\section{Reformansätze zur Alterssicherung in Deutschland und intergenerationelle Gerechtigkeit}

Frankfurt/M., Berlin, Bern, Bruxelles, New York, Oxford, Wien, 2001.

371 S., zahlr. Abb. u. Tab.

Volkswirtschaftliche Analysen. Bd. 8

Verantwortlicher Herausgeber: Christian Scheer

ISBN 3-631-37199-3 · br. DM 98.-*

Die deutsche Gesetzliche Rentenversichung folgt dem Umlageverfahren.

Dieses Finanzierungsverfahren und die damit verbundene Ausgestaltung des Generationenvertrages stehen in der Kritik. Politik und Wissenschaft müssen beantworten, wie eine zukunftssichere und gerechte Rentenreform aussehen soll. Als Beitrag zur Beantwortung dieser Frage werden unterschiedliche Reformen im Rahmen eines allgemeinen Gleichgewichtsmodells analysiert. Im Vordergrund stehen die intertemporalen Wohlfahrtswirkungen auf unterschiedliche Generationen. Die Reformübergänge werden auf ihre intergenerationellen Belastungswirkungen und mit Hilfe von Gerechtigkeitsprinzipien auf ihre ethischen Eigenschaften verglichen. Für eine umfassende Bewertung wird so die notwendige Verbindung von Inzidenz und Ethik hergestellt.

Aus dem Inhalt: Alterssicherung als Generationenvertrag · Konzepte von Generationenverträgen - Ethische Konzeptionen des Gesellschaftsvertrages . Die Gesetzliche Rentenversicherung in Deutschland · Reformvorschläge zur Alterssicherung - Dynamische Inzidenzanalyse - Simulationsergebnisse und Bewertung der Reformvorschläge

FrankfurtM - Berlin - Bern - Bruxelles - New York - Oxford - Wien

Auslieferung: Verlag Peter Lang $A G$

Jupiterstr. 15, CH-3000 Bern 15

Telefax (004131) 9402131

*inklusive Mehrwertsteuer

Preisänderungen vorbehalten

Homepage http://umw.peterlang.de 
Alexander Spermann - 978-3-631-75152-7 Downloaded from PubFactory at 01/11/2019 07:40:14AM via free access 